\title{
SOCIALISING CHURCH SPACE
}

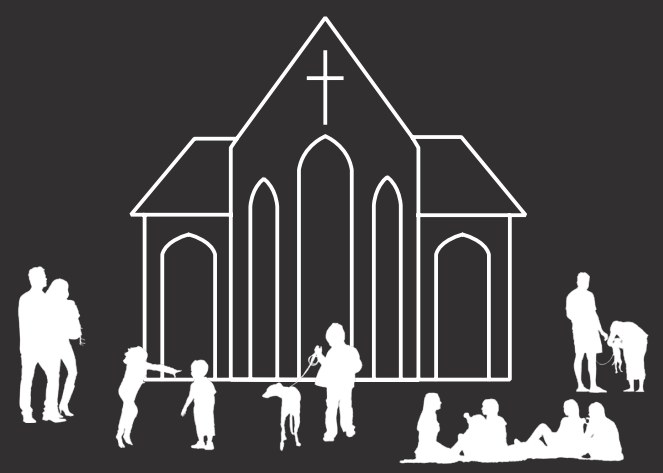

THADDEUS YOUNG 


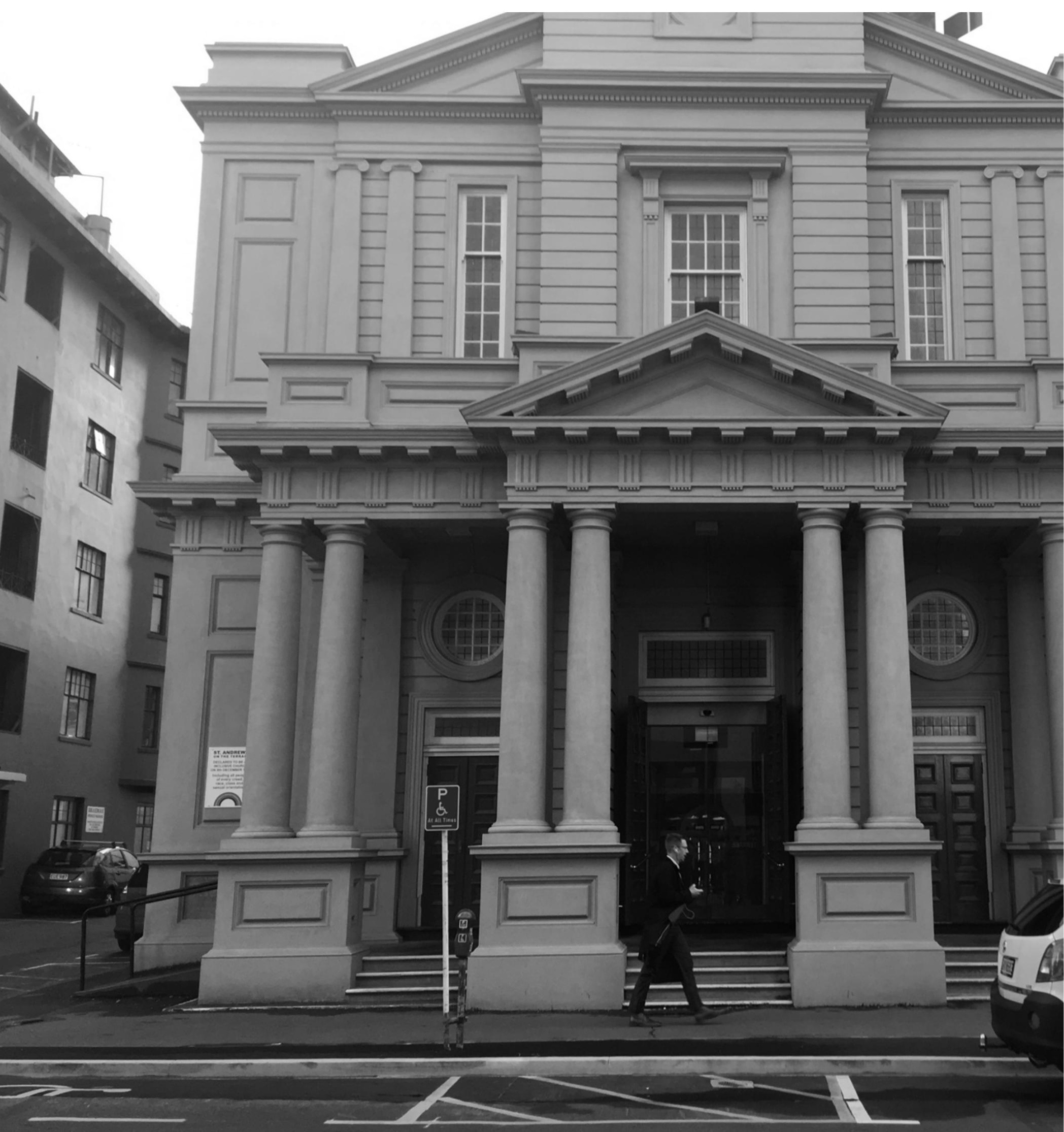




\title{
SOCIALISING CHURCH SPACE
}

\author{
by \\ Thaddeus Young
}

A 120-point thesis submitted to the Victoria University of Wellington in partial fulfilment of the requirements for the degree of Master of Landscape Architecture.

Victoria University of Wellington School of Architecture

2020 


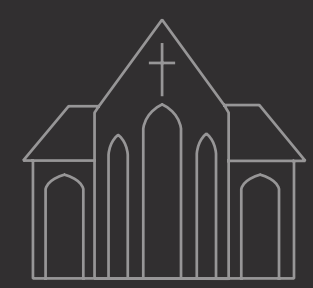




\section{Abstract}

For hundreds of years the Christian Church stood as the pillar of occidental cities, structuring society and the urban fabric.

At the time of European colonisation, the impact of the Church on New Zealand society was less significant than it had been centuries before. Social priorities were slowly shifting away from religious fanaticism, as such; the church did not influence the urban environment to the same level. Church buildings became increasingly isolated from their urban setting, with less impact on their surrounding environment.

In addition, New Zealand urban development was expanding, creating the need for vehicular transport. For the majority of Christians, driving to church continues to be commonplace. What little exterior space churches have is typically used as car parking. This space surrounding many church buildings is functional and utilitarian, resulting in an uninviting exterior with no pedestrian interactivity. This has limited the potential interaction between the church and local community.

To fully understand the New Zealand model, ten churches were identified and analysed in Wellington. Information and evidence were gathered on how to address the lack of inviting exterior church space. A comparative analysis model was used to identify sites with particular potential for improved design. Engagement with the respective church communities was then necessary to establish a deeper understanding of each site and the needs of the community. Comparative analysis and community engagement methods produced a set of criteria for designing in each space.

By following the same process for each church space, the resulting designs propose spaces which allow opportunities for both members of the church and the general public to interact. Designs specifically focus on creating vibrant spaces with less emphasis on the architectural qualities and utilitarian programmes of church space. They are also multipurpose and flexible, taking into account weekly engagement and potential future development. 


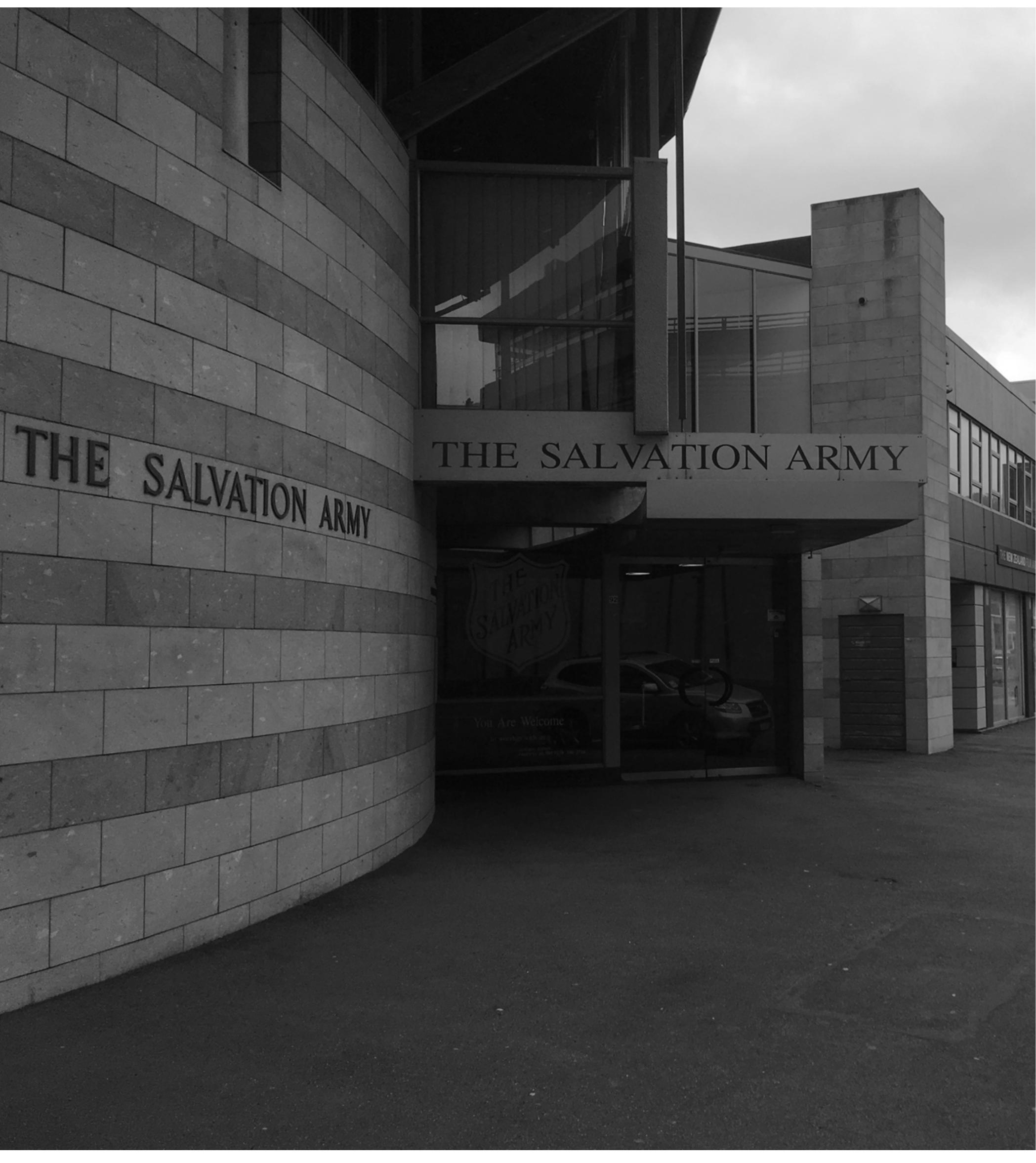




\section{Preface}

Central to my Christian faith is the idea that church is much more than a building; it is a collection of people from all walks of life who gather in fellowship to experience something much bigger than themselves.

Whether you believe in God or not, many church buildings are designed to evoke this reverence, but how do we treat the space around these sacred places?

I first became interested in this question after it was announced that the Wellington City Council wanted to put in place guidelines around how the car park of my church was used. As an inner-city church, our car park sits on prime real estate. This meant that the council considered a car park used primarily on Sundays as a waste of valuable space.

Determining what to do with that space has been a major challenge for my church and was the catalyst for my research into how other local churches treat the land surrounding their buildings. Immediately, obvious commonalities emerged. Many churches are not utilising surrounding land as a way of encouraging public engagement, creating tension between their sacred and secular spaces.

Would the lack of welcoming outdoor space impact the number of visitors stepping inside the building?

A pervasive concern facing the wider Christian community is the sharp decline of self-identifying Christians in recent years. While I firmly believe that Christian faith is so much deeper than the look of its churches, what if we are unintentionally limiting contact with an increasingly secular world by creating spaces that do not allow for interaction?

By creating spaces around church buildings that are inviting to the general public, we are creating opportunities for connection with a much wider group. The church should be as much a place for the public as it is for its congregation.

As part of this thesis, I will analyse outdoor spaces surrounding church buildings in Wellington, New Zealand and explore ways to make them more welcoming, focusing on the transition between their secular and sacred space.

'Church', and all it encompasses, should never be a mysterious place, misconstrued by the general public. As Christians in today's world, we should take every opportunity to break down stereotypes and initiate discourse around who we are and what we believe. By designing beautiful, carefully designed outdoor spaces that are open to everyone, we can bring a glimpse of the sacred outside and into the world.

Fig.0.02. (Left) Wellington City Salvation Army 



\section{Acknowledgements}

Firstly, to my supervisor Carles. Thank you for your constant drive and passion over the past year. I appreciate all the hours you have given me and how determined you were to get me moving in the days where I was struggling for motivation.

Thank you to those that assisted with the site specific research. Your help and generosity with your time was much appreciated and enabled me to explore avenues of research I did not envisage at the beginning. Special thanks go to the people of the Wellington Methodist Parish, Wellington Cathedral of St Paul and The Wellington City Salvation Army.

To the rest of my Landscape Architecture year group, I can safely say that without your support and friendship over the past four years my time here would have been significantly less enjoyable.

And lastly, to my parents and Olivia. I could not have done this without you. Your constant encouragement and advice was always greatly appreciated.

\section{Ethics}

Research ethics approval was obtained from Victoria University Human Resource Committee in order to conduct this thesis.

Approval no. 0000026379

The participant information sheet and consent form are included in the Appendix. 


\section{Table of contents}

$\begin{array}{ll}\text { Abstract } & v \\ \text { Preface } & \text { vii } \\ \text { Acknowledgements \& Ethics } & \text { ix }\end{array}$

\begin{tabular}{ll}
01 Introduction & \\
\hline \hline & \\
Research background & 01 \\
Research opportunities & 10 \\
Research aims and objectives & 13 \\
Methodology & 20
\end{tabular}

vii

ix 
05 Design techniques \& guidelines Introduction

Transitions between space

Inviting public space

Conclusion
129

132

134

143

\begin{tabular}{ll}
07 Conclusion & \\
\hline \hline Conclusion & 203 \\
Bibliography & 206 \\
List of figures & 208 \\
Appendices & 210
\end{tabular}

\section{Design implementation}

Introduction

Wellington Cathedral of St Paul

Wellington City Salvation Army

163

Wellington Methodist Parish

179

Conclusion

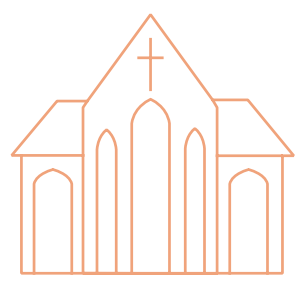




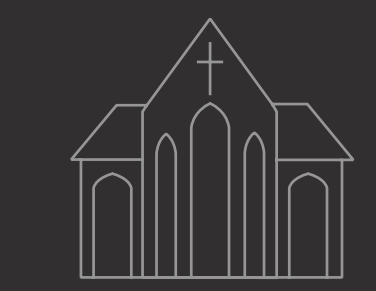

CHAPTER ONE 


\section{Research Background}

The research begins by looking at the historical significance of the church and its impact on society. How did the church and public space work so well in the past? Why was the church so dominant? 


\section{The Role of the Medieval Church \& Town square in Europe}

Churches and Cathedrals were built to inspire awe. They were central to many towns and cities and were designed to appear as though they were rising to heaven. "The more splendid the architecture, the more the church believed it was praising God" (Trueman).

The church was the centre for community activity, with religious services held several times a day. The building was not only used for religious purposes, but for town meetings, plays, and concerts. The public square in front of the church was a place where merchants and farmers would sell their wares and produce, with shops lining the edges of the space. Markets, festivals, and fairs were all held in the area in front of the church. The square allowed opportunity for a diverse range of people from the church community and general public to interact with one another.

The Church was perhaps the single most powerful institution in medieval life, its influence reaching almost every aspect of people's lives. Its religious observances gave shape to the calendar; its rituals marked important moments in an individual's life; and its teachings underpinned mainstream beliefs about morality, the meaning of life and the afterlife. (British Library)

Town Square

"A comfortable spot to gather for social, cultural and political activities. They were the pulsing heart of a community and fostered true urban sustainability"

("The Re-Emergence of The Public Square"). 
This content is unavailable.

Please consult the print version

for access.
This content is unavailable.

Please consult the print version

for access.
This content is unavailable.

Please consult the print version for access.
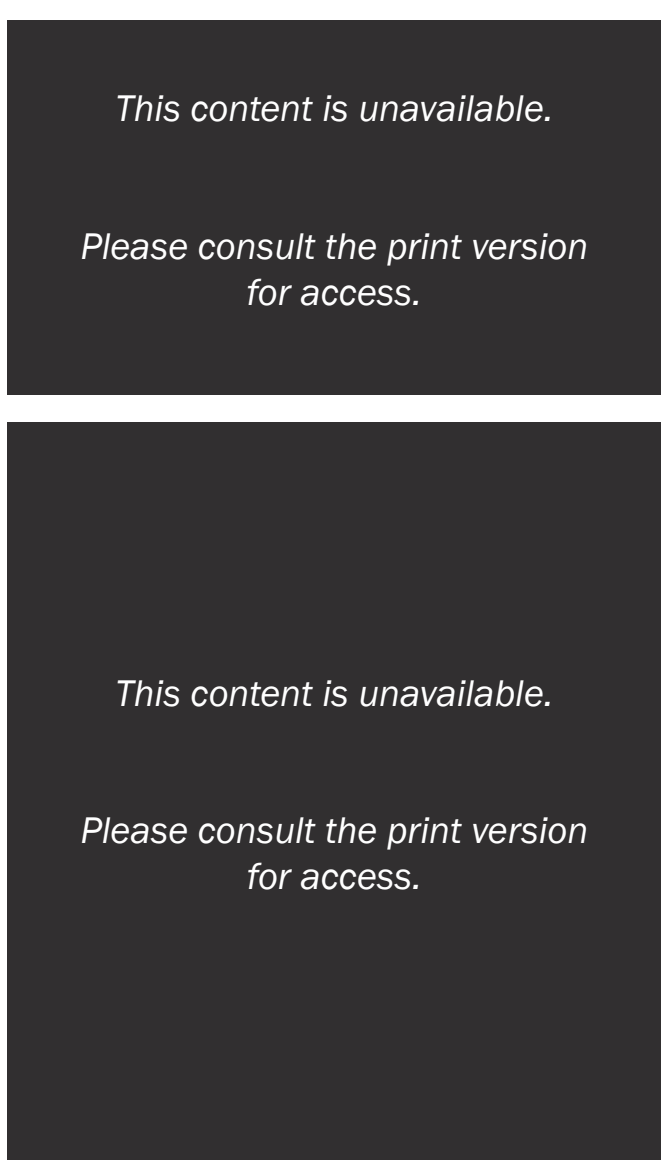

Fig.1.01. (Left Top) The Origin and Decline of the Papal States Fig.1.03. (Left Middle) Florence: View with the Chain Fig.1.05. (Left Bottom) Brunelleschi's Dome
Fig.1.02. (Right Top) Beginning of the Republic Messine Fig.1.04. (Right Middle) Filippo Brunelleschi's Dome Fig.1.06. (Right Bottom) Florence and Palazzo Rucellai 


\section{The Role of the Church \& Town square in New Zealand}

The church as a body did not have the same power and dominance over society in New Zealand as it did in medieval Europe. This is exemplified in the structuring of the main cities in New Zealand. Instead of the town square or church square being the central pivot point of the city, here in New Zealand cities were centralised by other significant landmarks.

Wellington is structured by its geography. The surrounding hills and harbour determined the extent of the inner city (Perceval). The city's grid point towards the harbour and a number of main south/north running streets end at the waterfront.

Auckland is another example of a city primarily orientated by its geography. The harbour and waterways dictate a lot of the roads and infrastructure (Shaw, Savill and Co.). Like Wellington the wharf was a key attribute to the city and access to and from the harbours was paramount (Shaw, Savill and Co.).

Christchurch is one example of the church having some hierarchy in the structuring of the city. Cathedral square stood as a central landmark from the city's early inception and can be seen in the first plan of the city. It was intended to be a grand centre for the city and the site of the proposed cathedral and grammar school (Christchurch City Council). However, despite its central position, the role Cathedral Square has been expected to play in the city's life has never quite been clear or satisfactorily defined (Christchurch City Council). 


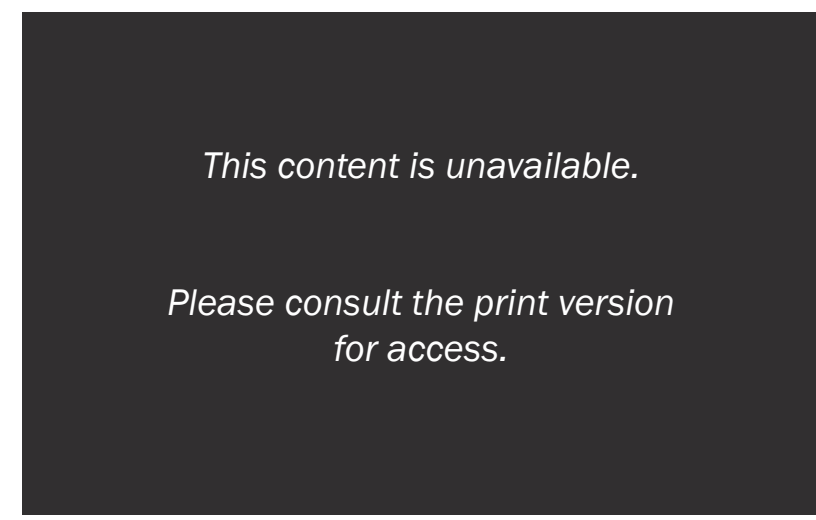

\section{Wellington}

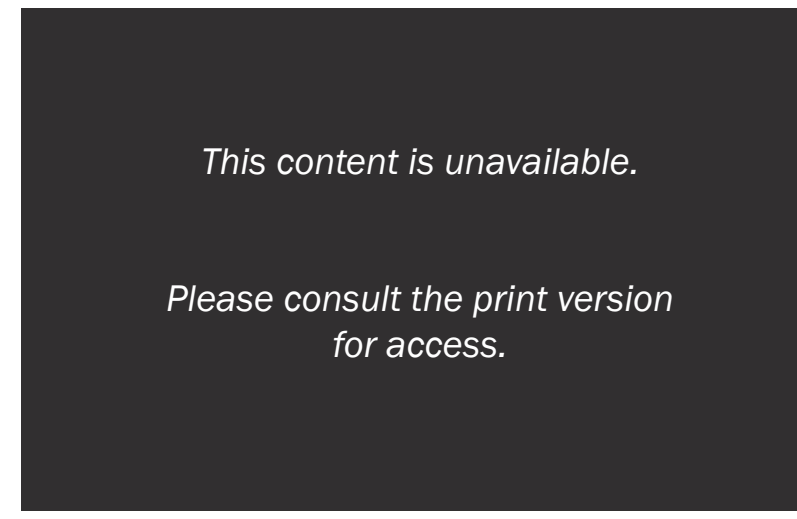

\section{Auckland}

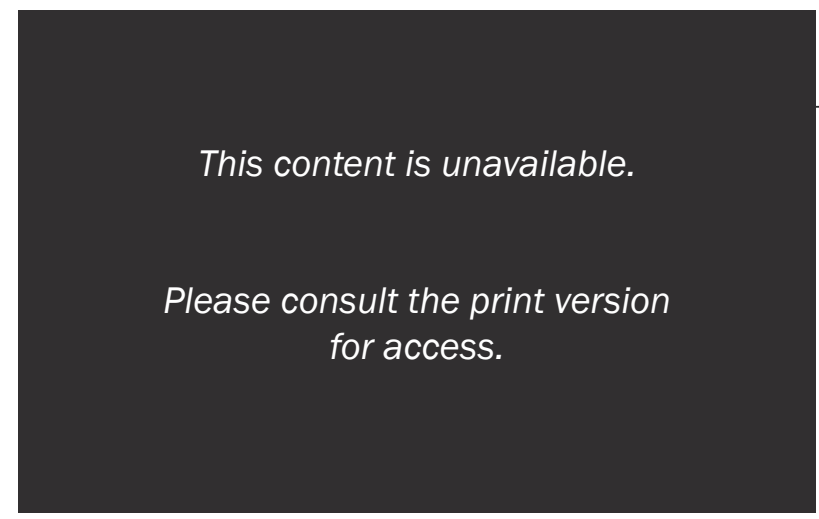

\section{Christchurch}




\section{New Zealand urban development - Urban Sprawl}

When looking at the urban structure of Wellington as a city, it is clear that urban sprawl has played a significant role in shaping the city. Of Wellington's 190,956 people, only 33, 639 live in inner city suburbs. This means that there is a certain reliance on transport.

Because New Zealand was colonised considerably later than countries in Europe, the world had advanced significantly in terms of infrastructure and technology. Roads were purpose built for motor vehicles. This, in combination with urban sprawl, has meant that New Zealand society, relies heavily on transport by car.

Wellington

I9ulation of Wellington 19,956
ulation of Inner city suburbs 3,639

New Zealand

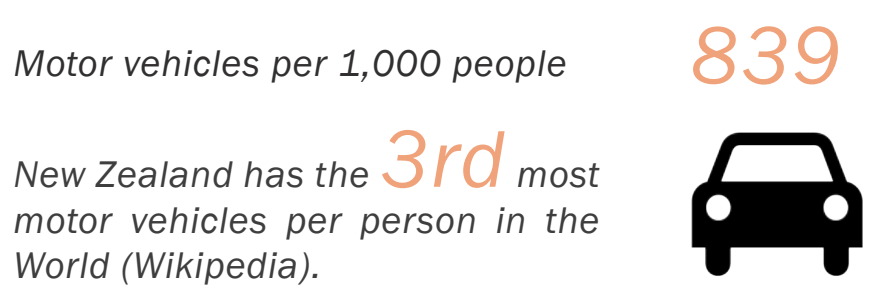




\section{The modern day church \& public space}

When the two models of Europe and New Zealand are compared, it is obvious at a glance which culture puts more emphasis on creating a social space surrounding its churches.

In Europe, the church sits in a commanding position, often centred in the town square. It is the focal point of the space. Not all people utilising the space attend the church, creating more opportunity for the church community to mix with the general public.

In New Zealand, the church does not have the same position; often appearing as yet another building in the urban fabric with very little social space surrounding it. The church is pressed up against neighbouring buildings, limiting usable space, with opportunity for social interaction confined to the footpath. 


\section{Europe}

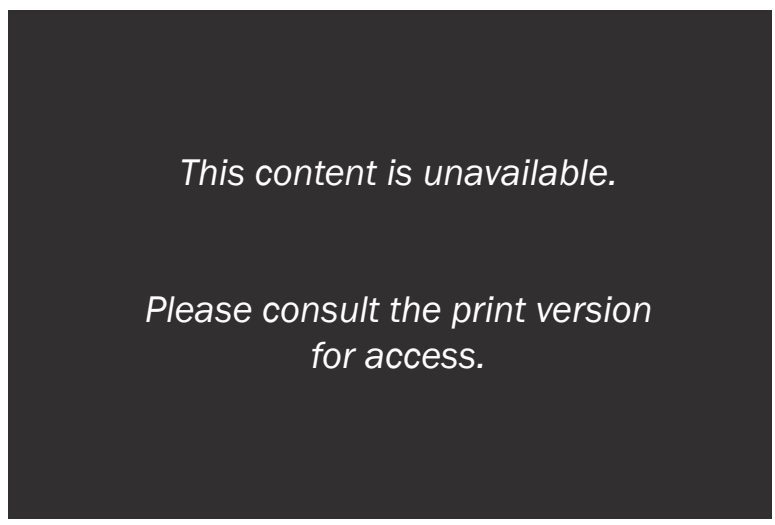

Borken, Germany Year of construction: 1150

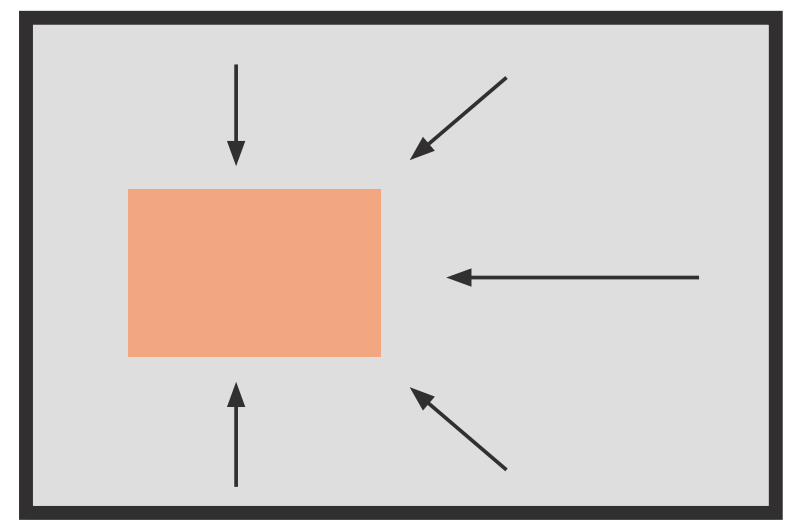

Public Space Church
Buildings

$\rightarrow$ Pedestrian flow

\section{New Zealand}

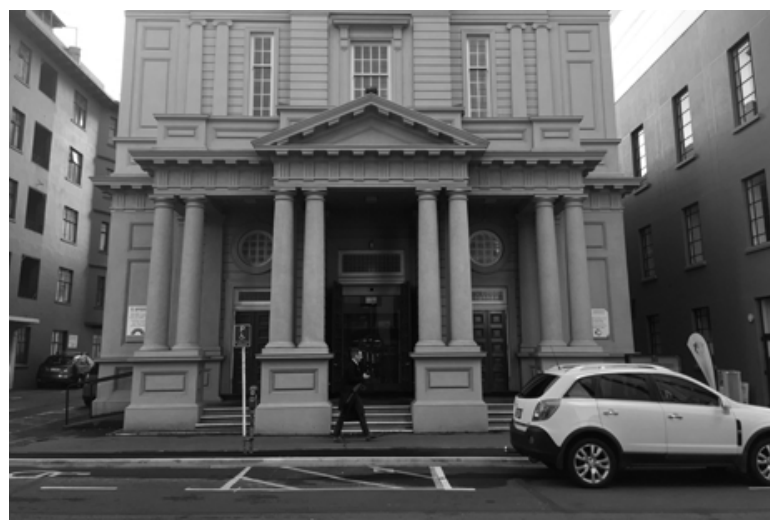

Wellington, New Zealand St Andrews on the Terrace Year of construction: 1923

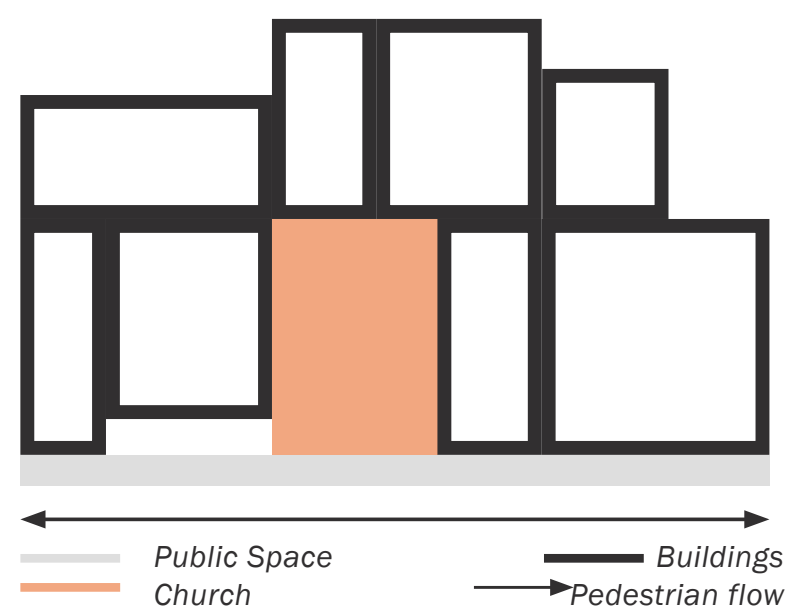

Fig.1.12. (Right Top) European church public space diagram Fig.1.14. (Right Bottom) New Zealand church public space diagram
Fig.1.11. (Left Top) Church Square St. Remigius, Borken Image 3 Fig.1.13. (Left Bottom) New Zealand church public space 


\section{Research opportunities}

Based off these two differing models of the European and New Zealand setting, opportunities for research presented themselves.

\section{Church links with context}
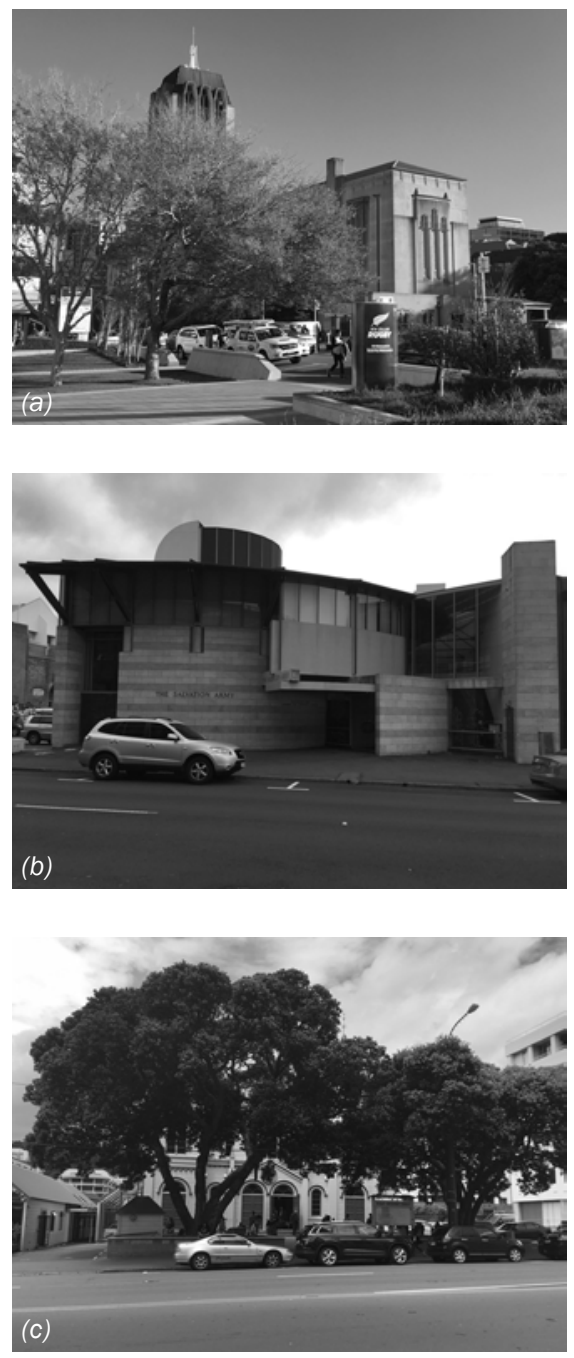

Firstly, looking at how the church could work better in its context. Instead of being a separate entity how could it work as a part of the urban fabric?

Fig.1.15. $a, b$ and c, (Left) Church links with context

Fig.1.16. $a, b$ and c, (Right) The church and its surroundings

\section{The church and its surroundings}
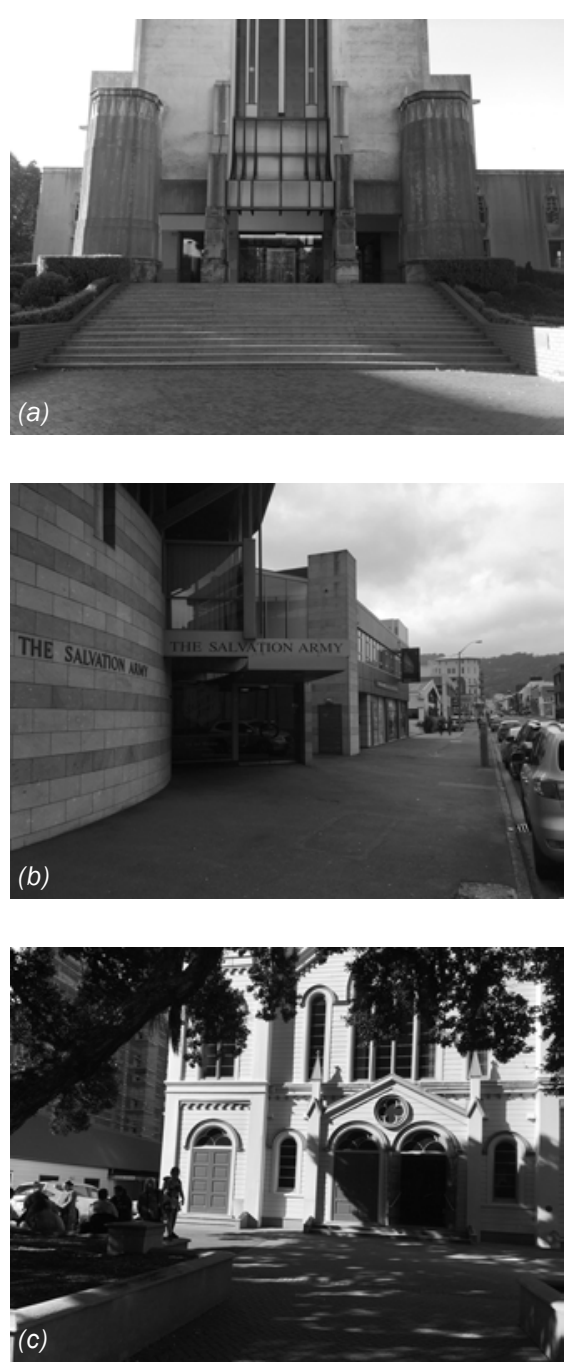

Secondly, looking at how the transition between the church and its context could be improved. How could redesign facilitate a smoother path for the pedestrian between the street and the church? 
The Christian community

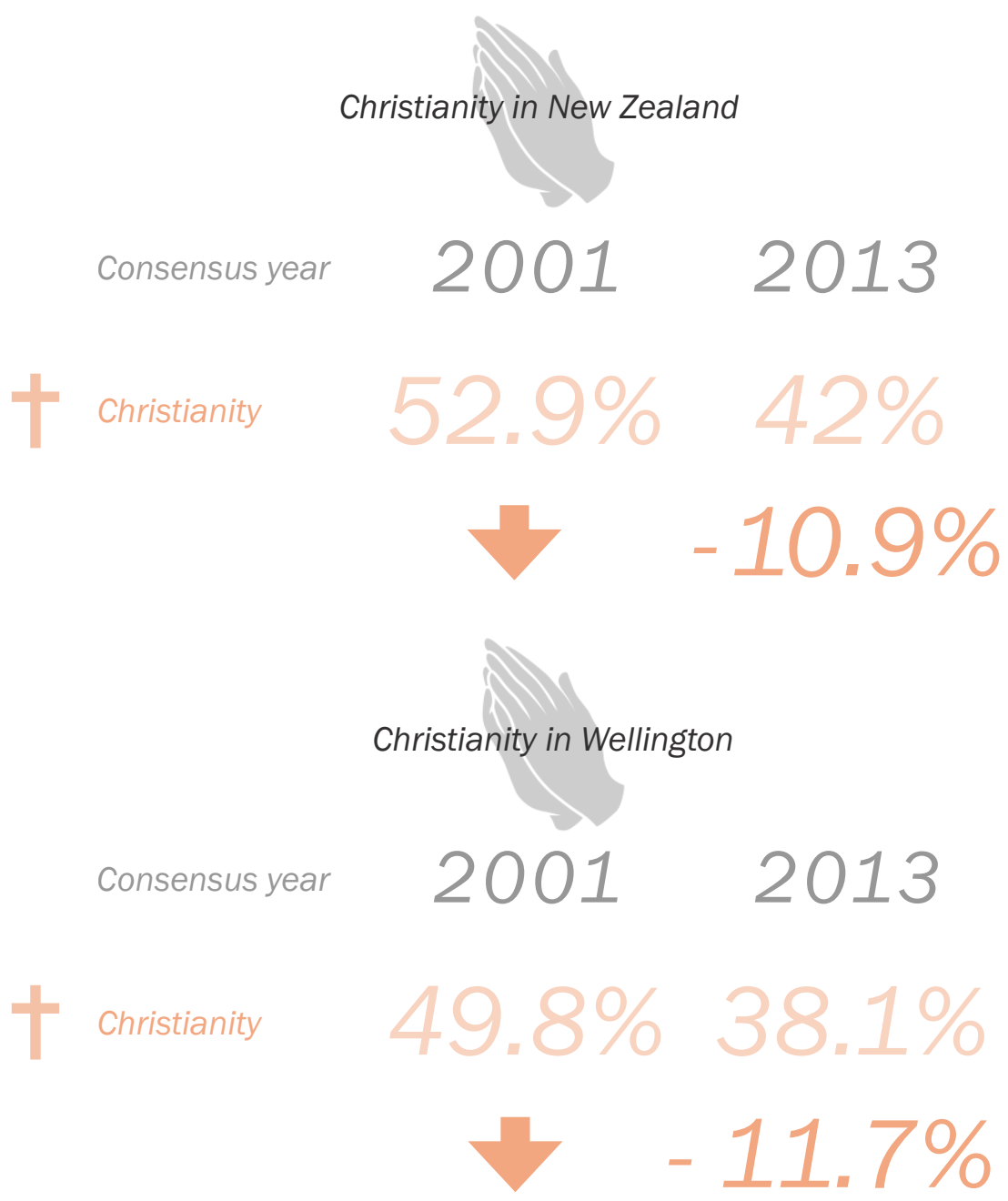

And thirdly, with churches having their own communities and congregation, how could the research work with these people to understand what they thought about their space and how they thought it could be improved. 

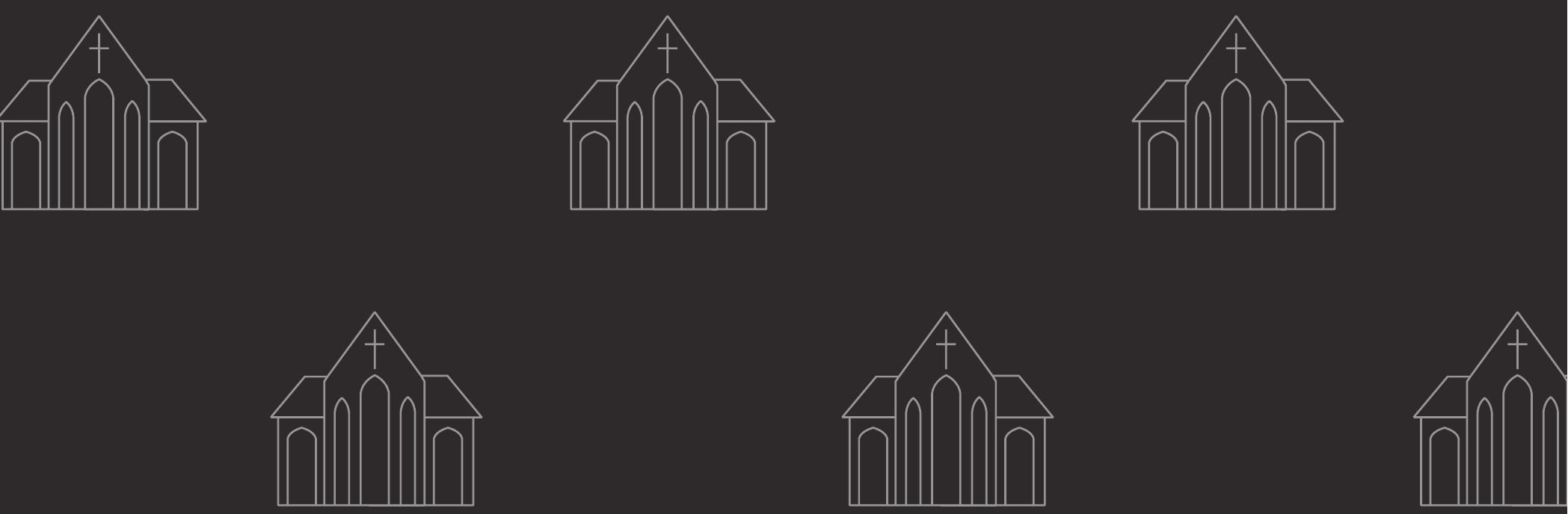

How can landscape architecture integrate church communities and the general public through inviting social space in Wellington?
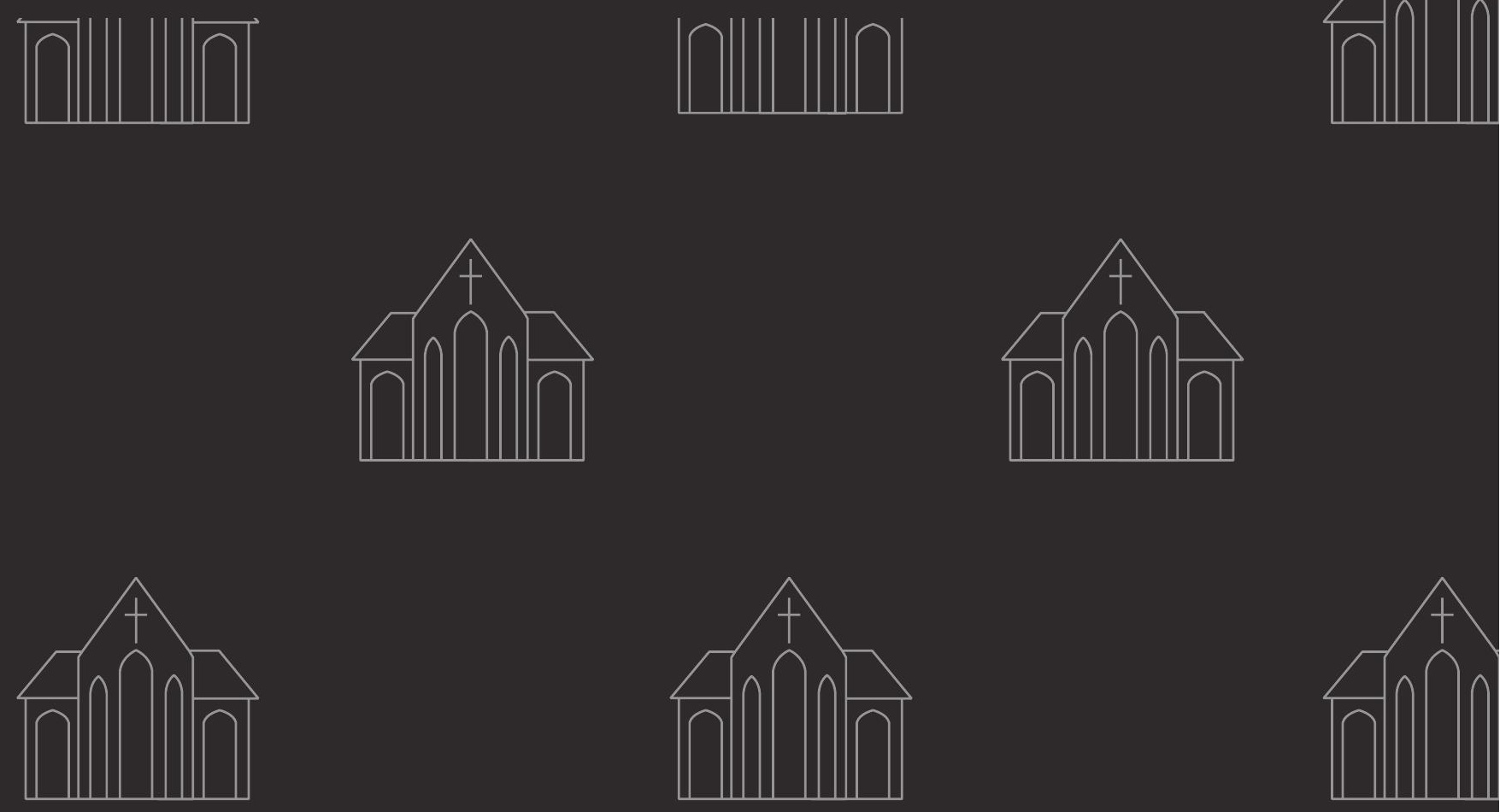


\section{Research aims and objectives}
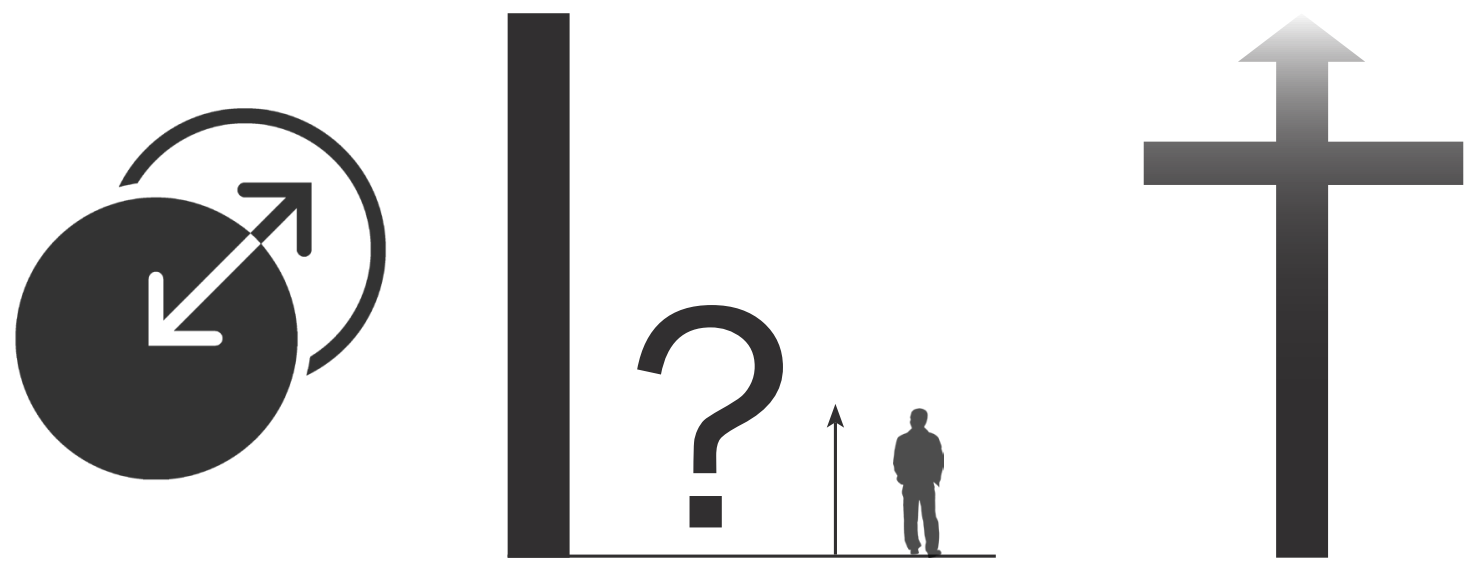

Transitions between space

To increase church "presence" at a street level

To soften the edges of what is normally a harsh meeting of building and land and to work in the interstitial space of the building and road

\section{Inviting public space}

To create inviting space that is useful for members of the church space and members of the public

To clearly communicate the spatial issues that exclude people from churches
Community engagement

To develop a situation where the growth of the church community can be better facilitated

To investigate community based landscape architectural methods 


\section{Research aims and objectives Transitions between space}

The transition between interior and exterior church space is often a zone that leaves much to be desired. Pedestrians are expected to navigate their way through an array of obstacles, making the transition difficult. Creating a space free of obstacles, with a clearer path, would allow more opportunity for churchgoers and passers-by to interact. It would also encourage people to explore the space.

Blurring the boundaries between church and public territories would bridge the gap between the church building and its context.

To increase church "presence" at a street level

To soften the edges of what is normally a harsh meeting of building and land and to work in the interstitial space of the building and road

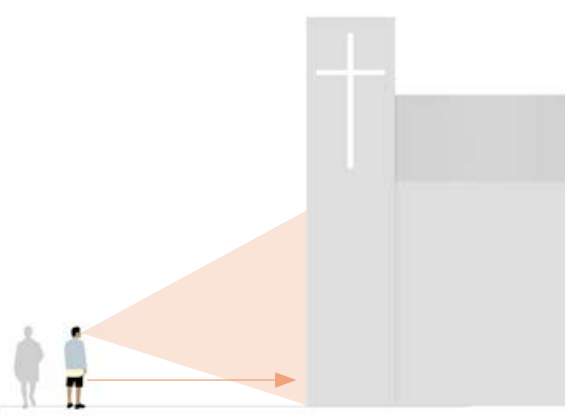

Full vision + movement

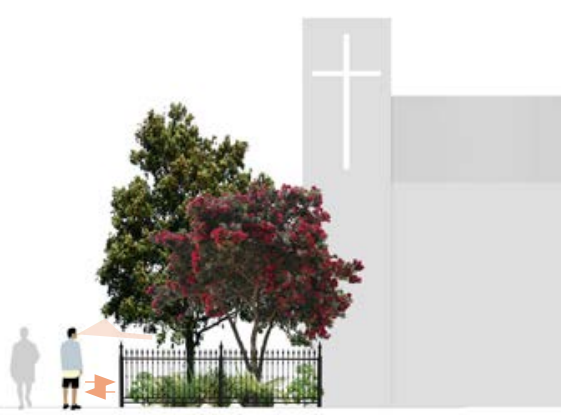

Limited vision + limited movement 

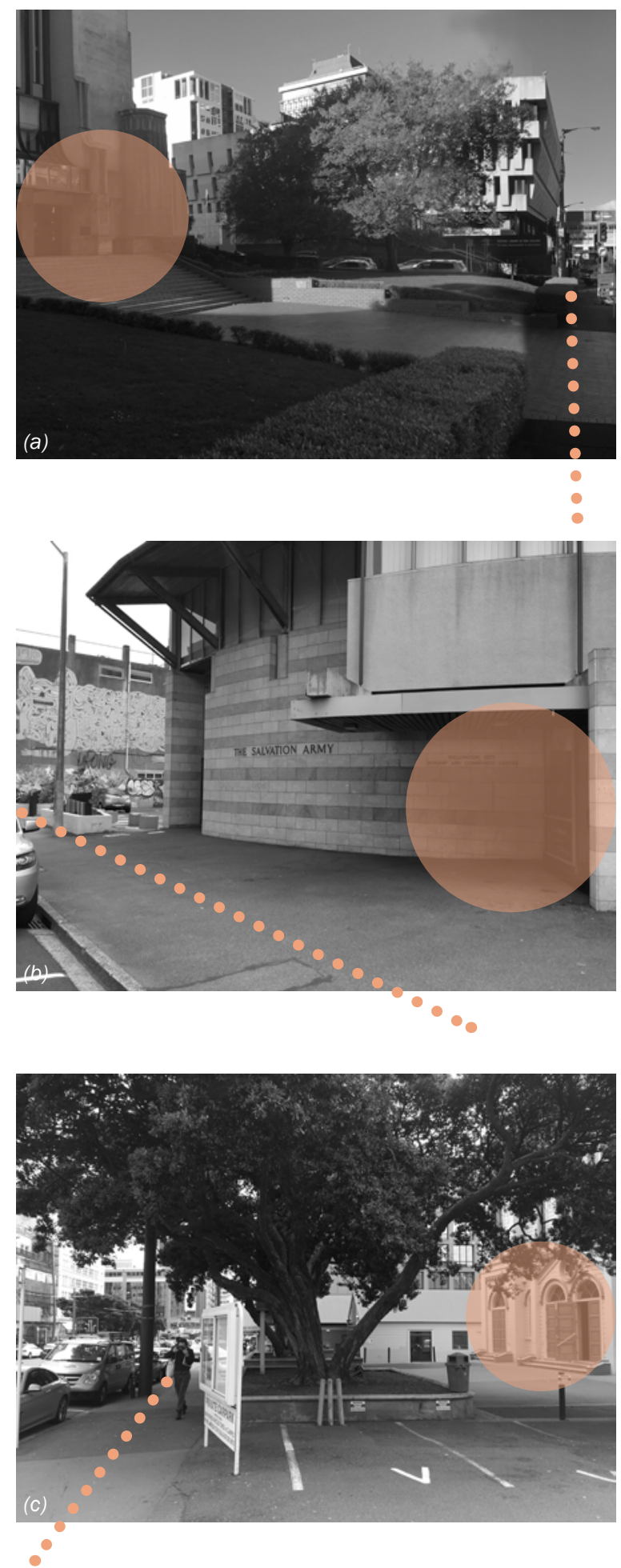

Fig.1.18. a, b and c, (Right) Church transitions between space 


\section{Research aims and objectives Inviting public space}

The most common situation with many churches across urban New Zealand is a focus primarily on the church building, with little to no thought given to how the space works as a whole.

In a number of cases, church buildings could be swapped across sites with very little impact on their surroundings. These buildings are not designed to interact with their context - their design is focussed on the experience one has once inside. There are very little areas for people to sit down and relax in. Instead, many of these spaces are used as thoroughfares, with little to no sense of permanency.

This, presents an opportunity for redesign. Creating an outdoor space that people are drawn to, while being functional, is key to the success of the design.

To create inviting space that is useful for members of the church space and members of the public

To clearly communicate the spatial issues that exclude people from churches 

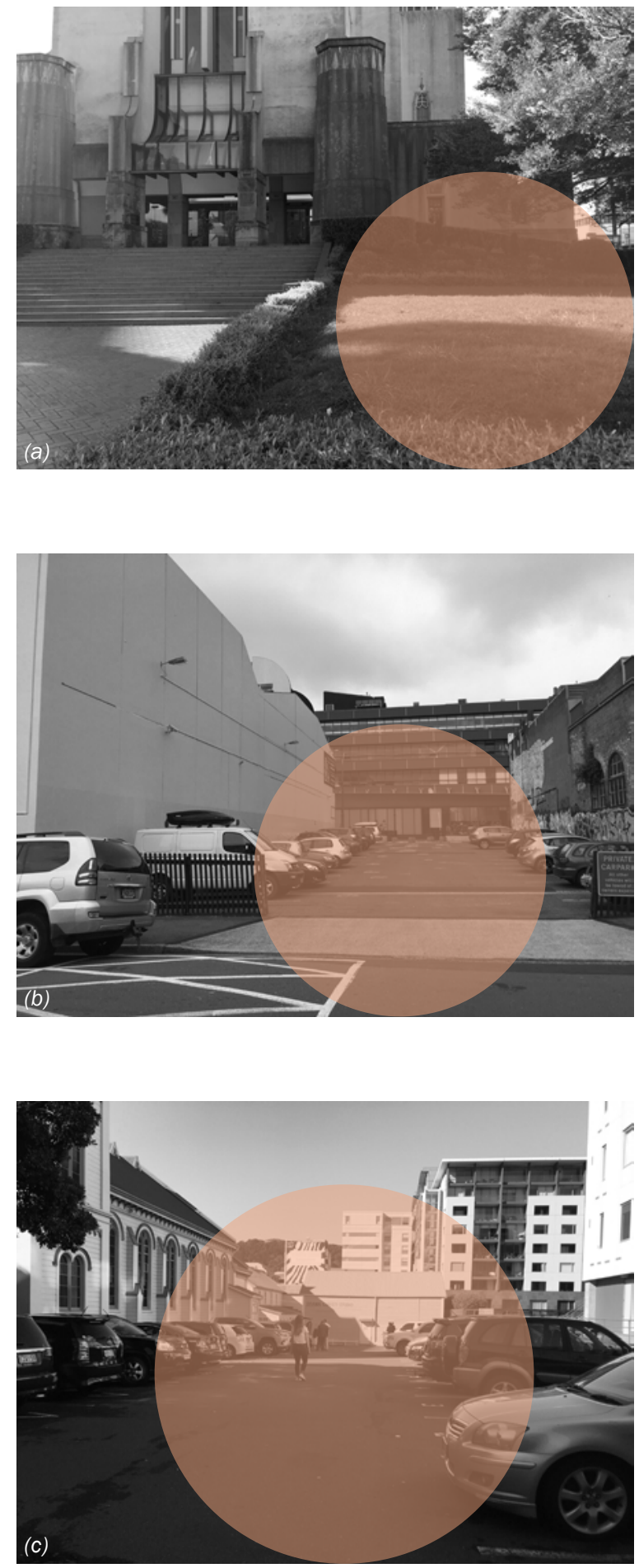

Fig.1.19. $a, b$ and c, (Above) Church public space 


\section{Research aims and objectives Community engagement}

There are two main groups that this research is targeting; the general public and the church community. The design needs to reflect a balance between both groups, resulting in a space where the two groups can interact.

Landscape architects are well versed at designing for the public; but designing for a specific group calls for conversations with that group.

Talking to people across sites will give significant insight into that church congregation. The history and background of the space from a first-hand account often reveals much more about a space than looking at old photos or plans. For this reason, the research would benefit from using a participatory design method.

To develop a situation where the growth of the church community can be better facilitated

To investigate community based landscape architectural methods 
General Public

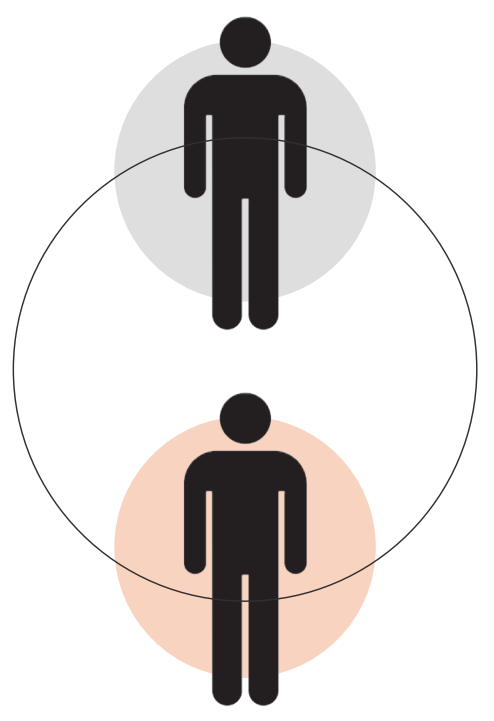

Church Community
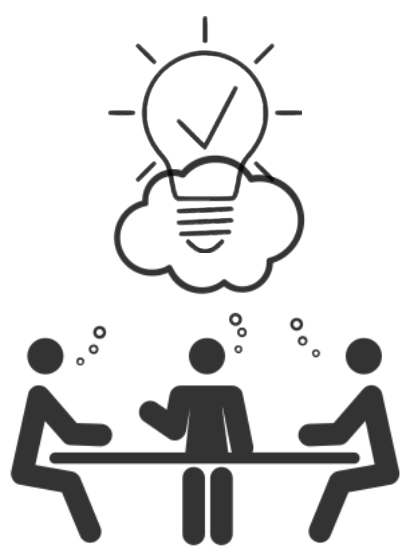

Participatory Design

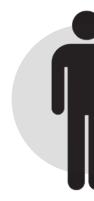

One people

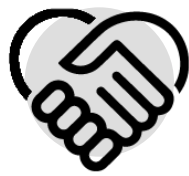

Outreach

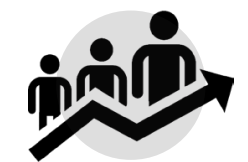

Growth 


\section{Methodology}

This research follows the method identified below. There are two main areas to the process. The case studies and comparative analysis is the first, discussed in chapter three. The second is the church community collaboration and community engagement discussed in chapter four.

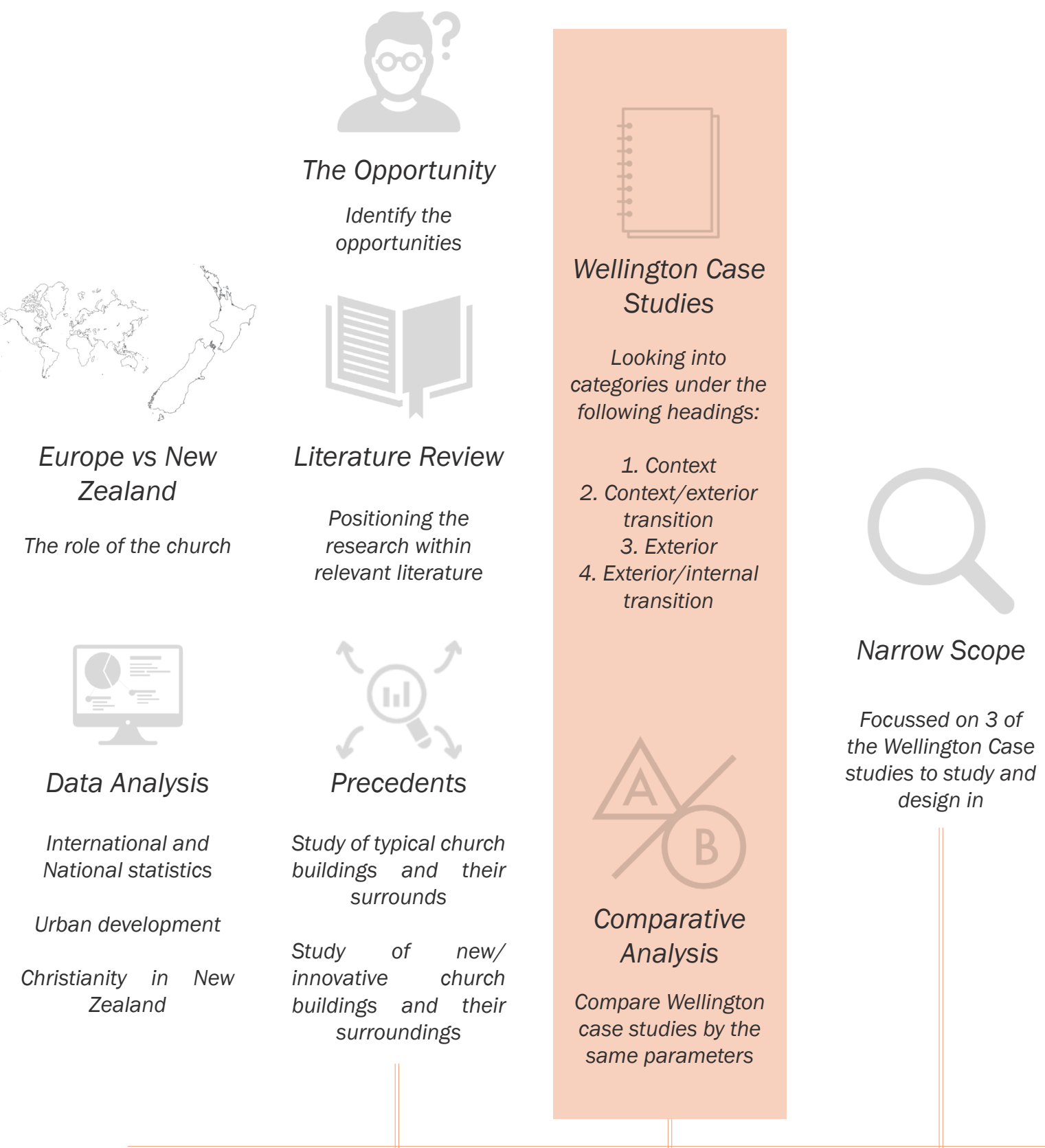




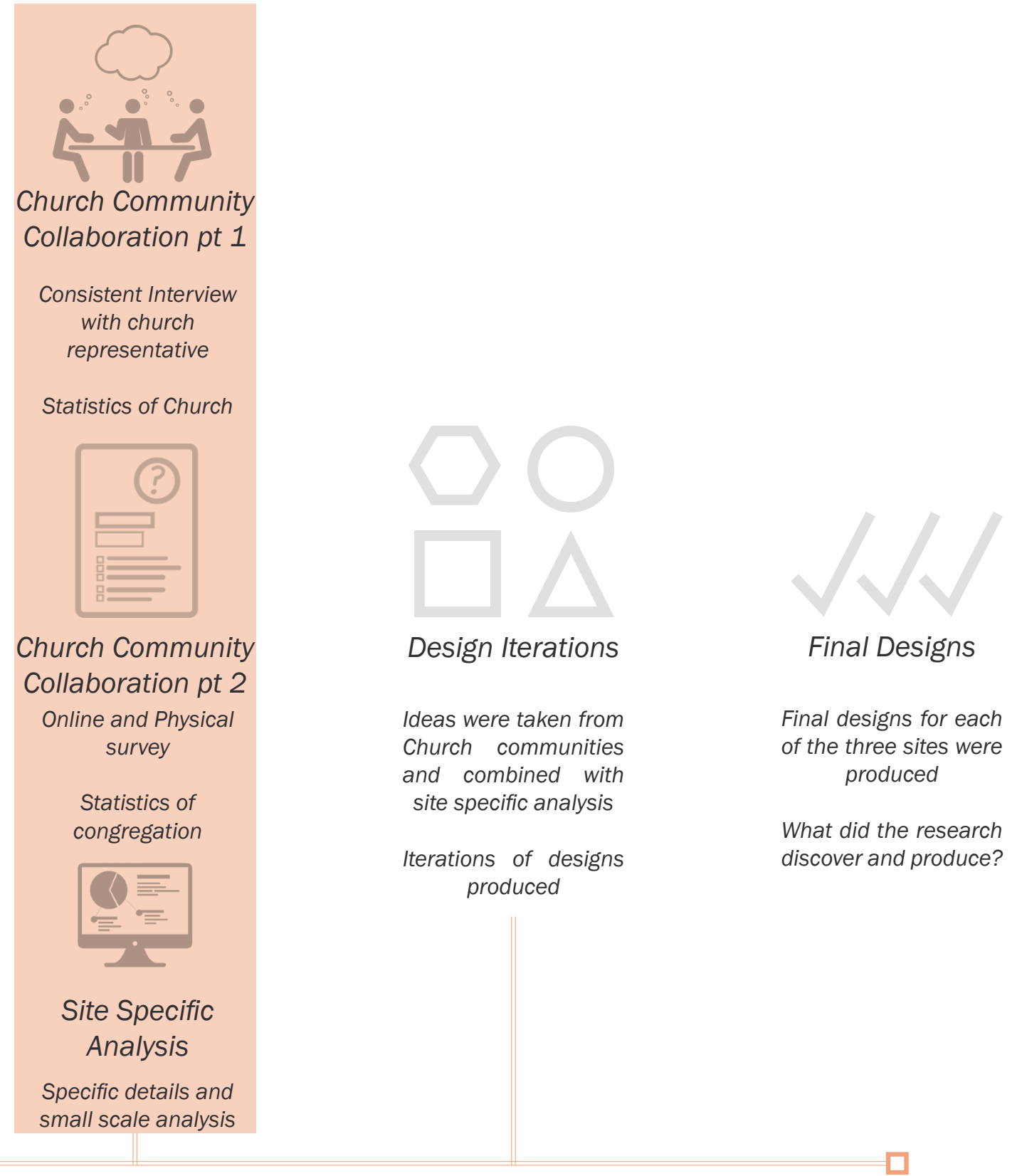

Fig.1.21. (Above) Methodology Diagram 


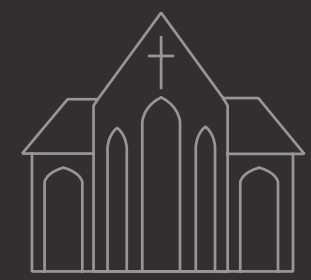

CHAPTER TWO 


\section{Positioning the research}

within relevant literature

The scope of literature investigated was based on the overall aims and objectives of this research. The literature gave definitions, background, examples and techniques to assist with the research, more specifically the analysis and design elements. 


\section{Transitions between space}

Key texts:

Form and Fabric in Landscape Architecture, City - Rediscovering the Center, Basics Urban Building Blocks, Urban Design Tactics

The transition between spaces can be categorised under 'thresholds' and 'edges'.

Catherine Dee states in her book, 'Form and Fabric in Landscape Architecture', an 'edge' can be defined as a linear interface between two spaces that have different functions or physical characters (Dee) (fig.2.1. \& fig.2.2.). Vibrant social environments can be created along the edges of a space (Dee). This is evident in public space where people frequently choose to sit, wait and occupy the edges of a space, rather than positioning themselves centrally (Dee). This is important in landscape architecture as design often involves facilitating potential social activities with appropriate physical forms, elements and relationships for edges (Dee). In terms of the New Zealand church model, the edges of a space are typically under-utilised and fail to connect the church building within its context. This is a problem faced by many other buildings and Dee goes on to give some context as to why. The edge condition is a "hybrid linear space" around space and buildings (Dee). The design of this space is a task for both architects and landscape architects; however, "too often architect and landscape architect fail to work together creatively to realise the design potential for this transitional space" (Dee).

Thresholds are places of transition. They help to integrate the physical landscape and the experience of it (Dee). They are typically places where people wait, rest, arrive and leave. If designed well, a threshold can provide visual and physical integration of the landscape if it possesses the qualities of both the spaces it connects (Dee). In this research, the threshold of the footpath into the church space will be analysed and improved. In conjunction with this, thresholds in the space, such as transitions from the car park to the church entrance, will also be analysed and improved. 


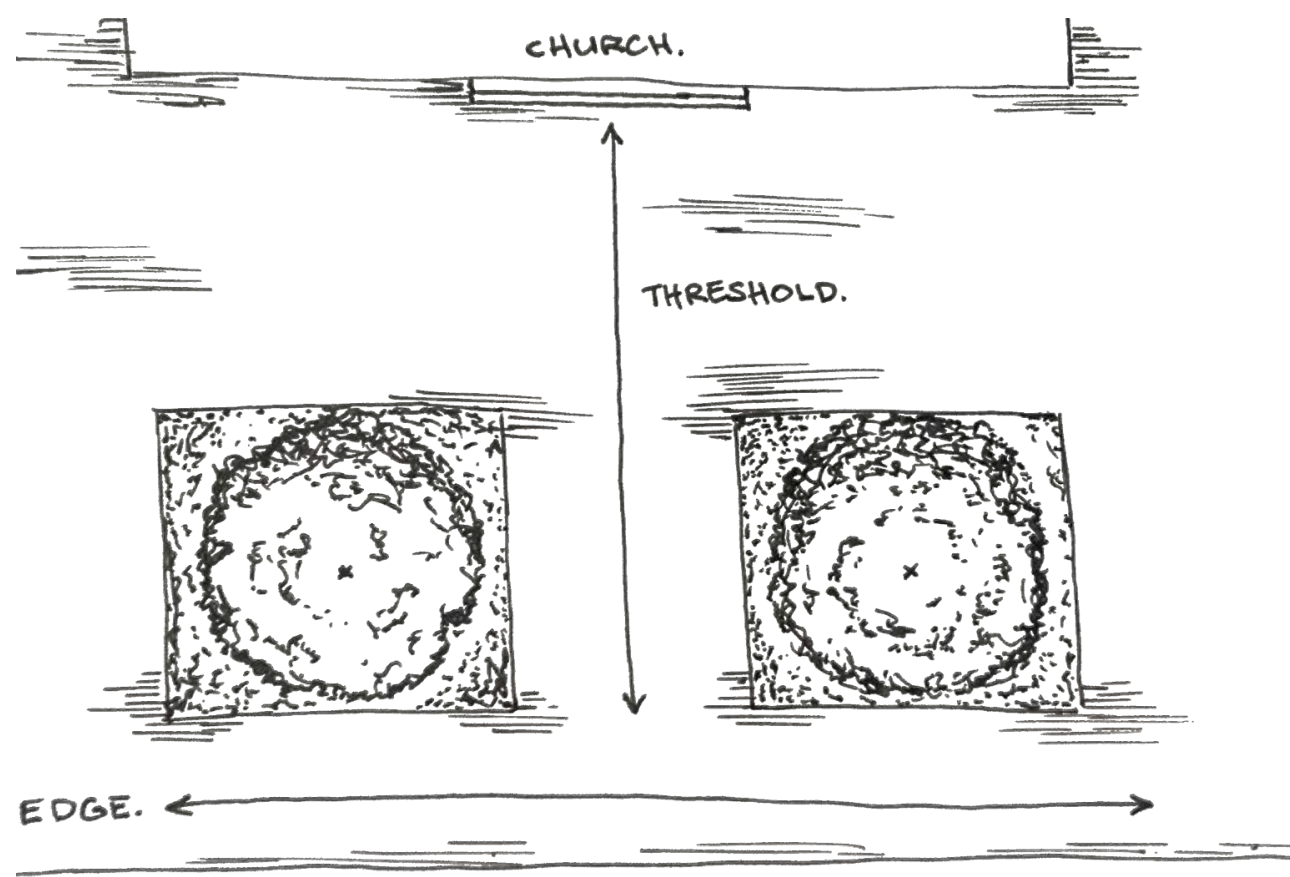

ROAD.

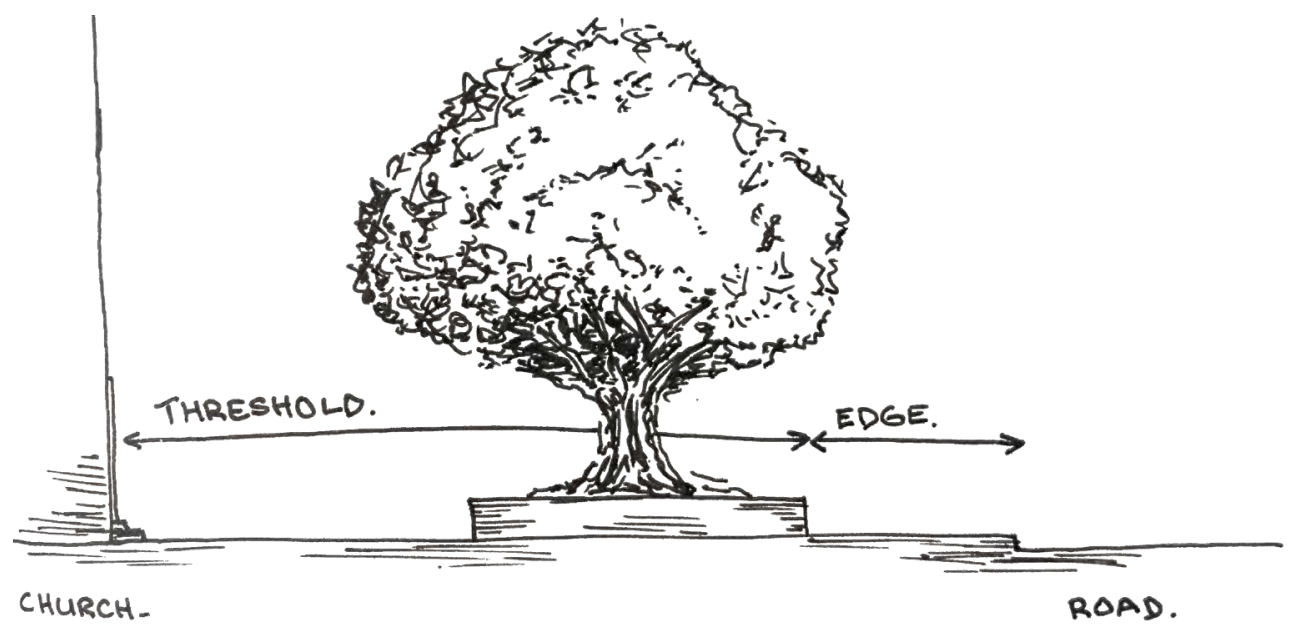




\section{Transition between space}

Understanding how people perceive the street is a fundamental area of this research; the way people move and interact with the space is often involuntary. Exploring techniques that manipulate people's involuntary actions in the street will be influential to design. Slowing the pace of pedestrians on a linear path to entice them into a space is something the research will look to employ. In 'City - Rediscovering the Centre', William Whyte states, "stoppages are so effective at inducing spill over traffic that merchants might well consider it worthwhile to deliberately create them" (Whyte). He goes on to give an example of a man who ran a stall that sold discount cigarettes on the street. The man was anxious to deter people going to another cigarette store two doors down. He used a street sign advertising the cigarettes that he would place on the footpath, but soon saw that the valuable function of the sign was not necessarily advertising the product, but obstructing the path of pedestrians. This meant that the main traffic flow diverted people towards his stall and, at the very least, slowed their pace. This example shows how space can be manipulated to change the flow of pedestrians. This led to further exploration of urban design related techniques on altering transitions and flows.

Thorsten Burklin and Michael Peterek discuss in their book, 'Basics Urban Building Blocks', the techniques used when looking at how the street transitions into a building. These techniques suggest ways to create a buffer zone between the street and the building (fig.2.3.). "This can take the form of a planted strip of land, a front garden or a private front courtyard" (Thorsten Bürklin). These are appropriate techniques when the transition is between a public space and a private space; however, this research explores the transition between public spaces, where movement needs to be more fluid. 


\section{This content is unavailable.}

\section{Please consult the print version}

$$
\text { for access. }
$$

space of the city.

Steven Peterson explains techniques used in the redesign of significant locations around Europe. The content most useful to this research was the chapter on 'the Tactics of Connection'. Of these tactics, two in particular related to the research. First, the overlapping of edges and patterns between different areas to establish a relationship and second, creating continuity of texture already in use in the area. Both these examples, in this case, were implemented on a large scale however, they could be transposed to a site smaller in scale. Catherine Dee explains that transitional space can be defined by a change in paving to mark a threshold, giving an example of a smaller scale intervention (Dee). This can be particularly useful in identifying and signifying building entrance thresholds (Dee). When a surface material extends from one space to another, so too does the threshold of that space. This technique has the ability to entice and invite people through that threshold and into the new space. 


\section{Inviting public space}

Key texts:

Life Between Buildings: Using Public Space, Want to Create an Inviting and Attractive Public Space?, City - Rediscovering the Center, Rethinking Urban Parks: Public Space and Cultural Diversity

For a space to be inviting and encourage social interaction, it must be open and inclusive to all members of society. Understanding the basic qualities of a successful public space is a key focus when looking to create an inviting and inclusive space.

In 'Life Between Buildings', Jan Gehl discusses how public space is used and perceived. He states that outdoor activities in public space can be simplified and divided into three categories: necessary activities, optional activities and social activities (Gehl). Each of these categories have very different requirements of the physical environment.

Necessary activities are activities that take place under all conditions (Gehl). They are more or less compulsory things like; going to work, shopping, waiting for a person, running errands, etc (Gehl). The physical environment only slightly influences necessary activities, as the user of the space typically has no other option (fig.2.4.). The activity is more or less independent of the exterior environment (Gehl).

Optional activities are those that happen under favourable exterior conditions (Gehl). They depend heavily on the weather and the quality of a space (fig.2.4.). They are activities like; going for a breath of fresh air, sitting down and relaxing, sunbathing and lying down. If the weather or quality of space does not permit these activities, they will occur infrequently (Gehl).

When an outdoor space is of a poor quality, only strictly necessary activities will occur (Gehl). When the quality of a space is of a high quality, necessary activities may take longer, as people enjoy the space more. In addition to this, a wide range of optional activities will also occur as the space becomes more inviting (Gehl).

Currently, the quality of exterior space in most churches would suggest that only necessary activities occur. While the church community may use the space for 
Quality of the physical environment

Necessary activities

Optional activities

Social activities
Poor

Good
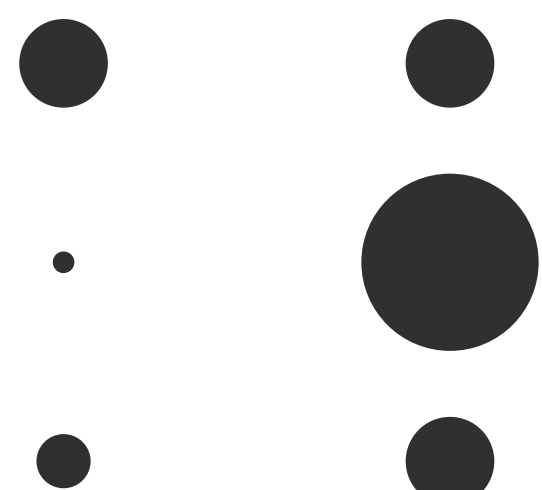

optional activities, the space does not frequently entice others to do so. Placing more emphasis on improving the quality of the space and making the area more multi-functional would increase the number of optional activities in the space.

Social activities are activities that depend on the presence of others and the interaction with others in a space (Gehl). These activities include conversations, children playing, communal activities and passive contacts. The latter being the most widespread and often unintentional (Gehl). Passive contacts are simply seeing and hearing others in a space. Social activities are often referred to as 'resultant' activities as they typically evolve from necessary or optional activities (Gehl).

The character of social activities varies significantly, depending on the context in which they occur (Gehl). Social activities in the city centre or city streetscape are generally more superficial, with the majority being involuntary, passive contacts (Gehl).

Understanding these forms of activity in the public sphere is an important aspect of physical planning and design. Even though the physical framework does not have a direct influence on the quality, content, and intensity of social contacts, planners and designers can affect and, in this case, increase the possibilities for interactions in the street and public landscape (Gehl). Understanding how people treat space and how that space allows, or could allow, for different activities is an important aspect of this research. 


\section{Inviting public space}

To make a space more receptive to necessary, optional and social activities, the quality of that space must be of a good standard. There are many factors that determine whether a space attracts or rejects people (Lister).

It is important that the space is inviting and interlocks the buildings with the surrounding space (Lister). This influences how people move through that space, where pedestrian flows and continuity between spaces is equally important.

Vegetation and water elements add necessary colour and texture to a space (Lister). Without these features, the space runs the risk of being 'hard' and boring. Variety in the space is needed to keep people interested.

It is important that all elements in the space are well maintained, meaning they are clean, unbroken and safe (Lister). Damaged street furniture, detached paving and broken streetlights make a space unattractive and prevent people from using the space.

To create a space of permanency, there must be something to do. These activities can be as simple as sitting, walking, eating, sunbathing, etc (Lister). In addition to this, activities of play often add an extra appeal to a space, whether that be a literal playground or elements that can be interacted with (Lister).

Having areas where people can sit and stand is essential to creating a space that people populate (Lister). A space that does not have these elementary features will simply be used as a thoroughfare. The locations of these areas are equally important. Not everyone wants to sit in the sun, or under a tree, there need to be an appropriate number of seating options that give the user a different experience (Lister).

William Whyte discusses the design of spaces in his book, 'City: Rediscovering the Center', where he investigates what makes a popular space. Much of the focus of this particular investigation revolved around sitting space. When comparing different sites to one another, he discovered that plazas with the 
most seating options tended to be among the most popular (Whyte). While this is not a profound discovery, it reinforces the importance of having a variety of seating options in public space, something that many church spaces do not have.

In 'Rethinking Urban Parks', the authors discuss various threats to public space and spatial inclusion. Where public space was once designed for all members of society, there are now certain patterns of design and management that exclude people (Setha Low). This can also influence the amount of social and cultural diversity. In some cases, the reason for exclusion can be put down to specific design techniques that are used to deter undesirables; however, privatisation, commercialisation and historic preservation are also having negative impacts on how a space is interacted with (Setha Low).

This is particularly relevant when looking at how churches and their exterior space are designed. Churches have long been designed with fences surrounding their exterior space, creating only one point of access. To enjoy the exterior space of the church, the user must pass through that one access point. This often requires passing through the church itself, which people unaccustomed to the activities of the church may find uncomfortable and intimidating.

Historic preservation is another example of design management that negatively effects the church. In a number of cases the church building and surrounding area are designated as heritage buildings. This restricts how much the building or space can be redesigned or altered. In some instances, certain elements in church space are designated as heritage and are thus preserved. This is often to the detriment of the site itself, limiting access and pedestrian connectivity. 


\section{Community engagement}

Key texts:

Religion for Atheists, Rethinking Urban Parks: Public Space and Cultural Diversity, Life Between Buildings: Using Public Space, Urban Design Toolkit, The Quality of Participatory Design.

In 'Religion for Atheists', Alain de Botton discusses elements of what religion did well from an atheists point of view. He discusses how these elements, if replicated, could benefit society in the modern day. One area that proved beneficial to this research was the chapter on community. In this chapter, de Botton states that the idea of neighbourliness began to be disregarded when the emphasis on congregating together to worship God ceased (Botton). He focuses on the inclusive nature of Christianity, "where people are openly told that the love of God and the fellowship of the Holy Spirit belong to all who have assembled" (Botton). This nature of belonging and inclusiveness extends to the idea that everyone is equal. The church gives people a new focus in life, where their social standing in society is irrelevant. As de Botton states, we are constantly judged by the position we hold and what we do, however, in the eyes of the church and God, we are all equal (Botton). This thinking allows people to relate to one another on a level that people do not normally relate.

This piece of literature highlights why the idea of community can be beneficial to society. It is the goal of the Christian church to open its doors to people and grow their congregation. By creating a space outside the church where the church congregation can interact with the general public, both groups can benefit from the communal nature that will be achieved.

In 'Rethinking Urban Parks', Setha Low, Dana Taplin and Suzanne Scheld discuss a set of rules based on William Whyte's principles for promoting the sociability of small urban spaces. They suggest ways to accommodate a diverse range of cultural backgrounds. The rules most relevant to this research are summarised into the following statements; 
- people need to be represented in space, whether that be in urban parks, historic national sites and monuments (Setha Low). More Importantly, their history must be preserved (Setha Low). If people are not represented, they will not use the space.

- creating safe and spatially adequate territories in the overall space enhances social interaction between diverse groups (Setha Low).

- different social standing and ethnic groups must be accommodated for, including how these groups use and value public space (Setha Low). This is essential to making design decisions that sustain cultural and social diversity (Setha Low).

Creating space that encourages interaction gives people the opportunity to be with others in a more relaxed and undemanding way. Jan Gehl states in 'Life Between Buildings', "Being among others, seeing and hearing others, receiving impulses from others, imply positive experiences, alternatives to being alone" (Gehl). Frequent meetings can be established through connections on the street or in public space. These meetings enable friendships and a sense of community to be maintained in a less demanding way, as opposed to a relationship that must be kept up by invitation (Gehl). However, as mentioned previously, these interactions will occur far more frequently when the space is of a high quality, one where people want to stay and spend time.

Because this research is designing in specific community space, there needs to be an element of engagement with the people of that community.

Community participation tools "are a means of identifying community concerns, values and expectations, providing useful information, creating opportunities for involvement in the design process and incorporating the ideas in design decision-making" (Ministry for the Environment). The results enable the designer to be better informed and creates a relationship with that community (Ministry for the Environment). This makes the design process much smoother and stronger. 


\section{Community engagement}

Investigating community based landscape architectural methods presented a number of participatory design documents.

The New Zealand 'Urban Design Toolkit' had a number of techniques related to participatory design and public engagement. These techniques ranged from focus groups, interviews and surveys.

Surveys are a systematic way of determining the views and opinions of a group of people (Ministry for the Environment). They can be anonymous or identifiable and can be undertaken by interview or questionnaire (Ministry for the Environment). By establishing an anonymous survey, large amounts of comparable and easily quantifiable data can be gathered and eventually used to provide objectives for planning future action (Ministry for the Environment).

Survey types most commonly used in urban design projects include 'public satisfaction surveys' and 'three question surveys' (Ministry for the Environment). These documents focus primarily on surveys that identify what the public think about a space and how it could be improved. This research would look to employ surveys that not only collect information on how the space could be improved, but also personal information around where people come from to get to the space, by what means do they get there and what they do when they are there.

In 'The Quality of Participatory Design', Katherine Crewe discusses the attitudes of a group of architects and landscape architects employing participatory design on the Boston Southwest Corridor between 1976 and 1986. Three main areas were examined in the study: the designers' opinions on the quality of participatory design, their evaluation of citizens' aesthetic contributions, and their reactions to community wishes as they encountered them.

The section dedicated to community wishes and how to accommodate them was particularly relevant to this research. This text demonstrated how to use community advice and feedback, which helped inform the way that the anonymous survey was used in this research. 


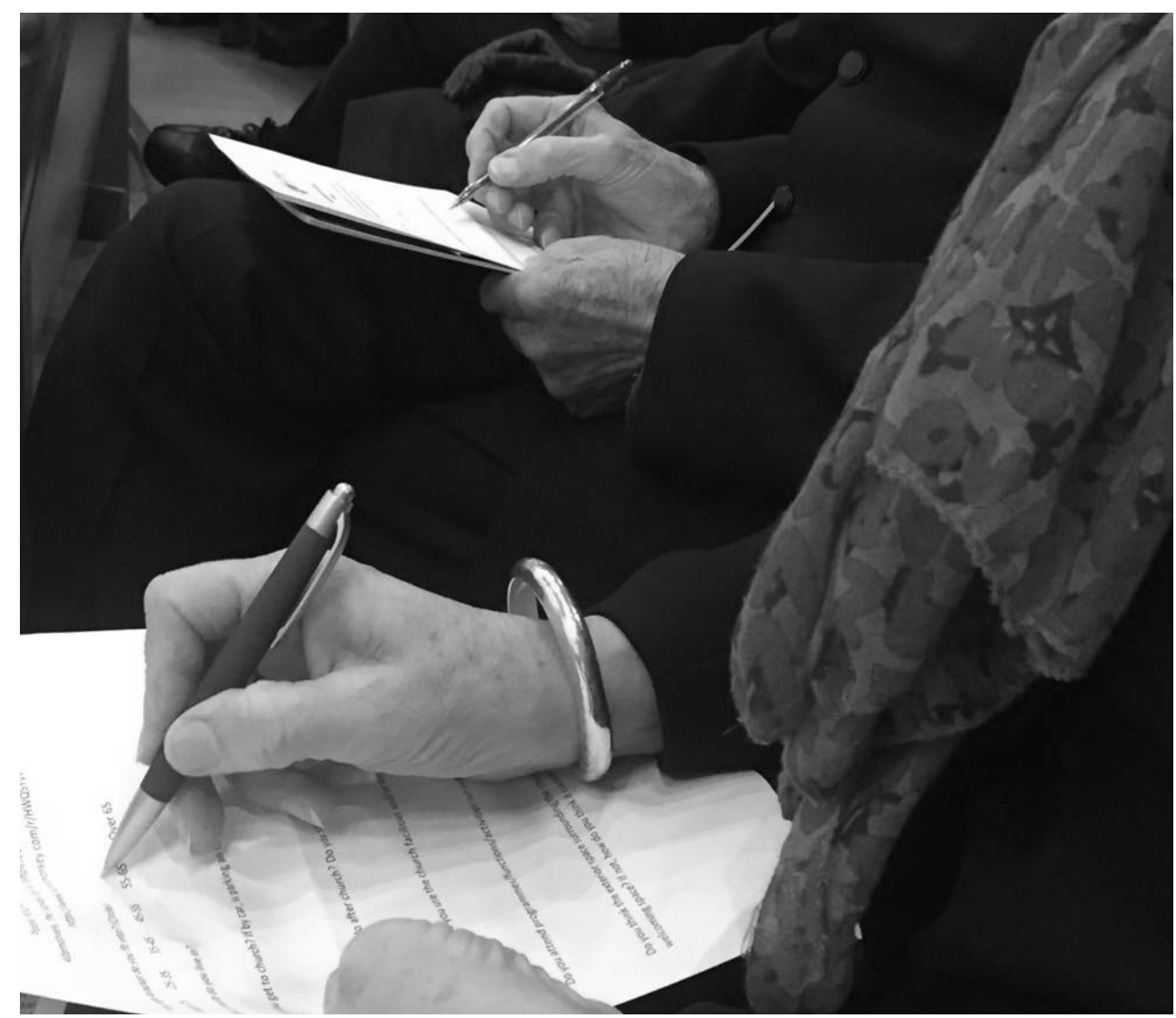

Fig.2.05. People filling out survey questionnaire

The study was based primarily on findings from a series of interviews. Each interview was divided into three sets of questions, each opening with a leading general question soliciting a short positive or negative answer, followed by open-ended questions designed to solicit full and detailed answers (Crewe). This method of community engagement enabled the designers to gather useful information and opinions from the participants. This same questionnaire method was applied to this research in the form of interviews or surveys. 


\section{Relevant literature conclusion}

The literature analysed helps to establish a strategic set of design techniques that can be incorporated into the design phase later in the research.

The design techniques include:

- Manipulating space - changing pedestrians perception of space and how they use it with subtle design moves. Altering the pace of pedestrians in an area to encourage them to move into another area.

- Extending surface materials from one space to another to bridge the two spaces and create an obvious transition.

- Using vegetation and colour in the space to make it more appealing and enticing to people.

- Strategic seating options in the space. Having seating in a variety of environments.

- Creating different areas of activity in a space to attract a more diverse range of people.

- Using surveys and interviews as a means of engaging with the church community. 


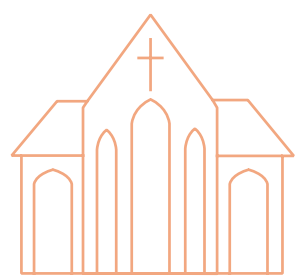




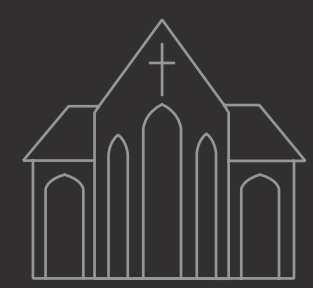




\section{Positioning the research}

within relevant precedents

The precedents analysed in this section look at different examples of how spaces around the church have been redesigned. The first is a European example of a redesigned church square in Germany. The second is a New Zealand example of a church in Auckland. The third is an example of a modern church design in Paris. 


\section{Church Square St. Remigius - Germany}

Church square in Borken, Germany is an example of how a town square and a church have been merged to create a more open and less privatised space. The square had previously been cut off from the church with large trees creating a boundary, splitting the two areas and making the sight shady and dull. Carparks also added to the problem with the church being surrounded by cars limiting pathways and access ways.

This research encountered the same problems and potential opportunities as this church space.

The redesign of the square established a more fluid connection between the two areas creating one space. The parking spaces have been removed to make space for outdoor restaurants, bicycle-parking racks and a play area making the space more pedestrian dominant. This redesign of the square has greatly improved how people move through the space and has made the exterior church space more open to the public, making it more inviting and welcoming to the movements of passers-by.

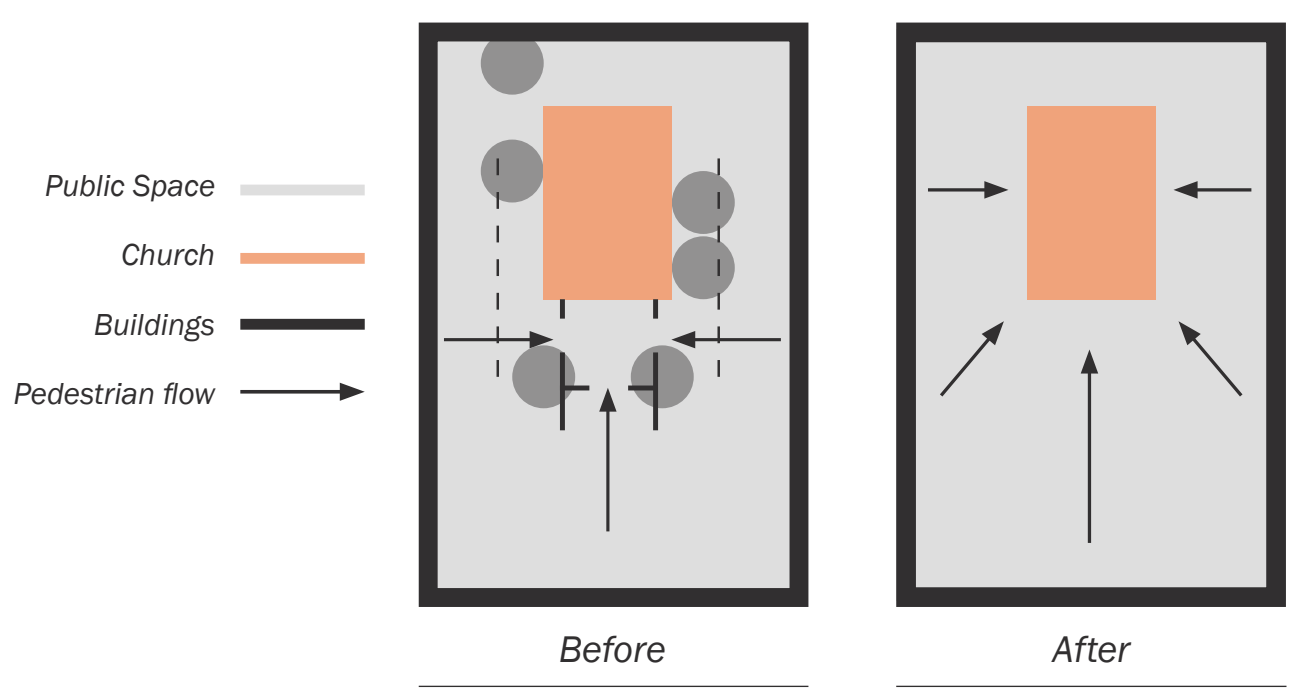


This content is unavailable.

Please consult the print version for access.
This content is unavailable.

Please consult the print version for access.
This content is unavailable.

Please consult the print version for access.
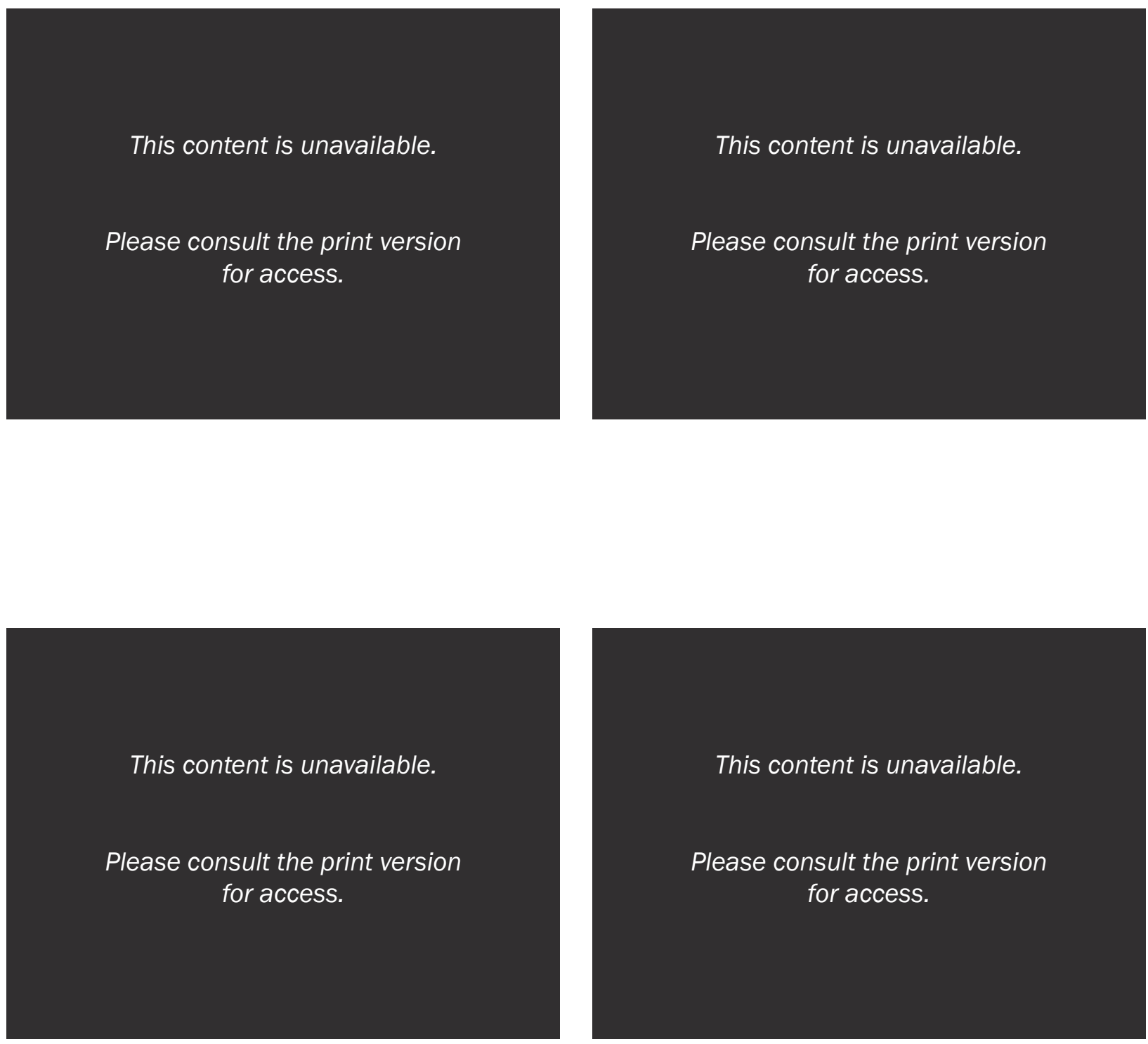

Fig.2.07. (Left Top) Church Square St. Remigius, Borken Image 1

Fig.2.09. (Left Bottom) Church Square St. Remigius, Borken Image 2
Fig.2.08. (Right Top) Borken, St. Remigius

Fig.2.10. (Right Bottom) Church Square St. Remigius, Borken Image 3 


\section{A New Zealand example St Patrick's Square - Auckland}

St Patrick's Square in Auckland is a good example of how public space and church space can work together. The space created allows pedestrian movement to leave the street and move into the slower paced nature of the park and church area.

The aims and objectives were particular interesting and helped to inform the research. These were, to;

- "Celebrate the Square's heritage, religious and cultural significance and its relationship to the Cathedral" (Architizer).

- 'Retain and enhance the Square as an 'urban oasis' where people can relax, meet and socialise" (Architizer).

- "Create a safe, comfortable and enjoyable day and night-time environment" (Architizer).

- "Use high quality materials befitting the unique nature of the place" (Architizer). 
This content is unavailable.

Please consult the print version for access.
This content is unavailable.

Please consult the print version for access.
This content is unavailable.

Please consult the print version for access.

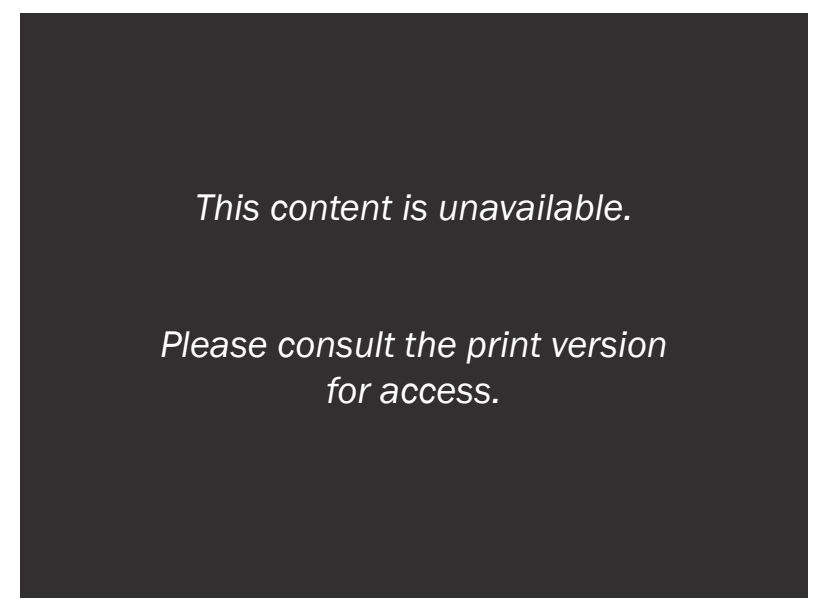

This content is unavailable.

Please consult the print version for access.
Fig.2.11. (Left Top) St. Patrick's Square Image 1

Fig.2.13. (Left Bottom) St. Patrick's Square Image 3
Fig.2.12. (Right Top) St. Patrick's Square Image 2

Fig.2.14. (Right Bottom) St. Patrick's Square Image 4 
This design exemplifies how the surrounding area of a church can be adapted into a space that is shared by a community and equally how the space can be interacted with by the church community. It demonstrates how pathways can be adapted to a more sympathetic form and how they can make a church space more inviting. Circulation and movement has been achieved through the use of these pathways which allows different communities to interact. The garden's pathways cut through a built up residential area and offer access to the backs of many of these buildings, serving as a back garden space.
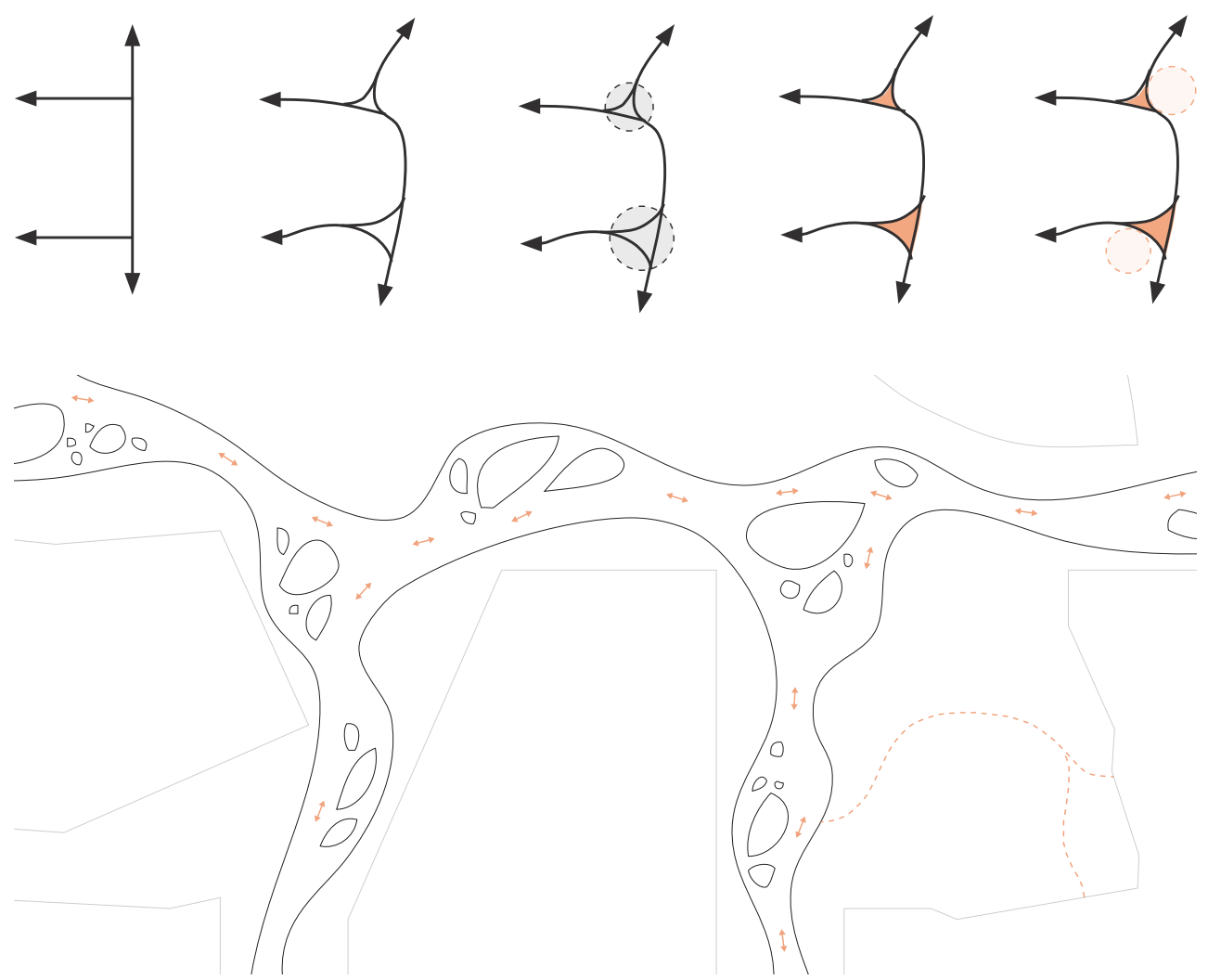

Fig.2.15. Circulation diagram 
This content is unavailable.

Please consult the print version for access.
This content is unavailable.

Please consult the print version for access.
This content is unavailable.

Please consult the print version for access.

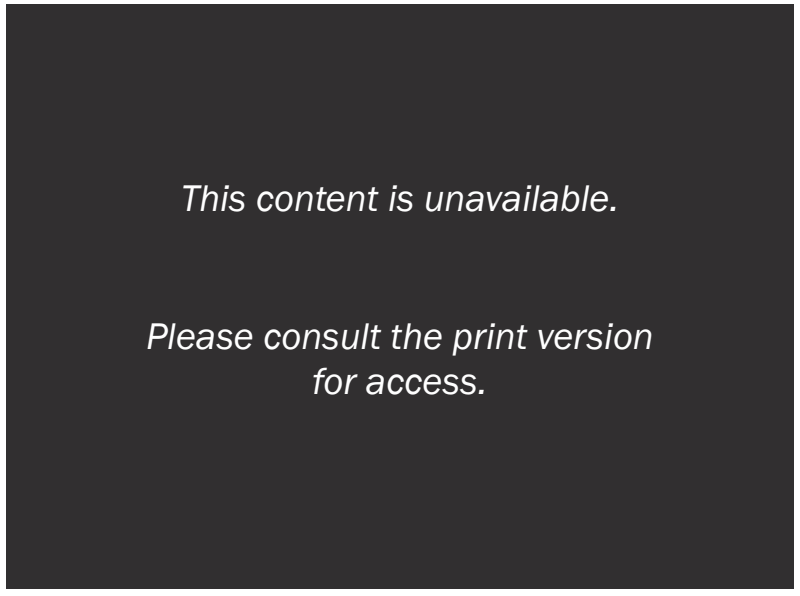

Fig.2.17. (Right Top) B4 Island Heart Garden Image 2

Fig.2.19. (Right Bottom) B4 Island Heart Garden Image 4 


\section{Relevant precedents conclusion}

By basing the precedents on a European, New Zealand and modern church example, the research gained insight as to how landscape architects approach the re-design of exterior church space.

Each precedent highlighted ways of improving the exterior space of churches . With the aims and objectives of this research in mind, it is evident that the same opportunities could be explored across selected sites.

Techniques for design were identified in each of the precedents. These include:

- De-cluttering the space in front of the church to make it more open and inviting.

- Creating thoroughfares around the church to create better pedestrian connectivity in the space.

- Creating areas of rest and permanence where there is a significant change in pace from the surrounding area.

- Creating open space and improving the transitions in and around the church.

- Using high quality materials to make the space more interesting and up to date.

These techniques will help to inform the design phase later in the process. 


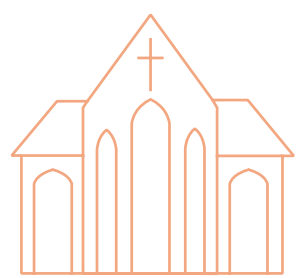




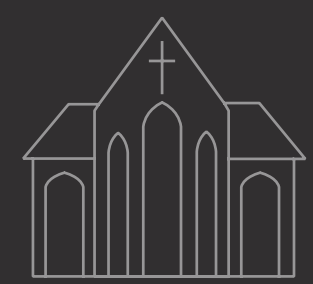

CHAPTER THREE 


\section{Site analysis}

Scope of research

The following chapter identifies the scope of the research and positions it in an urban context. Churches around Wellington were identified and analysed to gain a better understanding of the New Zealand model. Analysing the physical qualities of these sites and discovering what the strengths, weaknesses and potential opportunities were, was an essential part of this analysis. 


\section{Wellington inner city}

Given the nature of this research and the familiar decline of people following religion across the country, this research could be conducted anywhere where with a significant number of churches. Wellington was an easily accessible place for the scope of the research.

The inner city location enabled the research to identify a multitude of churches with the common trend of being amongst urban public space. Focussing on the inner city also meant there was more opportunity for diverse public engagement. If this research was to be conducted in suburban areas, the local population of that specific area may not reflect a diverse range of people. 


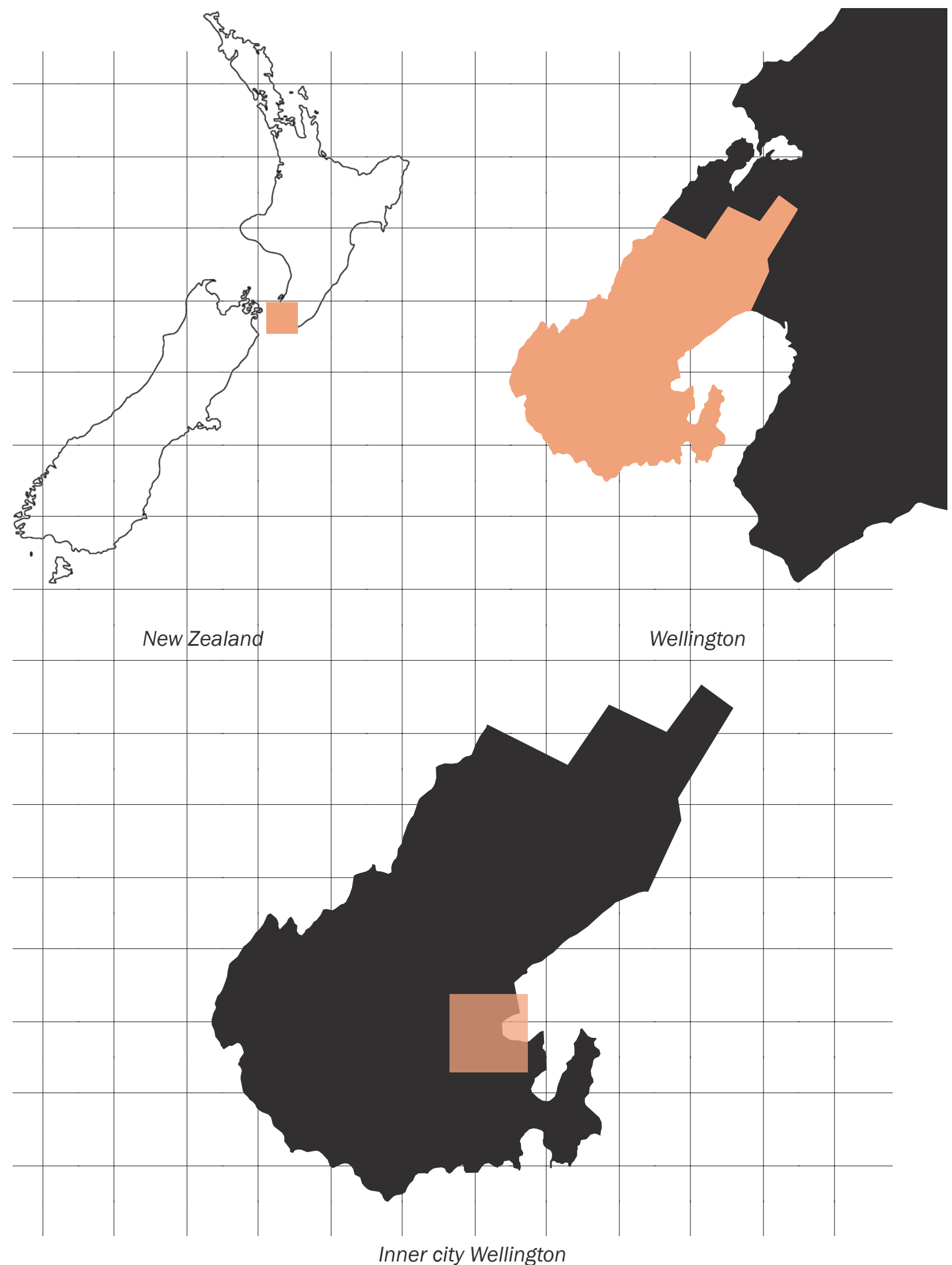

Fig.3.01. Scope of the research diagram 


\section{Criteria for church case study}

There were three key criteria for choosing churches to study. To gain a wellbalanced research study, the sites identified were a mix of denominations, dedicated church spaces and size. Focussing on these three criteria meant there was no set 'type' of church being researched and no bias, as every church was chosen with the three criteria in mind.

\section{Mix of denominations}

A mix of church denominations were analysed to record any differences or similarities between the different groups of the Christian church.

\section{Dedicated church spaces}

It was important to the research that the church buildings were designed specifically for the church and were not churches run out of regular buildings.

\section{Diversity in size of space}

To have a mix in size of space and building. Focussing on different sized spaces helped to distinguish the commonalities and differences across sites. 

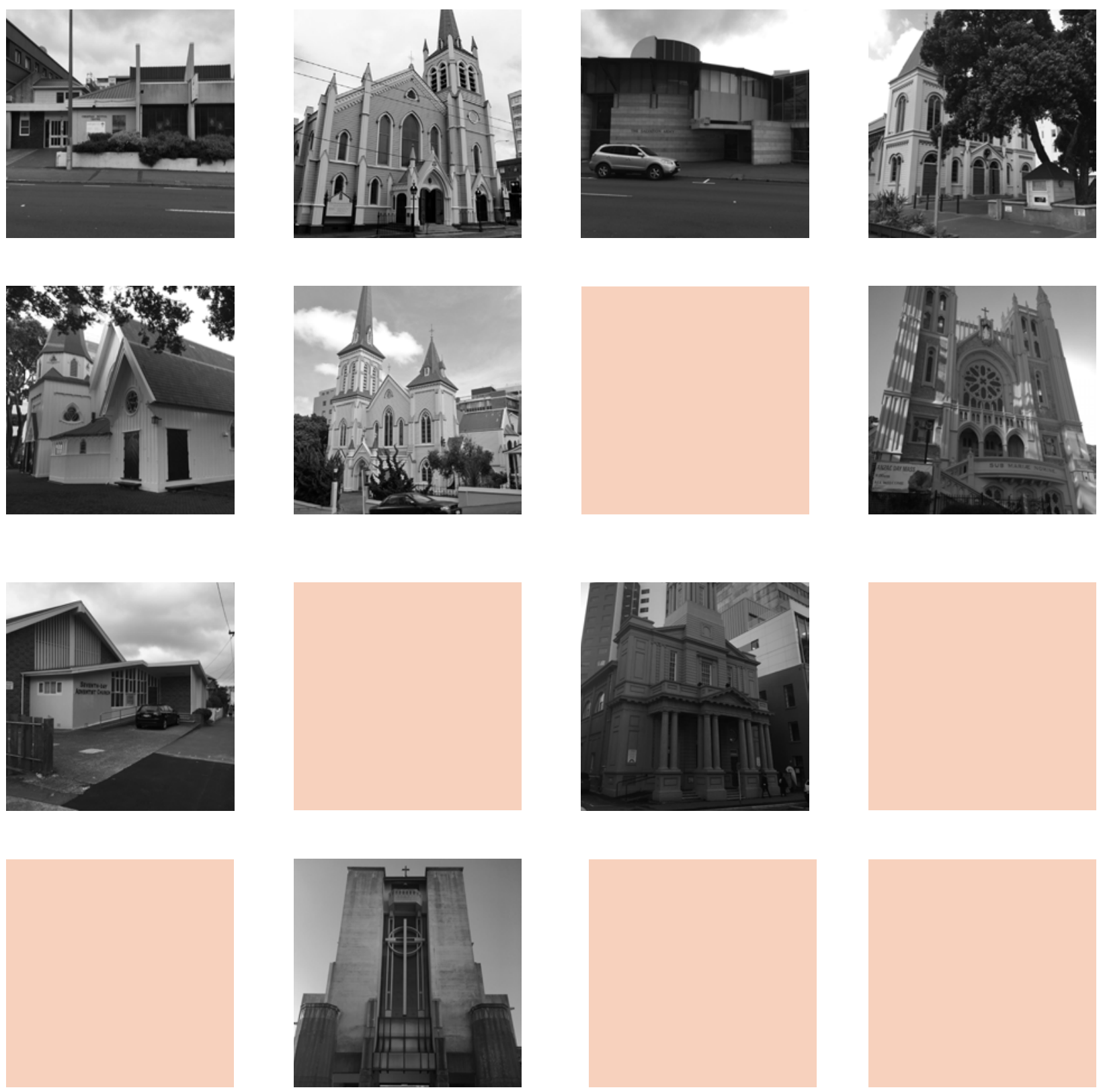


\section{Wellington city christian churches}

\section{0 selected churches}
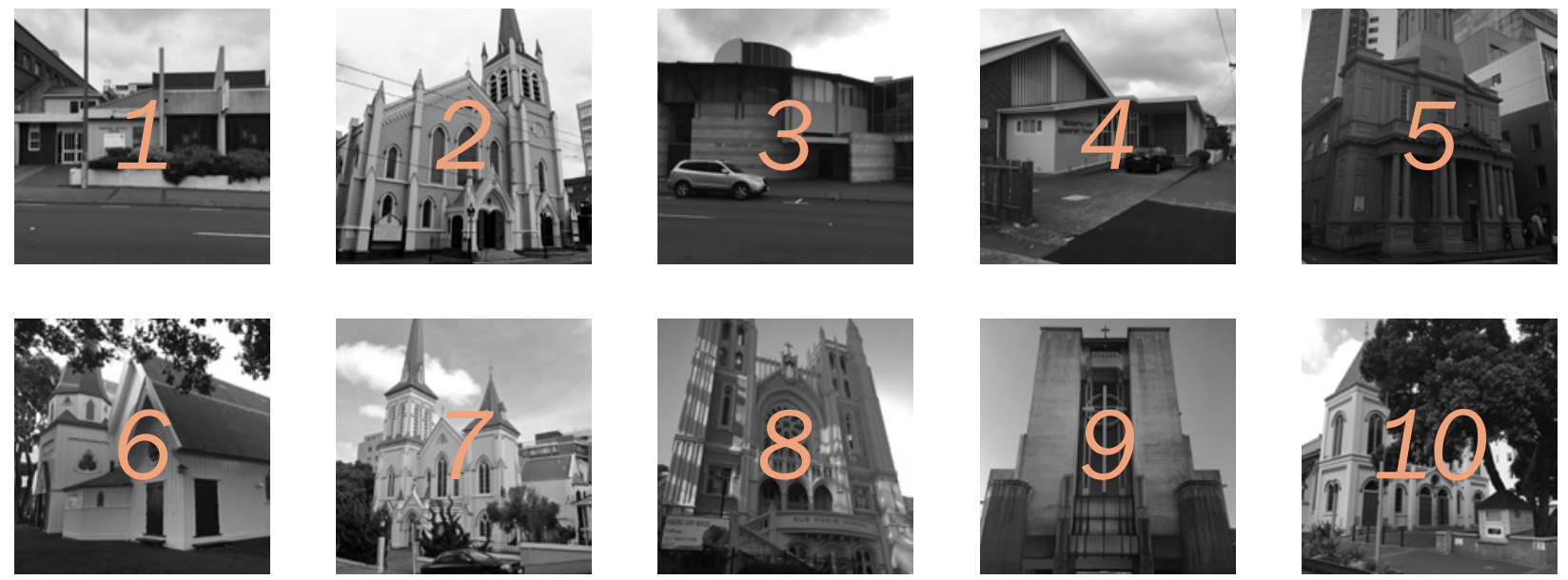

1 Christian Revival Centre

$6 \quad$ Old St Paul's

2 St Peter's Anglican Church

7 St John's Presbyterian Church

3 Wellington City Salvation Army

8 St Mary of the Angels

4 Wellington Seventh Day Adventist

9 Wellington Cathedral of St Paul

5 St Andrew's on the Terrace

10 Wellington Methodist Parish 



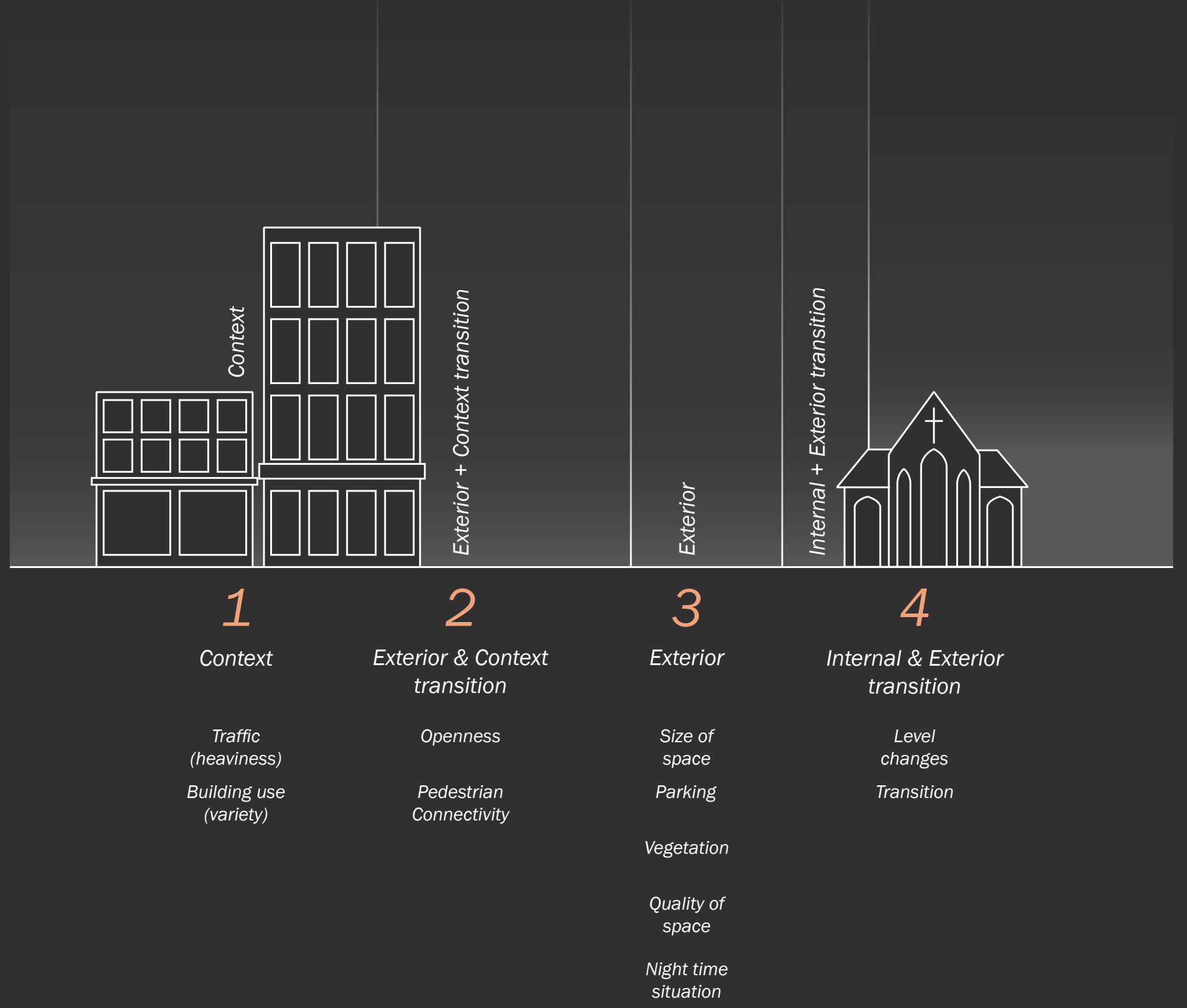




\section{Comparative analysis diagram}

Each of the ten sites were analysed under the same parameters;

- what was happening in the context, (traffic, Infrastructure)

- how the surrounding area interacted with the church space, (pedestrian connectivity, openness)

- how the exterior space worked, (size of space, parking and hard landscape, vegetation, night time situation, quality of space)

- how that space then transitioned into the interior of the church (level changes, transition) 


\section{Traffic}

New Zealand cities are structured to accommodate vehicles, often due to excessive urban sprawl. Because of this, it was important to investigate the context of each site in terms of vehicular traffic flows.

Evident in Wellington is an emphasis on the structuring of roads. Wellington has a relatively small inner-city area with many key roads only allowing one-way traffic.

Not only was it important to consider how heavy the traffic was, but also to look at how the church congregation accessed the church. How does the structure of the road allow for access to the church parking spaces?

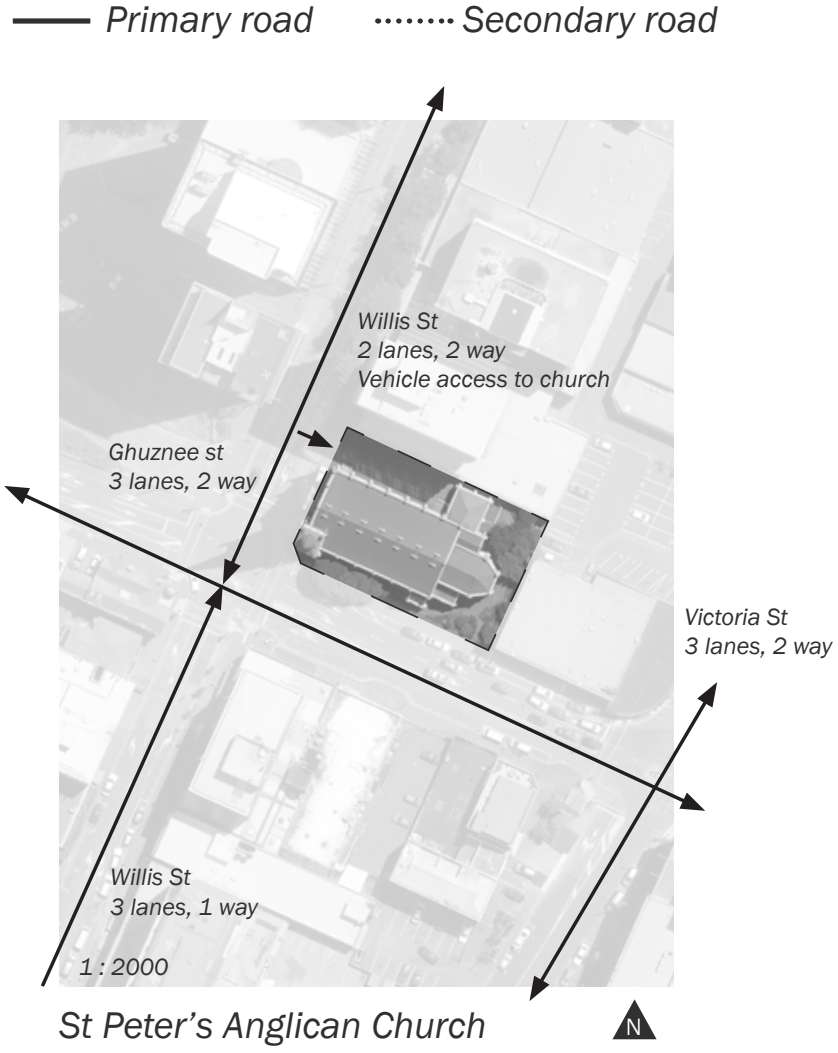

Fig.3.07. (Left Bottom) St Peter's traffic
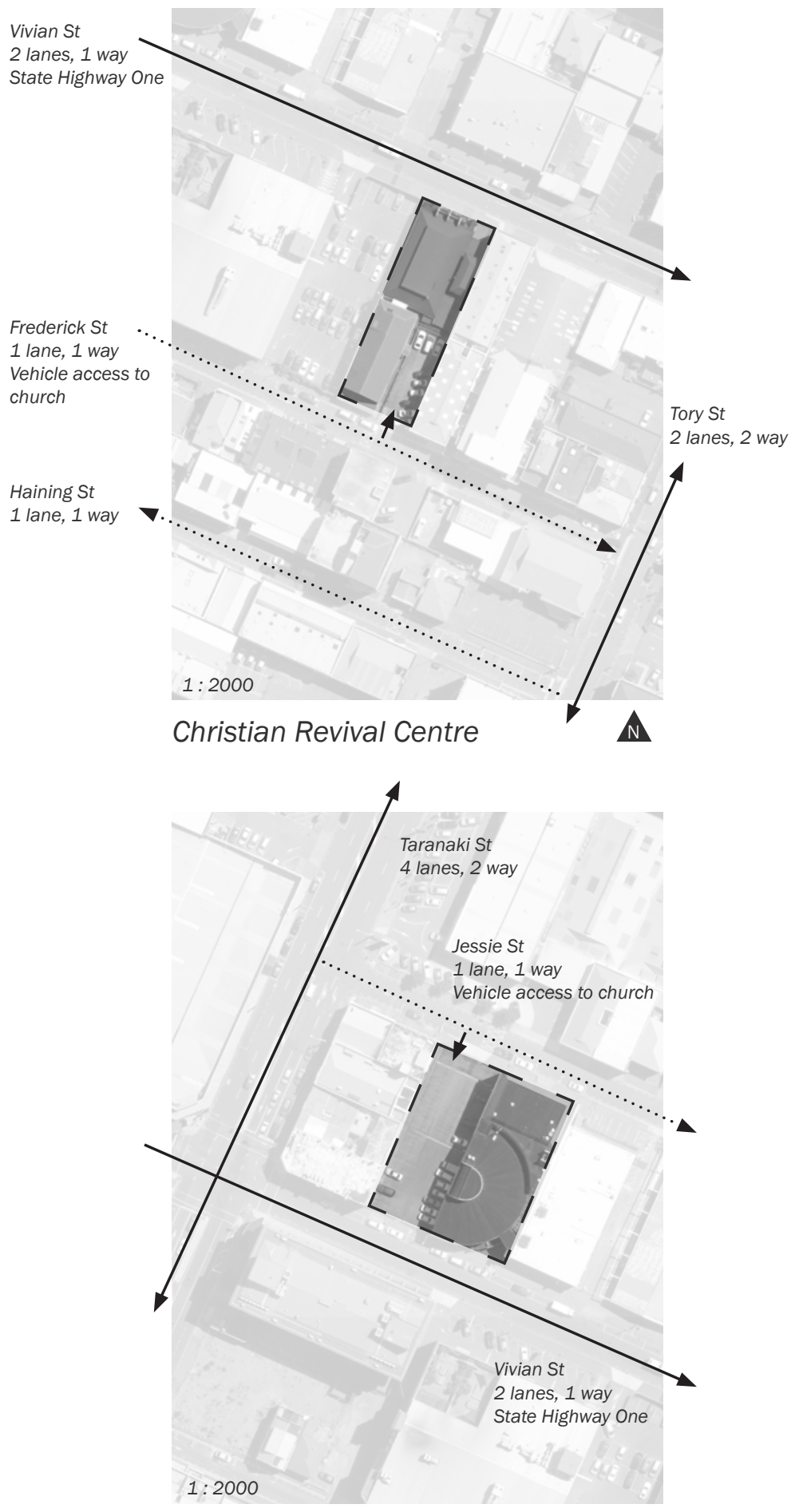

Wellington City Salvation Army

Fig.3.06. (Right Top) Christian Revival traffic Fig.3.08. (Right Bottom) Salvation Army traffic 

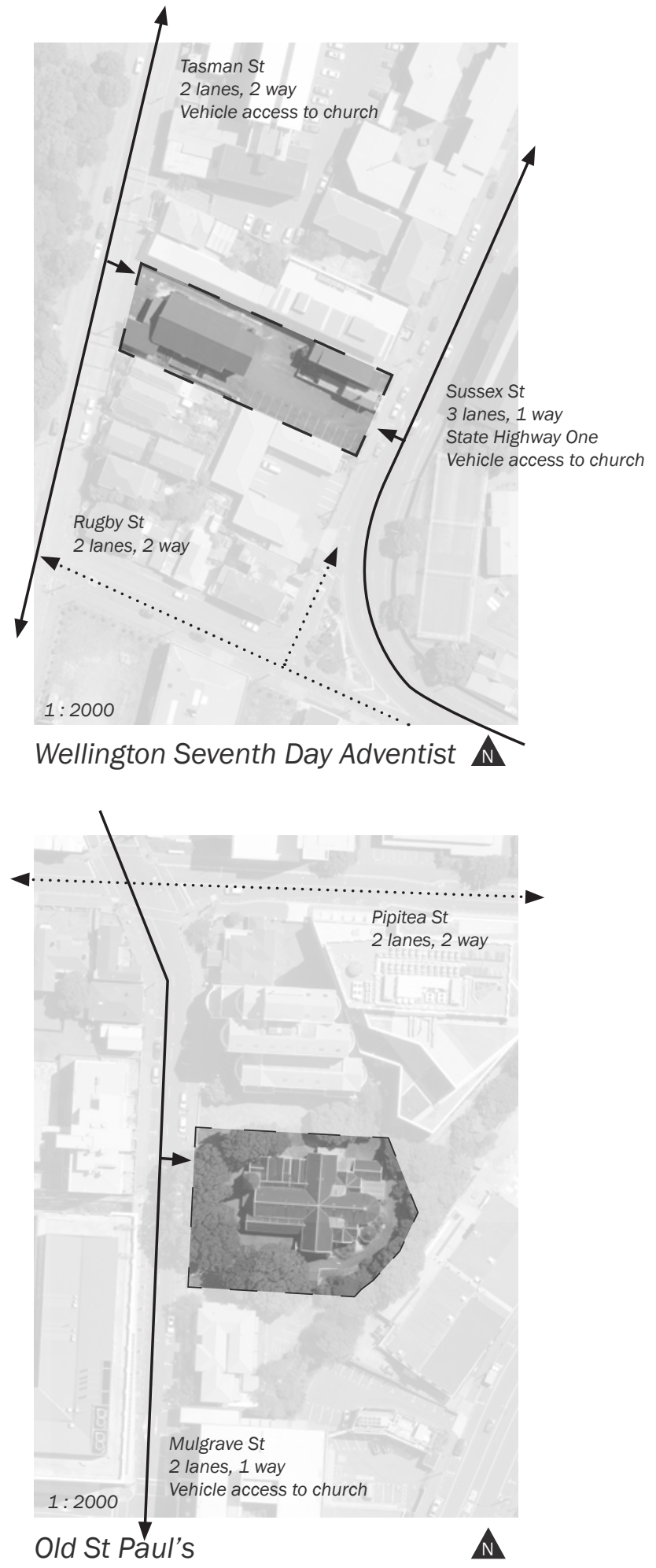

Fig.3.09. (Left Top) Seventh Day Adventist traffic Fig.3.11. (Left Bottom) Old St Paul's traffic
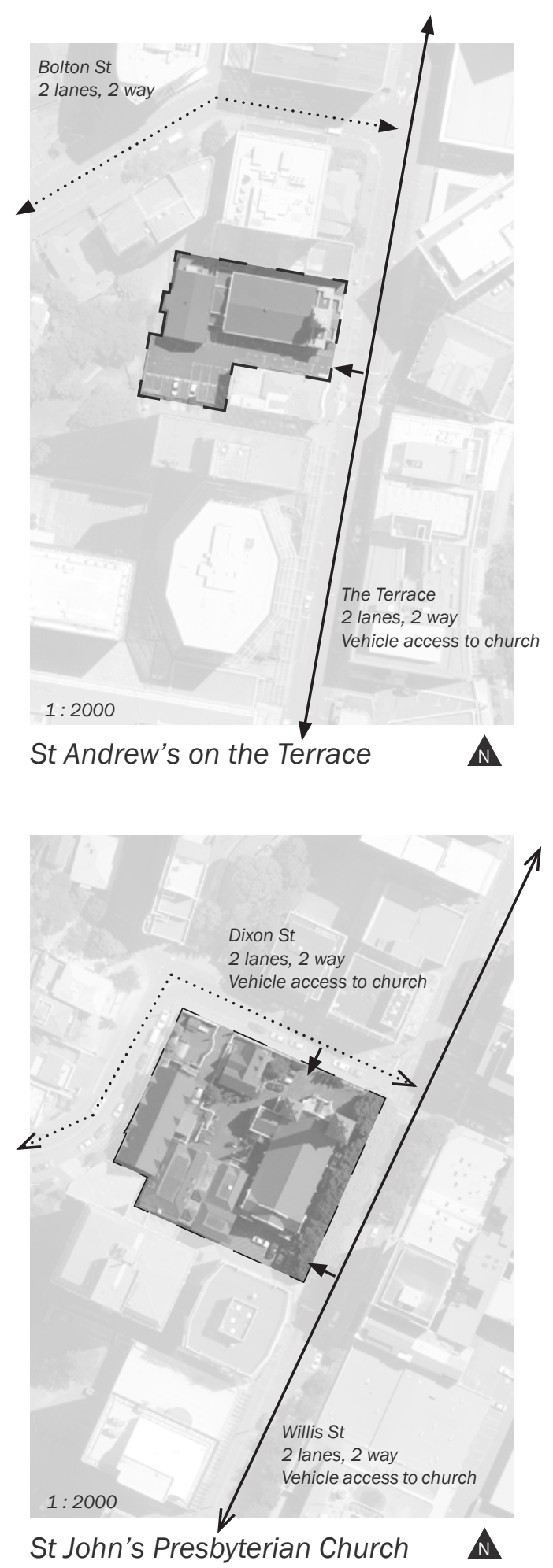

Fig.3.10. (Right Top) St Andrew's traffic Fig.3.12. (Right Bottom) St John's traffic 


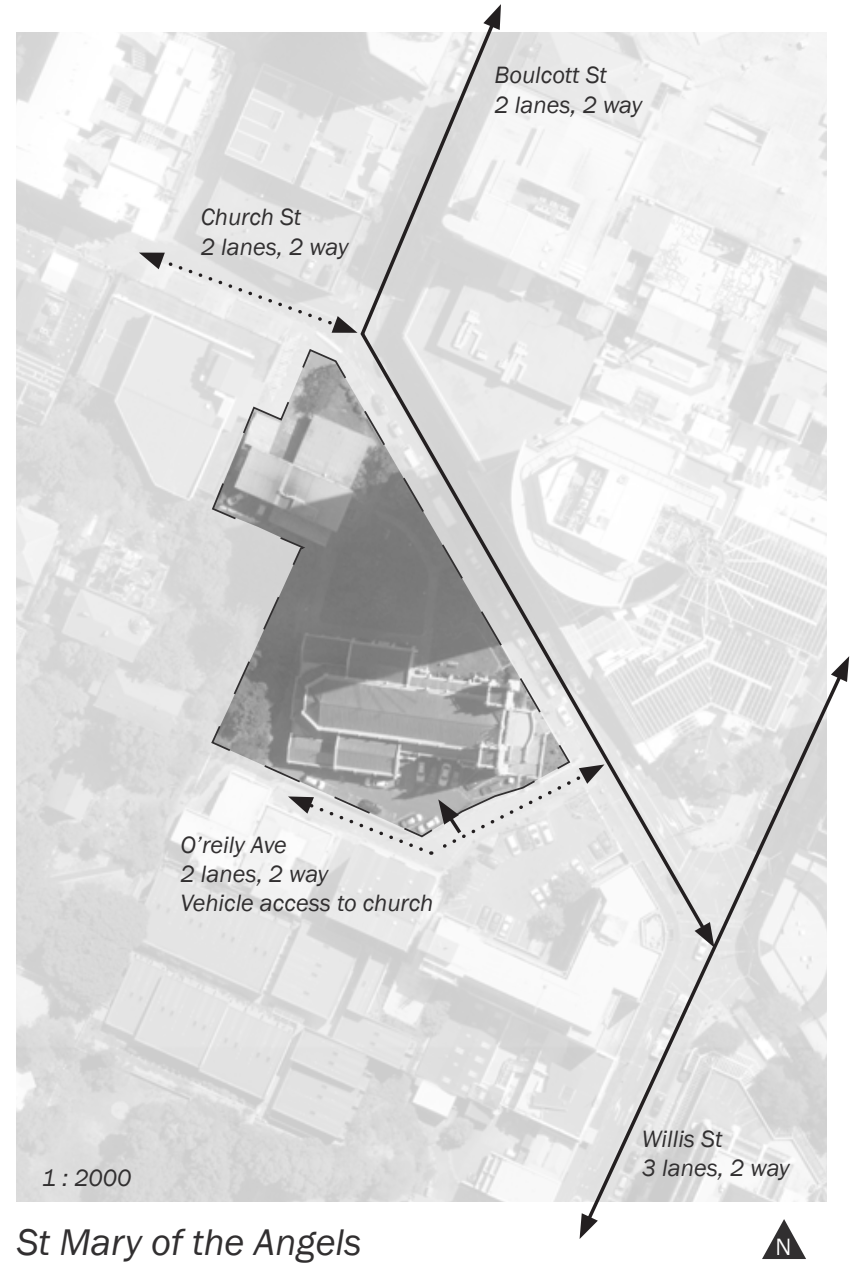

St Mary of the Angels

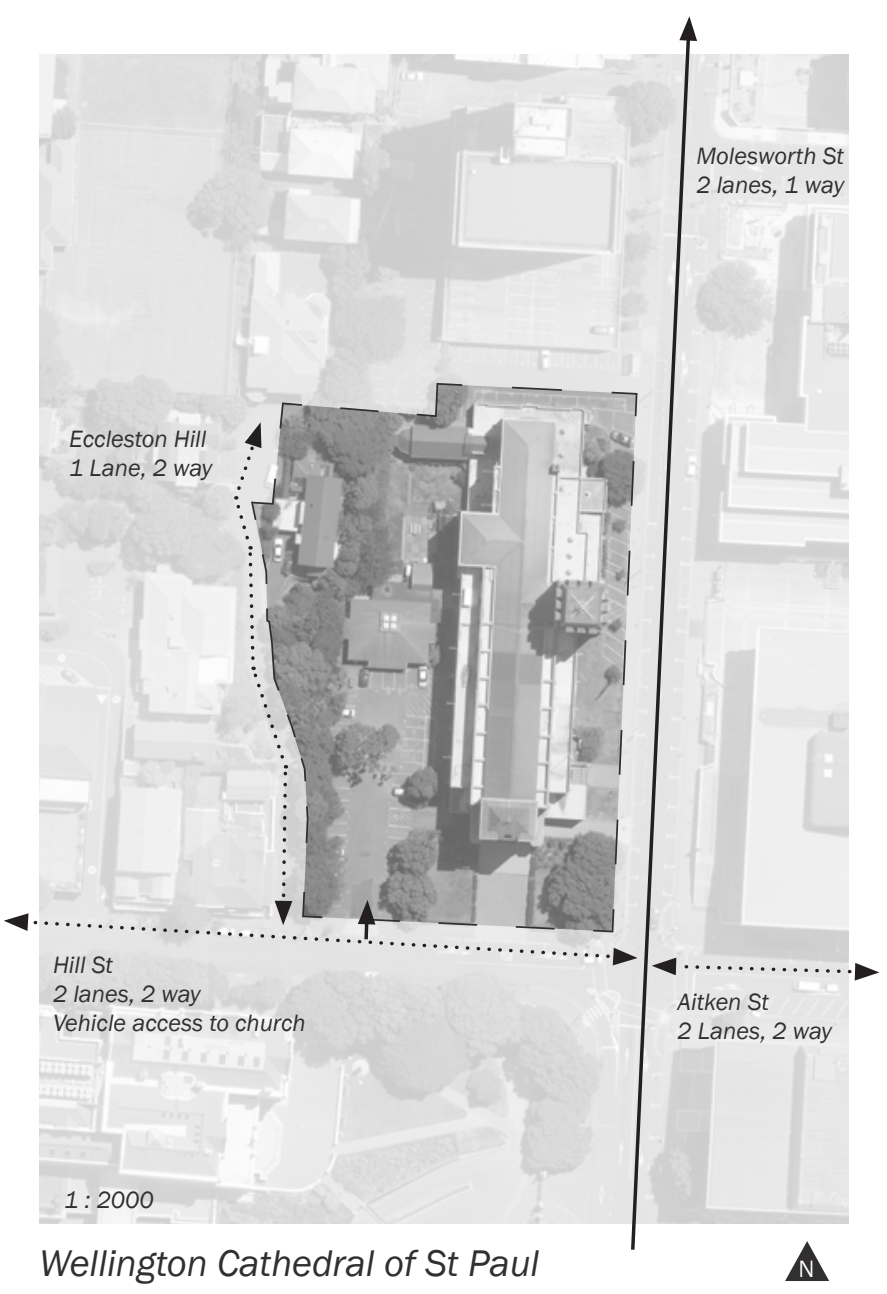

Wellington Cathedral of St Paul 


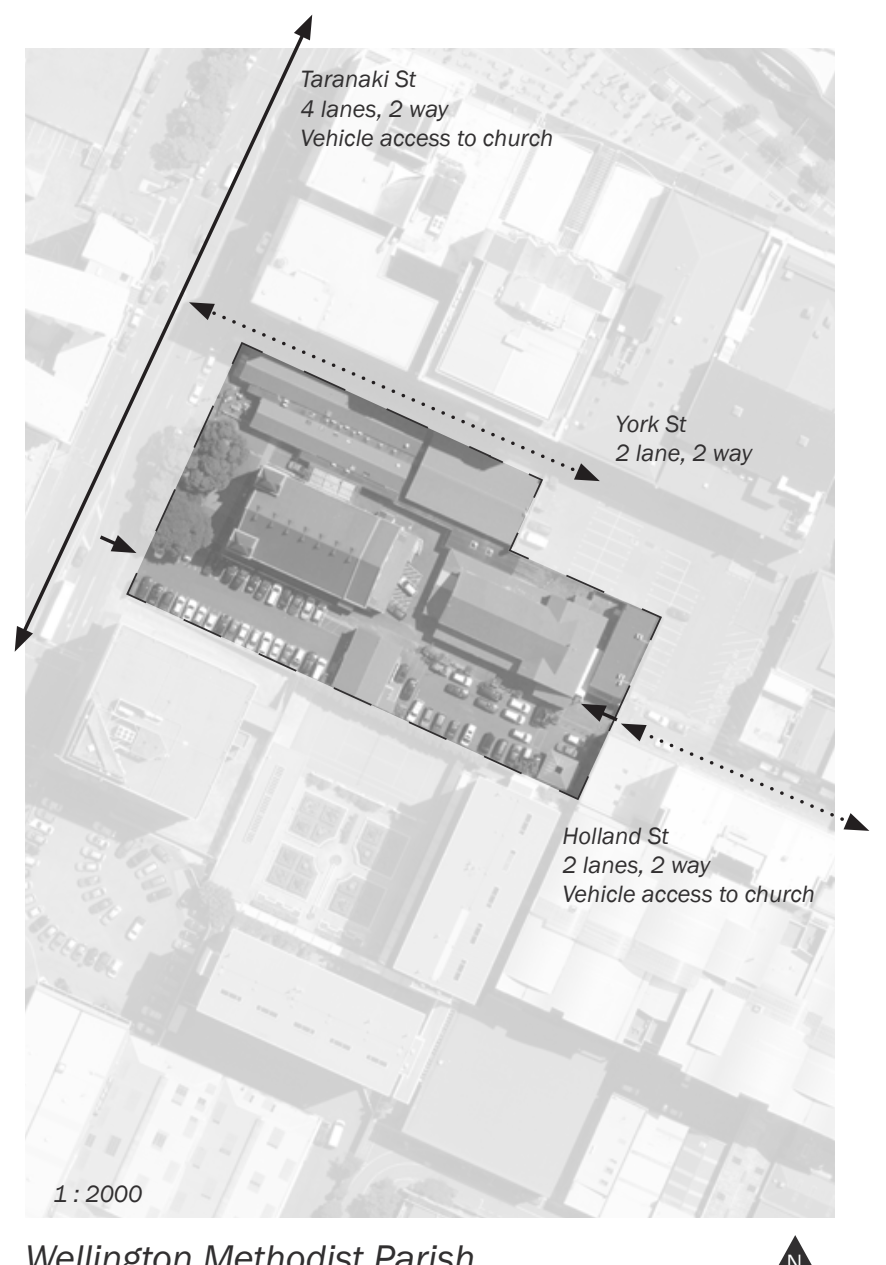

Wellington Methodist Parish

\section{Conclusions Context - Traffic}

It became evident that many of the church sites are situated on densely populated traffic routes, with three of the ten located on State Highway One. In these cases, the main entrance to the church is located relative to the highway. For example, the Wellington City Salvation Army main entrance is located on Vivian Street (State Highway One) with another entrance at the rear of the church building on Jessie Street. Access to the church car park is located on the quieter Jessie Street side. 


\section{Building use}

It was important to examine surrounding buildings to gain an understanding of how the area functioned as a whole. Designing functional outdoor space relies on catering to the needs of the immediate community. Understanding how surrounding buildings are utilised is crucial in terms of identifying the needs of the people being designed for. Midland Park located in the Wellington central business district is an example of this. Surrounded by office buildings, it is at its busiest during weekdays when office workers are meeting or taking lunch breaks.

Areas surrounded by buildings that serve different purposes and cater to different groups have a far more diverse range of people available to utilise the public space.

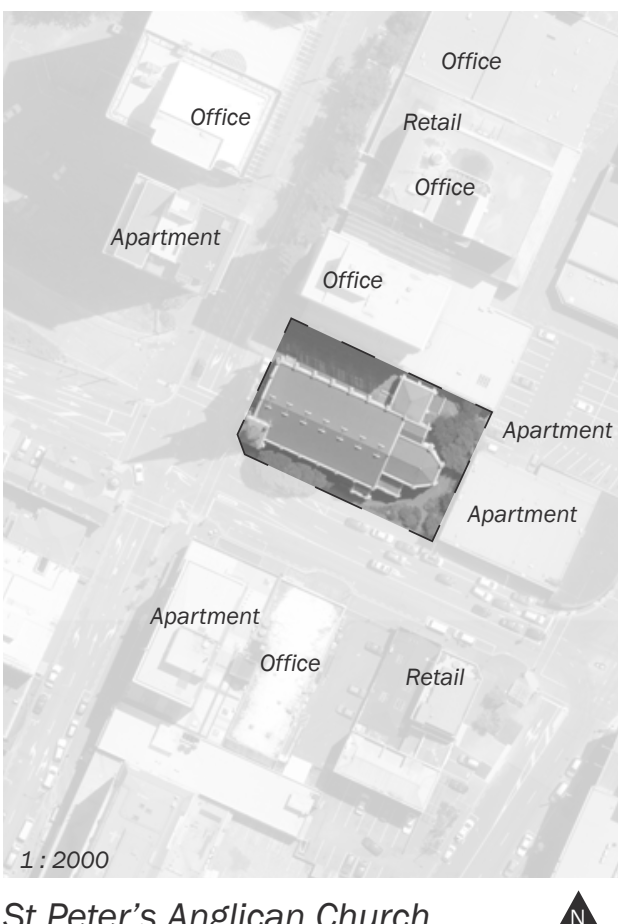

Fig.3.17. (Left Bottom) St Peter's building use
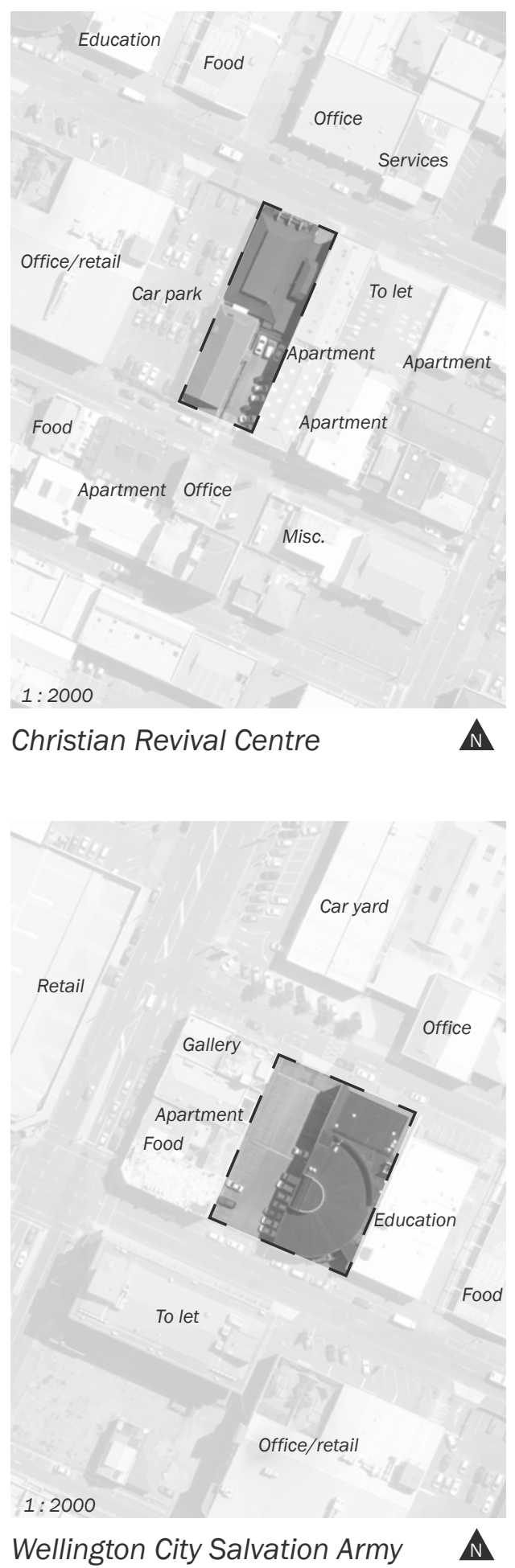

Fig.3.16. (Right Top) Christian Revival building use Fig.3.18. (Right Bottom) Salvation Army building use 


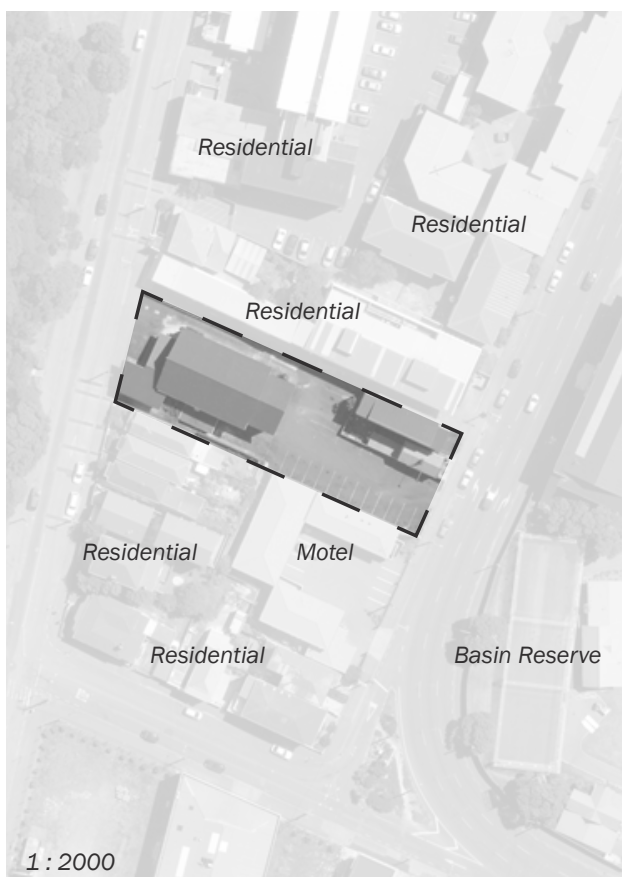

Wellington Seventh Day Adventist $\mathbf{M}$

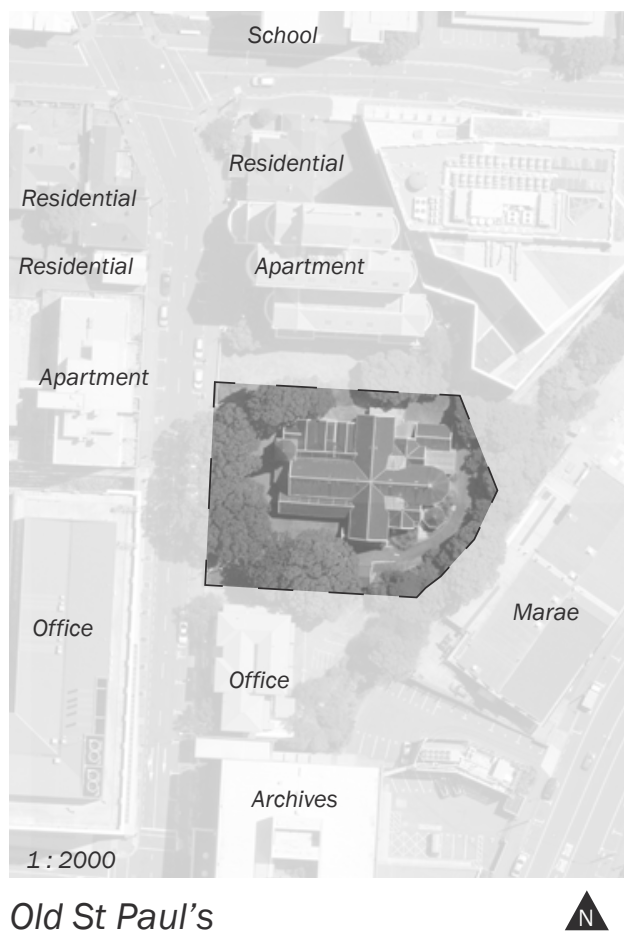

Fig.3.19. (Left Top) Seventh Day Adventist building use Fig.3.21. (Left Bottom) Old St Paul's building use
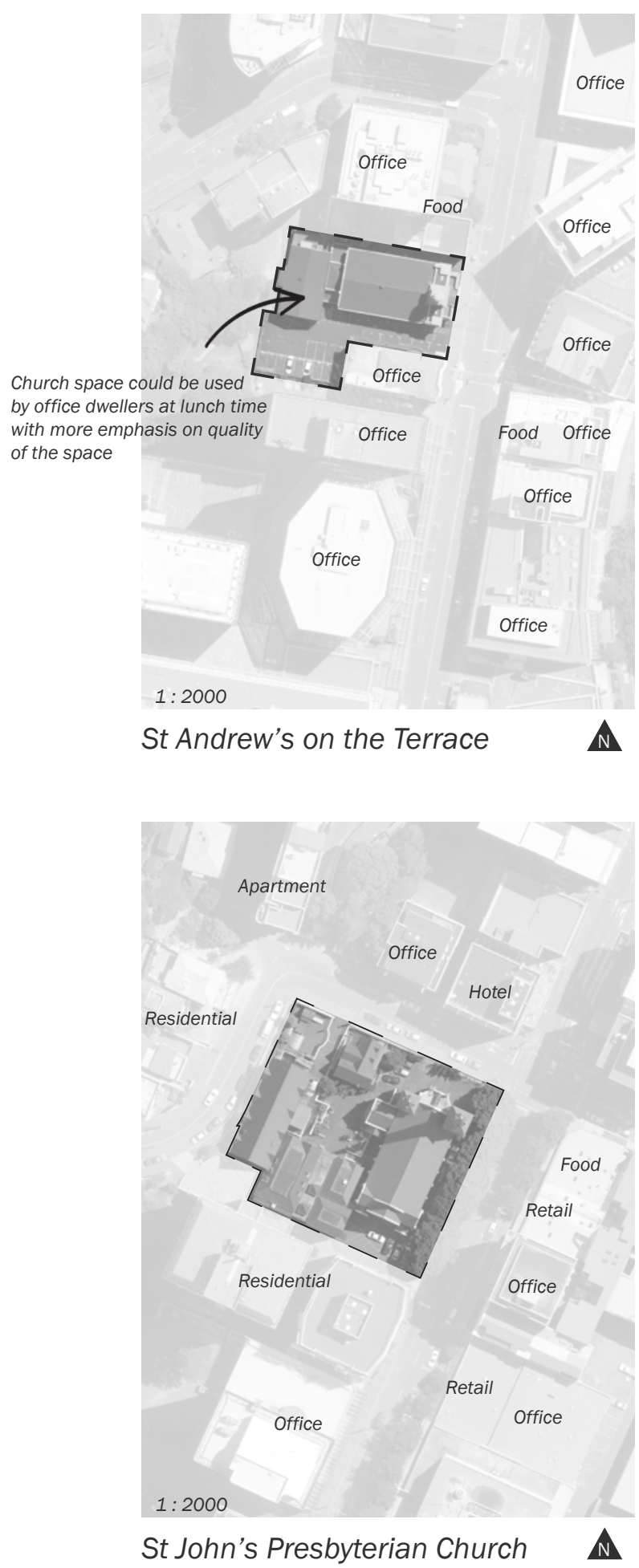

Fig.3.20. (Right Top) St Andrew's building use Fig.3.22. (Right Bottom) St John's building use 


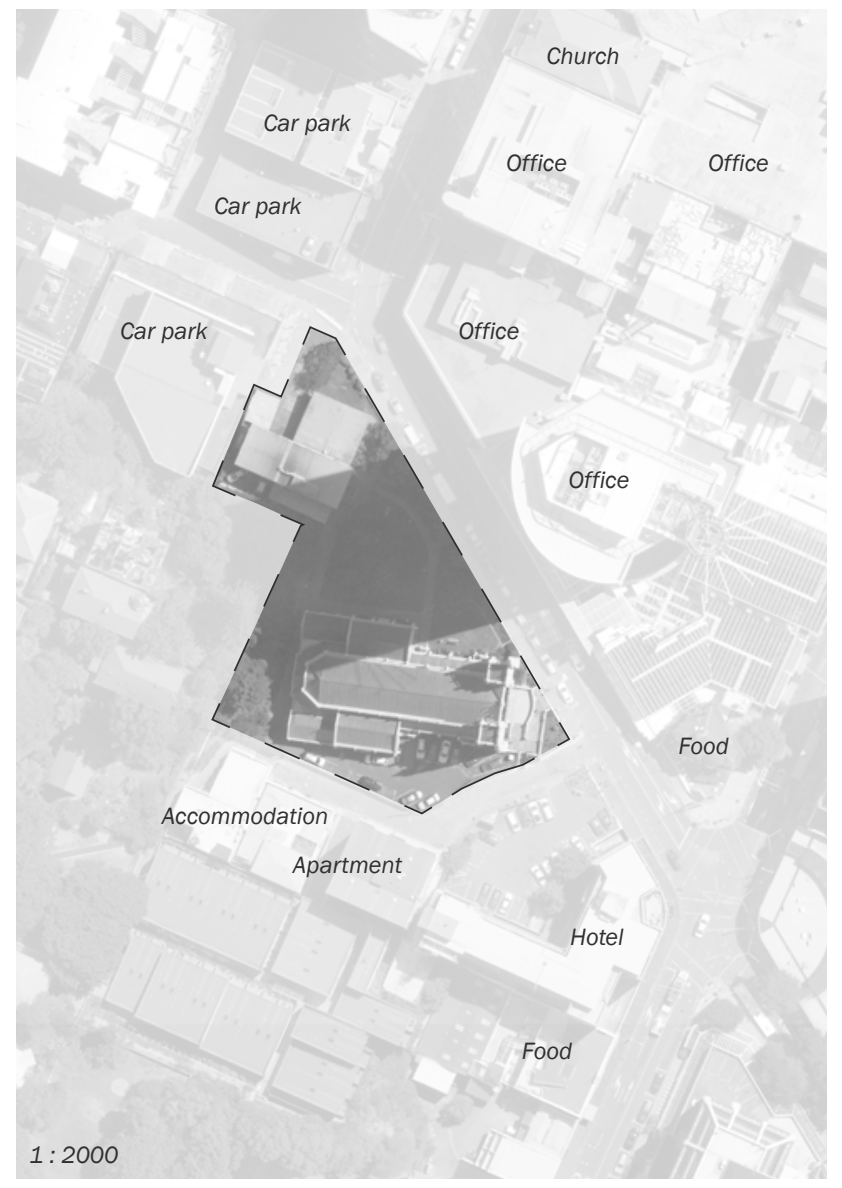

St Mary of the Angels

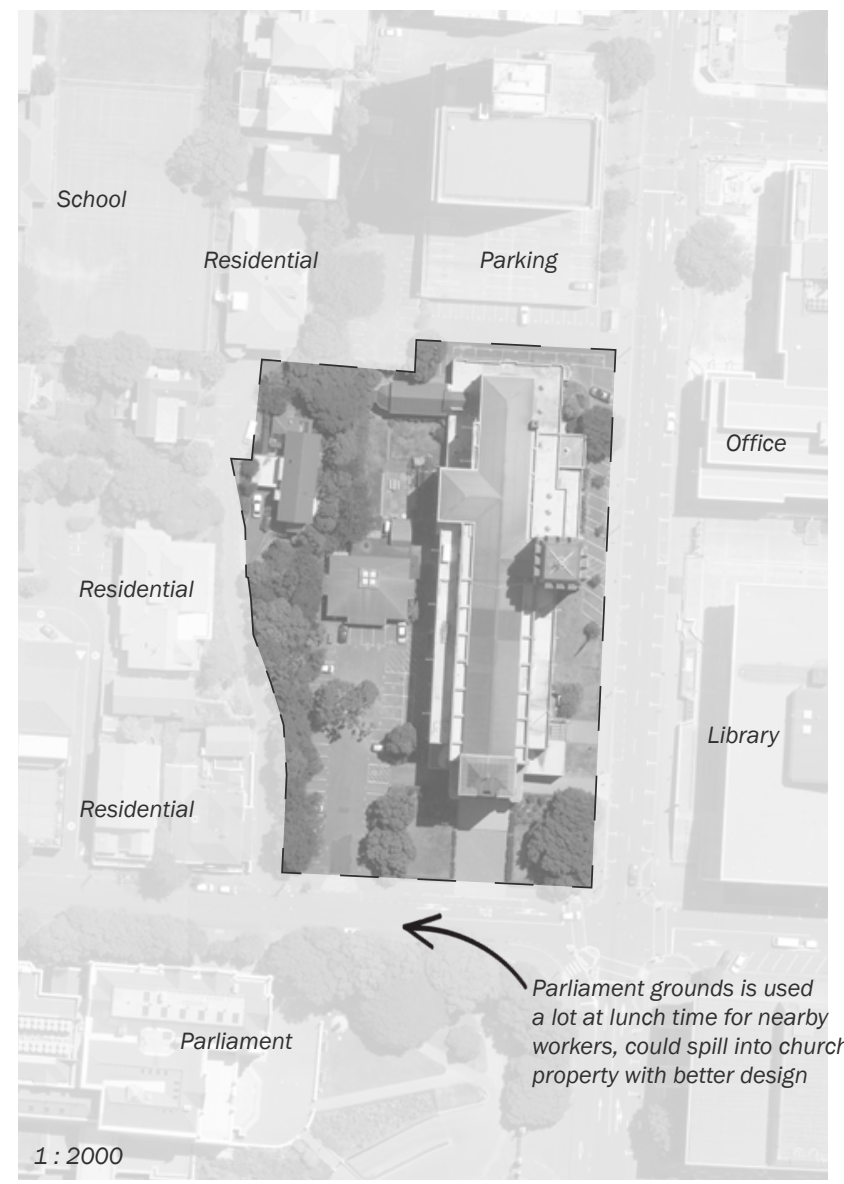

Wellington Cathedral of St Paul 


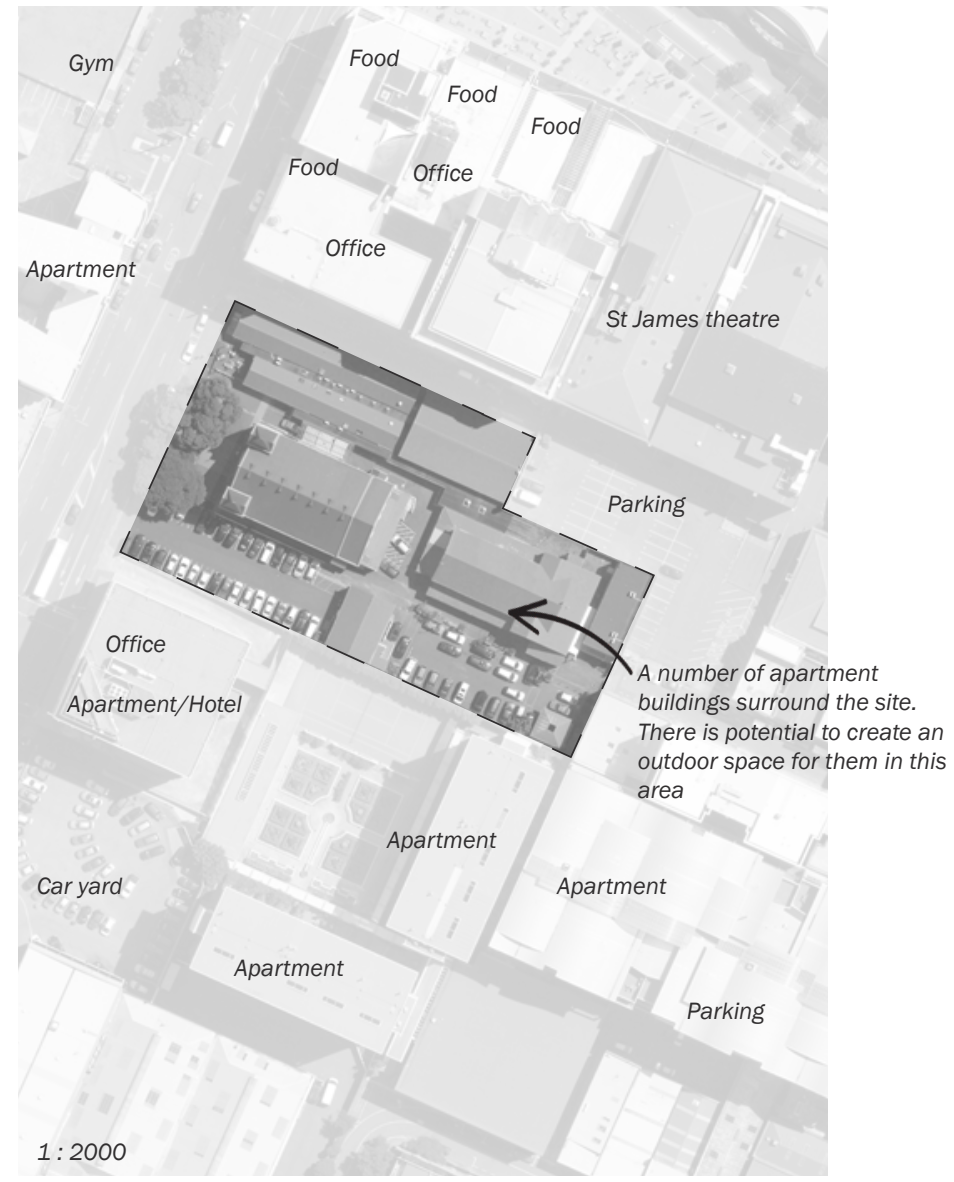

Wellington Methodist Parish

\section{Conclusions Context - Building use}

With the inner city as the scope of these case studies, the majority of buildings surrounding sites are office blocks or residential housing and apartments. This created an opportunity to design for a space that needed to be multipurpose and flexible, as it will be utilised across different times of the day and week by workers and residents. 


\section{Pedestrian connectivity \& Openness}

Many churches in Wellington face issues around pedestrian connectivity within the urban fabric. Christianity is a religion where people from all walks of life are welcome and encouraged to join in fellowship. Churches with limited pedestrian access are at a disadvantage when their mission is to draw people in. Fences and plant boxes are common among sites, blocking free access to church buildings, obstructing the space in unnecessary ways.

\section{....Pedestrian Blocked Partially connectivity blocked}

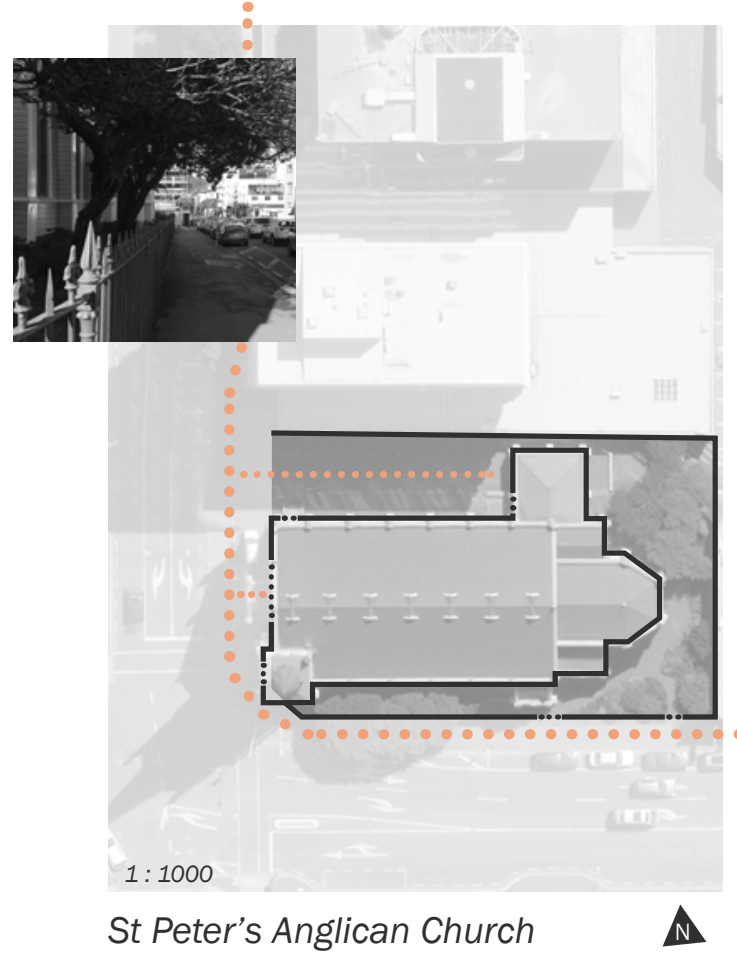

Fig.3.27. (Left Bottom) St Peter's connectivity
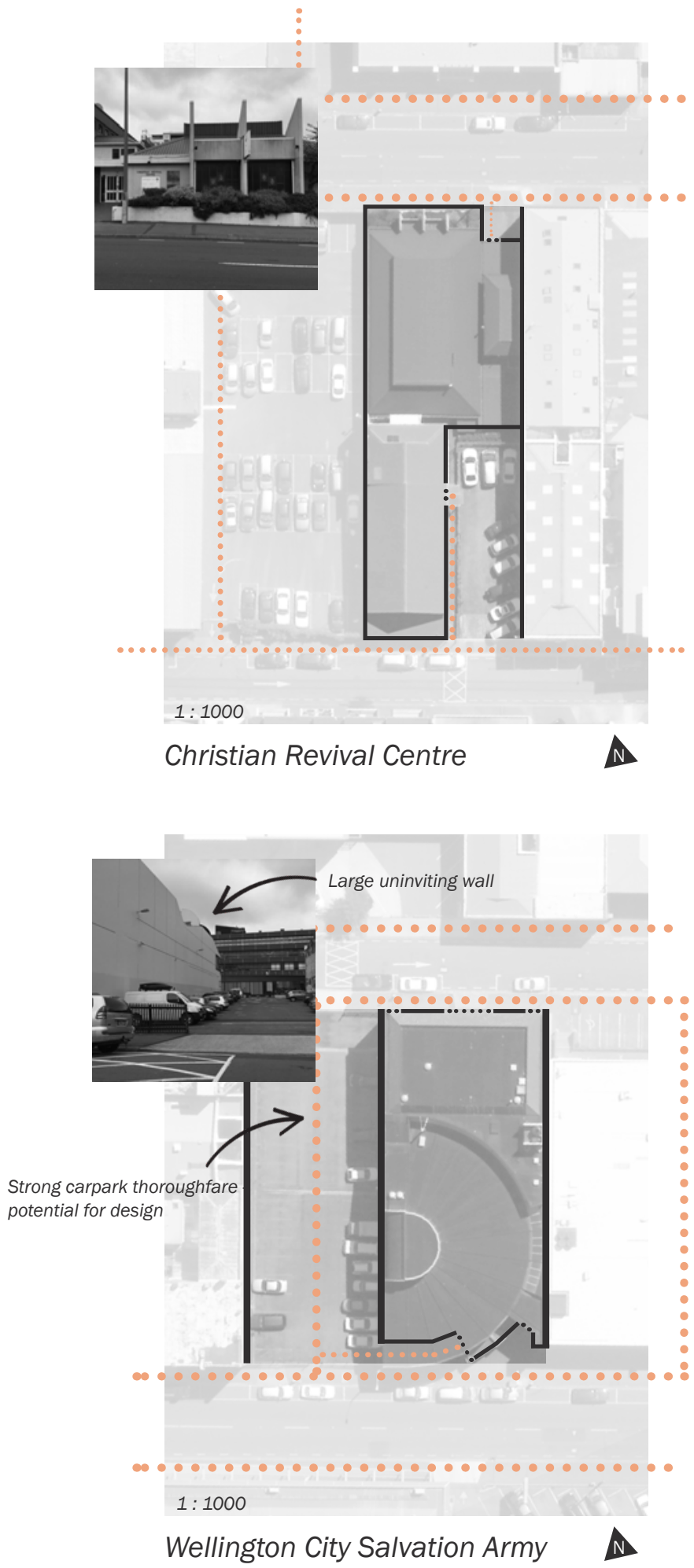

Fig.3.26. (Right Top) Christian Revival connectivity Fig.3.28. (Right Bottom) Salvation Army connectivity 

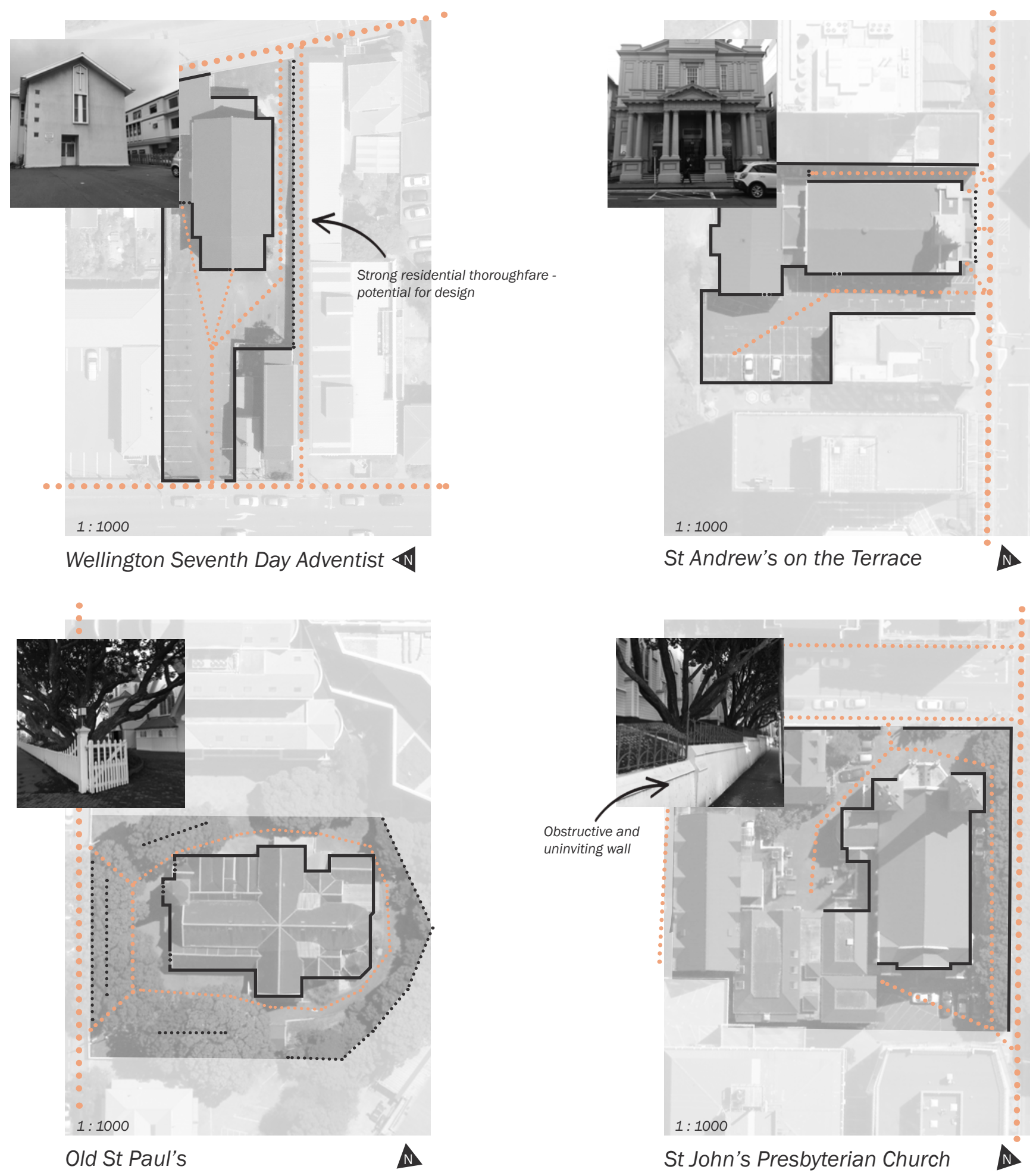

Fig.3.29. (Left Top) Seventh Day Adventist connectivity Fig.3.31. (Left Bottom) Old St Paul's connectivity

Fig.3.30. (Right Top) St Andrew's connectivity Fig.3.32. (Right Bottom) St John's connectivity 


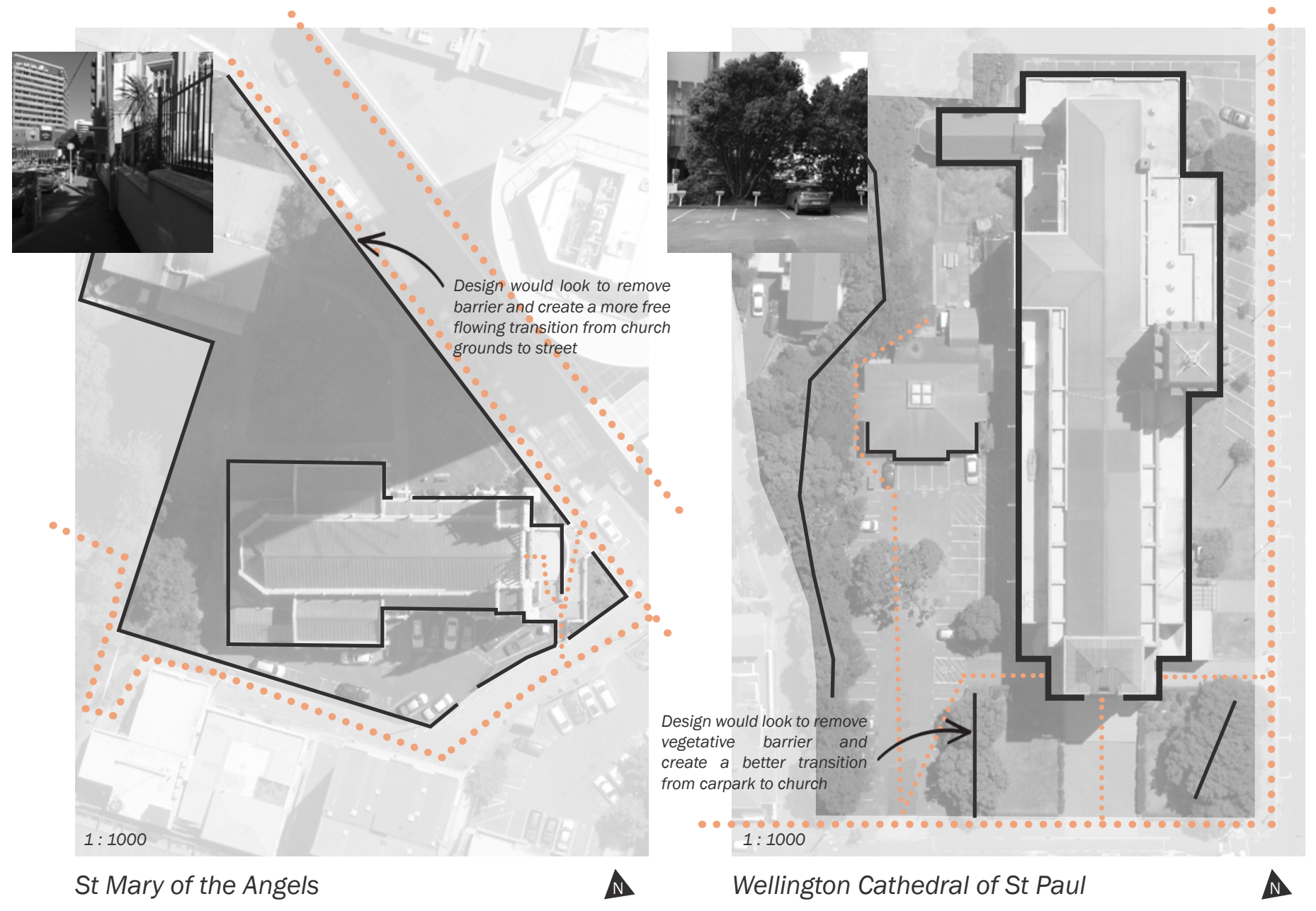

Fig.3.33. (Left) St Mary of the Angels connectivity

Fig.3.34. (Middle) Wellington Cathedral connectivity

Fig.3.35. (Right) Wellington Methodist Parish connectivity 


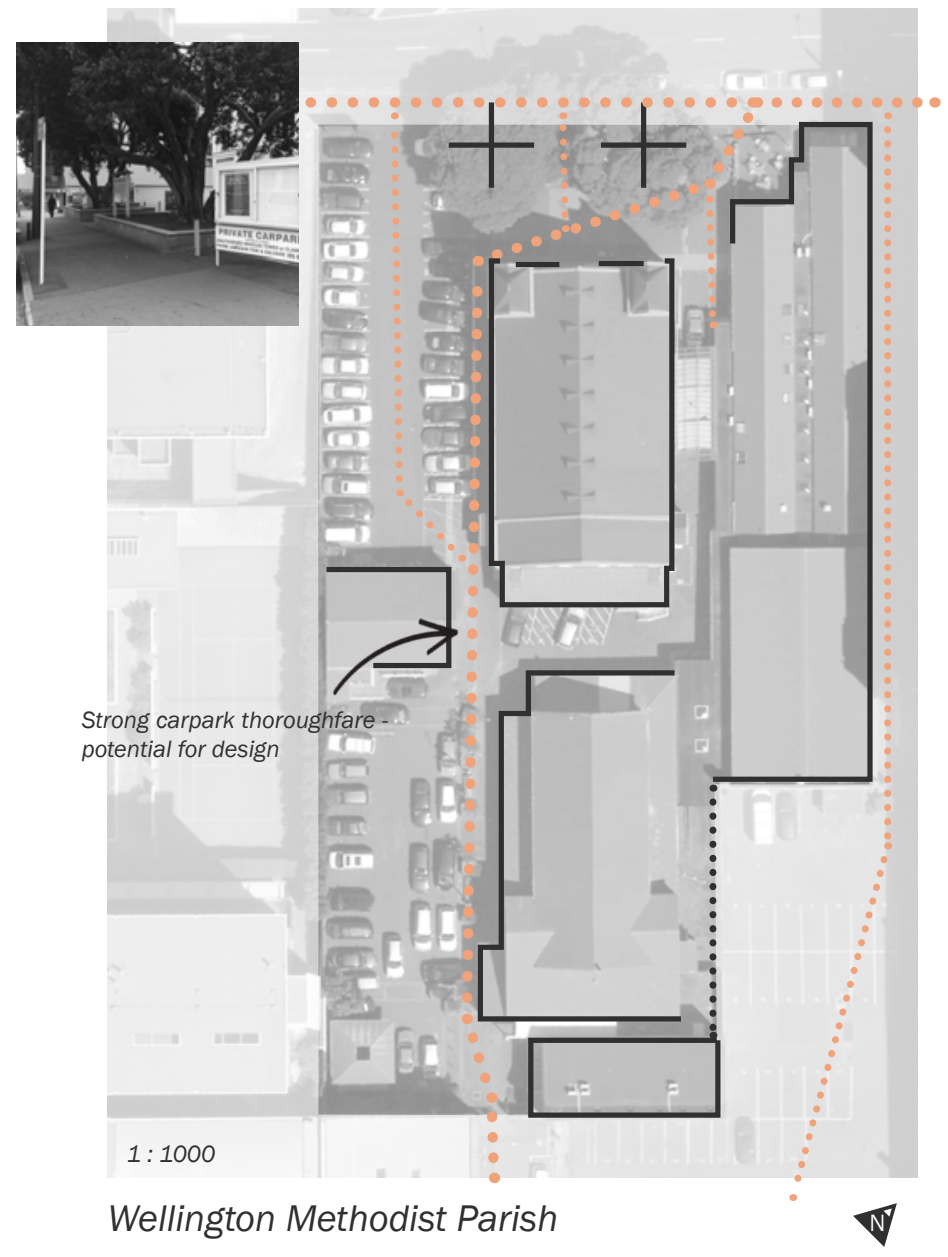

\title{
Conclusions Exterior \& Context transition Pedestrian connectivity \& Openness
}

\begin{abstract}
Many sites analysed have harsh edges where buildings are pressed against property boundaries. This limits the degree of open and inviting space, causing an abrupt transition between the building and its surroundings. In some cases, access to the site is restricted with large fences and blockades used to deter movement. The result is spaces that are poorly connected to their surrounding environment, deterring pedestrian engagement with the building itself.

Wellington City Salvation Army and Wellington Methodist Parish both have well established thoroughfares, despite a lack of inviting space. Having a degree of community engagement already established with a site is hugely beneficial to any potential design.
\end{abstract}




\section{Size of space \& Parking}

One criterion for the selection of church sites was the size of the church property. It was important to analyse sites differing in size to ascertain whether problems with accessibility were pronounced where lack of space was an issue.

It was also important to gain an understanding of how much area was dedicated to car parking on each site, given how pervasive the use of vehicles is.
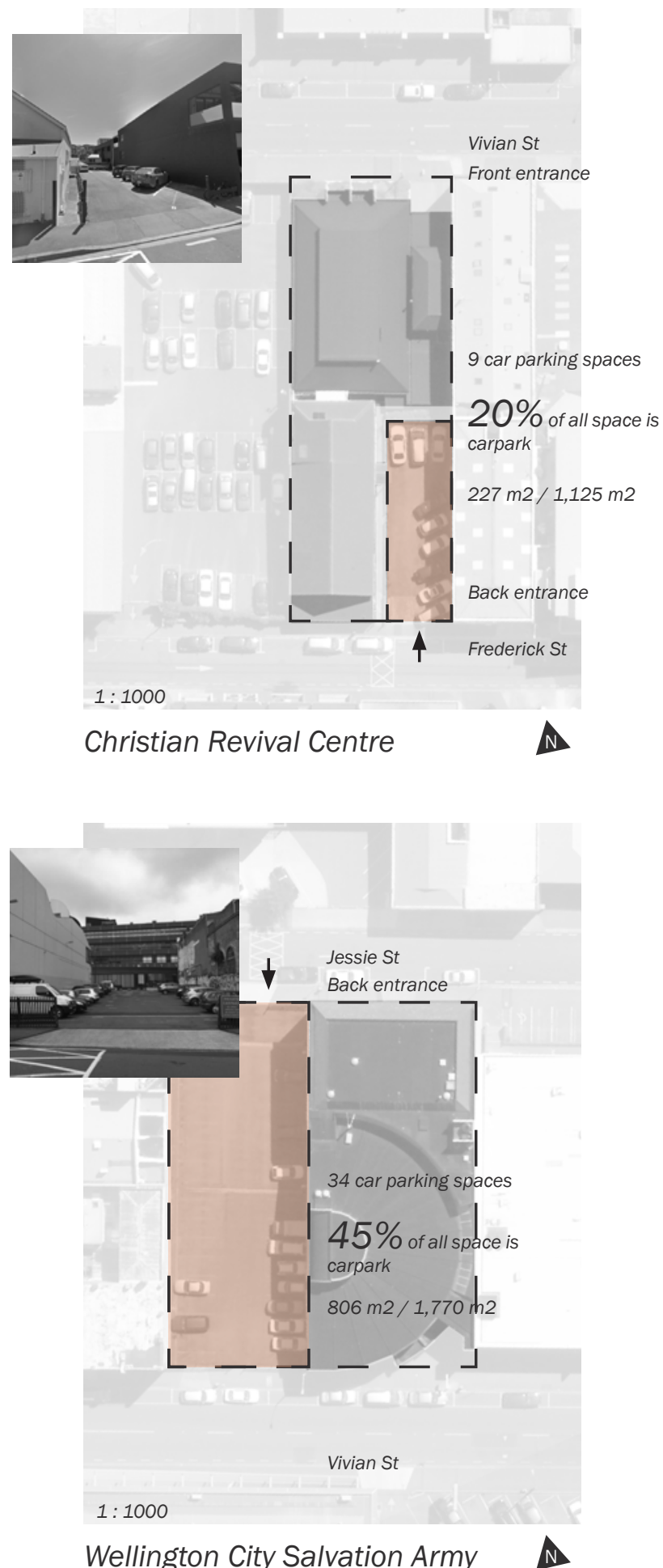

Fig.3.36. (Right Top) Christian Revival size \& parking Fig.3.38. (Right Bottom) Salvation Army size \& parking 


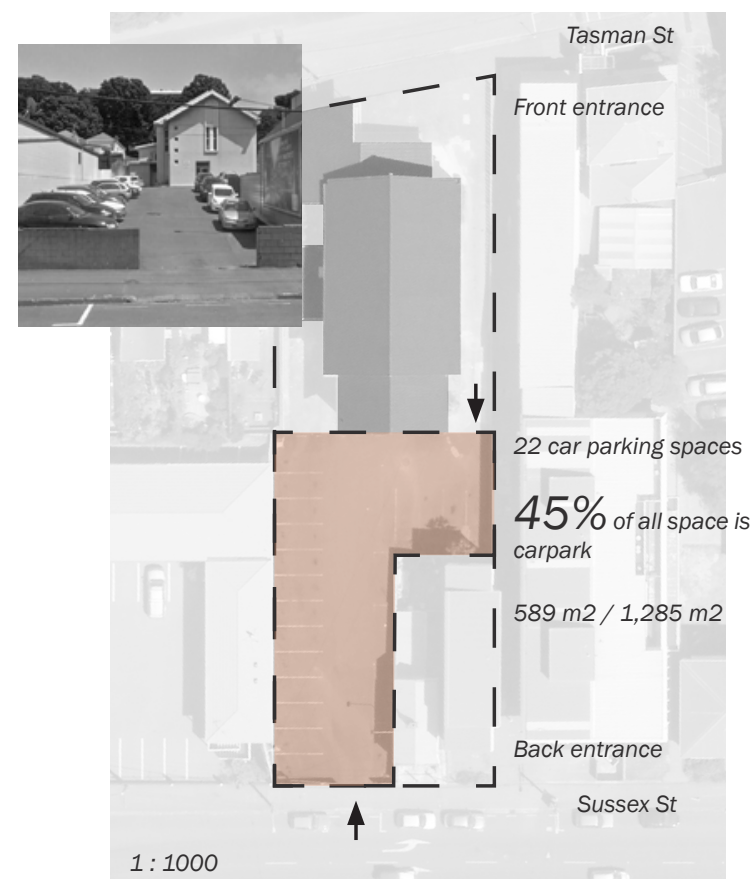

Wellington Seventh Day Adventist $\varangle \mathbb{N}$

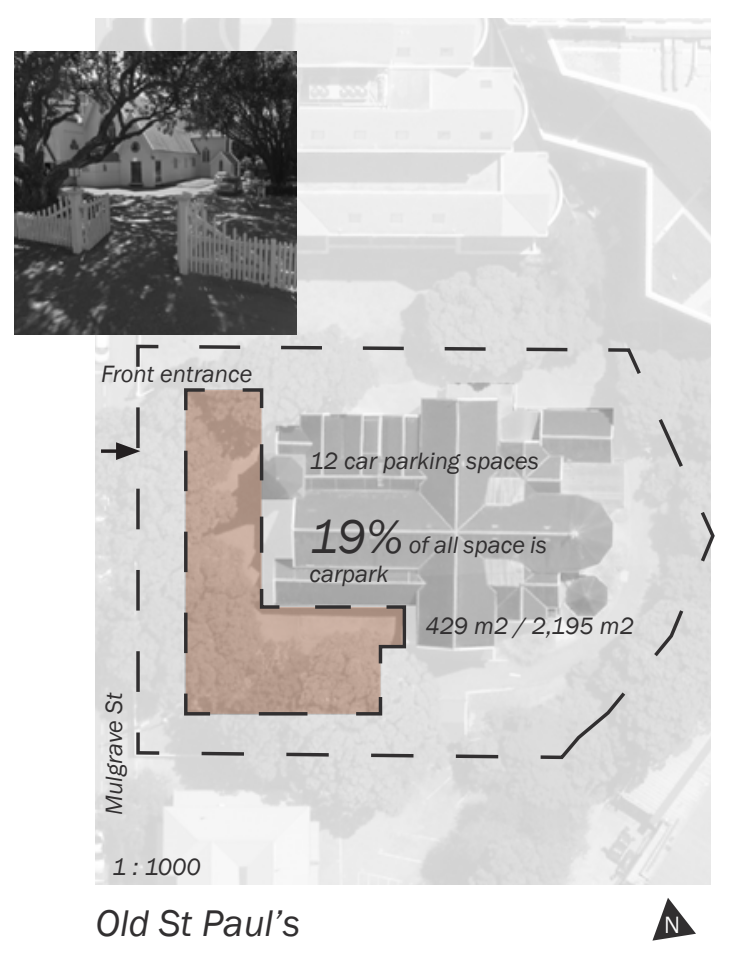

Fig.3.39. (Left Top) Seventh Day Adventist size \& parking Fig.3.41. (Left Bottom) Old St Paul's size \& parking
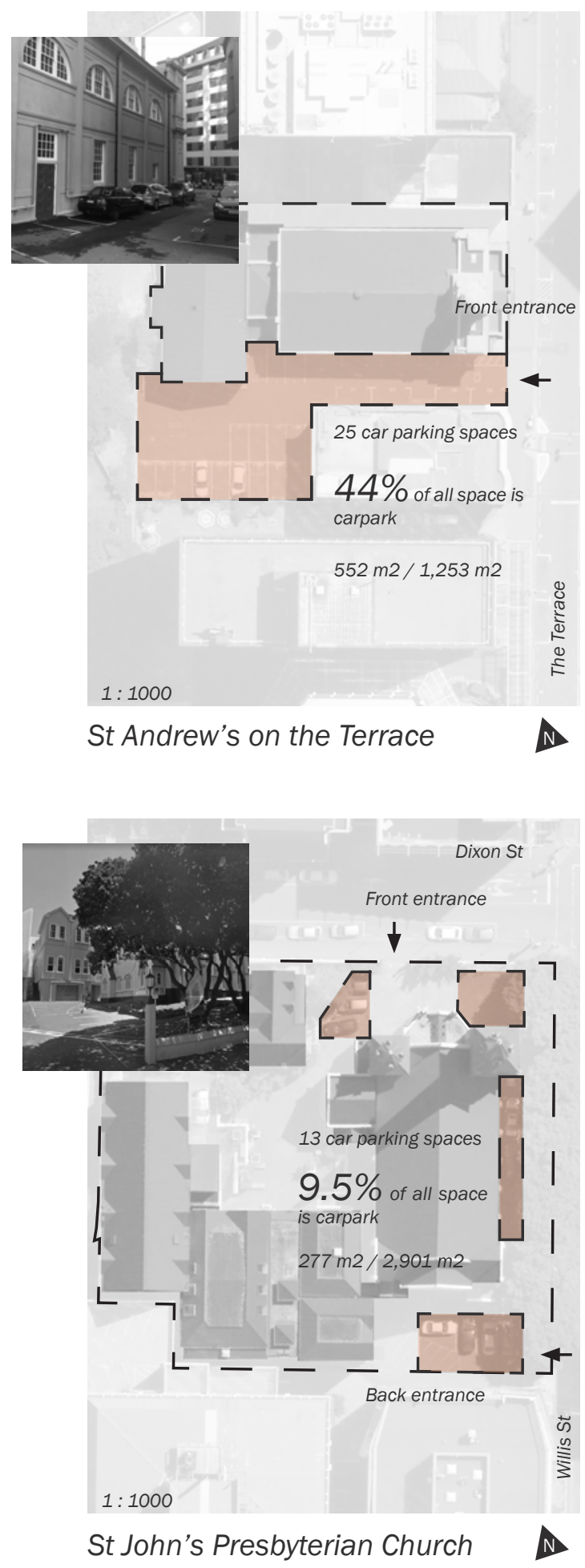

Fig.3.40. (Right Top) St Andrew's size \& parking Fig.3.42. (Right Bottom) St John's size \& parking 

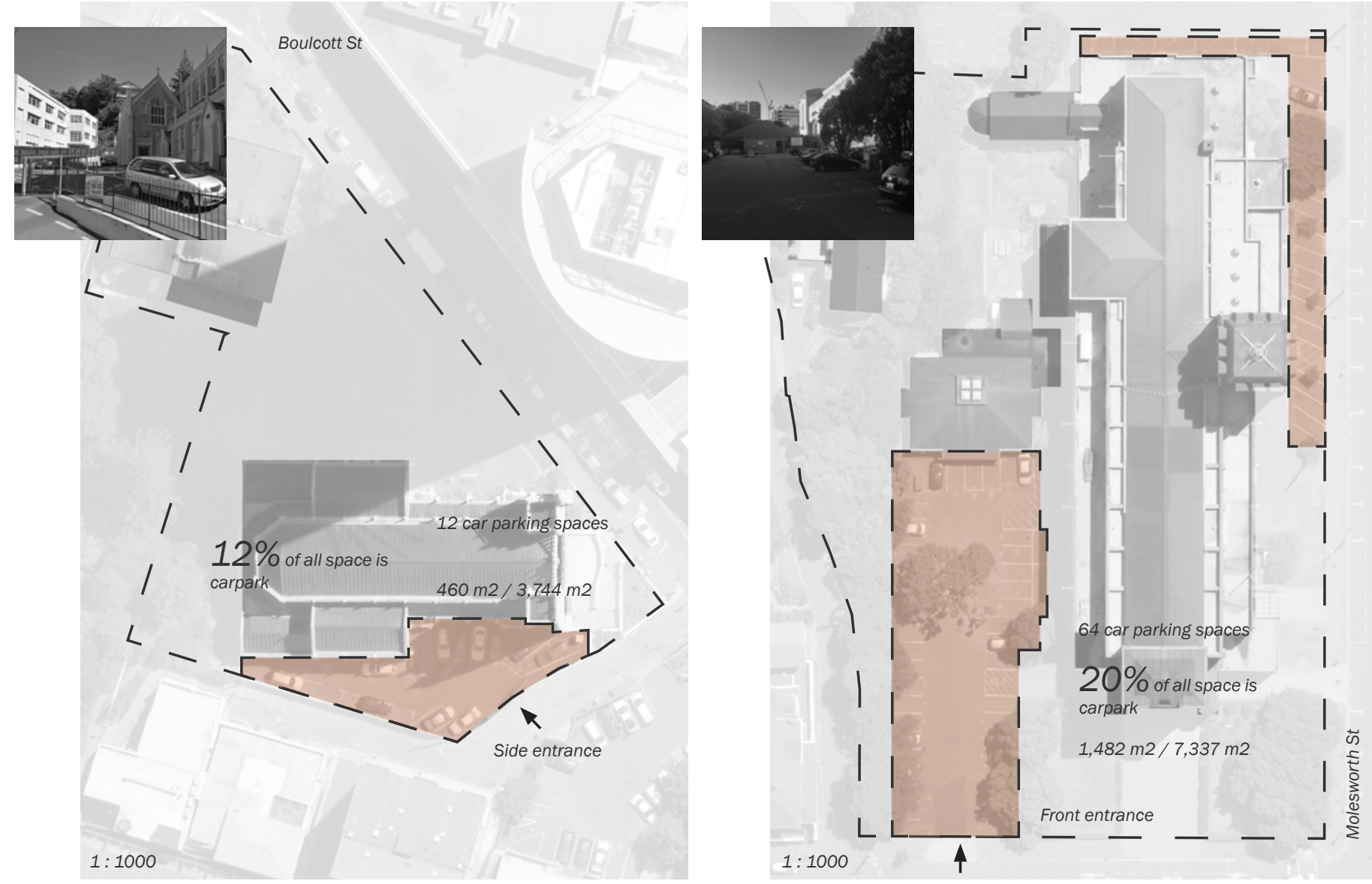

St Mary of the Angels 

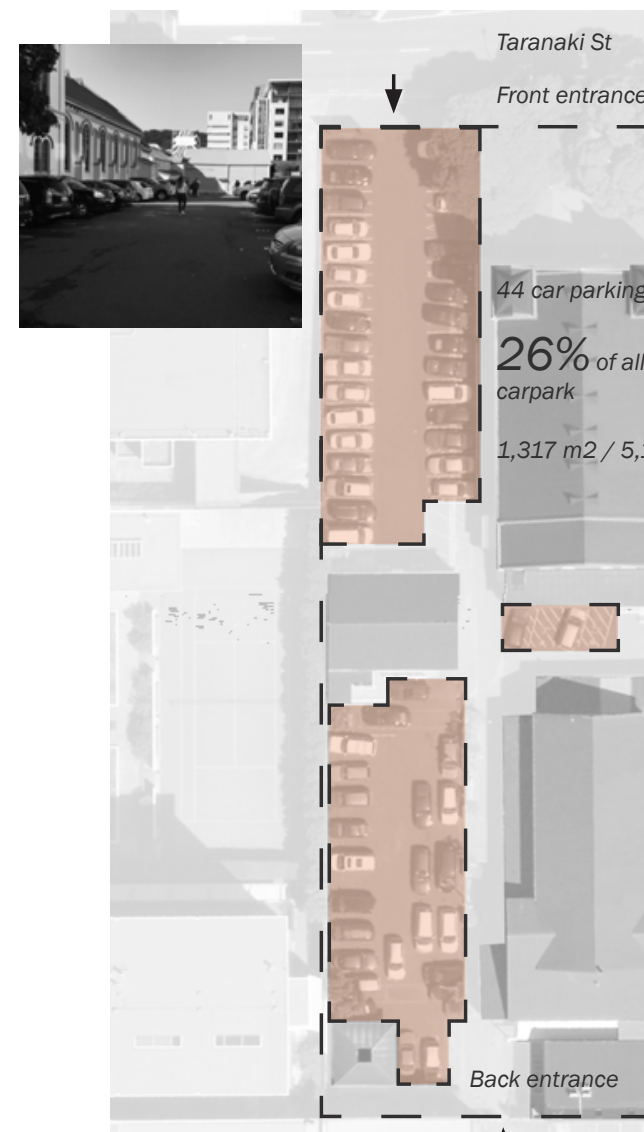

$1: 1000$

Front entrance

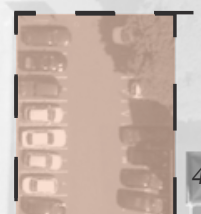
carpark

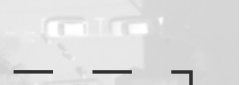

44 car parking spaces

$26 \%$ of all space is

$1,317 \mathrm{~m} 2 / 5,110 \mathrm{~m} 2$

Wellington Methodist Parish

\section{Conclusions}

\section{Exterior - Size of Space \& Parking}

It quickly became evident that parking is crucial to each church site. With only two exceptions, the main use of outdoor space is for car parking, with some car parks taking up to half of the overall property area.

There was no real difference between churches with small and large property boundaries. It was evident that it did not matter how large or small the space was, parking was always present. 


\section{Vegetation}

Vegetation is vital to improving the quality of a space and making it inviting. Many church spaces around the world are known for the look of their church grounds as much as they are for the building itself. With vegetation and planting playing such a key role in the discipline of landscape architecture, it was important to investigate how planting is used across each site.
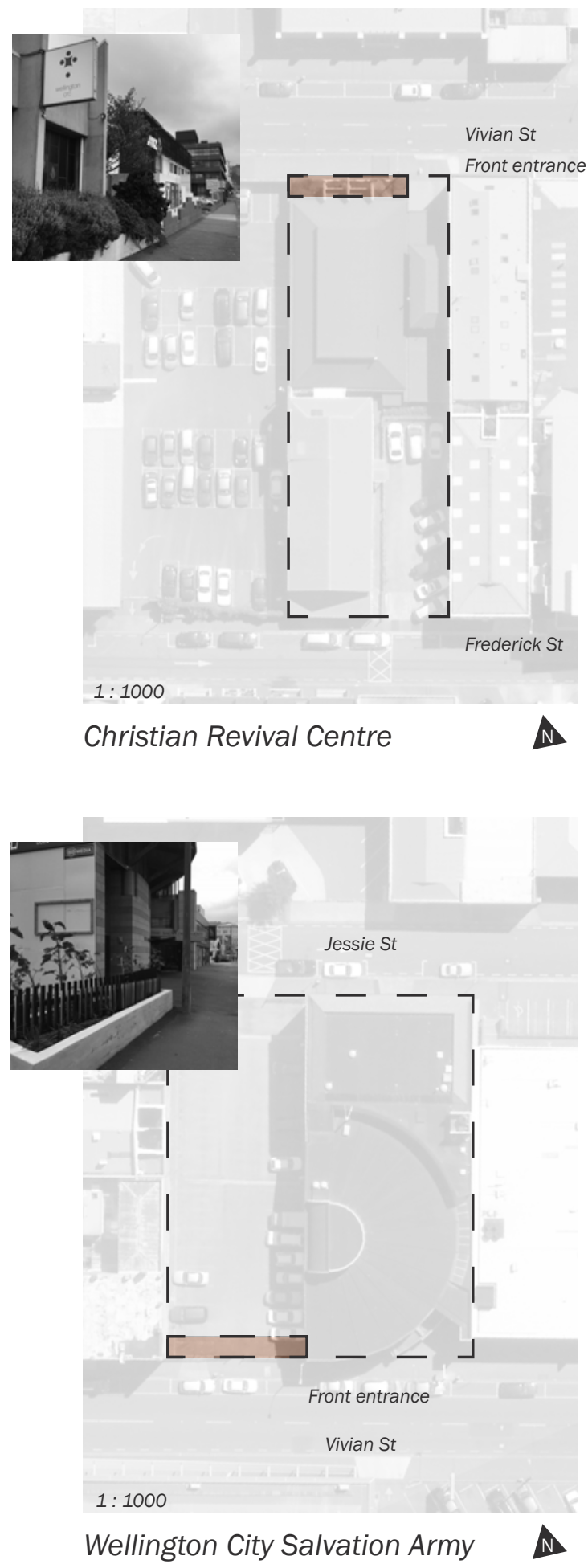

Fig.3.46. (Right Top) Christian Revival vegetation Fig.3.48. (Right Bottom) Salvation Army vegetation 


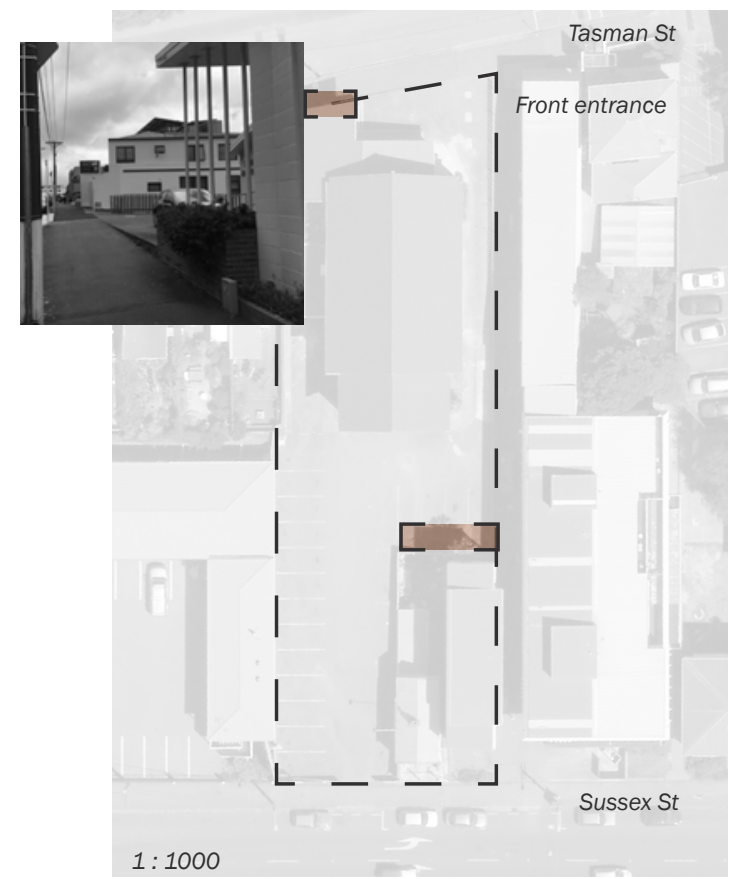

Wellington Seventh Day Adventist $\varangle \mathbb{N}$

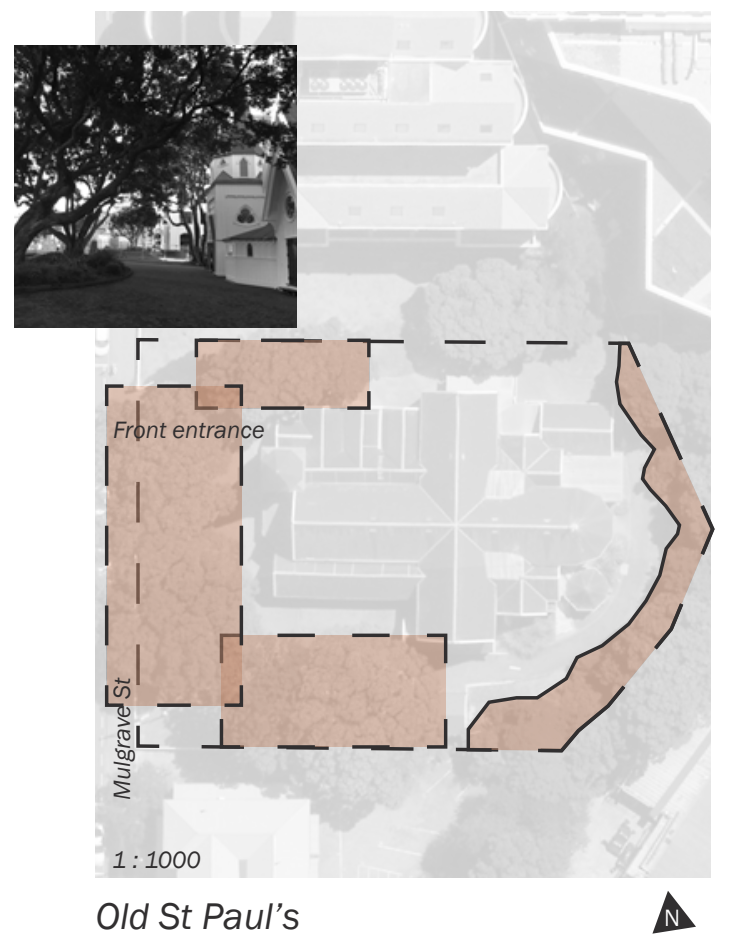

Fig.3.49. (Left Top) Seventh Day Adventist vegetation Fig.3.51. (Left Bottom) Old St Paul's vegetation

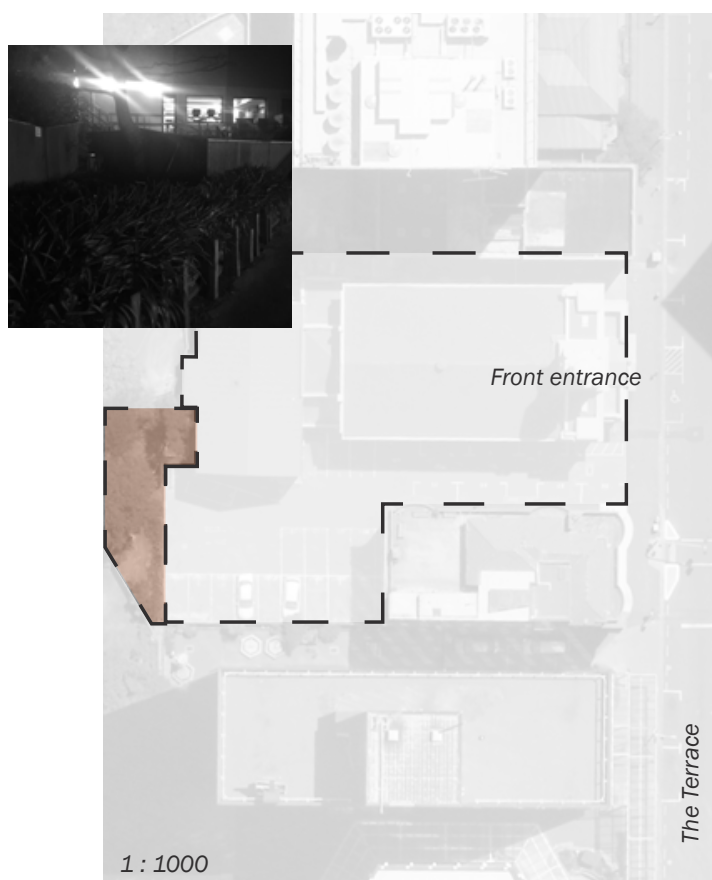

St Andrew's on the Terrace

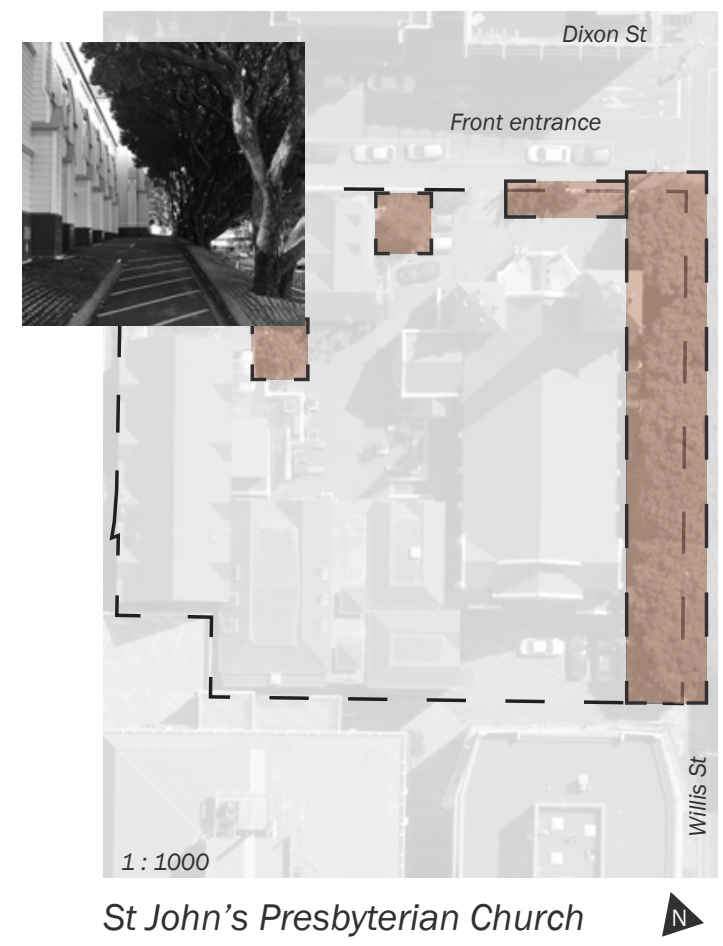

Fig.3.50. (Right Top) St Andrew's vegetation Fig.3.52. (Right Bottom) St John's vegetation 

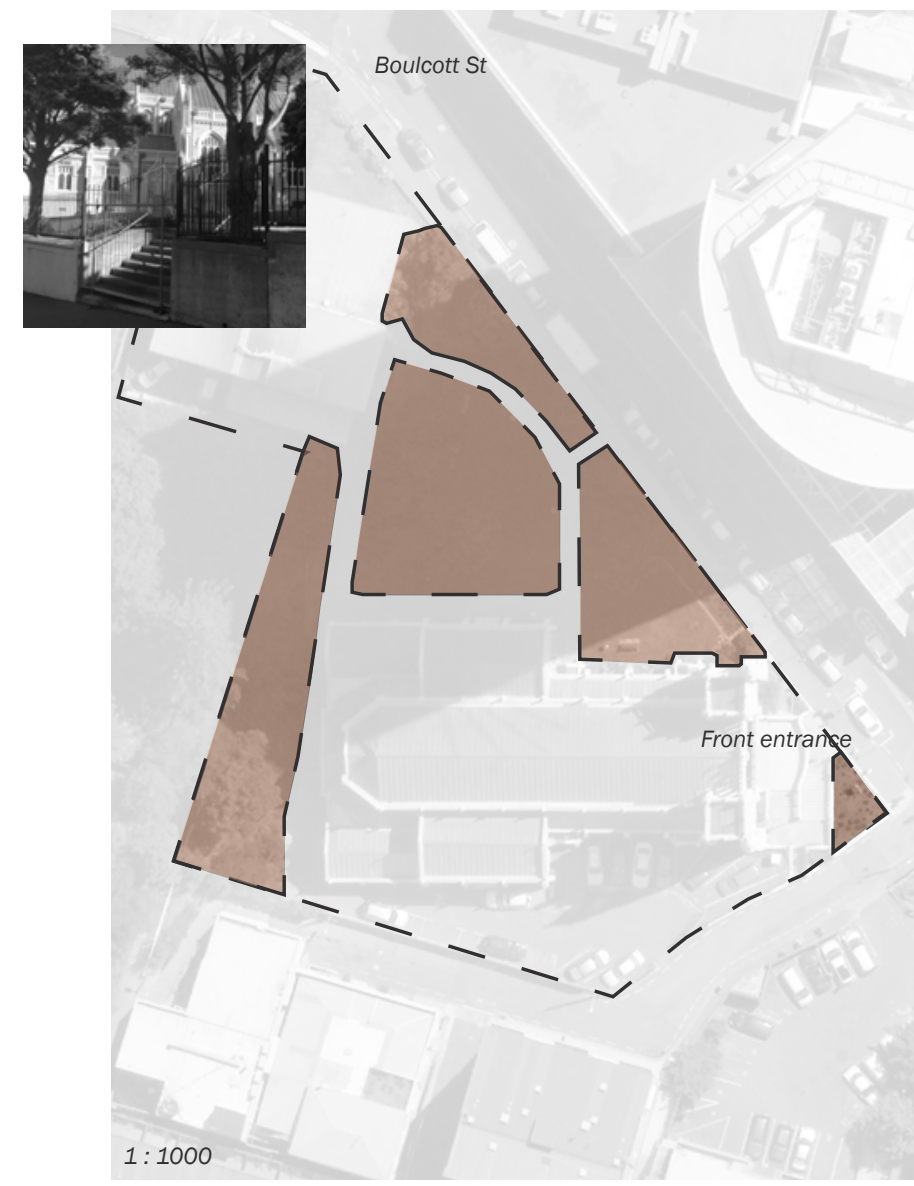

St Mary of the Angels

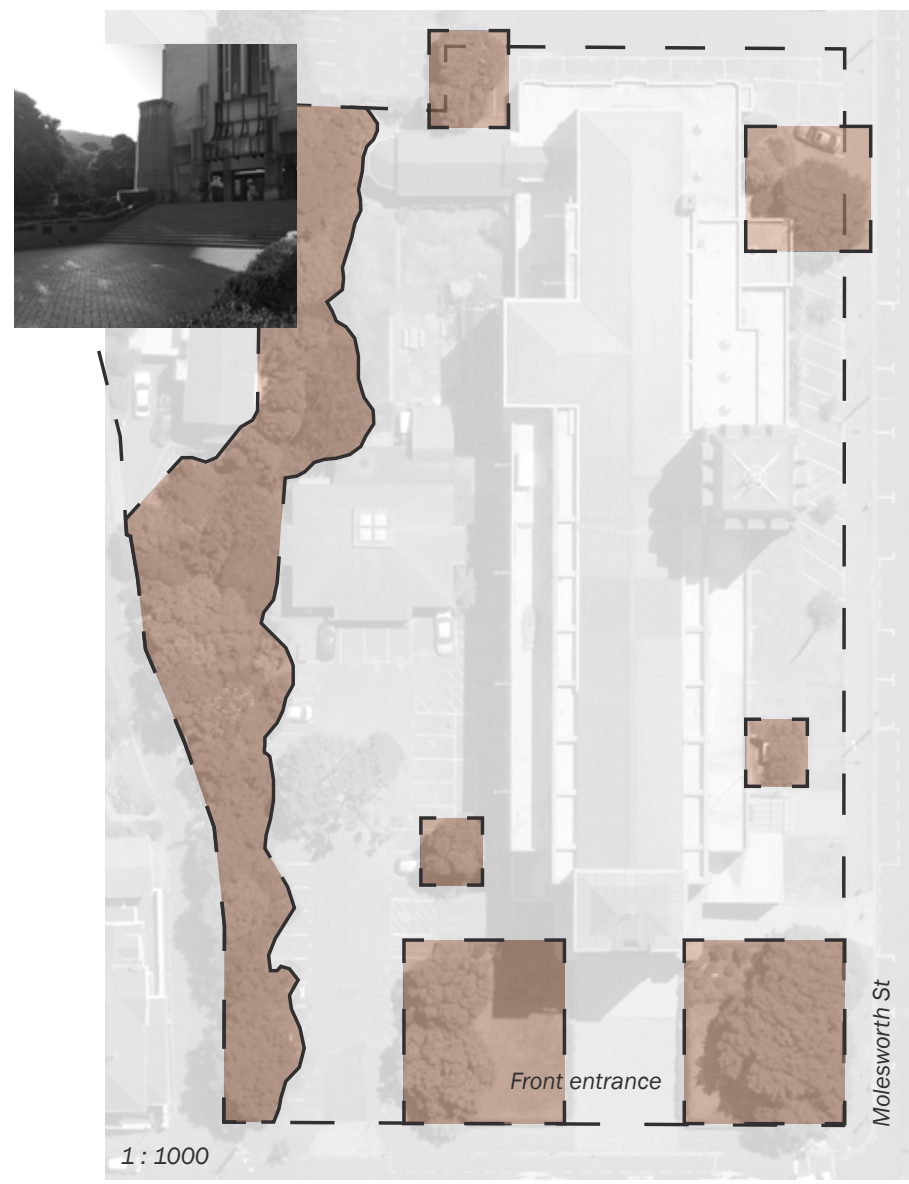

Wellington Cathedral of St Paul 


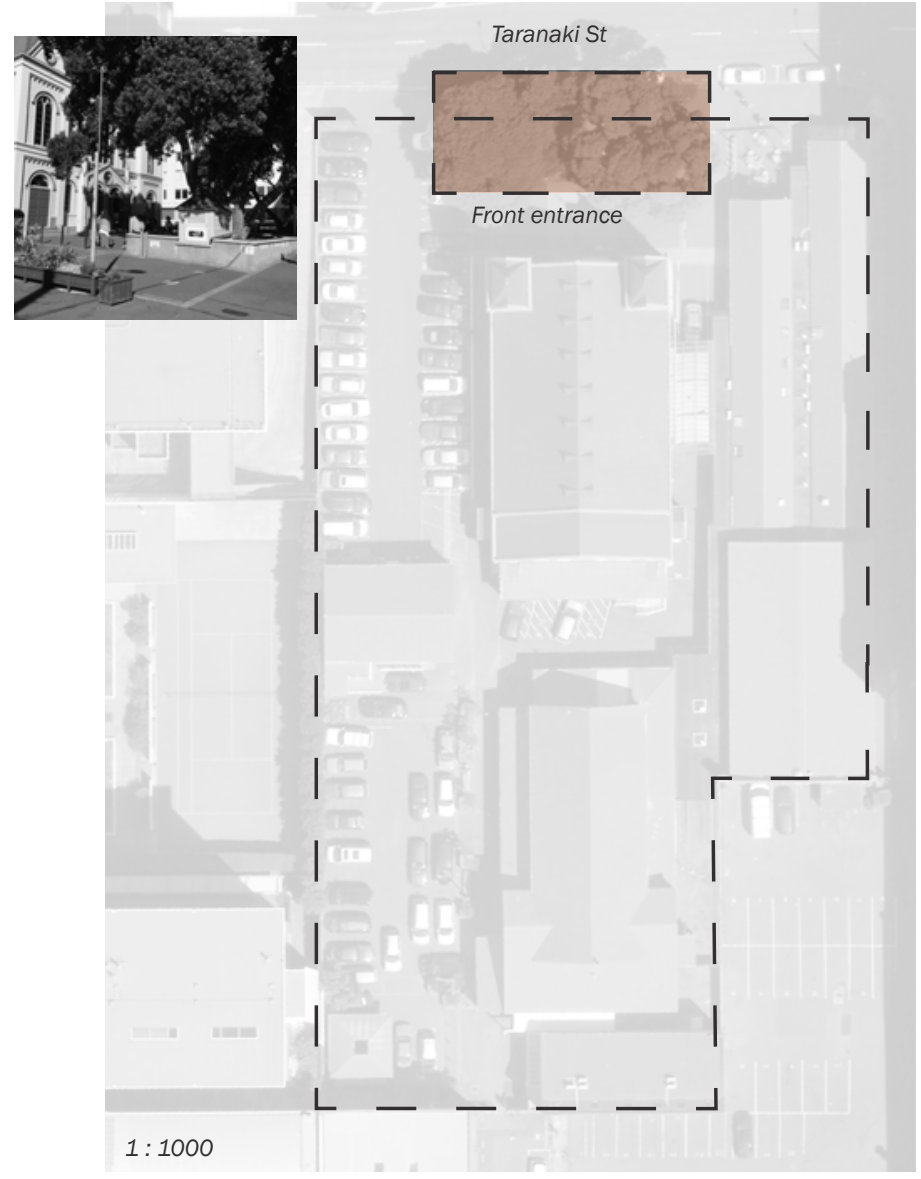

Wellington Methodist Parish

\section{Conclusions Exterior - Vegetation}

Evident across a number of sites is the use of pohutukawa trees outside church buildings. Both Old St Paul's and the Wellington Methodist Parish have large pohutukawa trees in front of the church. In both cases, these are marked as heritage trees, meaning that they are of significance to Wellington City and cannot be removed from the site. While these trees add colour and texture to the site, they also obstruct the movement of people from the footpath to the church entrance.

At many sites, vegetation appears to be an afterthought to the original design, with small planter boxes (relative to the size of the outdoor space) providing vegetation for each space.

In some cases, vegetation is also used to identify and mark the edge of the property and boundary lines.

Rarely does vegetation work with the rest of the site to create a cohesive overall space. In most cases, there are pockets of planting which could be considered as attempts to beautify the space. These spaces are often confined to designated areas. 


\section{Quality of space}

The quality of space is an important factor to creating a space that people are attracted to. Areas for sitting and standing are of paramount importance, as is colour and well-maintained vegetation. Without these features people are less inclined to stay in the space.

Wellington City Salvation Army

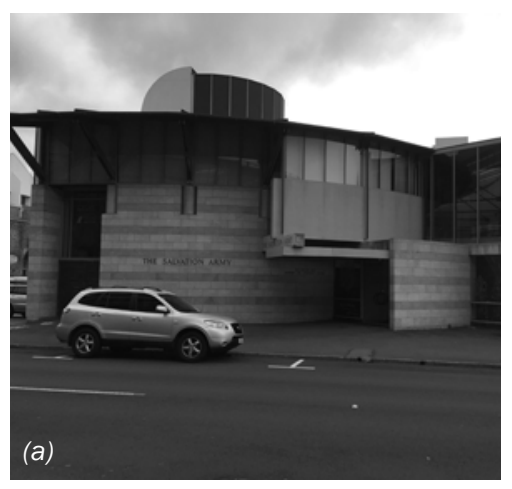

\section{Christian Revival Centre}
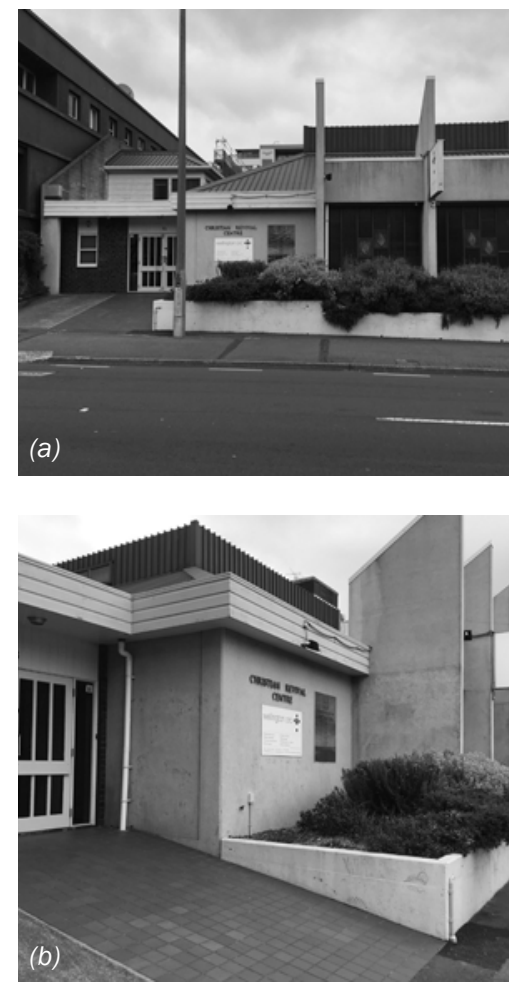

St Peter's Anglican Church
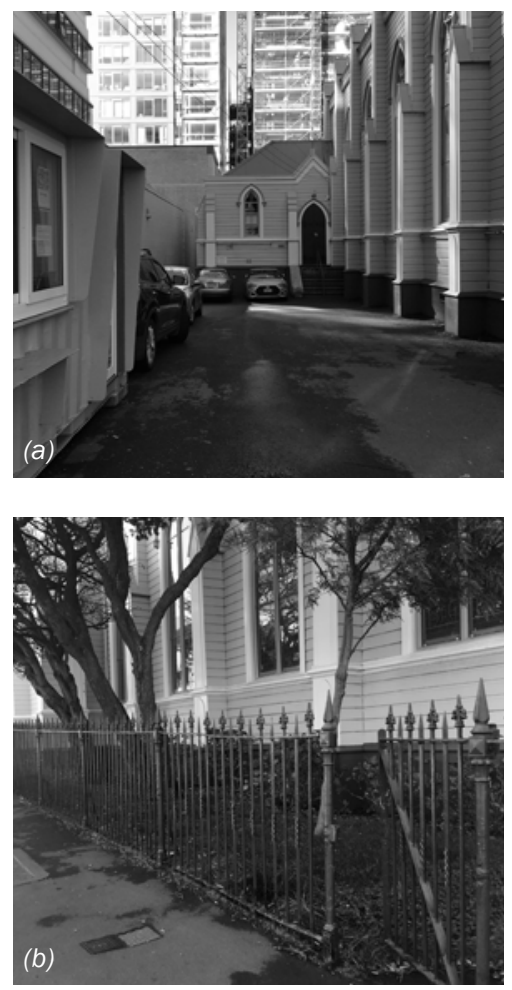
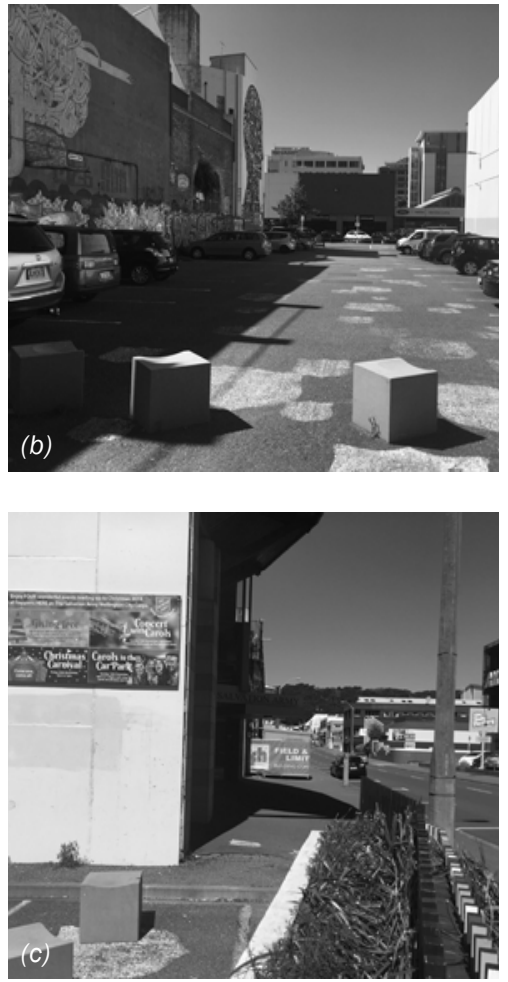

Fig.3.56. $a$ and b, (Left) Christian Revival quality of space Fig.3.57. $a$, and b, (Middle) St Peter's quality of space 
St Andrew's on the Terrace

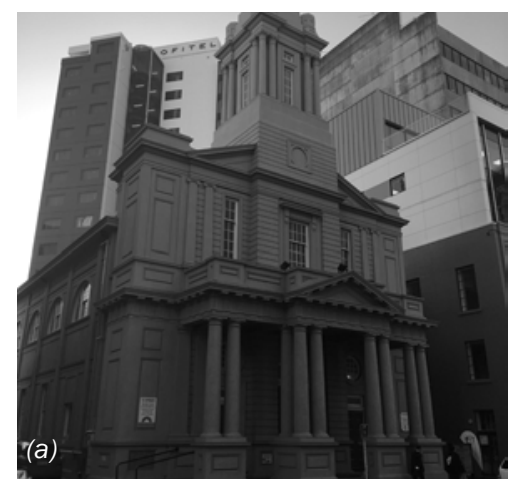

Adventist
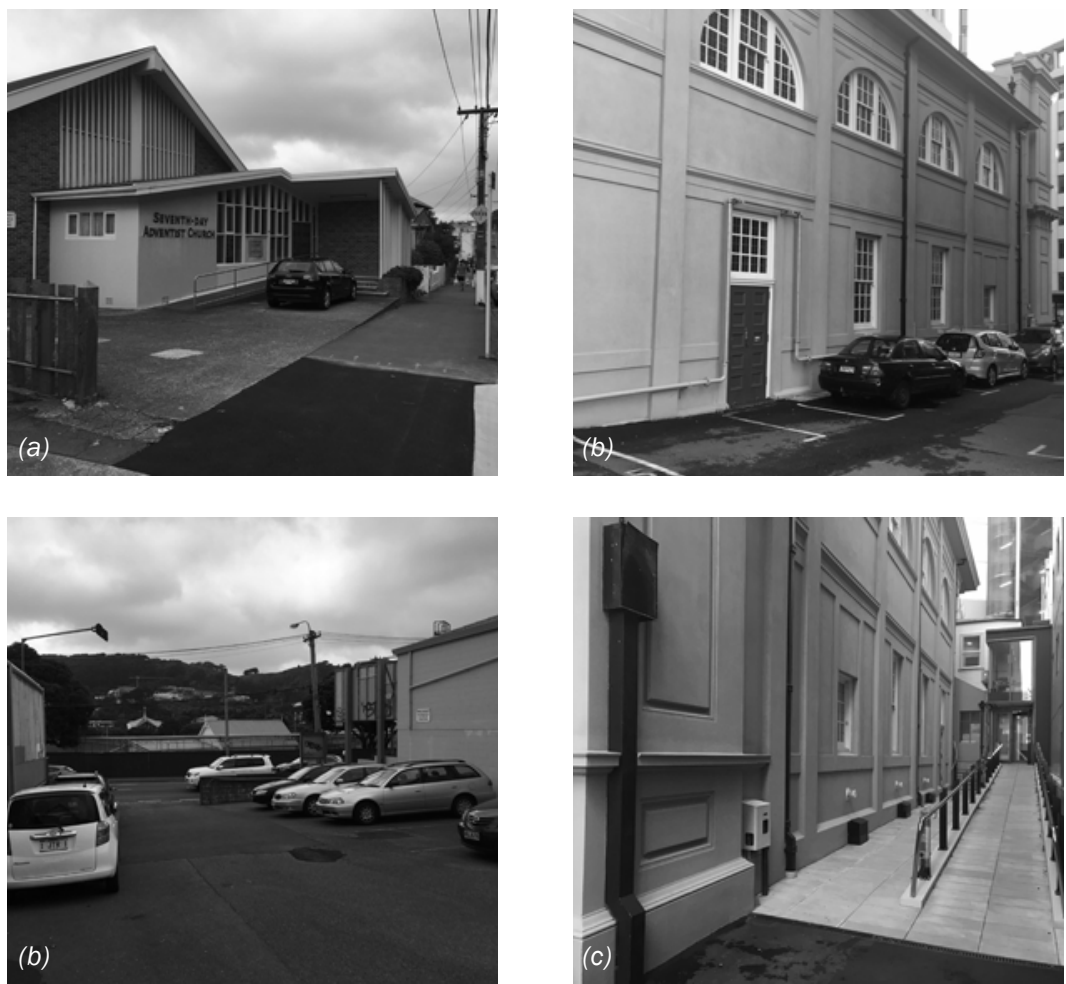

Old St Paul's
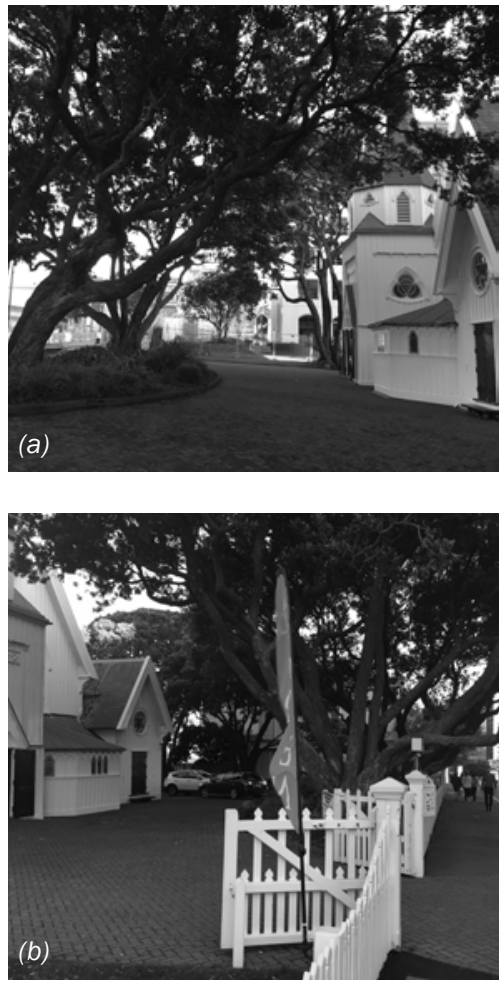
St John's Presbyterian Church
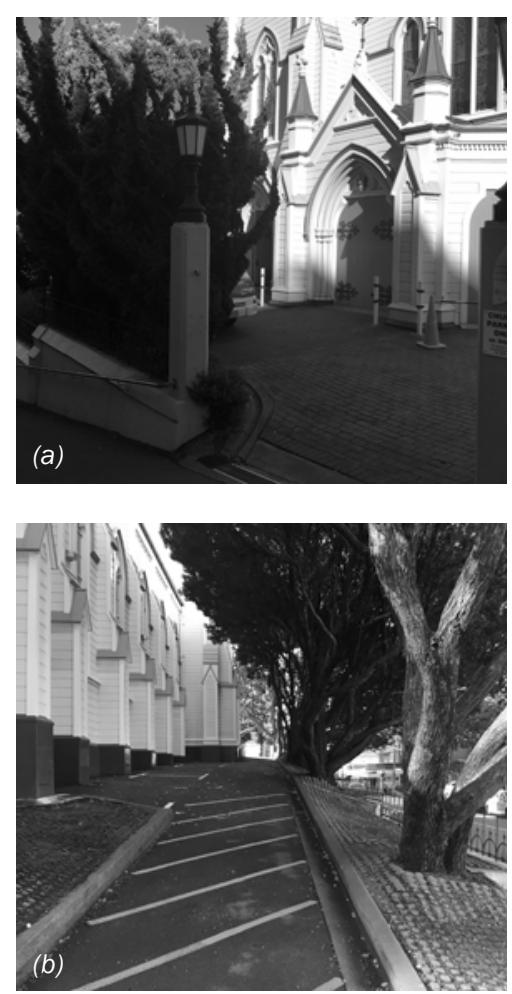

St Mary of the Angels
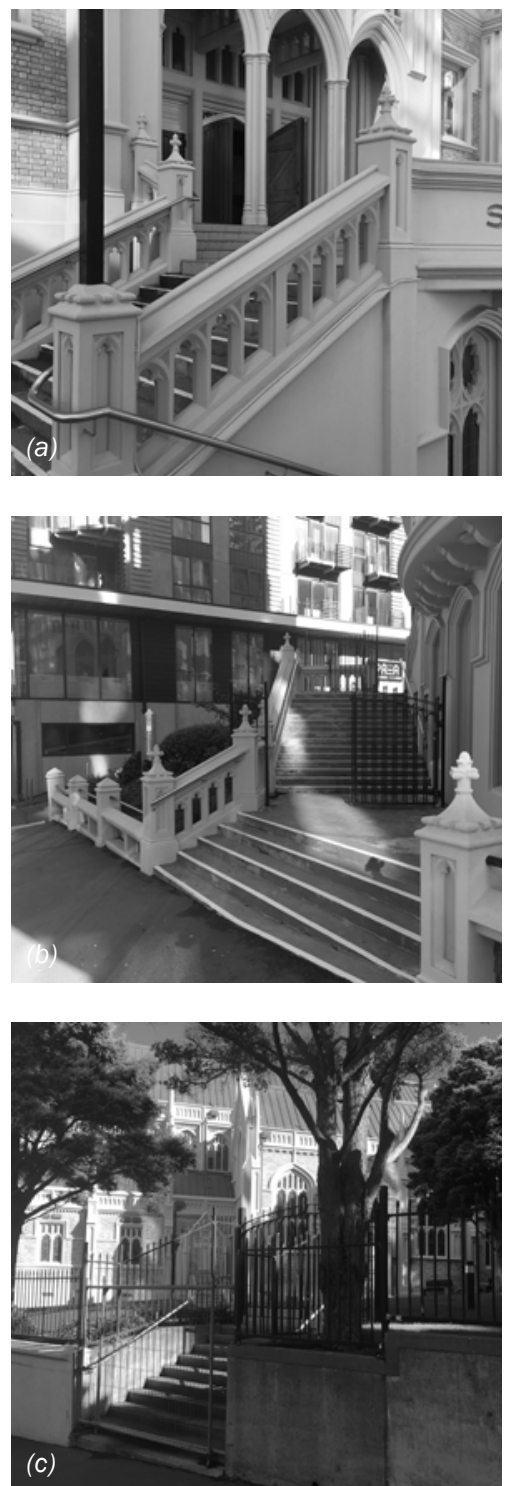

Wellington Cathedral of St Paul
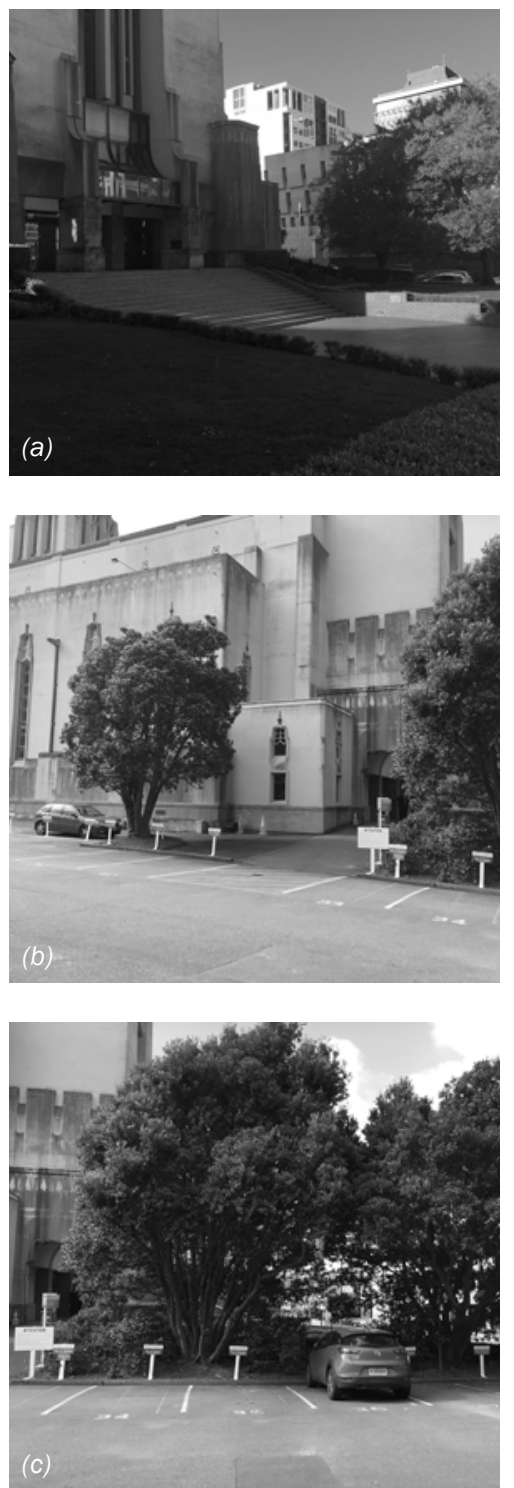

Fig.3.62. $a$ and b, (Left) St John's quality of space Fig.3.63. $a, b$ and c, (Middle) St Mary of the Angels quality of space 


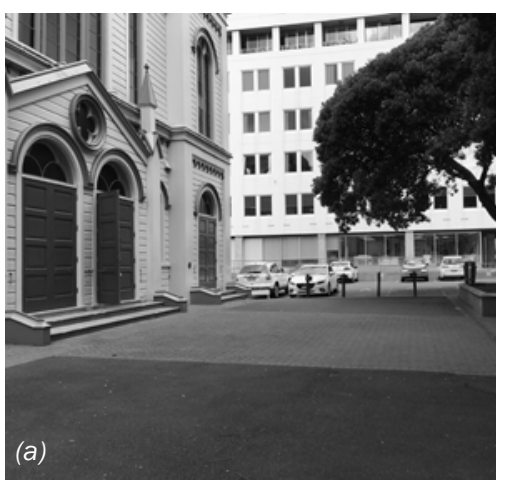

\section{Conclusions Exterior - Quality of space}

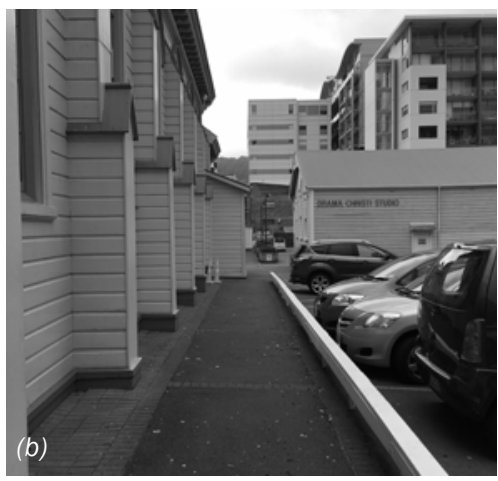

The quality of space proved to be a common issue for many of the sites. The only exception being St Mary of the Angels, however the space is somewhat inaccessible.

Loose asphalt and bland colours generally dominate the exterior space. In most cases, the church building is well maintained and appealing; however, the surrounding space leaves much to be desired.

There is very little in the way of seating and spaces of permanency. Dated and impractical design work dominates these sites.

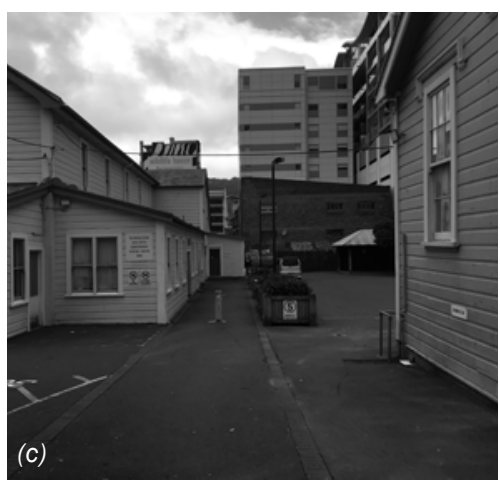

As it stands in most sites, each space relies heavily on the purpose of the building for its social interactions. The only unplanned interaction tended to be pedestrians using the site as a thoroughfare.

By increasing the quality of these exterior spaces, the number of activities and social interactions will grow. 


\section{Night time}

Lighting and a sense of safety is crucial to any space that is open to the public. With insufficient lighting, spaces go unused and people feel unsafe.

In a space where the goal is for people to congregate and feel comfortable, designing with safety in mind is key.

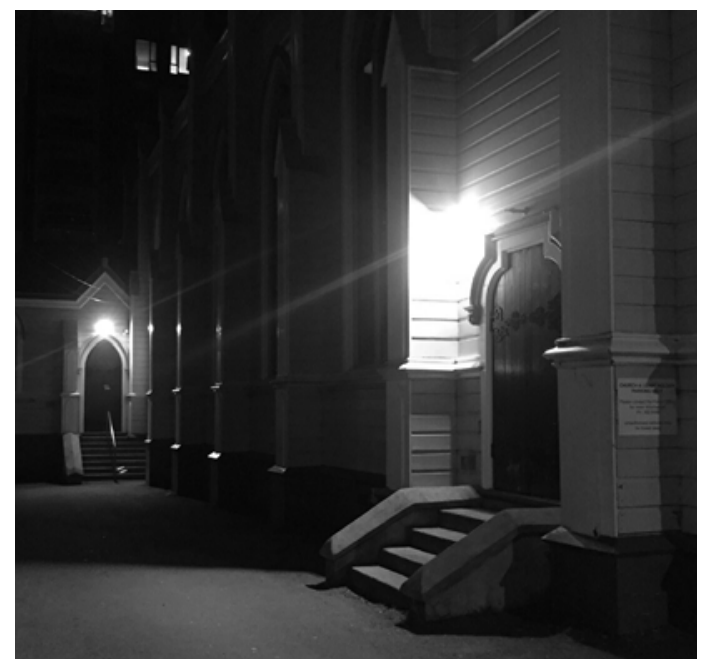

\section{St Peter's Anglican Church}

The entrance ways to the church are all well lit. Given the church's close proximity to the road, street lighting also has a significant impact on the site.

Fig.3.67. (Left Bottom) St Peter's night time

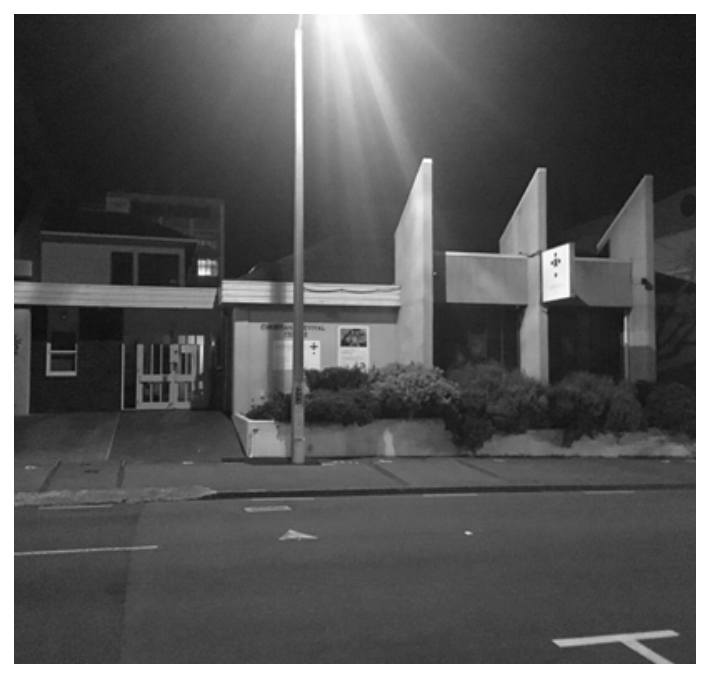

\section{Christian Revival Centre}

The church relies solely on a neighbouring streetlight on Vivian Street. The light is sufficient based on the size of the church. However, ground lighting would enhance the quality of the space.

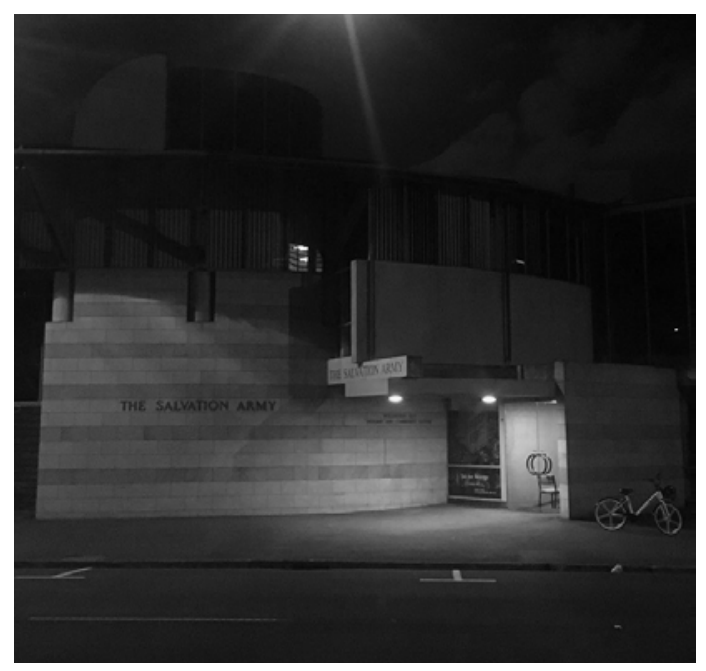

\section{Wellington City Salvation Army}

The entrance and main facade of the church are well lit. The adjacent carpark also has three streetlights attached to the exterior wall of the church.

Fig.3.66. (Right Top) Christian Revival night time Fig.3.68. (Right Bottom) Salvation Army night time 


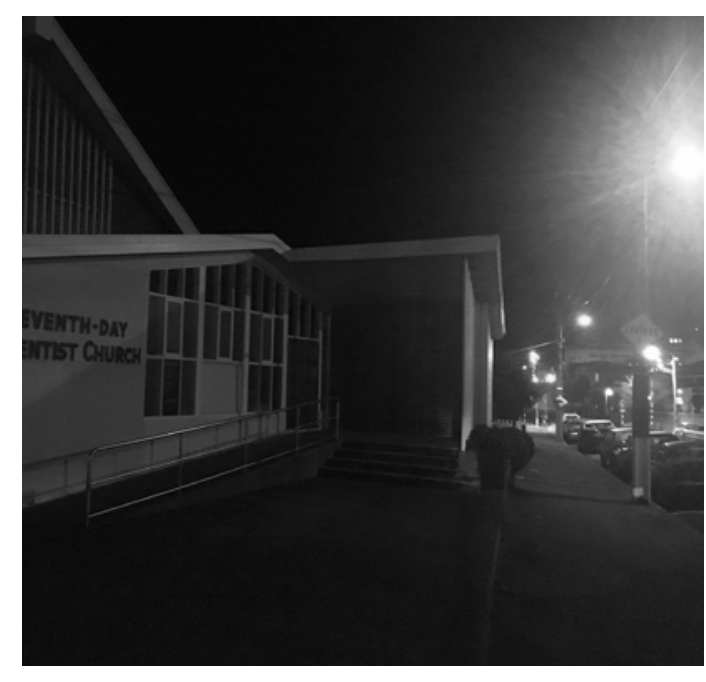

Wellington Seventh Day Adventist

There is no lighting on, or surrounding, the building. Street lighting is set back too far for it to make any positive impact on the site.

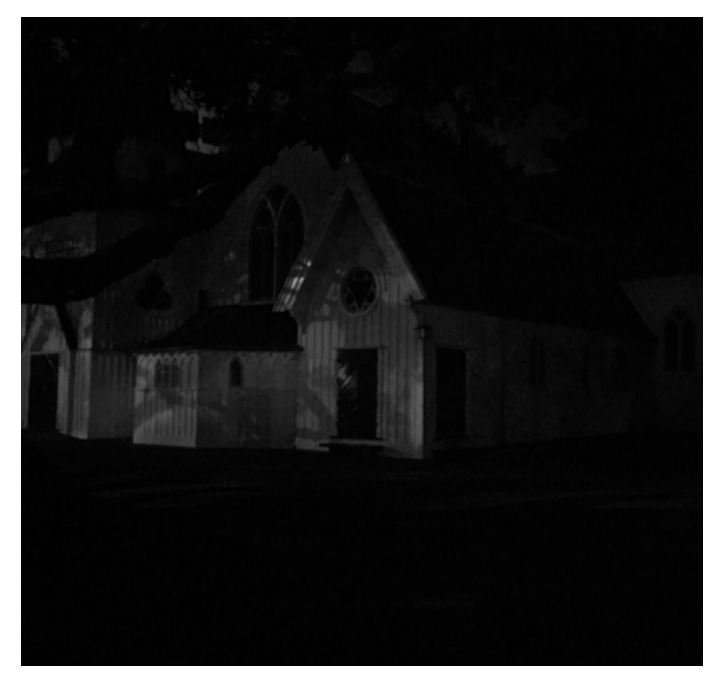

\section{Old St Paul's}

There is no lighting on, or surrounding, the church. It is also set back considerably from the road, meaning that street lighting has no effect on the site.

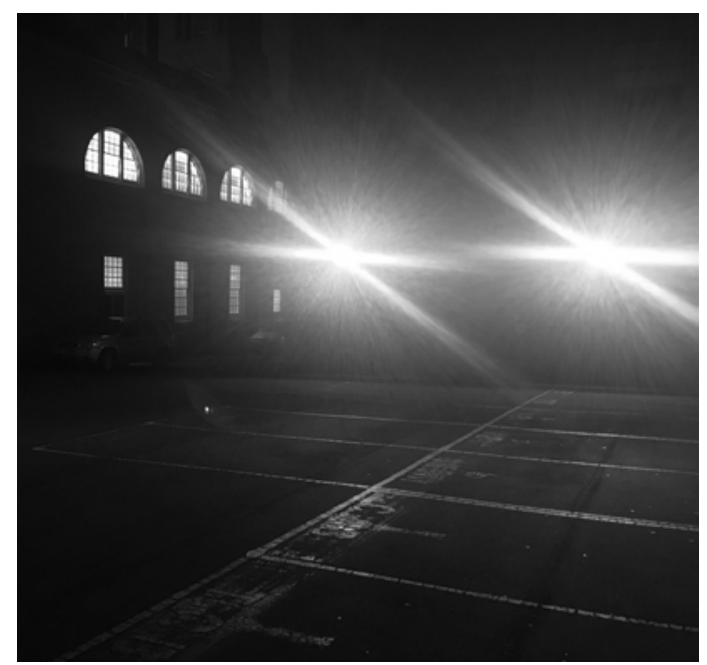

\section{St Andrew's on the Terrace}

The church itself has no outdoor lighting, however there are two security lights on the adjacent building offering light to the shared car park space.

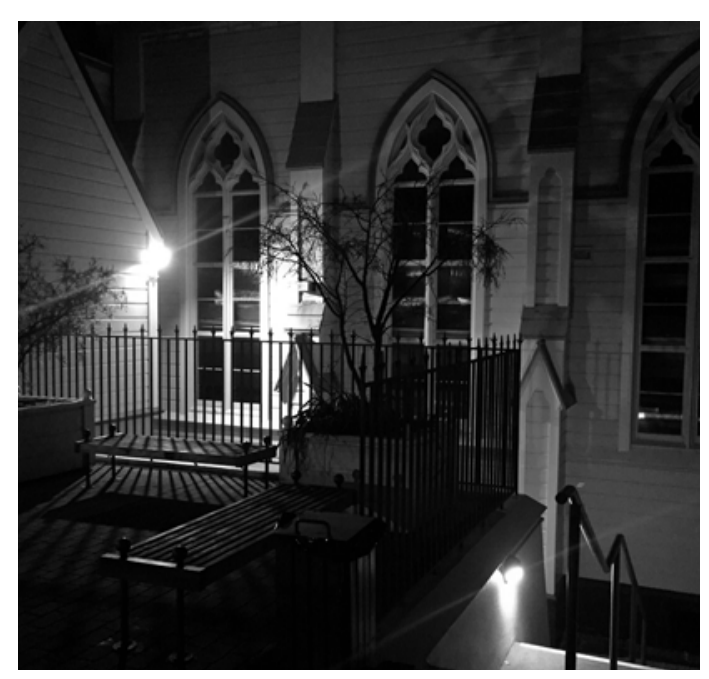

\section{St John's Presbyterian Church}

Lighting is used well throughout the site. The church is well lit at street level and in between the church buildings, creating a sense of safety. 


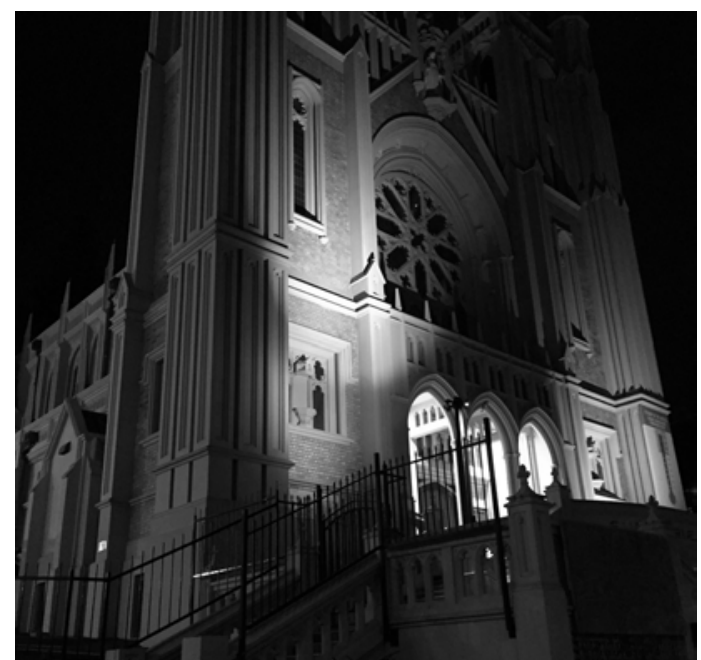

\section{St Mary of the Angels}

The church building and surrounding space are well lit.

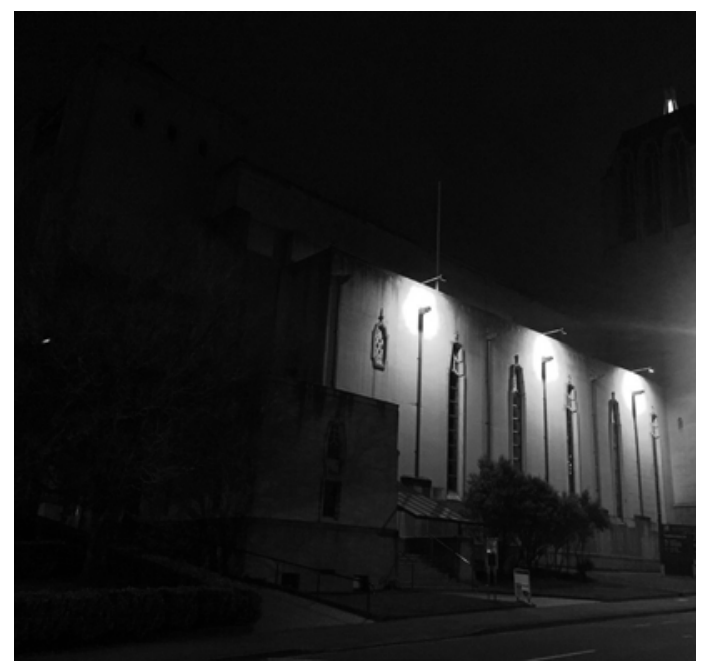

\section{Wellington Cathedral of St Paul}

Both sides of the church are well lit however; the main entrance has no significant lighting. 


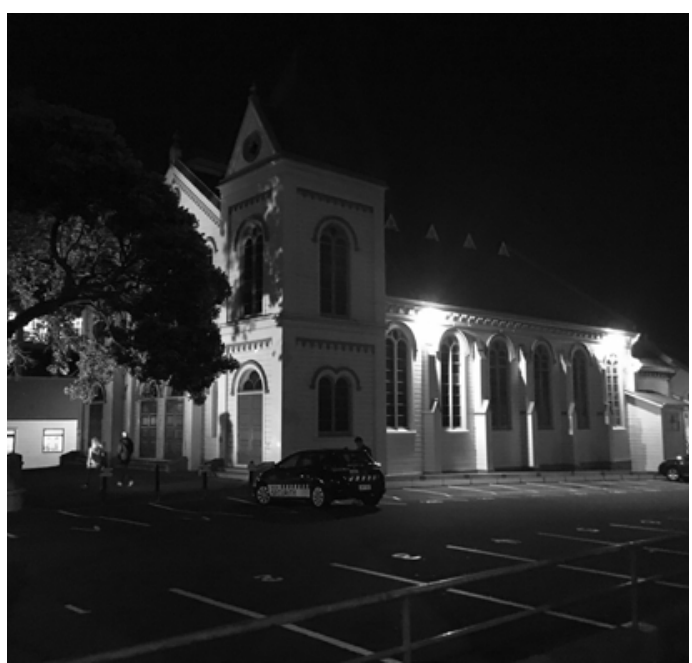

Wellington Methodist Parish

The site is well lit in terms of outlining the building however, more ground lighting could be used to highlight where people should walk.

\section{Conclusions Exterior - Night time}

The analysis on lighting finds it to be insufficient across many locations. Some sites have satisfactory levels of lighting, meaning there are no dark areas at night, while others have no lighting at all. Lack of lighting may be considered a precaution by some, with the assumption that insufficient light will deter undesirable groups from congregating in the space, however the opposite may also be true. 


\section{Level changes}

Assessing the degree of level changes in each space is an important aspect of the transition between the exterior and internal areas of the church.

The entrances to each church were analysed to see how accessible they were to all people.

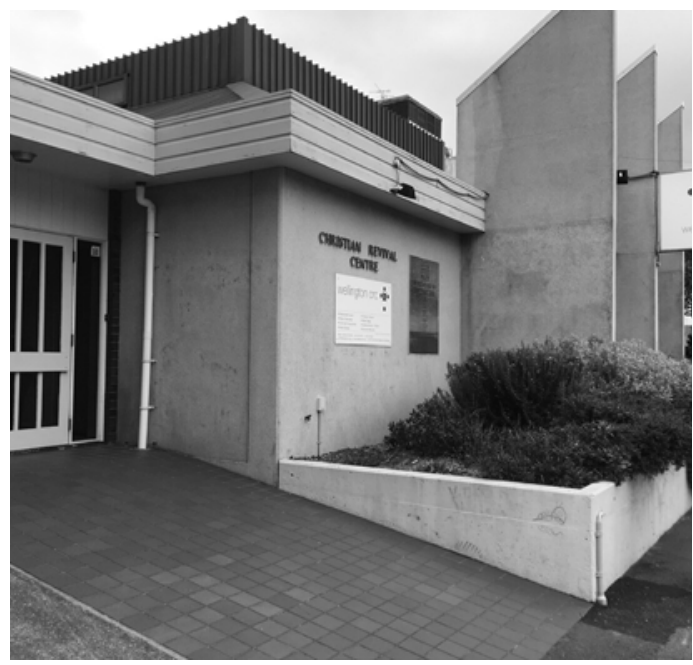

\section{Christian Revival Centre}

The site is relatively flat as a whole. The ground is sloped upon entry to the church making it accessible for disabled users.

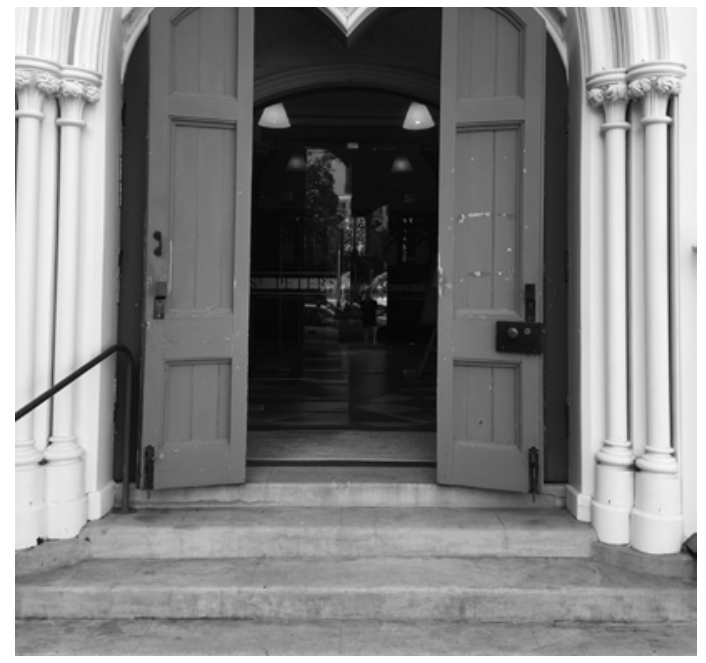

\section{St Peter's Anglican Church}

This site is relatively flat with stairs upon entry. It has a level change of one meter across the entire site.

Fig.3.77. (Left Bottom) St Peter's level changes

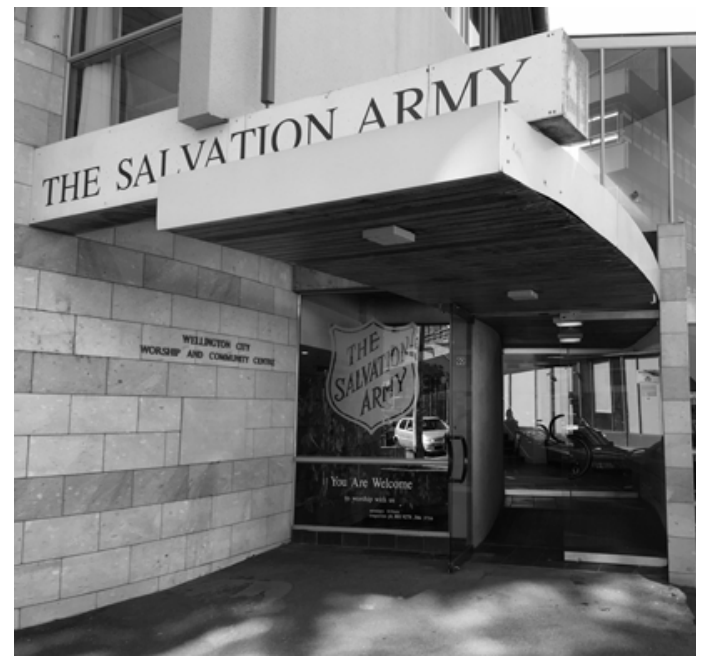

\section{Wellington City Salvation Army}

The main entrance is flat with a very low gradient ramp going into the building. Elsewhere the site is relatively flat with a gradual slope from the southern end of the carpark to the north.

Fig.3.76. (Right Top) Christian Revival level changes Fig.3.78. (Right Bottom) Salvation Army level changes 


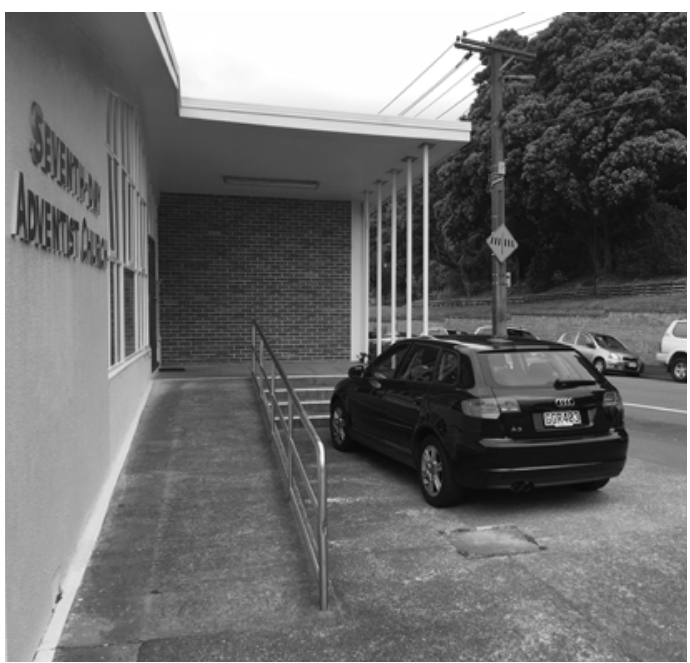

Wellington Seventh Day Adventist

The main entrance is elevated by four steps and ramp access. Elsewhere in the space, the site drops approximately three metres.

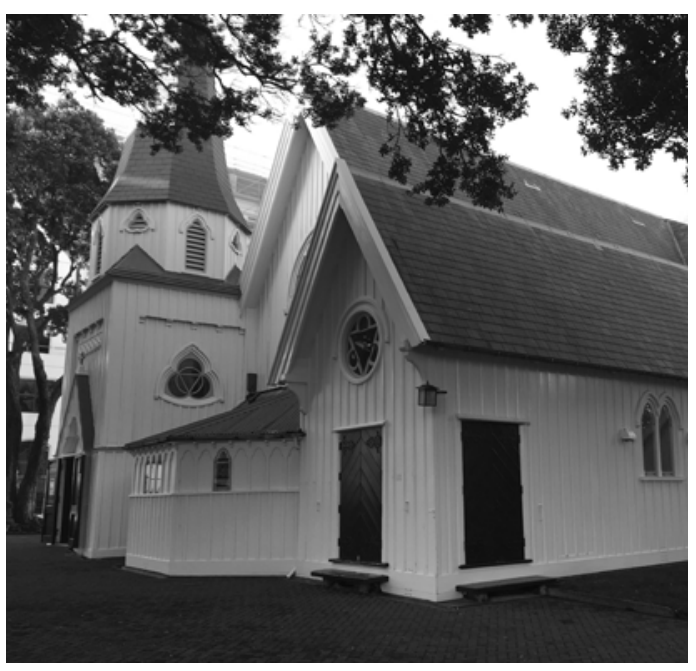

\section{Old St Paul's}

This site is relatively flat. The ground drops down towards the back boundary; however, this area is unused.

Fig.3.79. (Left Top) Seventh Day Adventist level changes Fig.3.81. (Left Bottom) Old St Paul's level changes

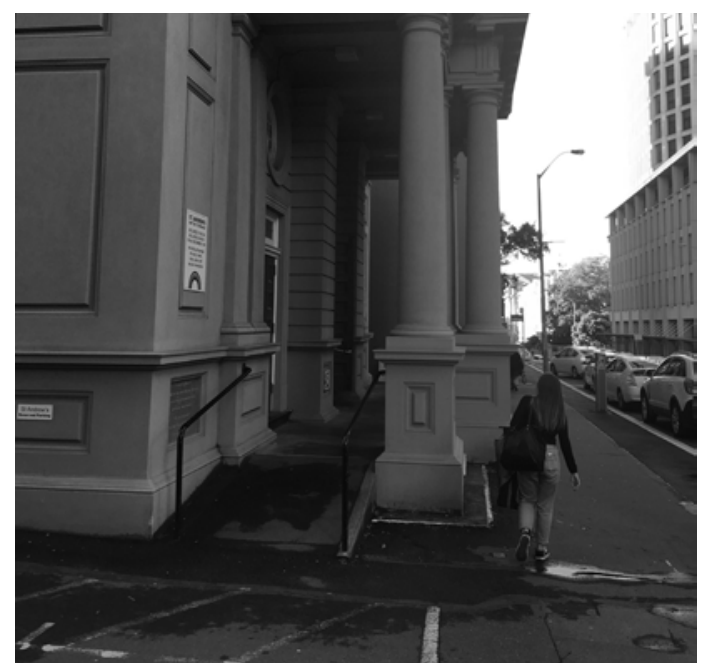

\section{St Andrew's on the Terrace}

The site is relatively flat as a whole. The ground is sloped upon entry to the church making it accessible for disabled users. Stairs also lead to up to the main entrance.

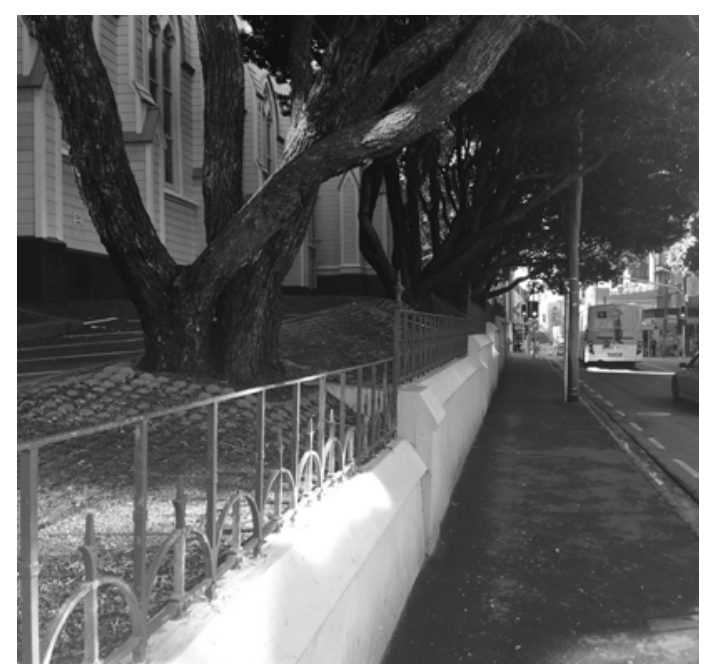

\section{St John's Presbyterian Church}

Here the site is elevated off the road by three metres to the church foundation. The site is set on a slope with retaining walls along the Willis Street side. 


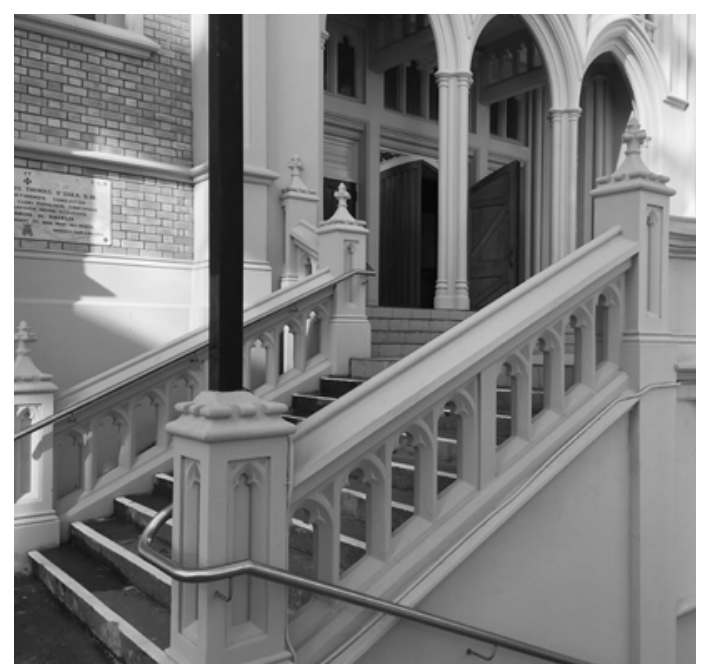

\section{St Mary of the Angels}

The site is set on a significant slope with the church elevated off Boulcott Street. Two sets of stairs go up to the main entrance, with a wheelchair accessible entrance around the side of the church.

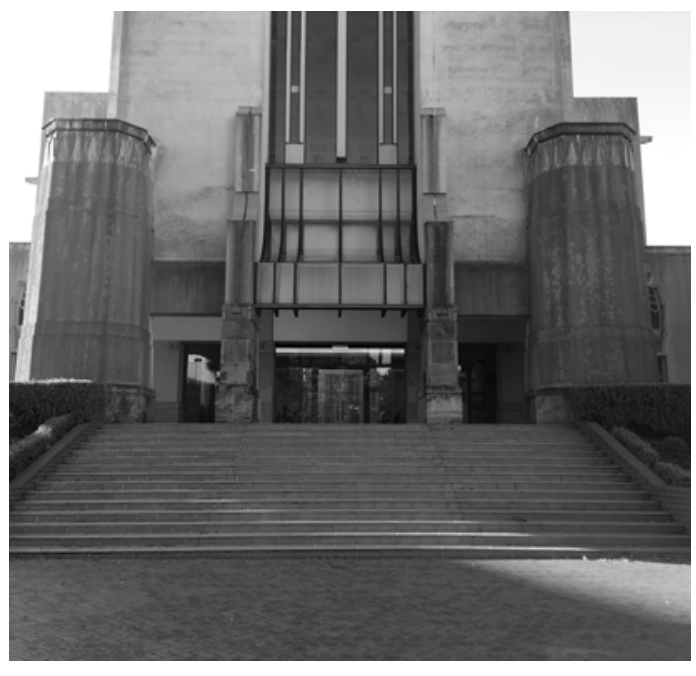

\section{Wellington Cathedral of St Paul}

The church itself is raised from the surrounding area and exterior space. The transition from the flat exterior space is sloped, with ramps on both sides and stairs going up the middle. 


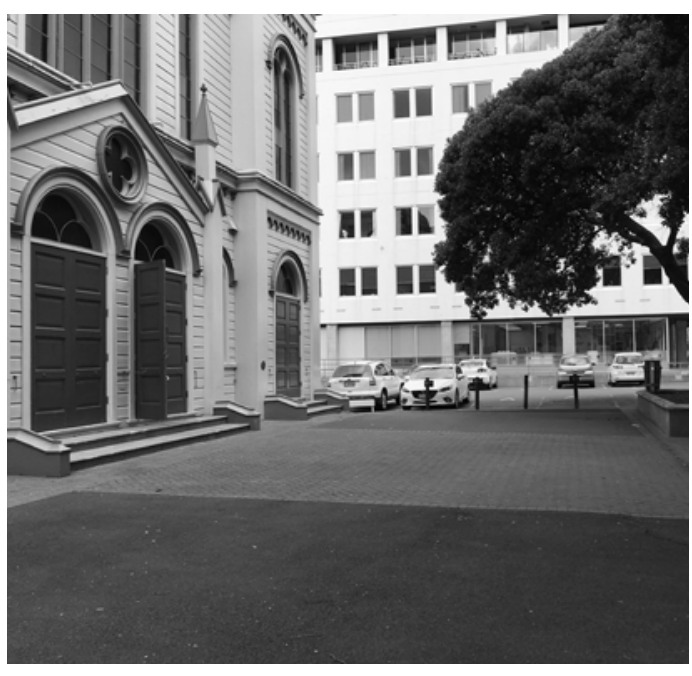

Wellington Methodist Parish

Overall, the site is relatively flat with a gradual slope from the Taranaki Street end to the Holland Street end. Stairs lead up to the main entrance with disability access around the side.

\section{Conclusions Internal \& external transition Level changes}

The majority of sites have little in the way of drastic level changes.

Several sites have stairs leading up to the main entrance of the church. The number of steps varies in each site, in some cases there are two or three, while others have full flights.

Having significant level changes in a space affect how people choose to use it. Sites that have a significant number of steps leading to the church may intimidate those unaccustomed to a church environment.

Having space that is level with the main entrance of the church makes the transition into the church more natural and less abrupt. 


\section{Transition}

The transition between areas in church space, especially the front entrance, is a crucial element to engaging with pedestrians. The entrance to churches should be inviting and welcoming, allowing passers-by to feel comfortable to walk inside.

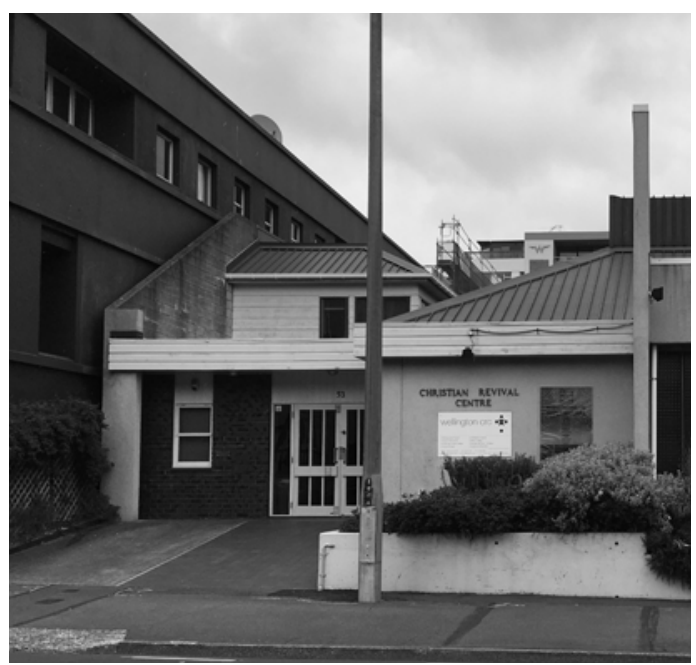

\section{Christian Revival Centre}

The transition from the footpath to church entrance is made difficult by the entrance being set back from the rest of the building. People have to go out of their way to access the front entrance.

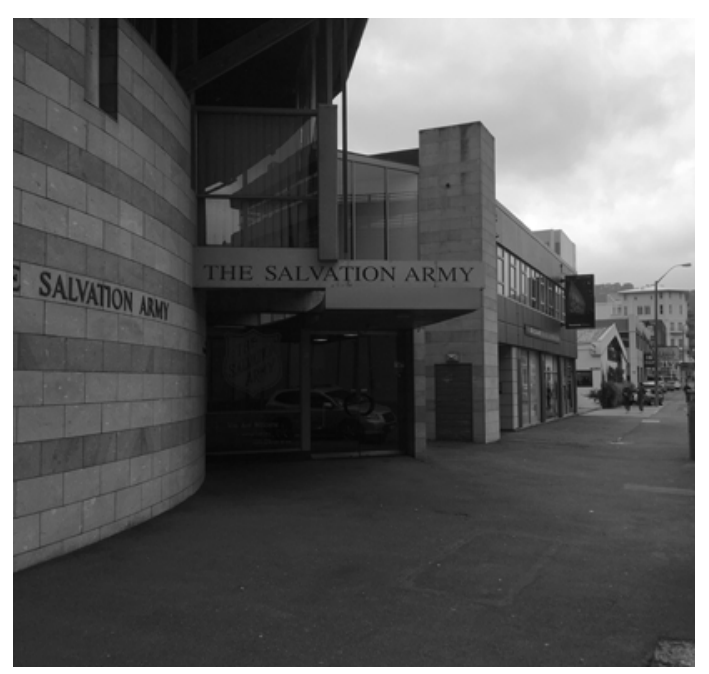

\section{Wellington City Salvation Army}

The curvature of the building enables pedestrians to transition from the footpath to the main entrance without changing direction. Despite this, the entrance is dark and uninviting. The building is also set back significantly from the road, meaning passers-by are unlikely to venture inside.

Fig.3.86. (Right Top) Christian Revival transition Fig.3.88. (Right Bottom) Salvation Army transition 


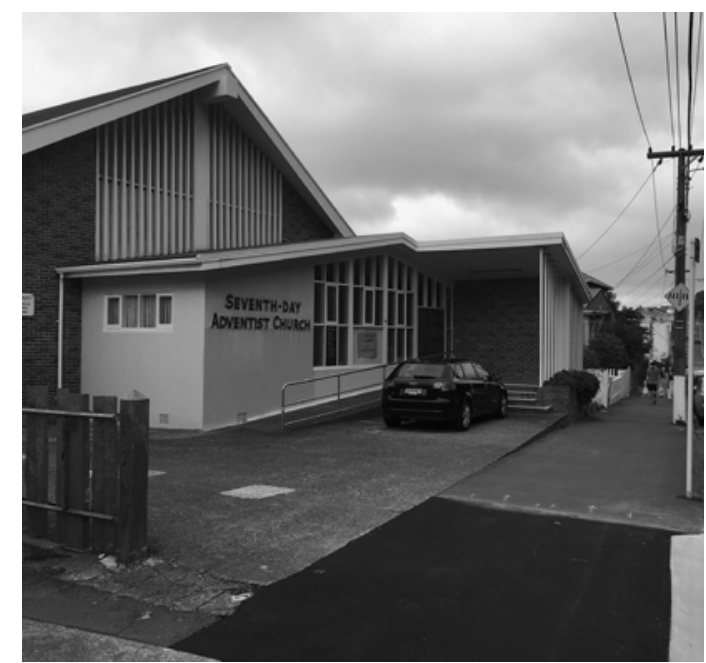

\section{Wellington Seventh Day Adventist}

The entrance space shows priority to pedestrians coming from above, as the space is not parallel to the street. Pedestrians must also compete with vehicles permitted to park in the transition area.

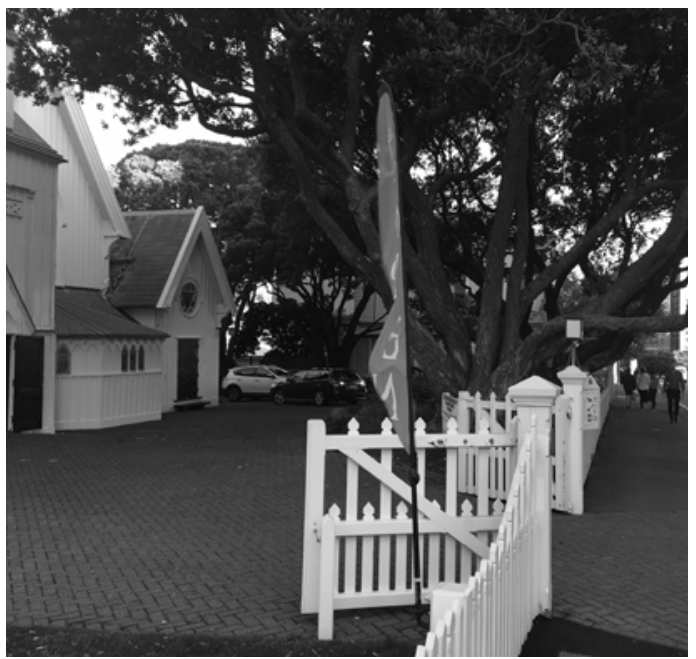

\section{Old St Paul's}

Large pohutukawa trees stand in front of the church building. They do not impact the transition between building and outdoor space, however, do dictate where the entrance is situated. There is no hierarchy between vehicles and pedestrians using the same entrance.

Fig.3.89. (Left Top) Seventh Day Adventist transition Fig.3.91. (Left Bottom) Old St Paul's transition

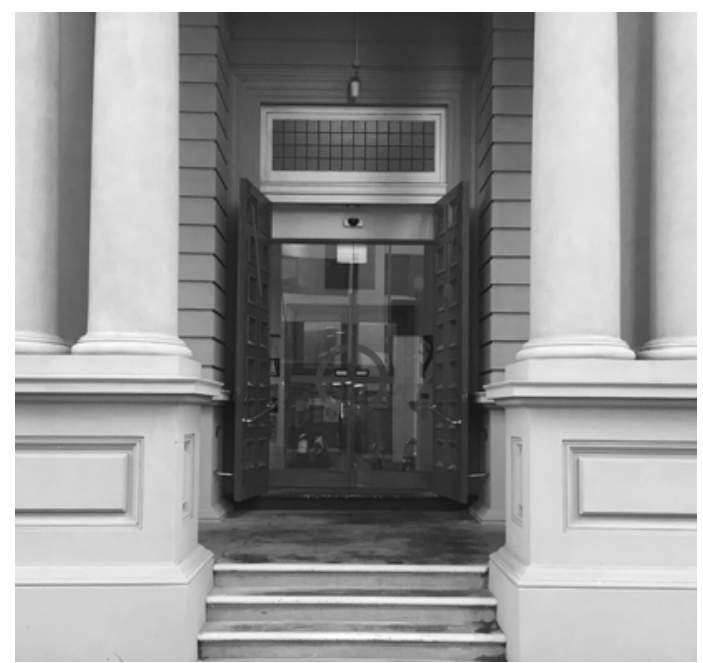

\section{St Andrew's on the Terrace}

The entrance space is relatively hidden from the street. The space is tight, making an abrupt transition from footpath to entrance. There is no opportunity for pedestrians to simply 'wander' inside.

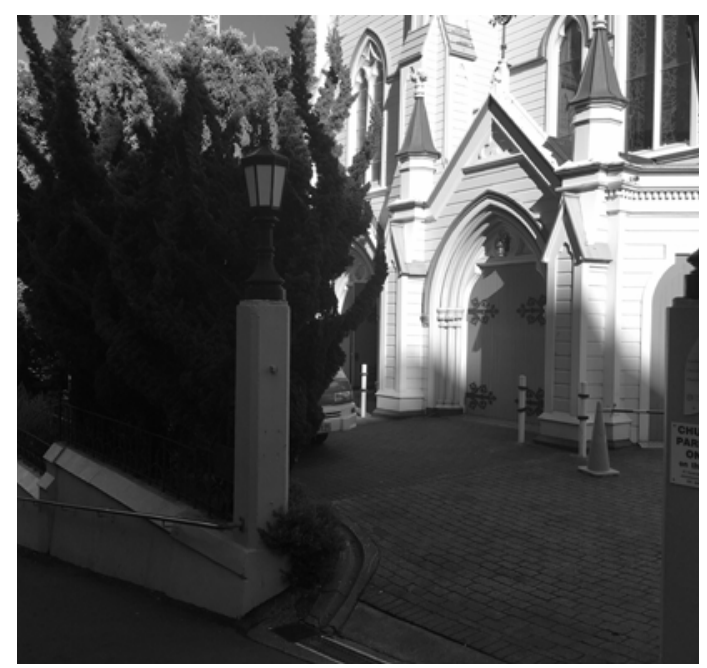

\section{St John's Presbyterian Church}

The transition between footpath and church entrance is made difficult by the multipurpose nature of the space. Vehicles also use the front entrance, meaning people are required to negotiate a path between cars. There is no hierarchy in the space between vehicles and pedestrians. 


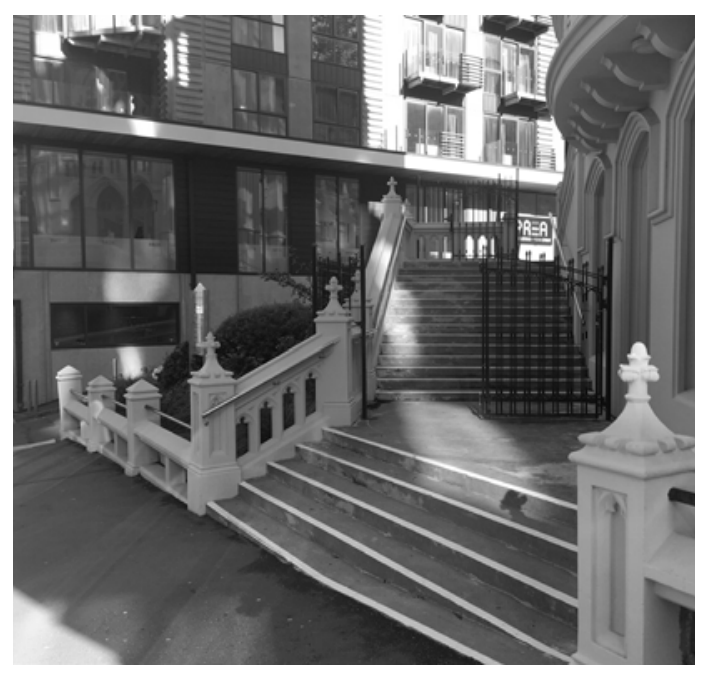

\section{St Mary of the Angels}

The transition from the footpath to the church entrance does not allow people to 'wander' in. Having the main entrance set back and elevated from the footpath limits the number of passers-by the church can attract. There is also no wheelchair access at the main entrance.

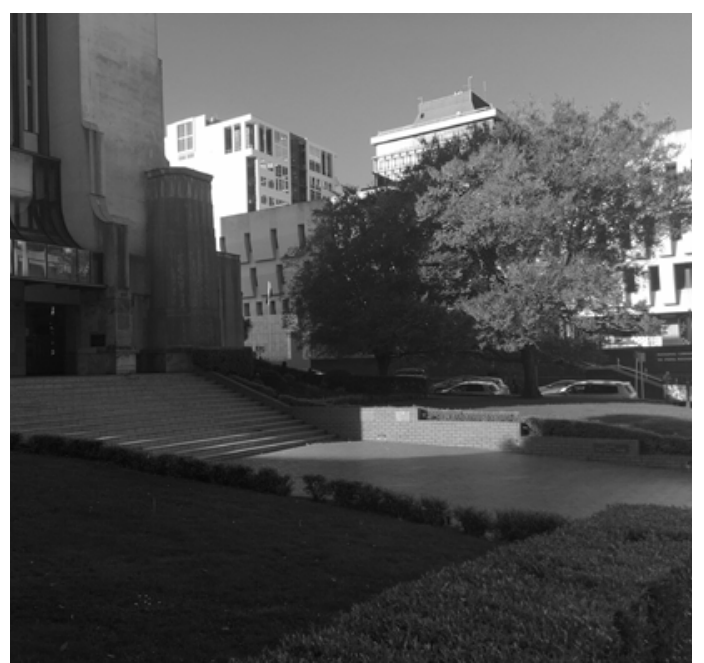

\section{Wellington Cathedral of St Paul}

The church is significantly set back from the footpath. While this has been designed to accommodate public space, it is more difficult to access the church as a pedestrian. 


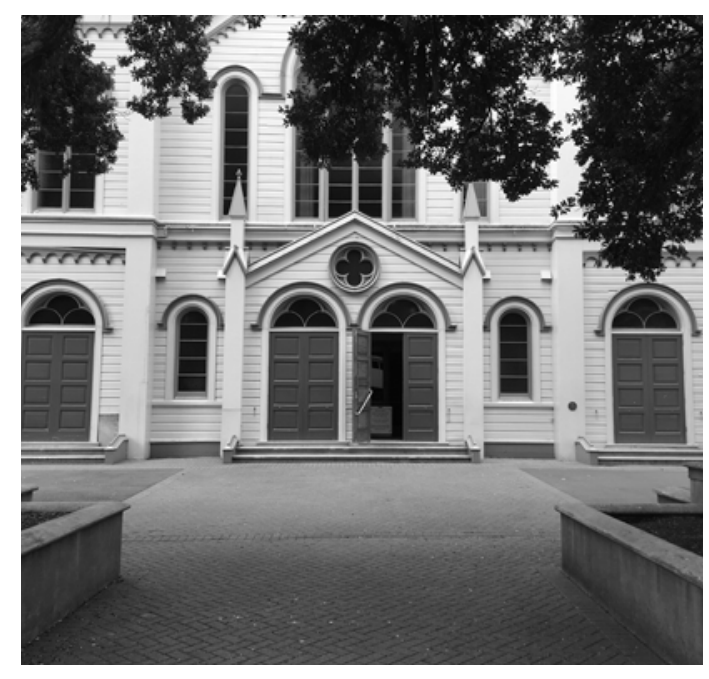

Wellington Methodist Parish

The church is set back from the road with two large pohutukawa trees occupying the space in front. These trees and the boxes they are planted in create a barrier between the footpath and church entrance.

\section{Conclusions Internal \& external transition Transition}

The transition from the footpath to the church entrance needs to be inviting, enticing passers-by inside the church building, however, in many sites analysed, this area is of poor quality. Loose and uneven paving, shade, and fences dominate many of the sites. Trees and other obstacles often line the footpath in front of the church buildings. As such, the transition from the street to church is often uncomfortable for pedestrians and uninviting to passers-by. 


\section{Comparative analysis table}

The data from each of the ten church spaces was collected and reviewed. The sites and their findings were then compared to determine what the main features or opportunities were and if there were any commonalities or differences between them. This table highlights four key criteria to improving the current situation in several spaces.

Context

Traffic (heaviness)
Building use (variety)

Exterior \& context transition

Openness

Pedestrian connectivity

Christian Revival Centre

St Peter's Anglican Church
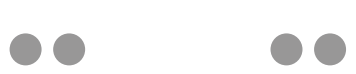

Wellington City Salvation Army
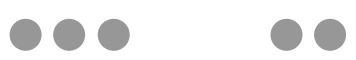

Wellington Seventh Day Adventist

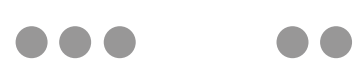

St Andrew's on the Terrace

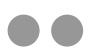

○

Old St Paul's

St John's Presbyterian Church

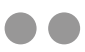

$\bullet \bullet$

St Mary of the Angels

10

$\circ$

Wellington Cathedral of St Paul

$\circ$

$\circ$

Wellington Methodist Parish 
Each category is ranked in relation to each site. One mark symbolizes 'a little', and three marks symbolizes 'a lot'. The orange marks symbolize the categories that proved the most significant for selecting sites with commonalities.

Exterior

\begin{tabular}{|c|c|c|c|c|c|c|}
\hline $\begin{array}{l}\text { Size of } \\
\text { space }\end{array}$ & Parking & Vegetation & $\begin{array}{l}\text { Quality of } \\
\text { space }\end{array}$ & $\begin{array}{l}\text { Night time } \\
\text { situation }\end{array}$ & $\begin{array}{c}\text { Level } \\
\text { changes }\end{array}$ & Transition \\
\hline 0 & 0 & 0 & 0 & 0 & 0 & 00 \\
\hline 0 & 0 & 00 & 0 & 0 & 0 & 00 \\
\hline 00 & 00 & 0 & 0 & 00 & 0 & 0 \\
\hline 00 & 0 & 0 & 0 & 0 & 00 & 0 \\
\hline 0 & 0 & 0 & 00 & 00 & 0 & 00 \\
\hline 0 & 0 & 000 & 00 & 0 & 0 & 0 \\
\hline 0 & 0 & 00 & 00 & 00 & 00 & 0 \\
\hline 000 & 0 & 000 & 000 & 000 & 000 & 0 \\
\hline 00 & 00 & 00 & 00 & 0 & 00 & 00 \\
\hline 000 & 00 & 0 & 0 & 0 & 0 & 0 \\
\hline
\end{tabular}




\section{Comparative analysis table conclusions}

There were a number of common trends throughout each of the ten churches. There was no significant difference between the denominations of the churches analysed. St Mary of the Angels (Catholic) is the only church that had a high quality of space, however, with only one Catholic church analysed, it is not accurate to conclude that all Catholic churches treat space like this. The size of each church space did have a small effect on what churches were more or less successful. The larger spaces tended to score better across each category. However, they all face the same issues around transitioning and inviting, interactive space.

When looking at the categories of analysis, four were identified as key areas for improving the situation in each space. These were, establishing better pedestrian connectivity, creating better transitions within the space, improving the quality of space and making the space flexible to activities and car parking.

Pedestrian connectivity is poor, both in the wider context (connecting the space to its surroundings), and in the close context (transitioning within the space) Two sites have well established thoroughfares, however, fail to add a level of permanency which would encourage pedestrians to utilise the space. The quality of each space is also very poor with little to no vegetation or inviting features encouraging people to use the space. With urban development in New Zealand and Wellington so expansive, a substantial part of the exterior space in many churches analysed is dedicated to car parking. Three churches in particular have a poor connection between the church building and exterior space. These churches also have large car parks demonstrating poor pedestrian connectivity between car park and building. These three churches then became the focus for design.

These sites were: Wellington Cathedral of St Paul (Anglican), Wellington City Salvation Army (Salvationist), Wellington Methodist Parish (Methodist)

Key criteria for design from the comparative analysis process

\begin{tabular}{|c|c|c|c|}
\hline $\begin{array}{c}\text { Wider context } \\
\text { transitions }\end{array}$ & $\begin{array}{l}\text { Close context } \\
\text { transitions }\end{array}$ & Quality of Space & Flexibility \\
\hline $\begin{array}{l}\text { Work with existing } \\
\text { thoroughfares and } \\
\text { facilitate new ones }\end{array}$ & $\begin{array}{c}\text { Link spaces to one } \\
\text { another } \\
\text { Remove obstructions }\end{array}$ & $\begin{array}{l}\text { Increase Vegetation } \\
\text { Improve Paving } \\
\text { Create spaces for }\end{array}$ & $\begin{array}{l}\text { Keep as much parking } \\
\text { as possible whilst } \\
\text { enhancing the space }\end{array}$ \\
\hline & & sitting and standing & $\begin{array}{l}\text { Make the space } \\
\text { flexible to the weekend } \\
\text { and weekday setting }\end{array}$ \\
\hline
\end{tabular}



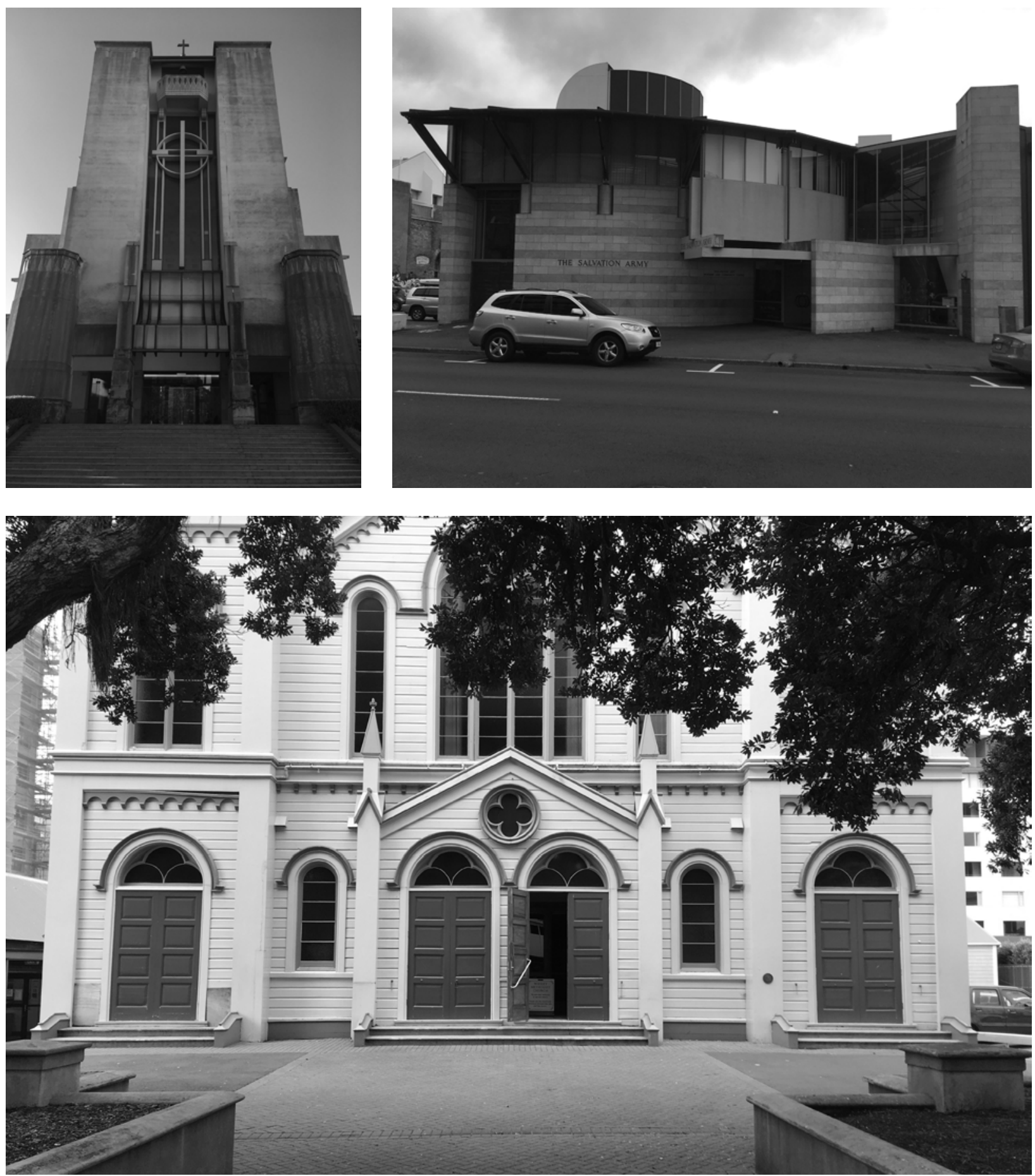


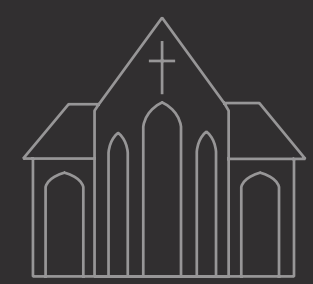

CHAPTER FOUR 


\section{Site specific analysis}

The selected sites

This chapter analyses the three selected sites in more detail, highlighting elements related to pedestrian connectivity and car-parking. Sites are then analysed at a closer scale, where the quality of space and transitions between spaces can be determined.

This analysis focuses on the participatory design and community engagement techniques used at this stage of the research. The data collected from engaging with the community is then broken down and combined with the results from the comparative analysis.

Commonalities across all three sites

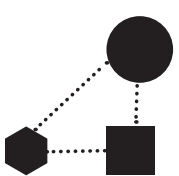

Wider context transitions

Work with existing thoroughfares and facilitate new ones

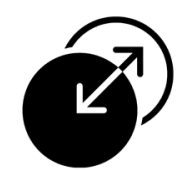

Close context transitions

Link spaces to one another Remove obstructions

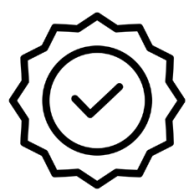

Quality of Space

Flexibility

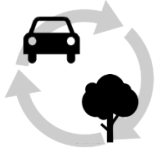

\section{Increase Vegetation Improve Paving Create spaces for sitting and standing}

Keep as much parking as possible whilst enhancing the space Make the space flexible to the weekend and weekday setting 


\section{Community engagement method}

In each of the sites, two main communities were designed for; the general public and the community using the church and its surrounding space during the week. It was important to understand who attends the church, where they come from and how they interact with the space. It was also important to understand how the congregation feel about the church space, what they deem important and how the site could potentially change for their benefit, as well as for the general public.

Interviews were held at the three selected churches, with representatives of the church answering general questions about the congregation and what sort of programmes or activities are held at the church. The data generated from the interviews was then used in conjunction with site analysis to inform how the space could change, while incorporating features that were identified as important to the church community.

Anonymous surveys were also conducted at each site, assisted by those representatives previously interviewed. These surveys were made available to the whole church congregation and were designed to gather data on how far people travelled to get to church, the general age of the congregation, how many programmes or activities people attended, and general ideas and opinions on the current site situation and how it could change. This data was then used to assist the design phase of the research, allowing for some level of collaborative design.

The opinions of each respondent were archived and used to inform the design process. The most useful question from the survey was, "Do you think the exterior space surrounding the church works well? Do you think it is an open and welcoming space? If not, how do you think it could be improved?"

The results were organised under general topics and common answers were grouped together. A tally system was used to define the most common responses, and these provided key feedback for design. 


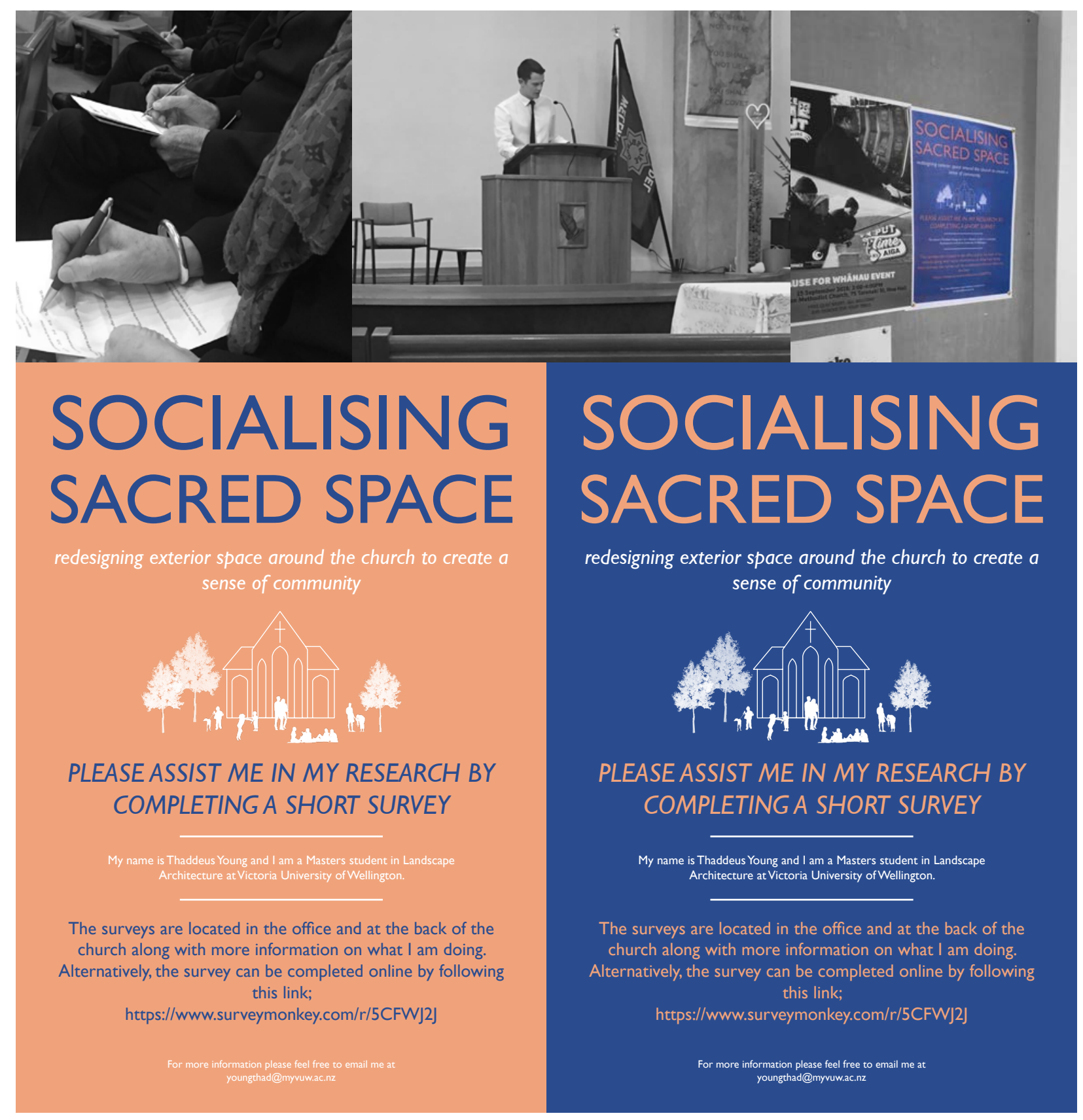

Fig.4.01. a, b and c, (Top) Church community images

Fig.4.02. (Bottom) Informative survey posters used in each church 


\section{Wellington Cathedral of St Paul}

\section{Commonalities across all three sites}

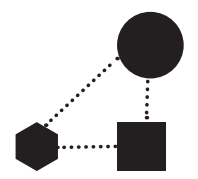

Wider context transitions

Work with existing Link spaces to one thoroughfares and

facilitate new ones

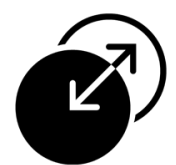

Close context transitions Remove obstructions

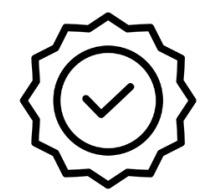

Quality of Space

Increase Vegetation Improve Paving

Create spaces for sitting and standing

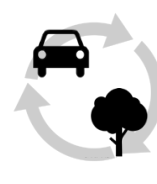

Flexibility

Keep as much parking as possible whilst enhancing the space Make the space flexible to the weekend and weekday setting

Commonalities in the specific site

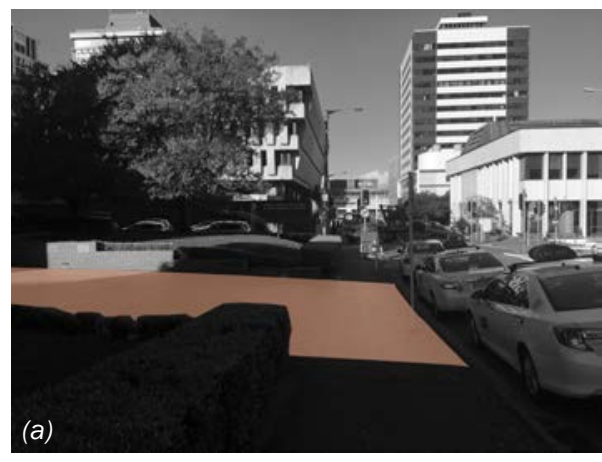

Footpath filters into site with inviting paving

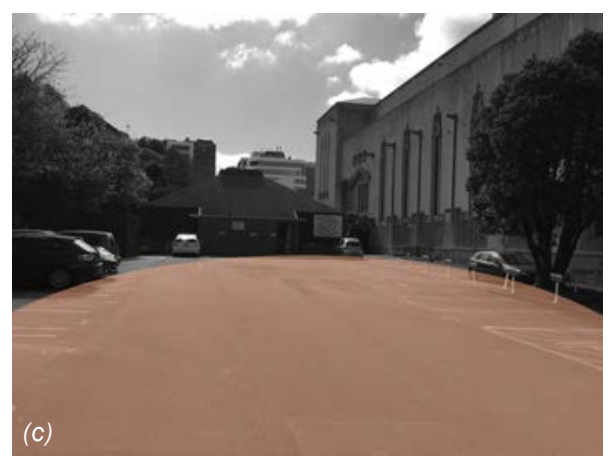

Car park space

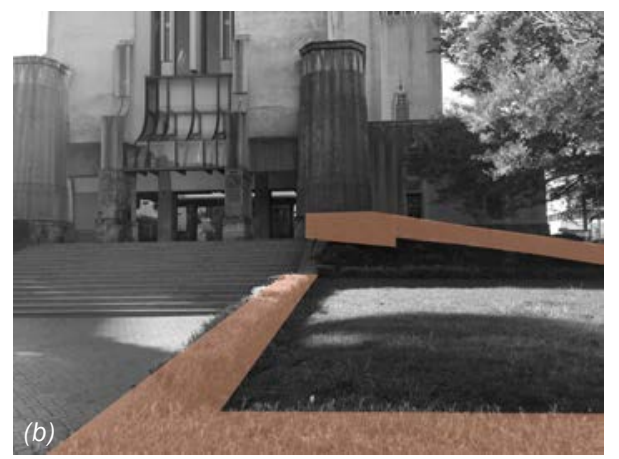

Gardens and lawn are appealing but inaccessible

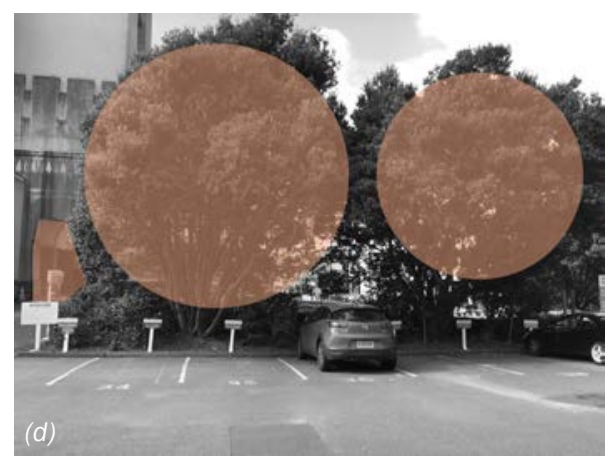

Transition from church to carpark 


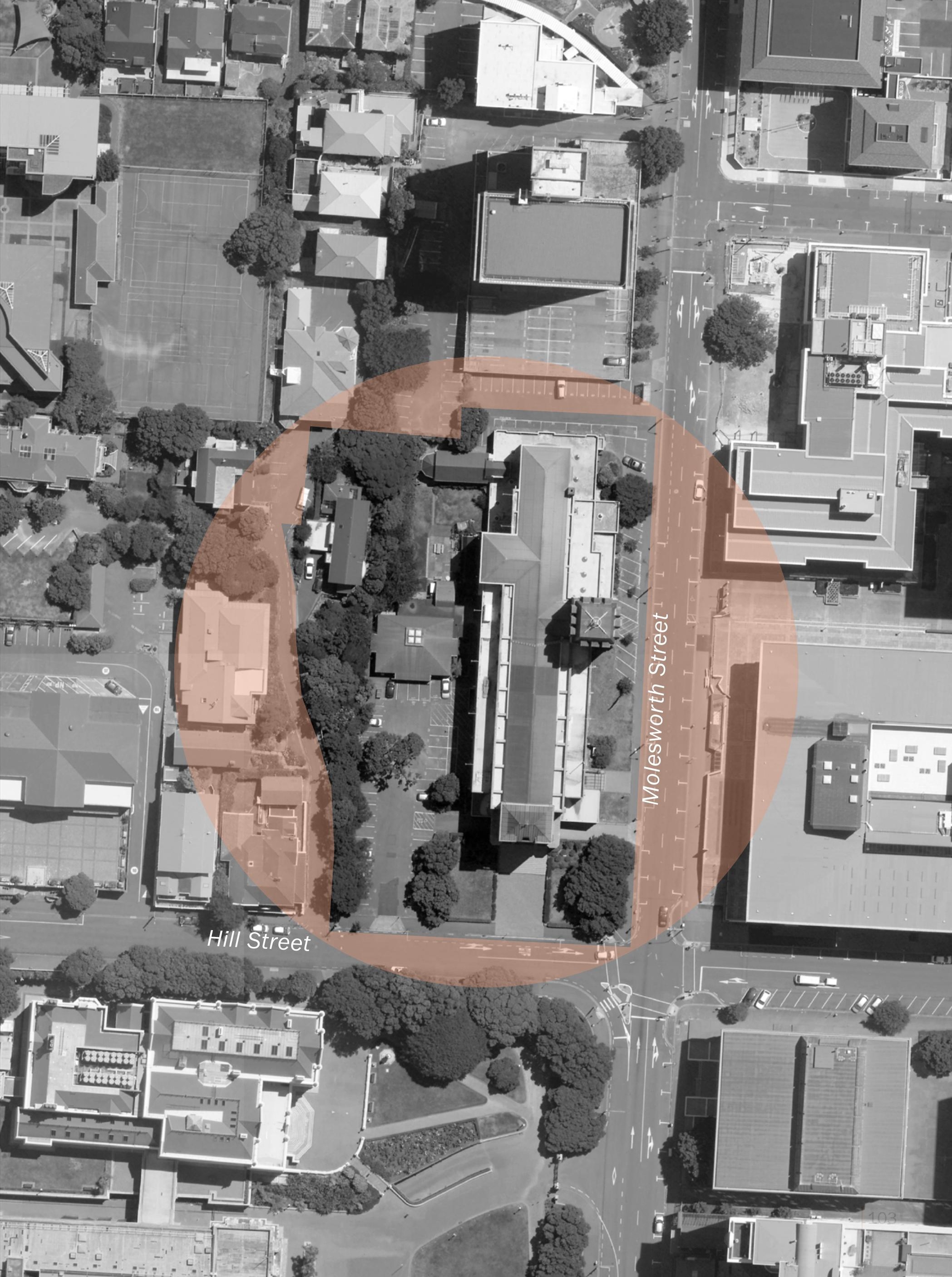




\section{Church background and analysis plan}

Located opposite Parliament grounds, Wellington Cathedral of St Paul was built as a beacon of spirituality for those leading the country (Wellington Cathedral of St Paul).

The dream for an Anglican Cathedral in Wellington began even before Wellington was announced as the country's capital, however planning for the Cathedral began in earnest around 1865 (Wellington Cathedral of St Paul). The two original St Paul's churches in Wellington were at capacity and the need for a larger, more impressive structure was obvious to the Anglican diocese at the time (Wellington Cathedral of St Paul).

Originally inspired by the great medieval Cathedrals of Europe, design changes were needed in order to make the building suitable for an earthquake prone area (Wellington Cathedral of St Paul). The design became less ornate, utilising stronger, reinforced concrete.

Architect Cecil Wood was appointed in 1938 to lead the project and in 1943, land adjacent to parliament was purchased as the Cathedral site (Wellington Cathedral of St Paul). Wood's design for the Cathedral was inspired by the buildings he studied during his pre-war travels, including Stockholm Town Hall and Southern California Art Deco architecture (Wellington Cathedral of St Paul).

The foundation stone was laid in 1954 by a young Queen Elizabeth upon her first visit to New Zealand, with construction beginning the following year (Wellington Cathedral of St Paul). Ten years later, in 1964, the first congregation moved in to the new, partially-built buildings. Various projects continued up until 1992, when the decision was made to raise the final amount needed to complete the Cathedral. Dedication of the completed Cathedral took place in May, 1998 (Wellington Cathedral of St Paul).

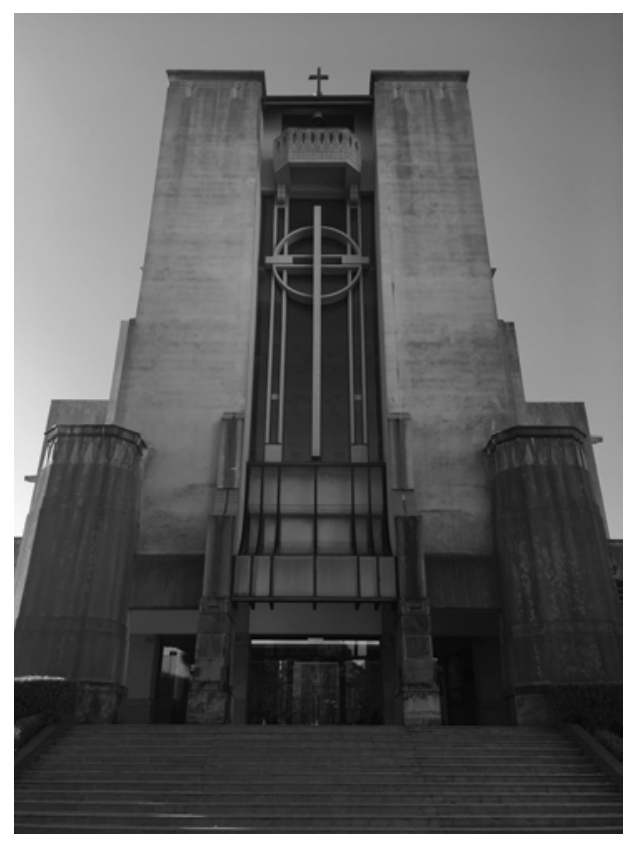

Primary parking space

Property boundary

Main thoroughfare

Secondary thoroughfare

(X) Numbers relate to photos 


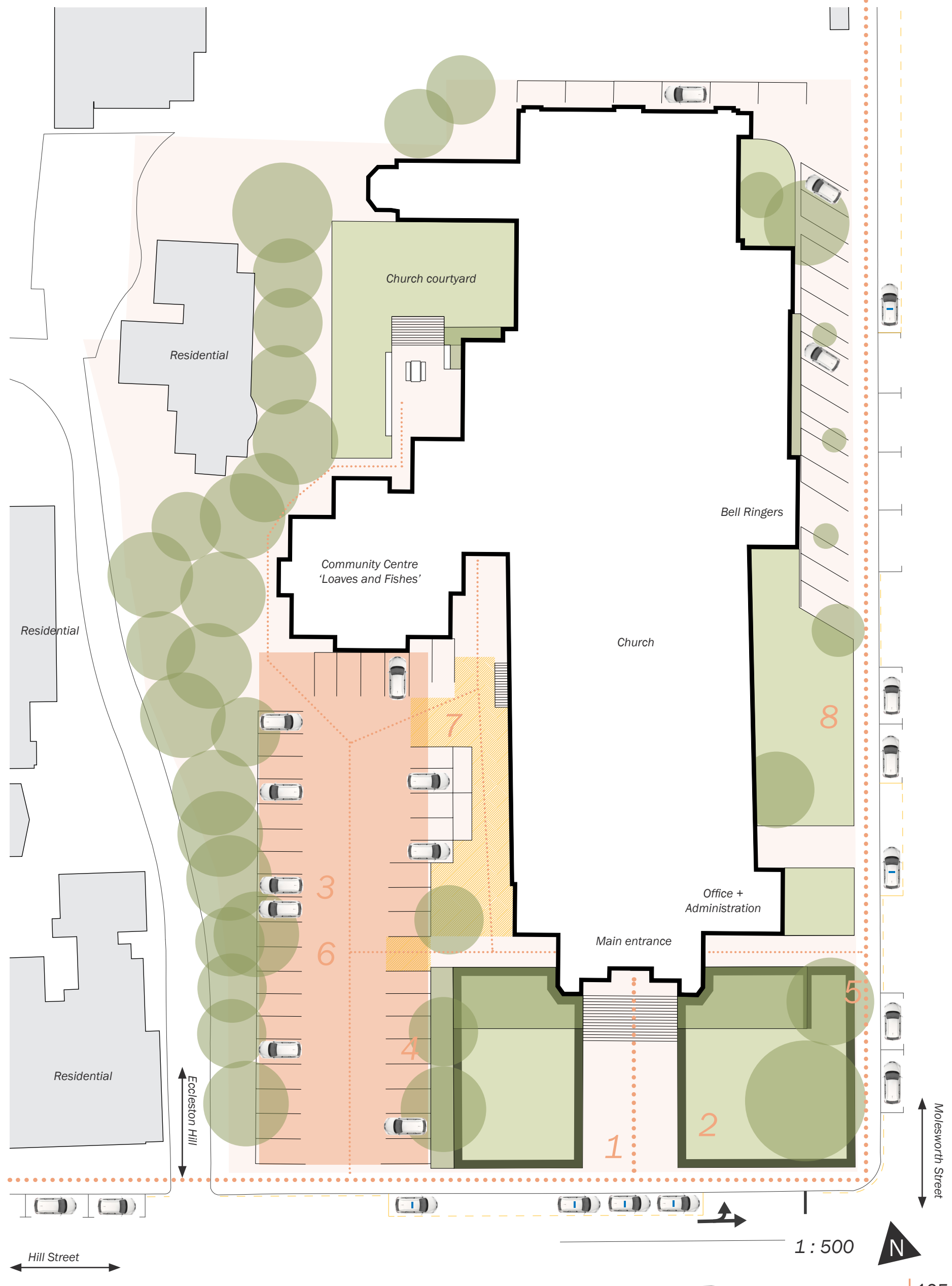




\section{Analysis overlay images}

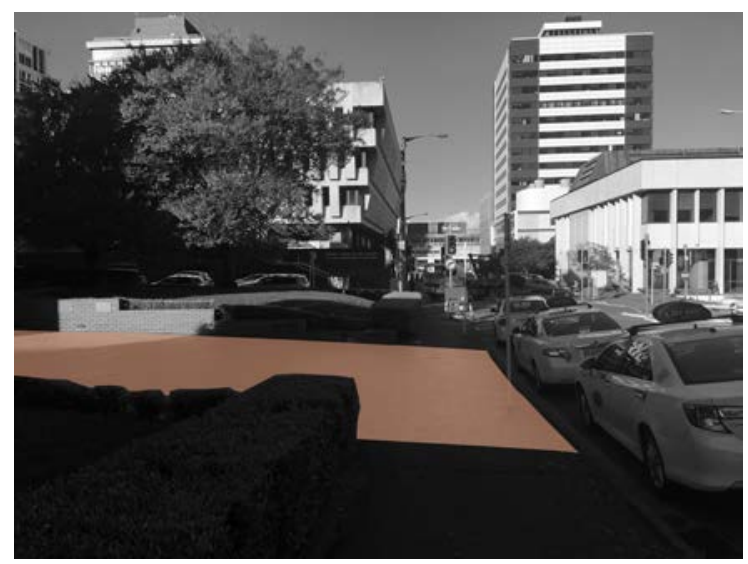

\section{Front entrance - Good paving}

Having the paving spill out onto the footpath is a good technique for drawing people into a space. The different texture and pattern attract the eye, adding interest. This technique could be implemented across all sites.

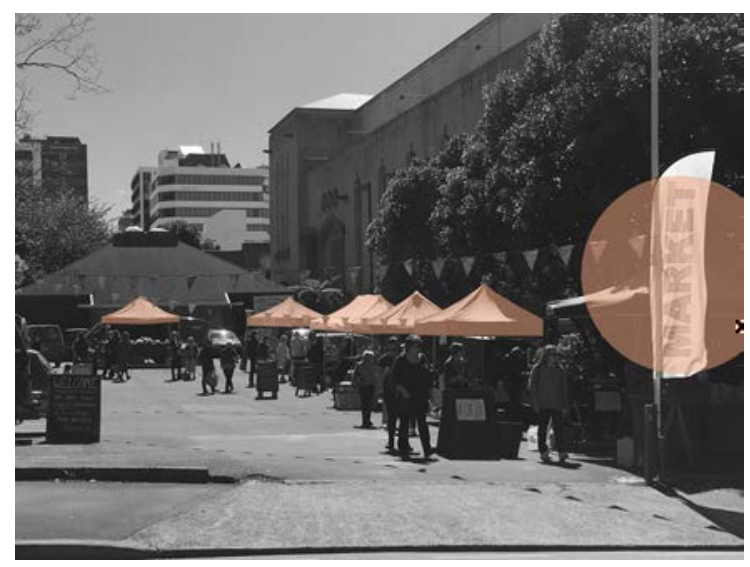

\section{Market programme}

On Saturdays, the car park is used as a market space. This is a chance for local communities to engage with the church community. Enabling this type of interaction is an important consideration when designing usable church space.

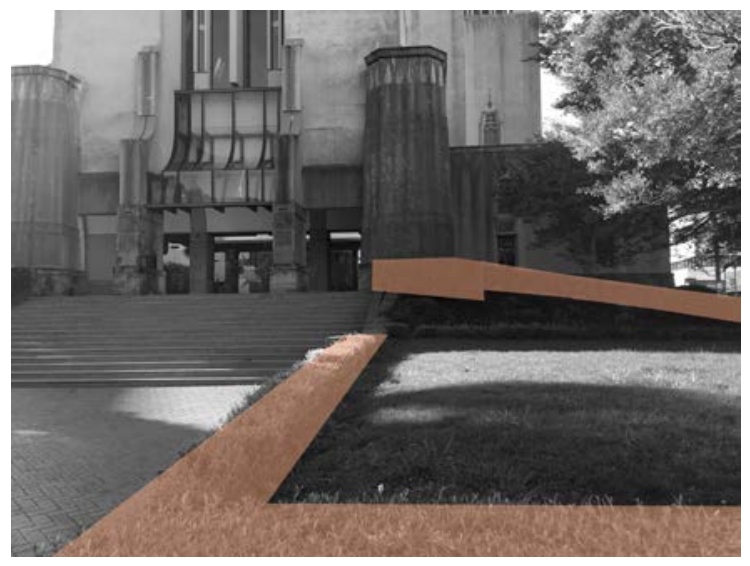

\section{Front space - Inaccessible}

The space in front of the church is purely aesthetic. The lawn is inaccessible and the space that it occupies is unused. This area, if made more accessible, would be an ideal spot for local workers to have lunch.

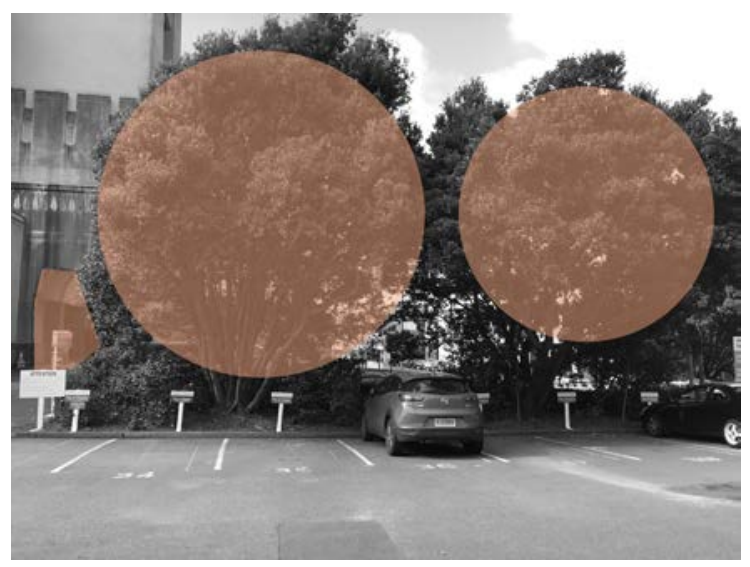

\section{Transition from car park to church}

The transition from the car park to the church lacks connection. Planting blocks sight and movement to the church. An established path running along this edge would steer pedestrian movement away from the car park, creating more space. 


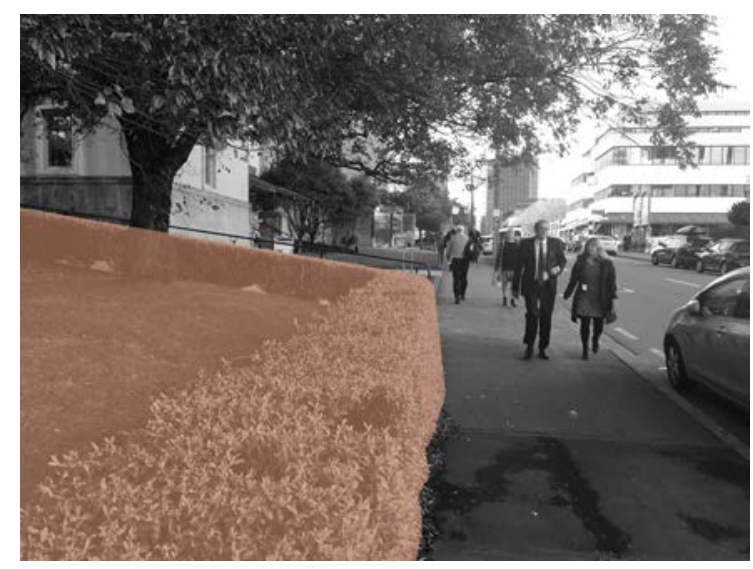

\section{Hedging - Obstructive}

Hedging obstructs any access to the lawn in front of the church. Parts of the hedge could be removed, creating a transition from the footpath.

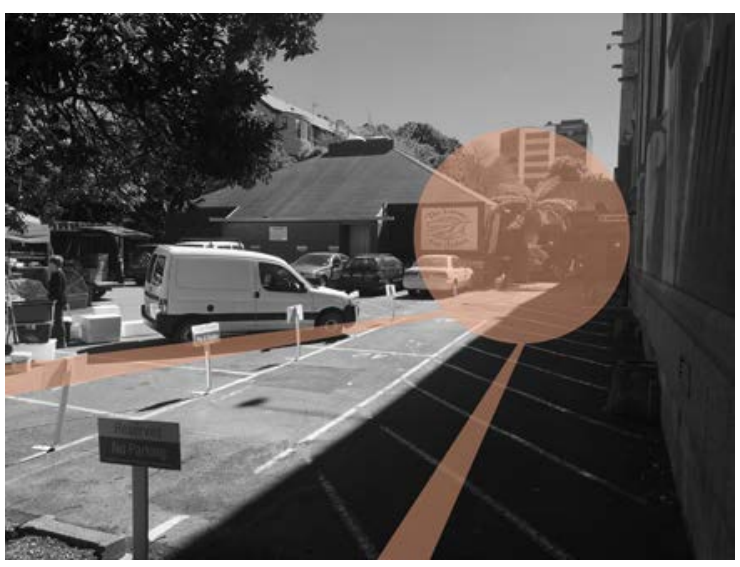

7. Connection to community centre

The 'Loaves and Fishes' offers meals to the community and homeless. This building has no established path, people must walk through the car park to reach the building. Defining a path to the building will improve connectivity.

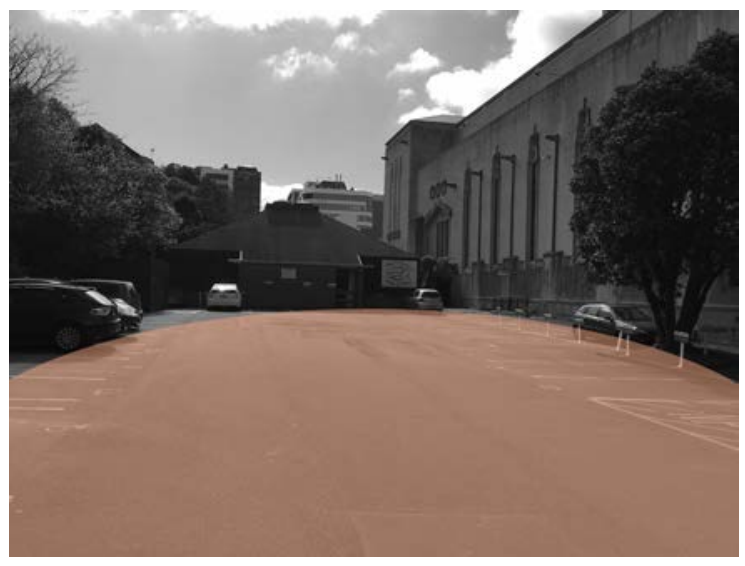

\section{Car park (weekday)}

This car park is heavily used on a Sunday. There are thirty-eight parks with additional parking along the eastern edge of the church. Significant gaps between each side of the car park could be brought closer together to allow more space for a pedestrian access.

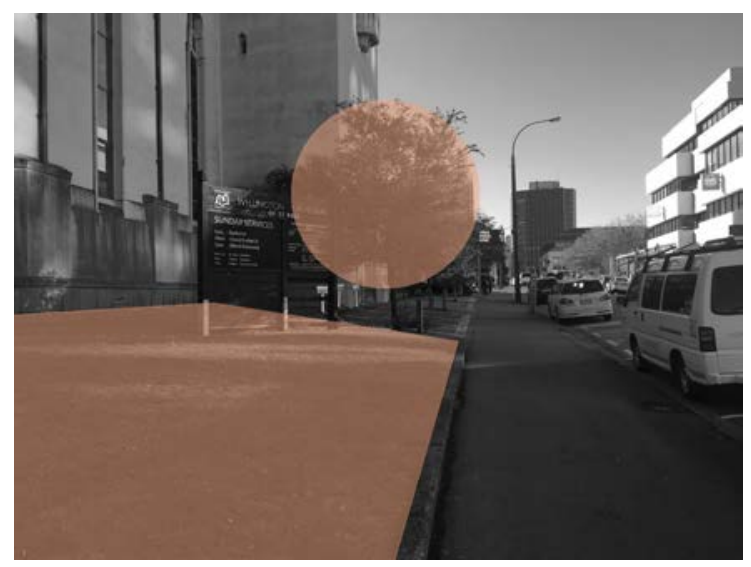

\section{Vegetation}

The Eastern side of the church along Molesworth Street works well. The church is slightly removed from the footpath, creating room for vegetation and lawn which softens the impact of the building on its surroundings, and makes the space more appealing. 


\section{Community engagement}

Demographics

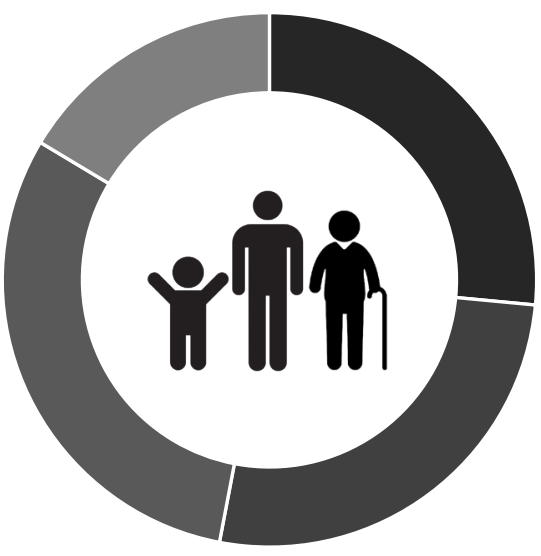

Age
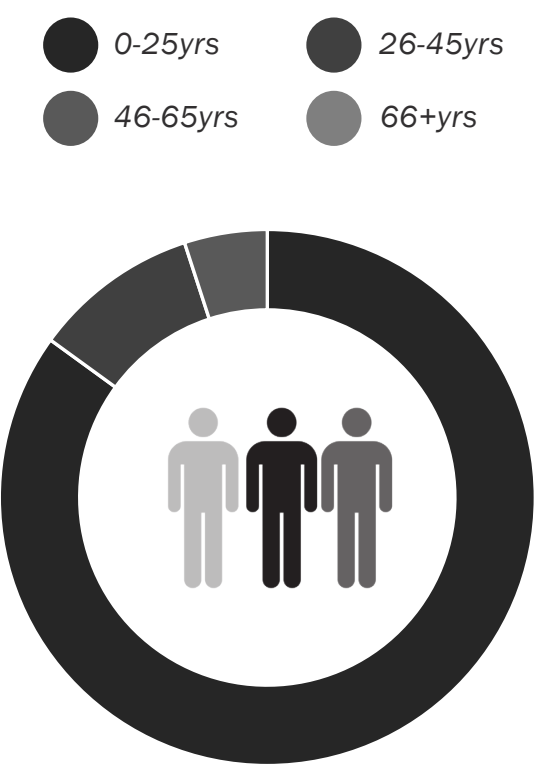

Ethnicity

NZ European

Chinese

Maori

Car parking

Carpark usage
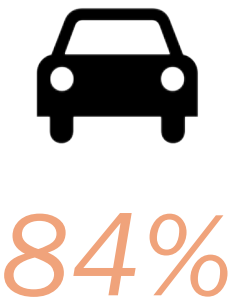

Out of the 31 respondents, 26 drive and use the carpark.

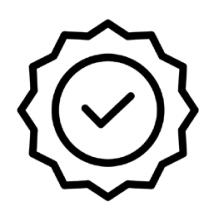

Quality of space

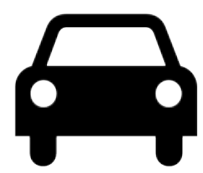

Improve parking
Carpark importance
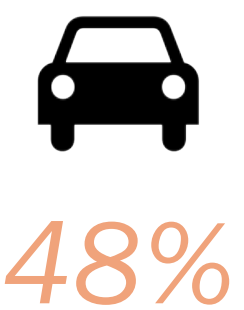

Out of the 31 respondents, 15 said the carpark is important with no one saying it is not. The other 16 did not say or were indifferent

\section{Community Ideas}

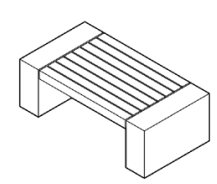

More Seating

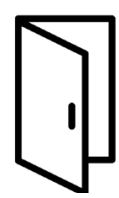

More inviting space 


\section{Church Community by Suburb}

Larger circle - More people

+ Church location

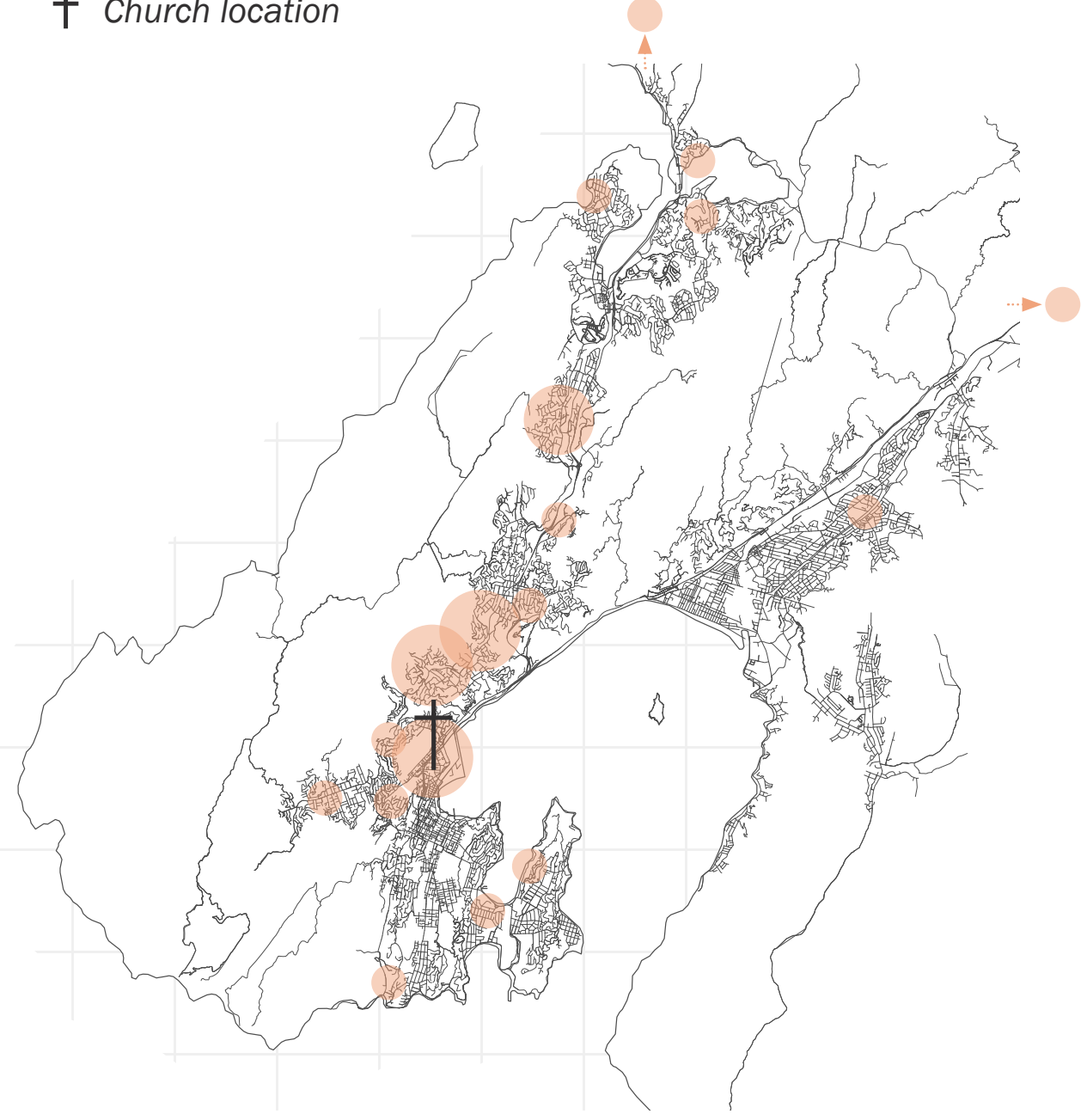

31

Survey responses

4 Ngaio

4 Khandallah

4 Thorndon

3 Tawa

2 Owhiro Bay

2 Wilton

1 Whitby

1 Raumati South

1 Karori

1 Maupuia

1 Mana

1 Wairarapa

1 Newlands

1 Lower Hutt

1 Kilbirnie

1 Titahi Bay

1 Grenada Village

1 Kelburn

Conclusion

The most common response across the thirty-one participants indicated a desire for increased seating and better waiting areas.

Most survey participants live outside of the inner city. Of the thirty-one respondents, only four people live in the inner city, with twenty-six travelling to church by car. This data reinforced the need for car parking in the church space.

As identified during site analysis, the lawn area in front of the church is inaccessible, with hedges lining the edge space. The church community also identified this as a problem, indicating through survey responses they want the space to be more accessible and usable. 


\section{Wellington City Salvation Army}

\section{Commonalities across all three sites}

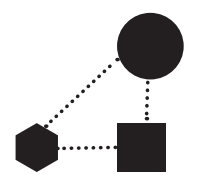

Wider context transitions

Work with existing Link spaces to one thoroughfares and

facilitate new ones

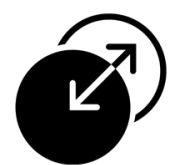

Close context transitions Remove obstructions

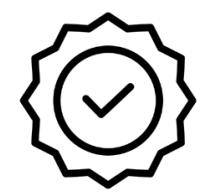

Quality of Space

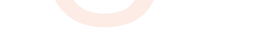

Increase Vegetation Improve Paving

Create spaces for sitting and standing

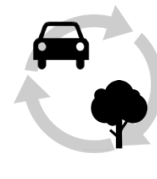

Flexibility

Keep as much parking as possible whilst enhancing the space Make the space flexible to the weekend and weekday setting

\section{Commonalities in the specific site}

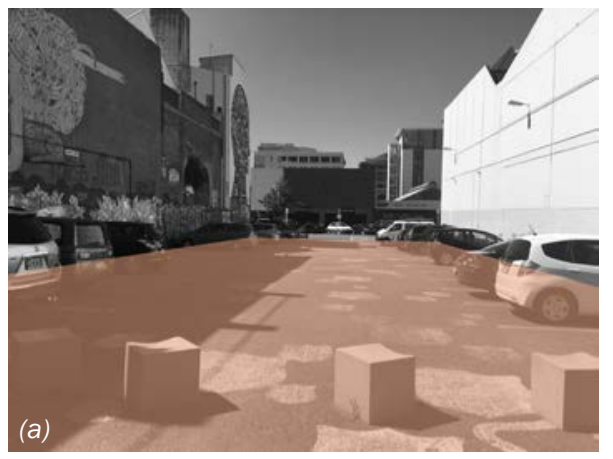

Car park used as thoroughfare

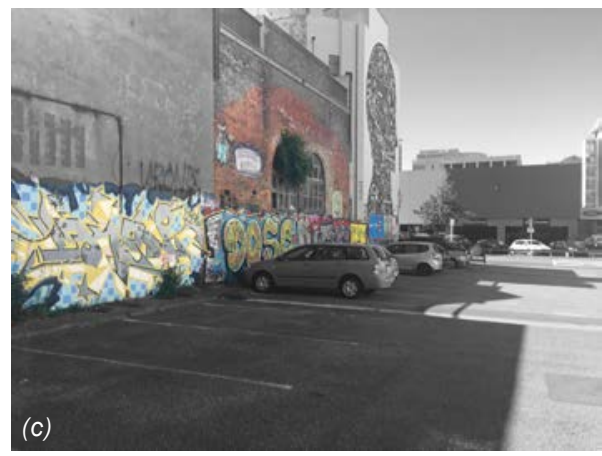

Current car park takes up all space

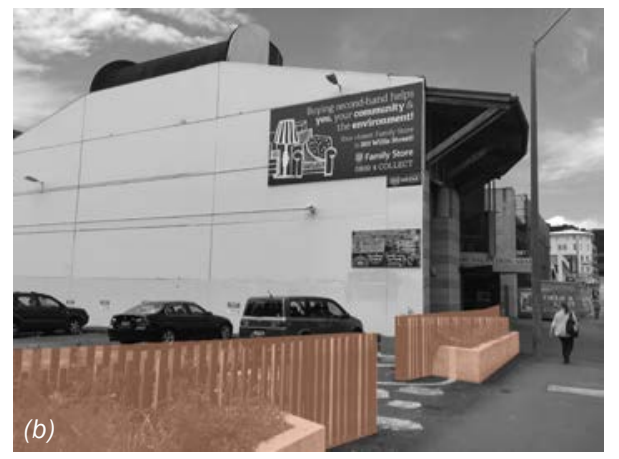

Current level of vegetation and seating

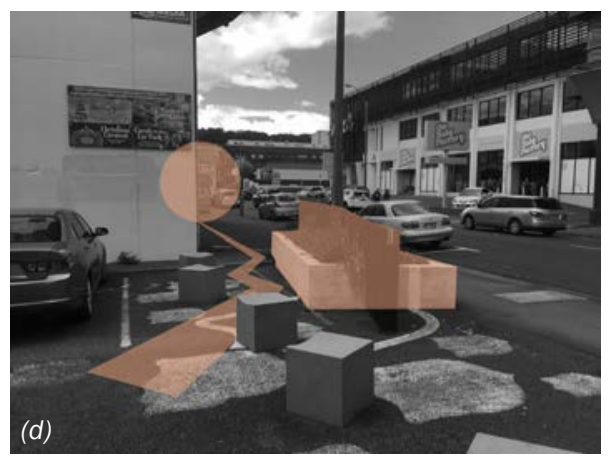

Transition from church to carpark 


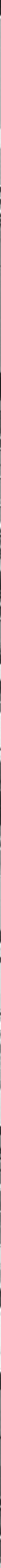




\section{Church background and analysis plan}

As part of the international Salvation Army movement, Wellington City Salvation Army aims to provide practical service to the inner-city community of Wellington.

The church's location was chosen in the early 20th Century due to its proximity to the rougher parts of the city, including Wellington's Chinatown in Haining Street, once described as "the most notorious slum area in New Zealand" (Stuff).

The original building was designed by Edward J Saunders, a pioneer of the Salvation Army movement in Australia who designed many early Salvation Army buildings. The Citadel was one of six buildings Saunders designed in Wellington alone (Wellington City Heritage - Saunders). The CQ Hotel on Cuba Street, formerly the 'People's Palace' is his last standing building in Wellington (Wellington City Heritage - Saunders).

By 1980 the church had outgrown its original Vivian Street building and the decision was made to re-build on the same site. This new building was designed by Warren \& Mahoney Architects and was opened in the 1990s

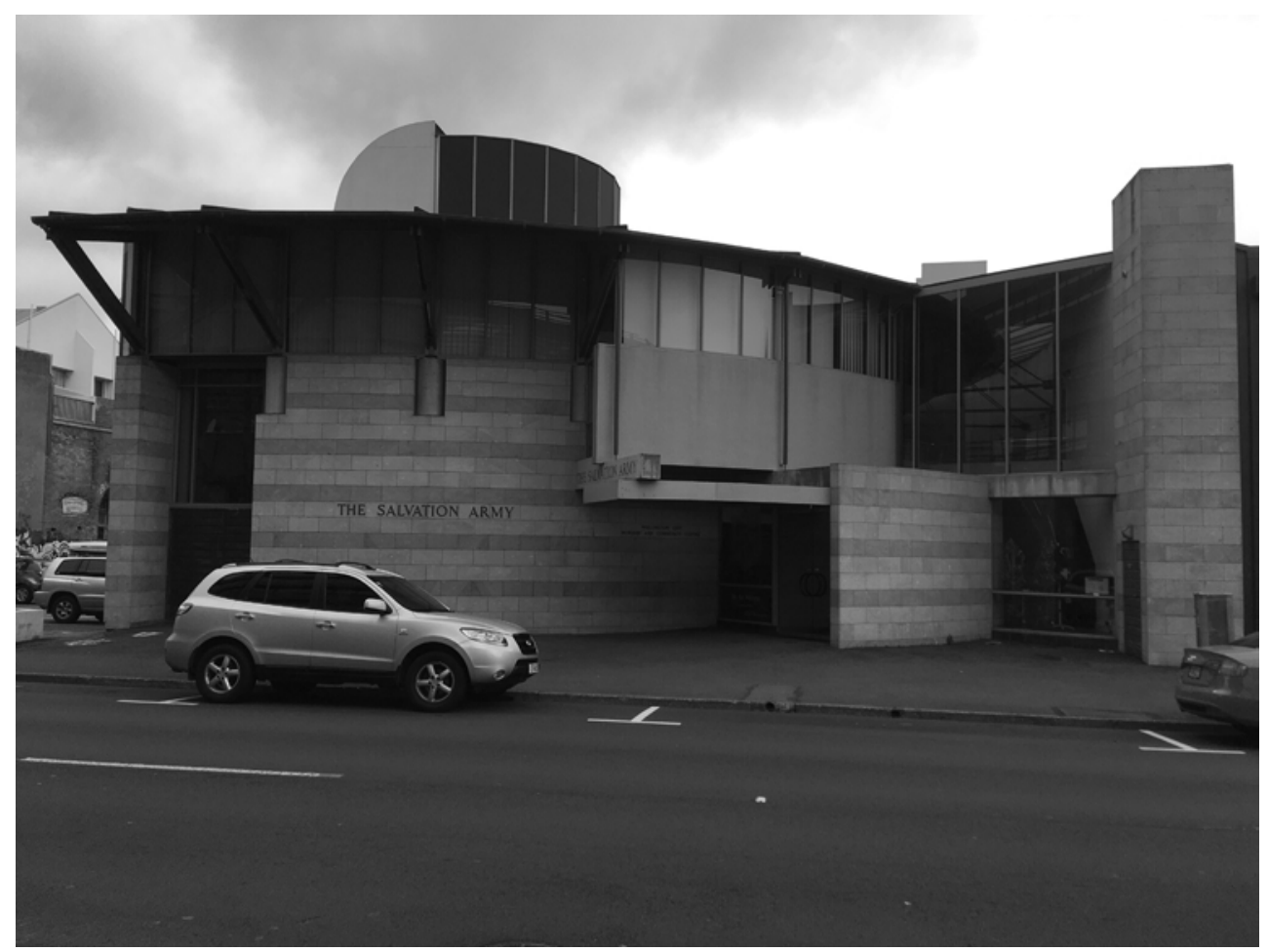




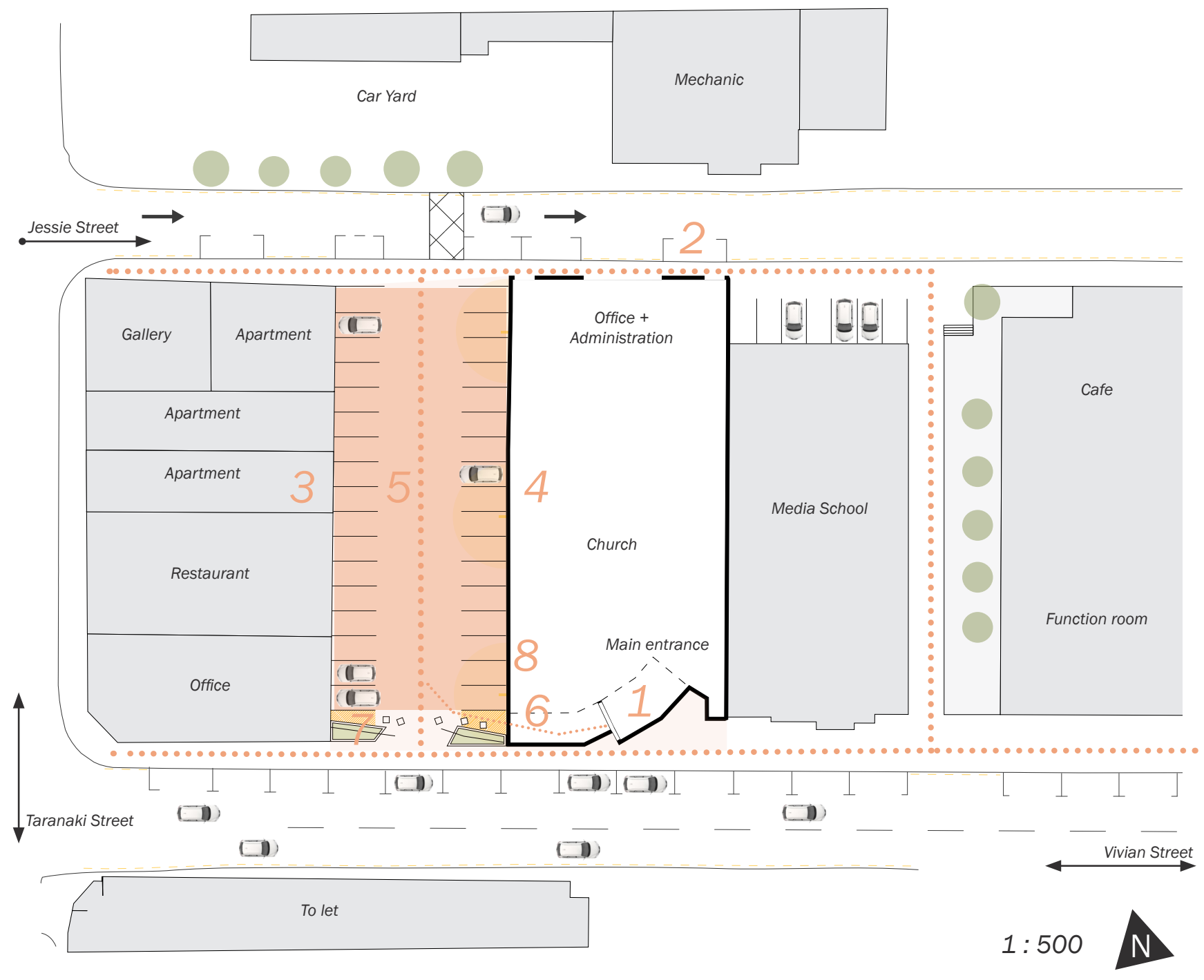

Primary parking space

Property boundary
Secondary thoroughfare

(X) Numbers relate to photos

Main thoroughfare 


\section{Analysis overlay images}

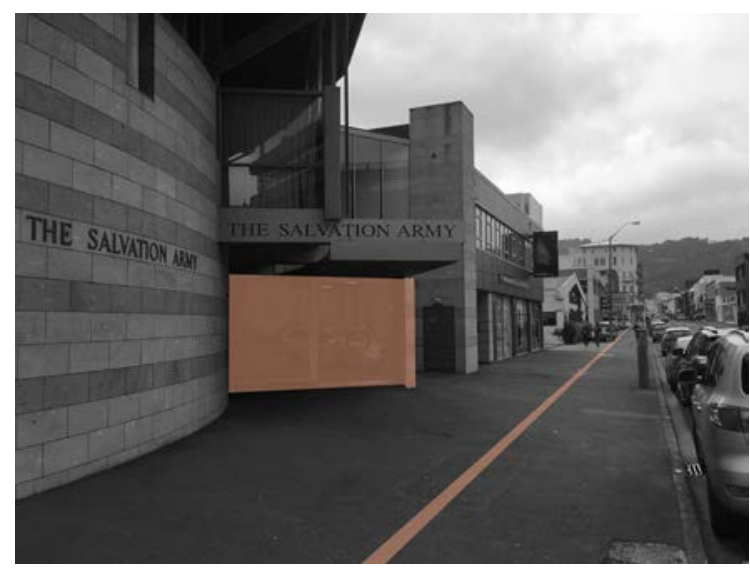

\section{Front entrance - Intimidating wall}

The front entrance is inviting as the cantilevered roof extends out over the footpath. This creates a subtle channelling towards the church. Unfortunately, the exterior wall of the church is so large and dense that it detracts from the entrance way. Softening this area with planting or lighting would improve the site.

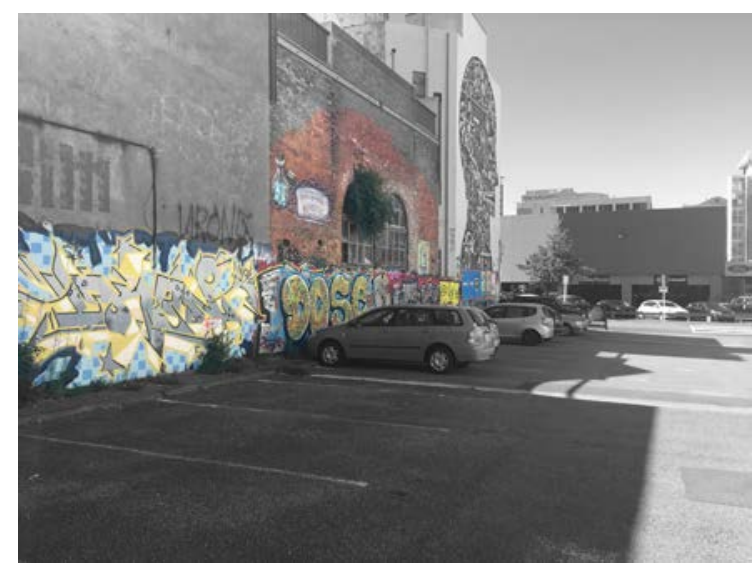

\section{Adjacent wall - Character}

The exterior wall of the neighbouring building has plenty of texture and colour and is more visually stimulating than the church wall on the opposite side of the car park. Graffiti shows some level of community engagement, whether encouraged or not, with many people coming to paint and take photos of the street art.

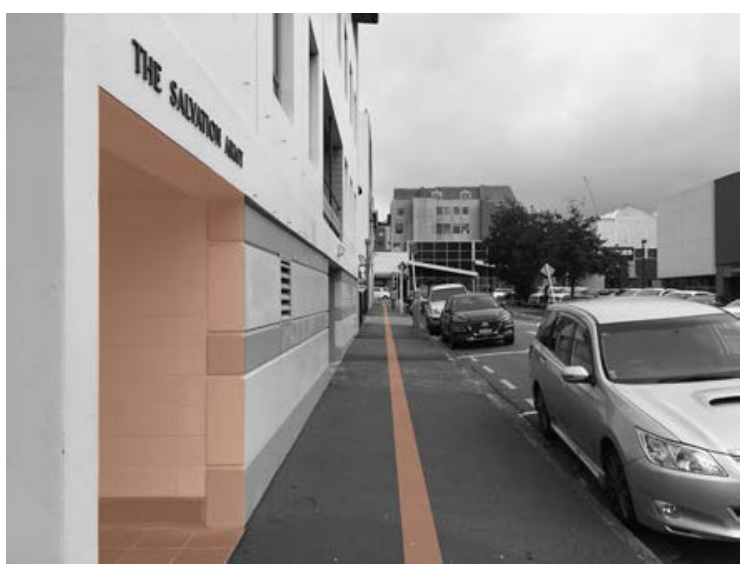

\section{Back entrance - Uninviting}

The back entrance to the church, located on Jessie Street, is used more during the week than the front, providing direct access to the administration offices. This is an uninviting entrance way and has a poor connection to the footpath. There is nothing indicating to pedestrians that this is a church entrance, except a poster next to the concealed doorway.

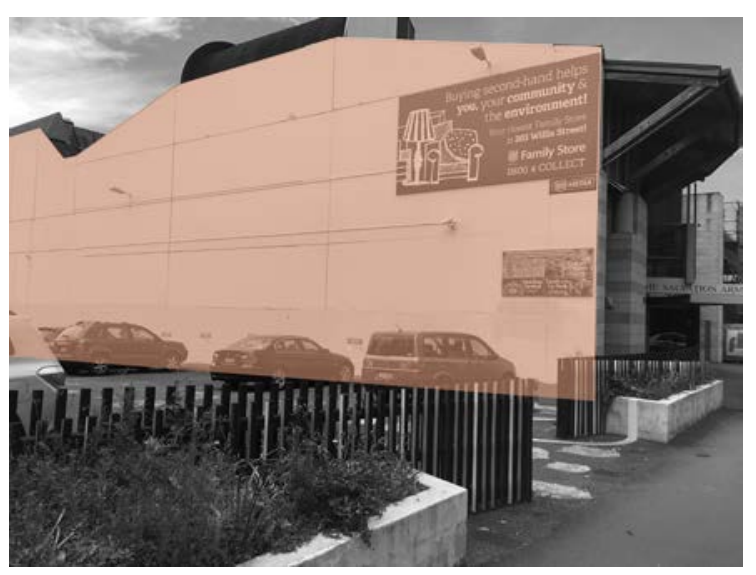

\section{Exterior wall}

The exterior wall of the church building dominates the car park. As it is one colour and three storeys high, it towers over the site. Some texture or colour would improve this feature significantly - this could be anything from planting to street art.

Fig.4.22. (Left Top) Front entrance - Intimidating wall Fig.4.23. (Right Top) Back entrance - Uninviting Fig.4.24. (Left Bottom) Adjacent wall - Character Fig.4.25. (Right Bottom) Exterior wall 


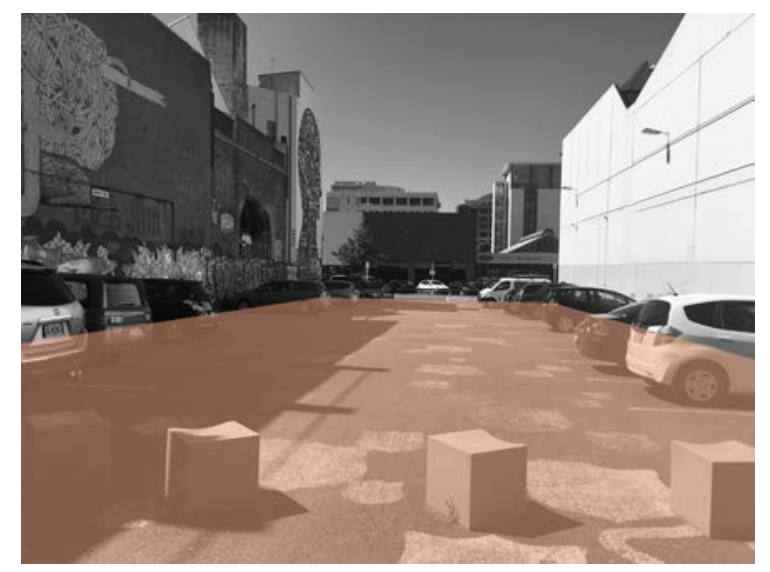

5. Car park (weekday)

There are thirty-four parks in the car park, which are all occupied on a Sunday. Throughout the week, the carpark is generally half-full. It also is used as a public thoroughfare with pedestrians walking to and from Vivian and Jessie Street.

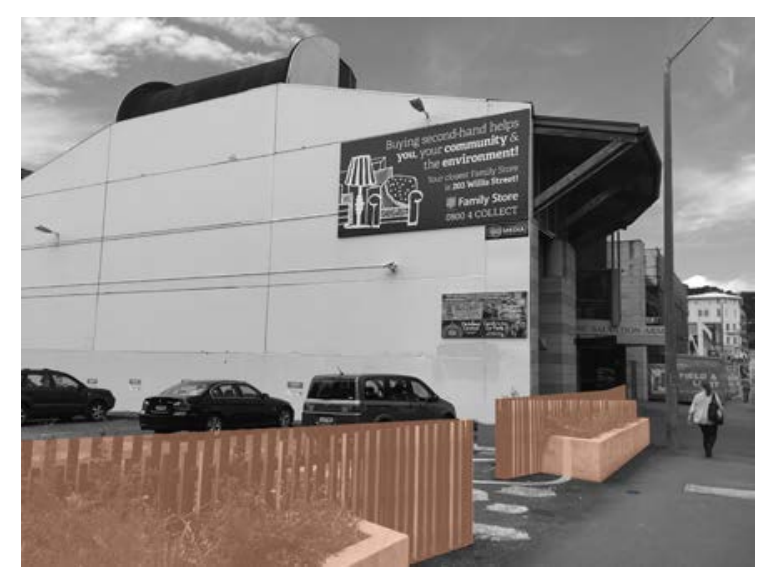

\section{Planter boxes}

The planter boxes add some level of colour and interest to the site, forcing pedestrians away from parked cars and channelling movement down the middle of the car park. Despite some practicality, the planter boxes obstruct the site. Something more organic and moveable would potentially provide a better solution.

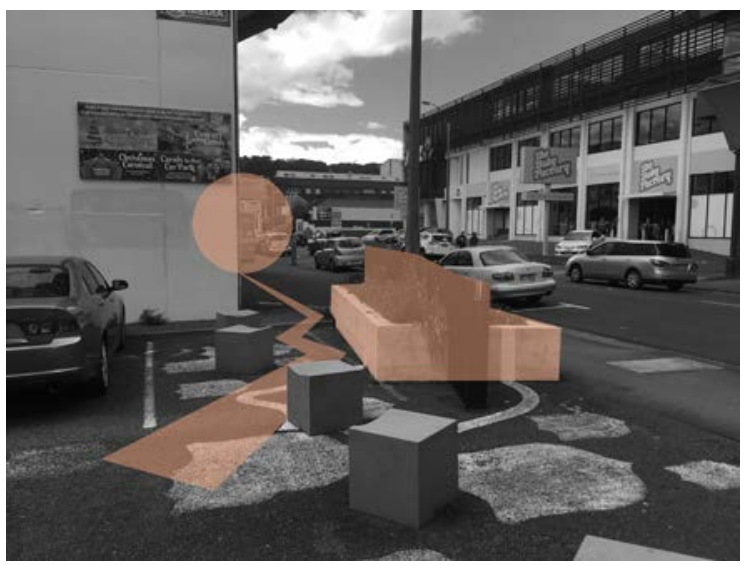

\section{Transition from church to carpark}

The transition between the car park and church is poor. The space is tight, with planter boxes too close to the exterior wall of the church. These boxes create obstacles and block a clear path to the entrance.

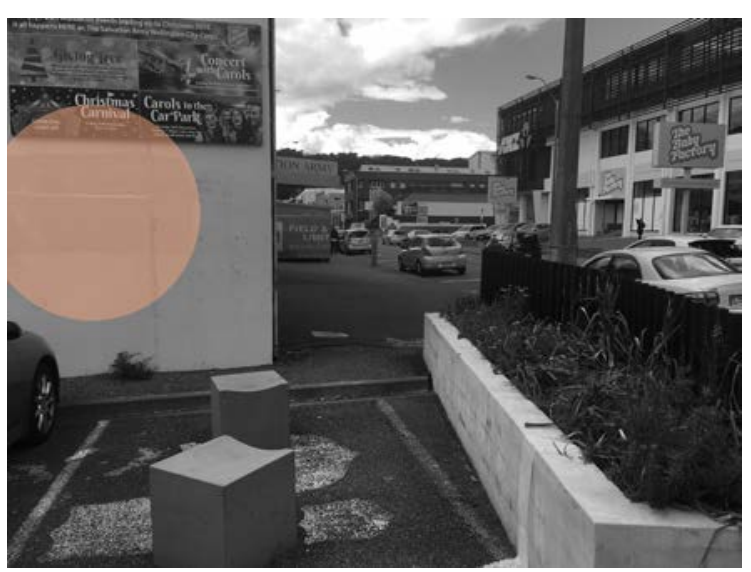

8. Graffiti

Patched over graffiti and the use of graffiti-proof paint at street level indicate that the church community does not want the church wall becoming a spot for additional graffiti. Planting over the wall would increase visual appeal and remove the possibility of it being vandalised in this way. 


\section{Community engagement}

Demographics

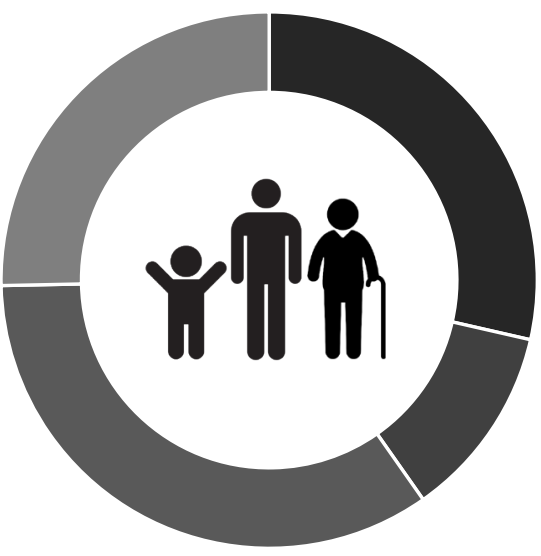

Age
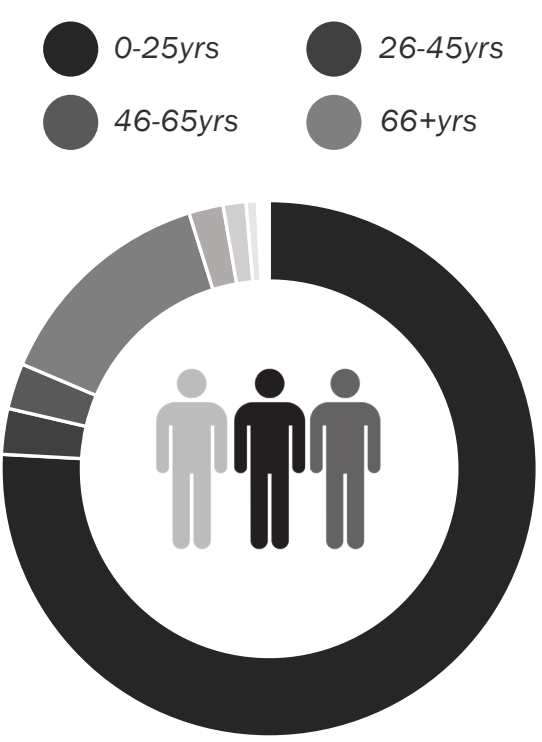

Ethnicity

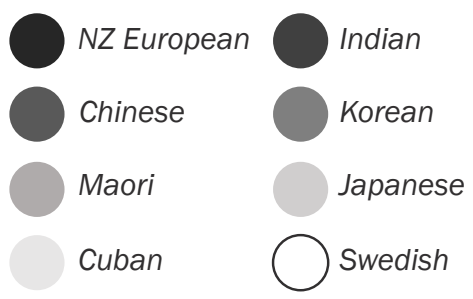

Car parking

Carpark usage
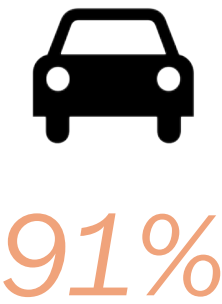

Out of the 47 respondents, 43 drive and use the carpark.

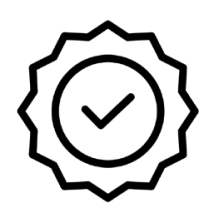

Quality of space

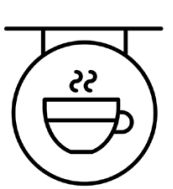

Better programming
Carpark importance
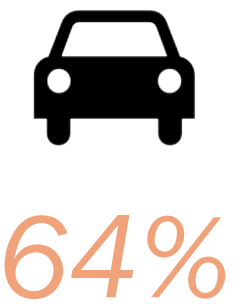

Out of the 47 respondents, 30 said the carpark is important with only 2 saying it isn't. The other 15 did not say or were indifferent

\section{Community Ideas}

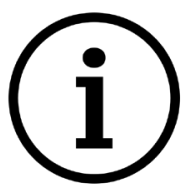

More information \& branding

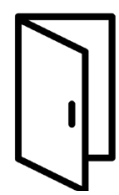

More inviting space 


\section{Church Community by Suburb}

Larger circle - More people

+ Church location

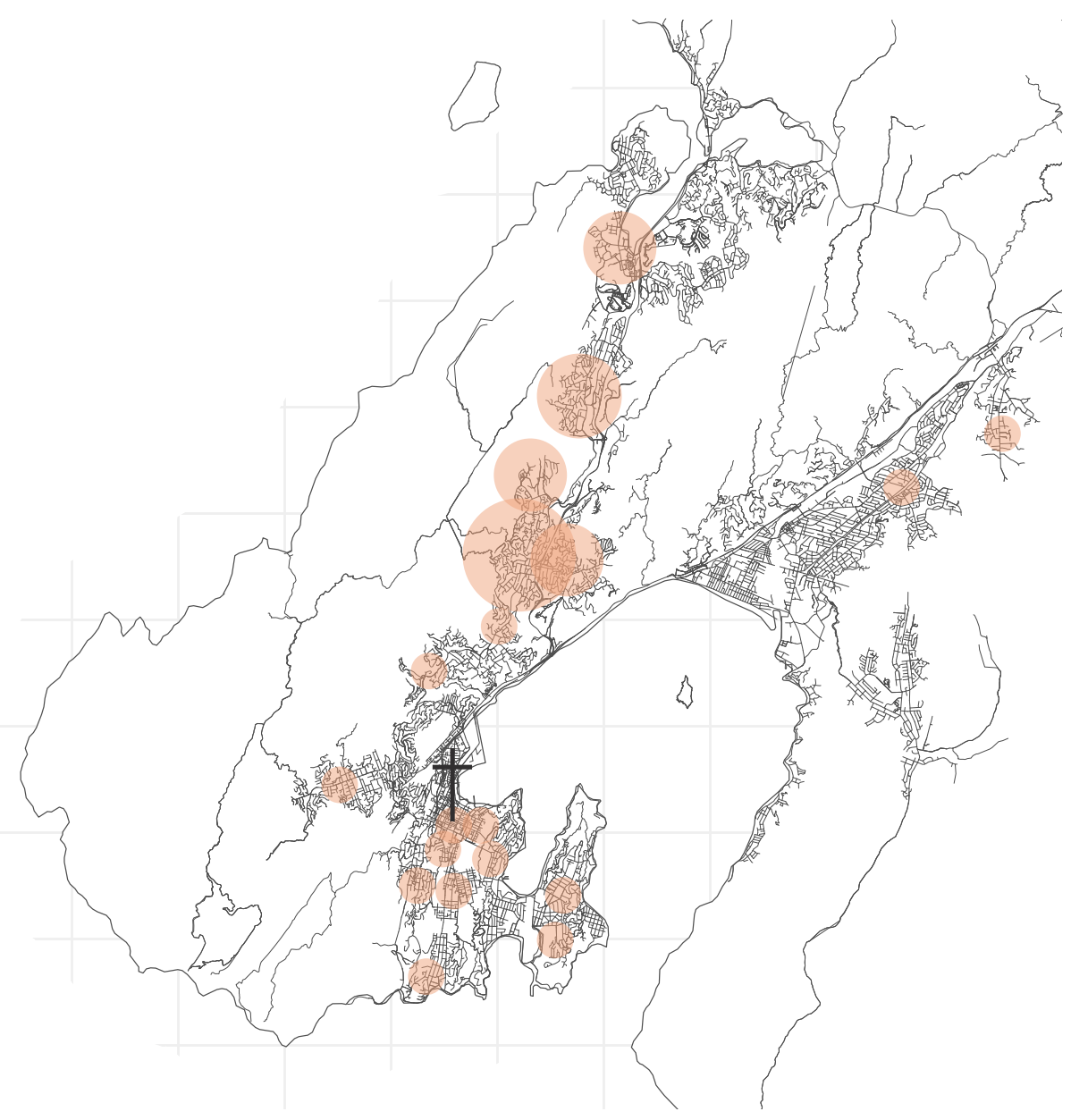

11

Survey responses

9 Johnsonville

6 Tawa

4 Churton Park

4 Newlands

3 Porirua

2 Khandallah

2 Crofton Downs

2 Northern Suburbs

2 Lower Hutt

2 Brooklyn

2 Mt Victoria

1 Te Aro

1 Karori

1 Stokes Valley

1 Mt Cook

1 Hataitai

1 Miramar

1 Newtown

1 Island Bay

1 Strathmore

Conclusion

Most survey respondents commented on the lack of engaging outdoor space at the church. Respondents suggested programming, such as a temporary coffee station or soup kitchen, could be designed for.

The front entrance of the church is another area of concern for participants. Many respondents stated that the space is uninviting and "cold". They also mentioned a lack of information or branding for people passing by.

The vast majority of survey participants live outside of the inner city. Of the forty-seven respondents, only two live in the inner city. Forty-three travel to church by car, once again reinforcing the need for car parking in the church space. 


\section{Wellington Methodist Parish}

Commonalities across all three sites

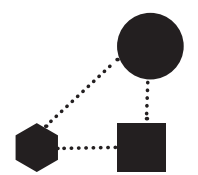

Wider context transitions

Work with existing Link spaces to one thoroughfares and

facilitate new ones

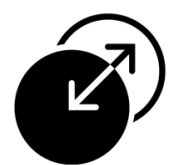

Close context transitions Remove obstructions

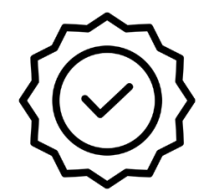

Quality of Space

Increase Vegetation Improve Paving

Create spaces for sitting and standing

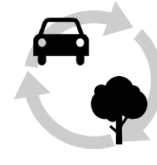

Flexibility

Keep as much parking as possible whilst enhancing the space Make the space flexible to the weekend and weekday setting

Commonalities in the specific site

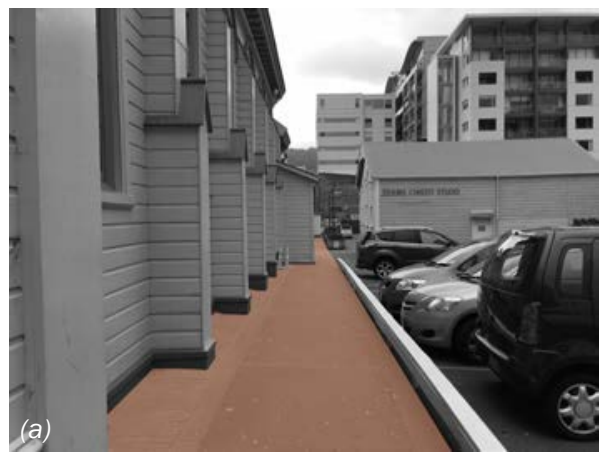

Site has a well established thoroughfare

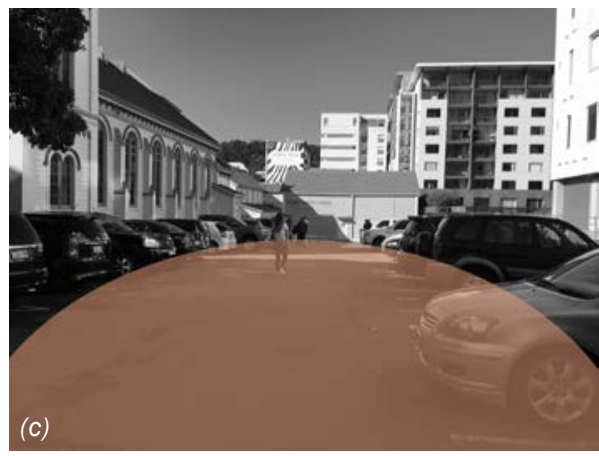

Car park space

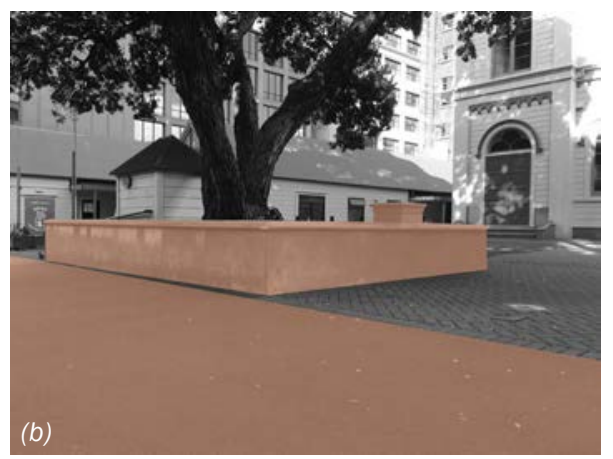

Landscaping is poor and creates transitional problems

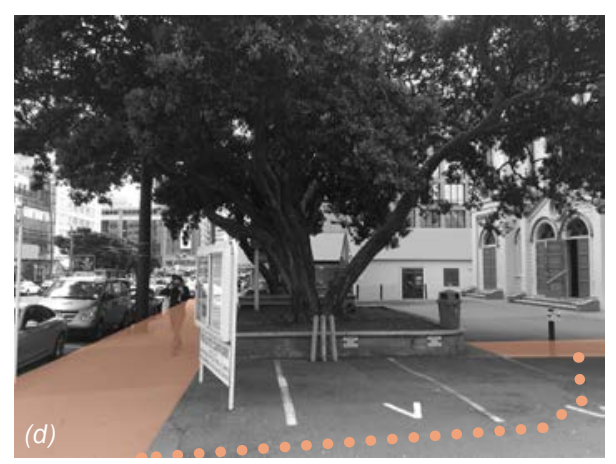

Transition from church to carpark 


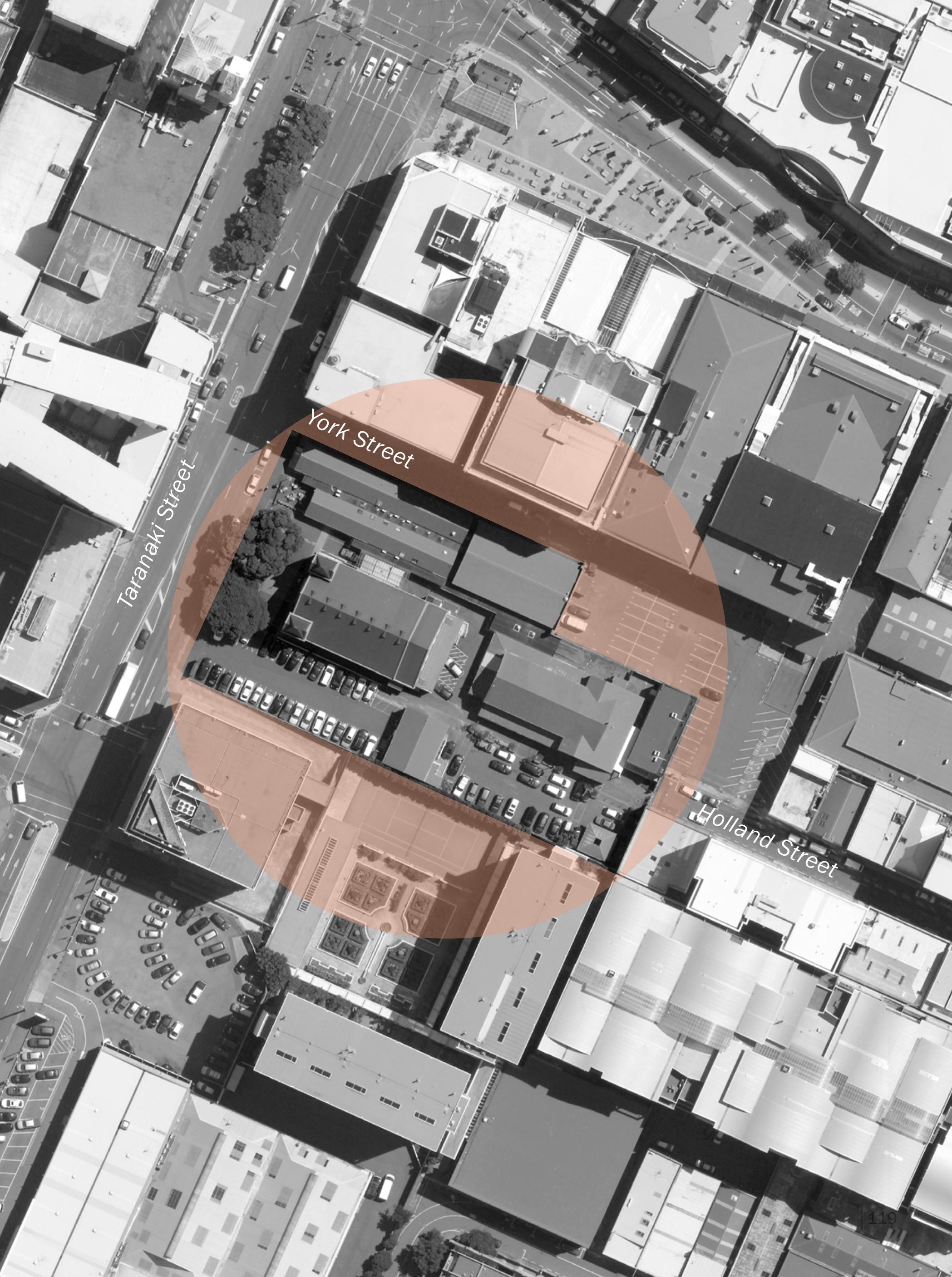




\section{Church background and analysis plan}

Based in the heart of Wellington, the Wellington Methodist Parish accommodates people from a wide variety of cultures and walks of life. Diversity is something the Wellington Methodist Parish cherishes, with weekly church services in multiple languages, including Fijian, Samoan, Tongan, English and Maori.

The Wellington Methodist Parish dates back to 1839 when missionaries held the first Methodist service in Wellington at Te Aro Pa (Wellington City Heritage). Later churches were built on property located on the corner of Manners and Cuba Street which were destroyed by earthquakes (Wellington City Heritage). After a fire in 1879 which destroyed the final church on Manners Street, the decision was made to purchase land on Taranaki Street where a new church could be built, outside of council inner-city regulations that required stone, brick, or concrete boundaries to mitigate the risk of fire (Wellington City Heritage).

Designed by Thomas Turnbull, the church building was opened in 1880 (Wellington City Heritage). Before 1900, the church's congregation was large with the 450-seat church at full capacity, however as people relocated to the outer city, attendance dropped (Wellington City Heritage). To compensate for this, the church was turned into an inner-city mission in 1949 (Wellington City Heritage). Thanks to this change in focus and the growth of the Samoan community in Wellington, the Wellington Methodist Parish remained active, opening a number of new buildings catering to various church groups (Wellington City Heritage).

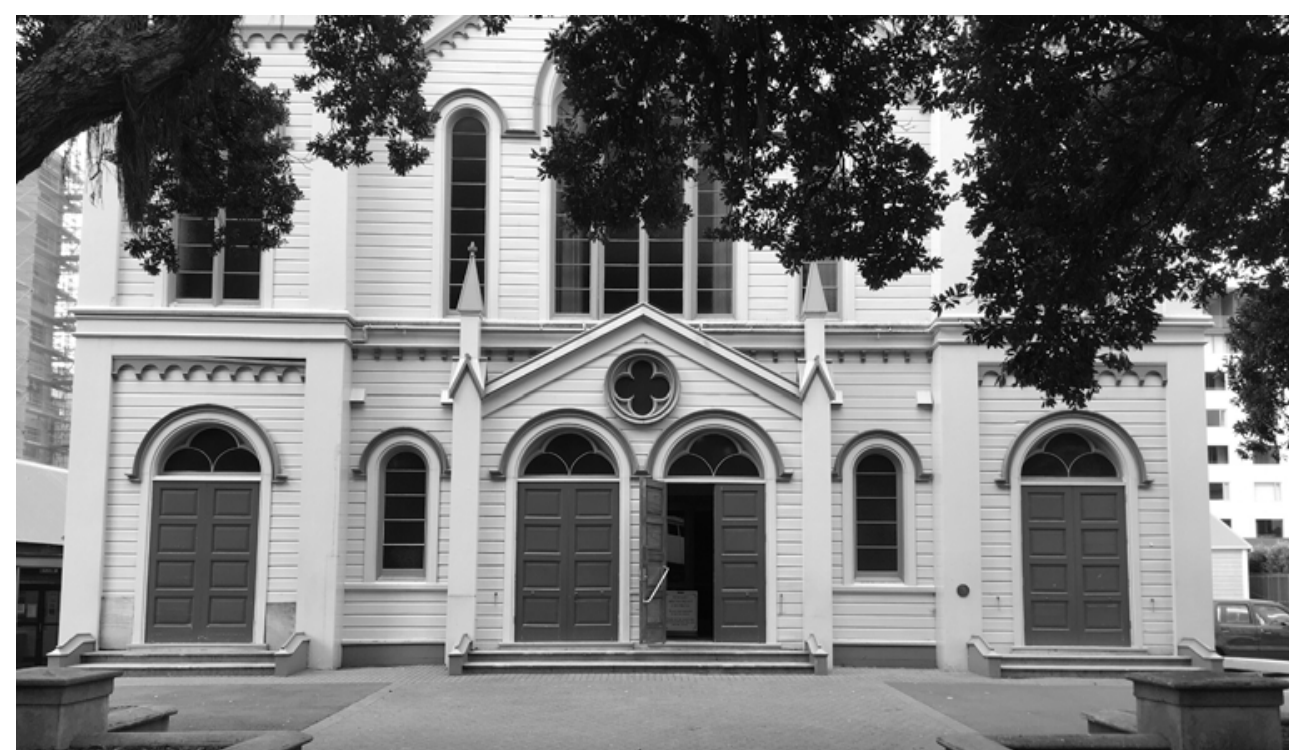

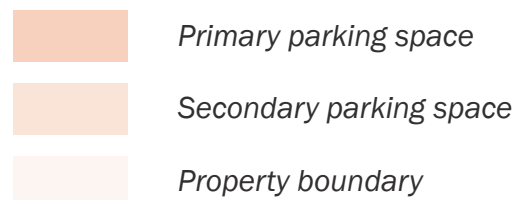

Property boundary
Main thoroughfare

........ Secondary thoroughfare

(X) Numbers relate to photos 


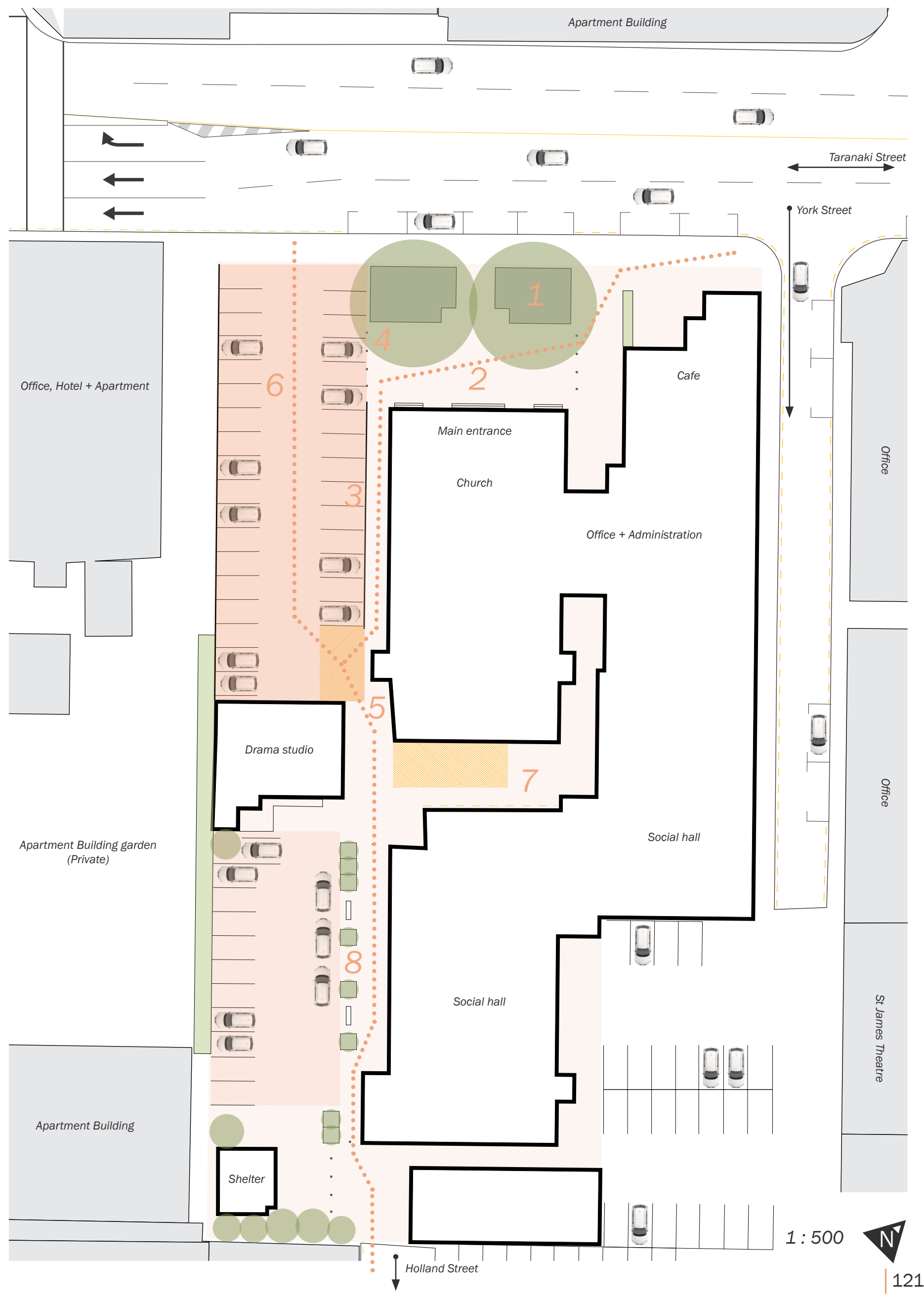




\section{Analysis overlay images}

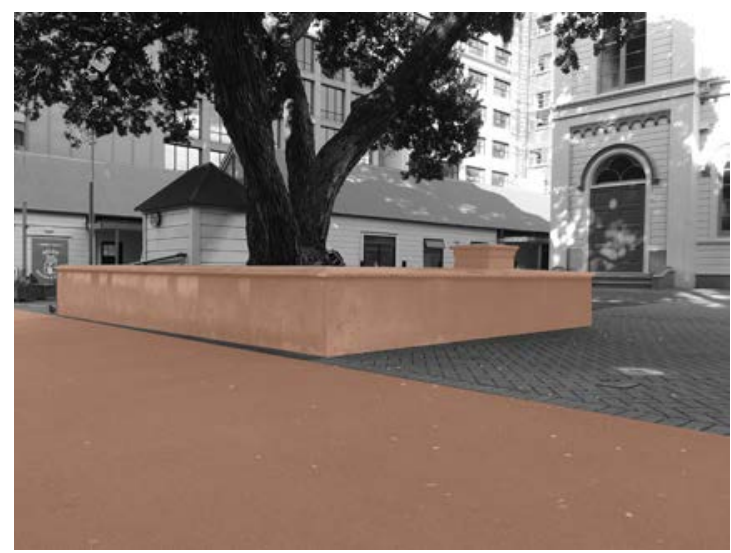

\section{Front planter boxes}

Planter boxes and trees in front of the church deflect movement and serve as large obstacles. There is no established seating, pedestrians are forced onto a direct path to the church.

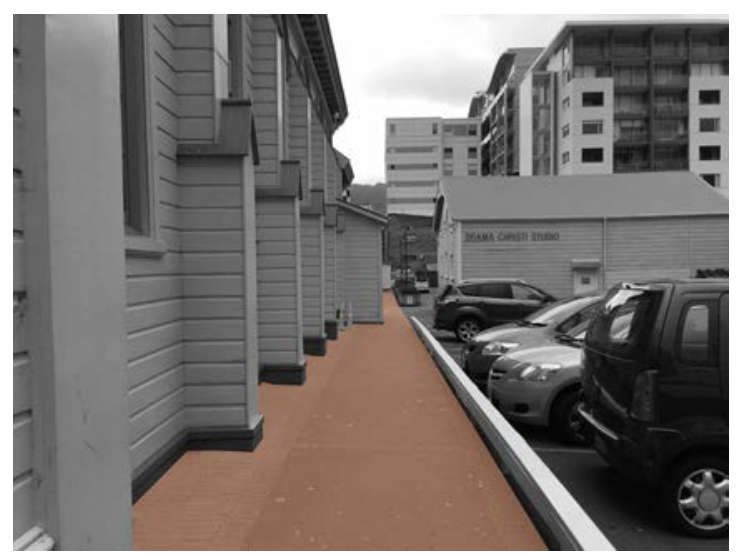

\section{Thoroughfare channel}

The thoroughfare is a well-established path running along the southern edge of the church and car park. There is potential for the edge of the church to softened by planting or seating along the path.

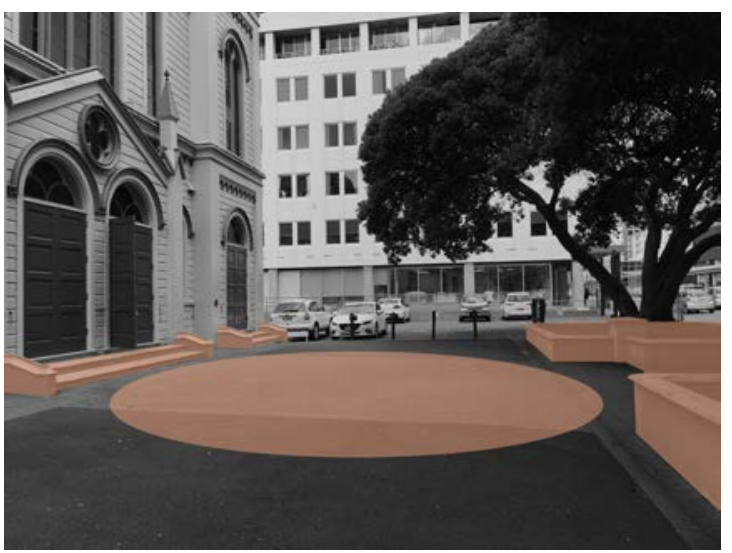

\section{Front entrance}

Between church services, congregations wait in this area. There is little seating and no wheelchair access point. Wheelchair access is located through the office space around the side of the building.

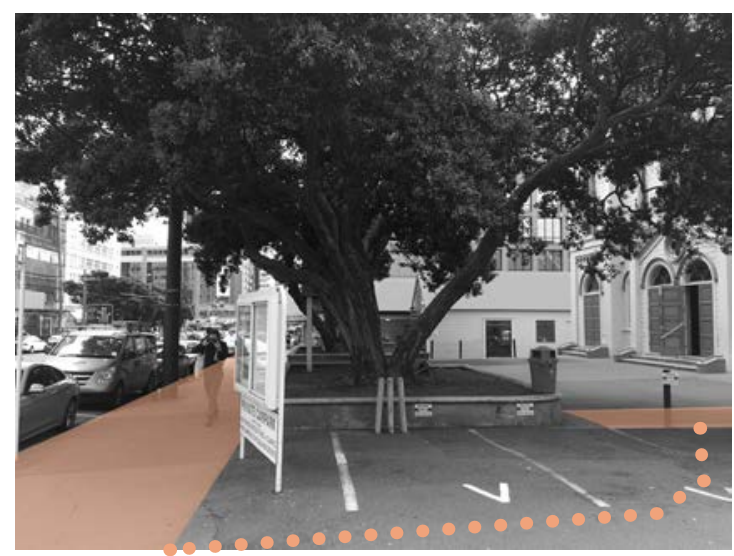

\section{Thoroughfare disconnect}

This thoroughfare does not run directly between footpaths; people either walk through the front of the church space, or through the car park. Defining this journey and connecting it to the public footpath, while avoiding the car park, would make it more accessible, utilising an already established public interaction. 


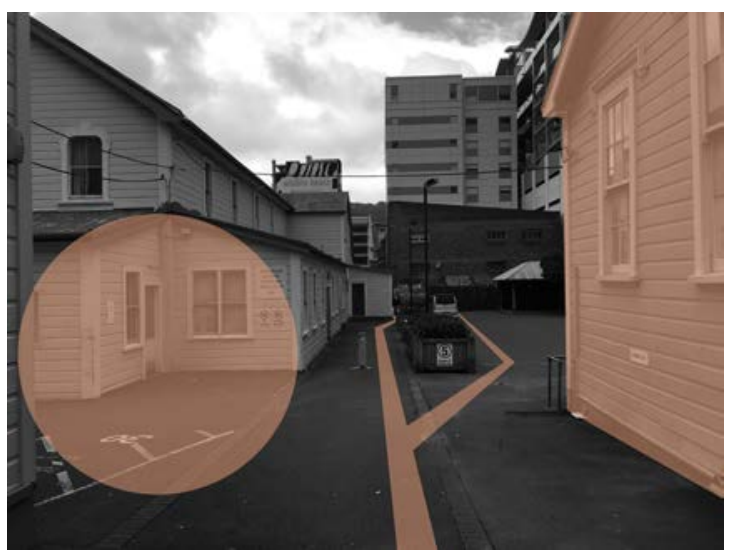

5. Thoroughfare pinch point

Halfway through the site, the thoroughfare becomes narrow due to the surrounding buildings. This, along with the quality of the space means people do not spend time in the area.

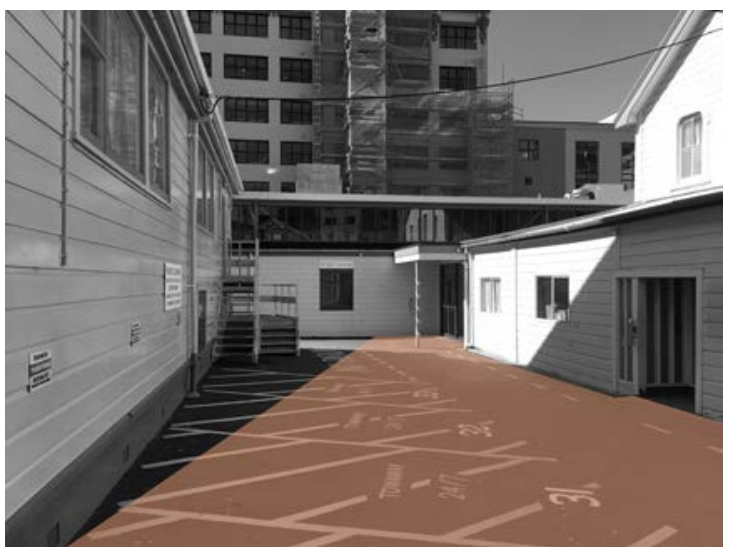

\section{Connection to social hall}

The two social halls around the back of the church building are frequently used by members of the congregation for lunches, youth sleepovers and other events. Here, there is no real connection to the exterior space. The space outside of these halls could provide more opportunity for interaction between the public and church community.

Fig.4.41. (Left Top) Thoroughfare pinch point Fig.4.42. (Right Top) Car park

Fig.4.43. (Left Bottom) Connection to social hall

Fig.4.44. (Right Bottom) Lighting and Vegetation

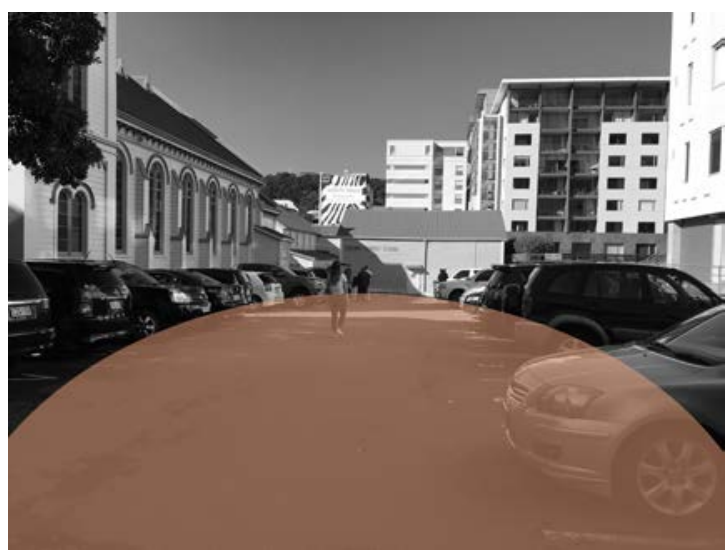

\section{Car Park}

The car park has forty-four parks in total, which are filled on a Sunday. During other times of the week, the church rents parking spots to the general public. Many pedestrians also walk through the space.

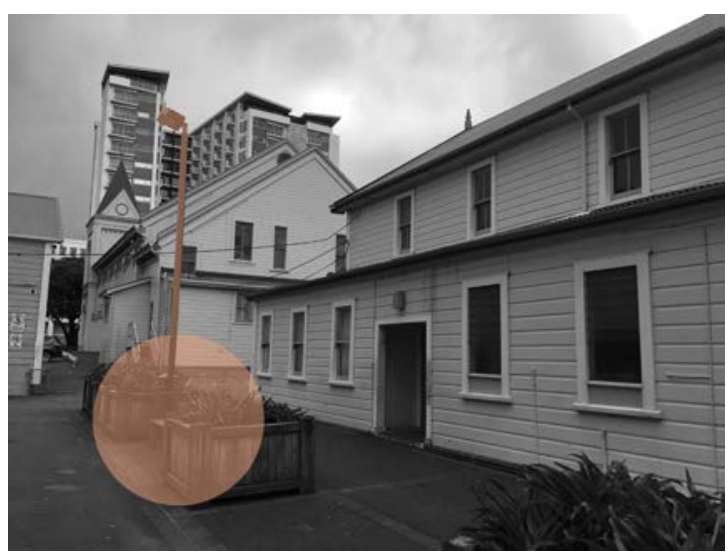

\section{Lighting and Vegetation}

The current lighting situation relies on downlight lampposts to light the space along the thoroughfare, while planter boxes direct movement. 


\section{Community engagement}

Demographics

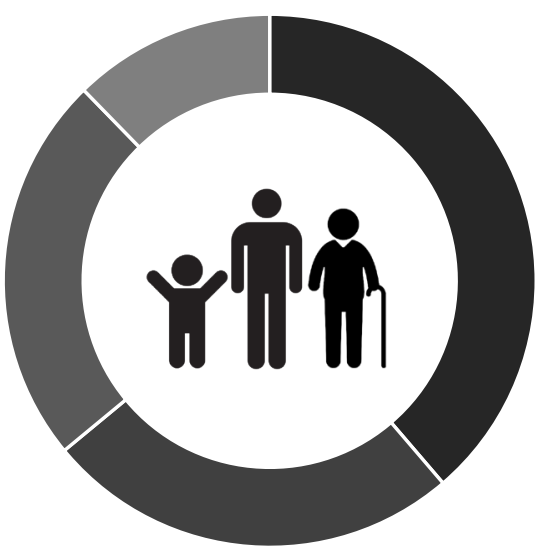

Age
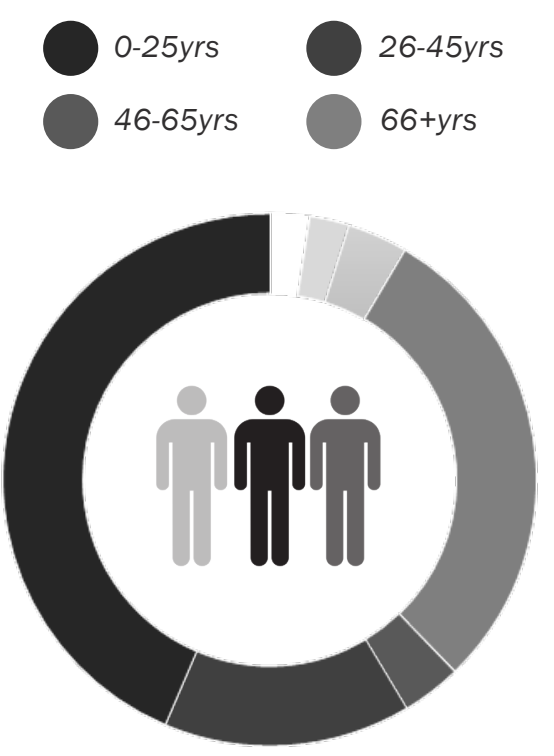

Ethnicity

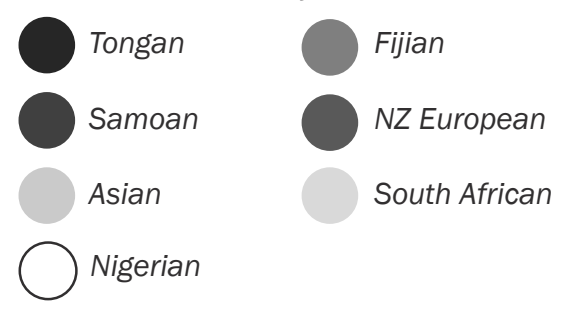

Car parking

Carpark usage
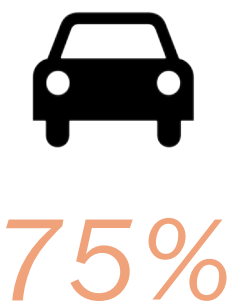

Out of the 40 respondents, 30 drive and use the carpark.

\section{Community Ideas}

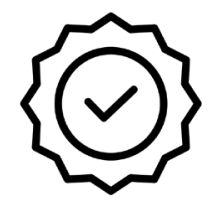

Quality of space

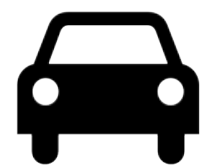

Improve parking

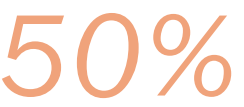

Out of the 40 respondents, 20 said the carpark is important with only 1 saying it isn't. The other 19 did not say or were indifferent

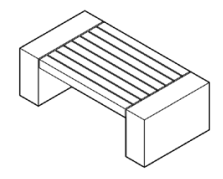

More Seating

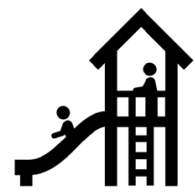

Safe kids play area 


\section{Church Community by Suburb}

Larger circle - More people

$\dagger$ Church location

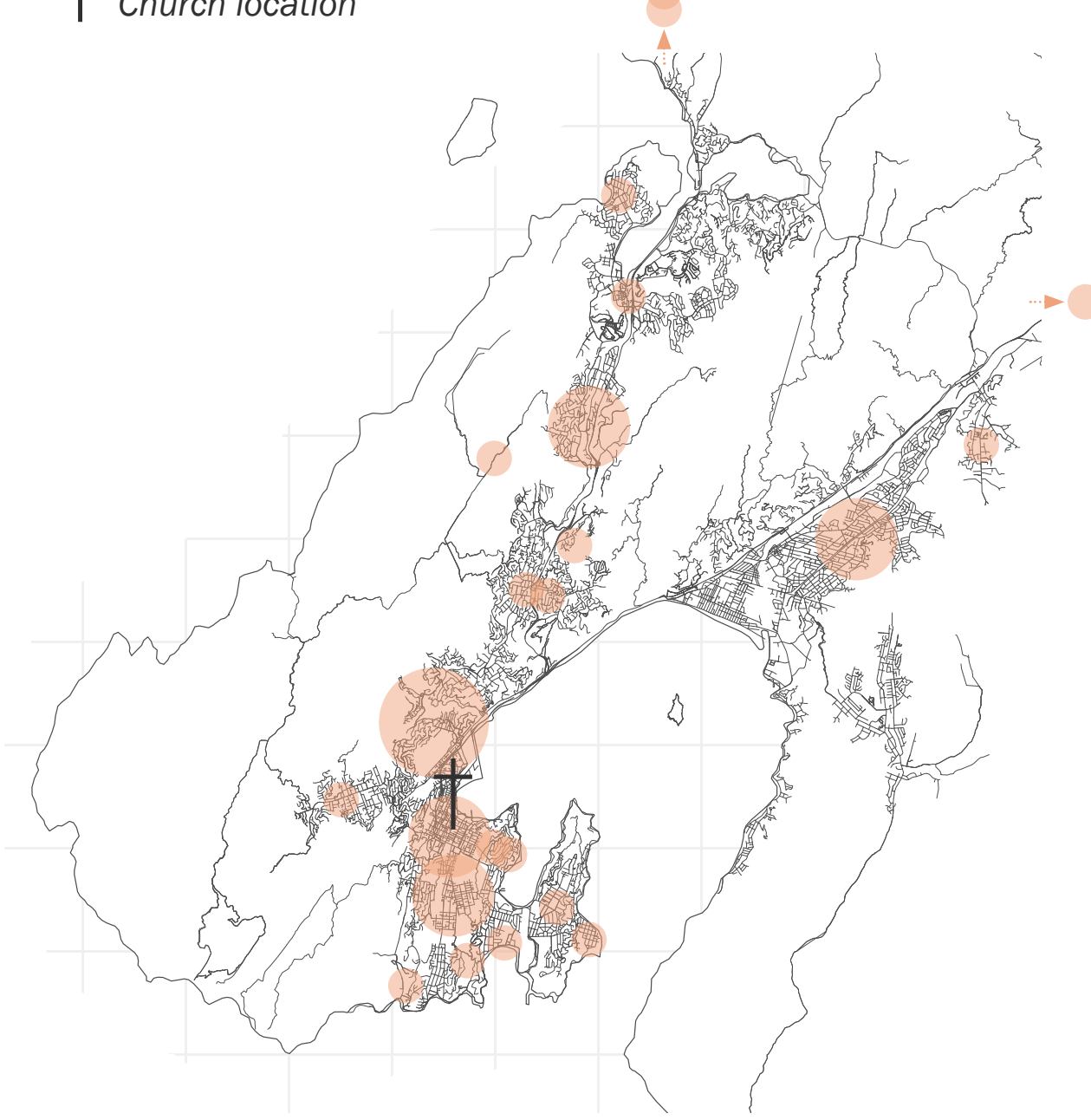

40

Survey responses

7 Northland

4 Te Aro

3 Tawa

3 Newtown

3 Lower Hutt

2 Miramar

2 Johnsonville

2 Newlands

2 Karori

1 Ohariu Valley

1 Woodridge

1 Waikanae

1 Titahi Bay

1 Mt Victoria

1 Stokes Valley

1 Hataitai

1 Plimmerton

1 Seatoun

1 Southgate

1 Porirua

1 Lyall Bay

Conclusion

The most consistent survey feedback included improving the quality of the outdoor space. As identified in the analysis, there is a significant lack of seating options across the site. This was reinforced by the church community.

As with other sites, most survey participants live outside of the inner city. Of the forty respondents, only four live in the inner city. Thirty respondents travel to church by car, requiring car parking facilities.

Having an element of play in the site was a desire of many of the respondents. With a third of the church congregation aged zero to twenty-five, this could be an appropriate feature to add to the design. 


\section{Site specific analysis conclusion}

When comparing the results of the participatory design surveys with the findings from the comparative analysis process, it became evident that they were very similar.

It was clear from feedback that the majority of respondents at each site thought their church space could be improved with better design thinking.

Enhancing the quality of space across all sites was universal between both the surveys and comparative analysis.

Both site analysis and survey results determined improvements to car-parking were necessary. With survey results indicating the majority of church-goers are elderly, accessible parking is significant.

While pedestrian connectivity and obstacles to transitioning through the church space were not directly mentioned in the survey results, they were consistently referred to in other ways. 'More inviting space' was a common statement. The transition between the street and front entrance was also often eluded to.

While the desires from the community were carefully considered, they did not entirely dictate the design of each space. A balance of information from the community and results from the comparative analysis were important to take forward into the design process. 
Criteria for design from the participatory design survey

Wellington Cathedral of St Paul

Community Ideas

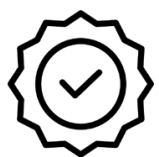

Quality of space

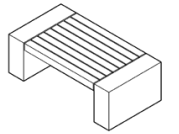

More Seating

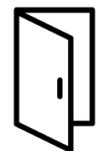

More inviting space
Wellington City Salvation Army

Community Ideas

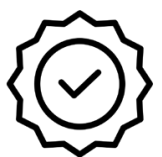

Quality of space

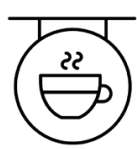

Better

programming

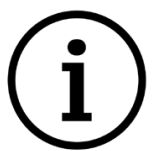

More information \& branding

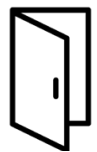

More inviting space
Wellington Methodist Parish

Community Ideas
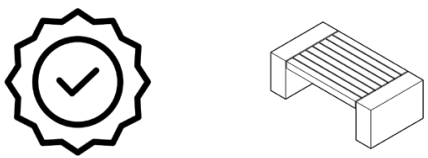

Quality of space

More Seating

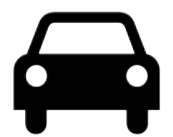

Improve parking

Criteria for design from the comparative analysis process

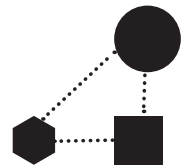

Wider context transitions

Work with existing thoroughfares and facilitate new ones

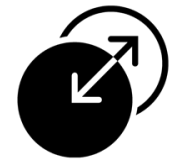

\section{Close context transitions}

Link spaces to one another Remove obstructions

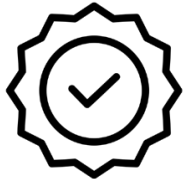

Quality of Space Improve Paving Create spaces for sitting and standing area

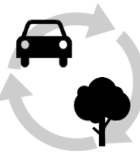

Flexibility

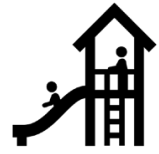

Safe kids play 


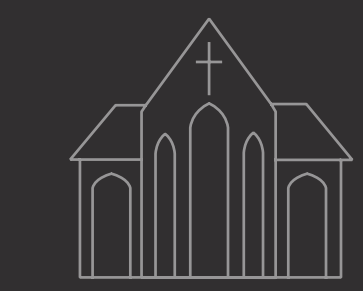

CHAPTER FIVE 


\section{Design techniques and guidelines}

The following techniques and guidelines identify how each space will be treated during the design process. The techniques were gathered from both the literature and precedents analysed in earlier phases of the research. Each technique is centred around the four key criteria gathered from the comparative analysis and community engagement surveys.

Commonalities across all three sites and positioning them within the overall aims and objectives

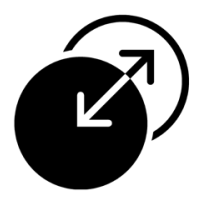

Transitions between space

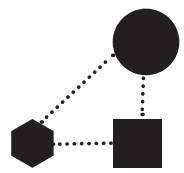

Wider context transitions

Work with existing thoroughfares and facilitate new ones

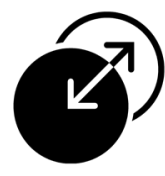

Close context transitions

Link spaces to one another

Remove obstructions

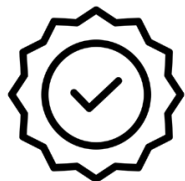

Quality of Space

Flexibility

Increase Vegetation Improve Paving

Create spaces for sitting and standing
Keep as much parking as possible whilst enhancing the space Make the space flexible to the weekend and weekday setting 


\title{
Wellington urban design criteria
}

\author{
Wellington City Council - Plans, policies and bylaws
}

The following are key criteria laid out by Wellington City Council for urban design in the city.
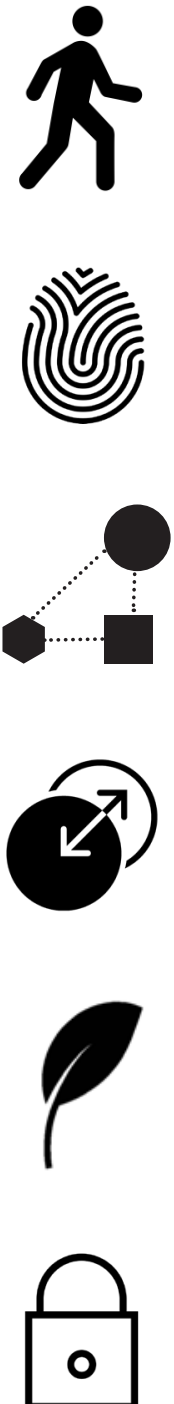

"Walkability - making Wellington's streets and spaces as people-friendly as possible. Well-designed streets are critical to creating attractive and lively public spaces" (Wellington City Council).

"Sense of identity and place - identifying and enhancing the qualities and characteristics that make Wellington special, including conserving the city's built heritage" (Wellington City Council).

"Connectivity - making sure there are good connections and it is easy to move to and through the central city, town centres and suburbs" (Wellington City Council).

"Accessibility - easily accessible places and spaces so everyone can get around" (Wellington City Council).

"Sustainability - recognising the natural environment and using sustainable design solutions where appropriate" (Wellington City Council).

"Safety - making sure public places and spaces are as safe and pleasant for people as possible" (Wellington City Council). 


\section{Criteria from research for improving church space}

The following are key criteria formulated from the comparative analysis research
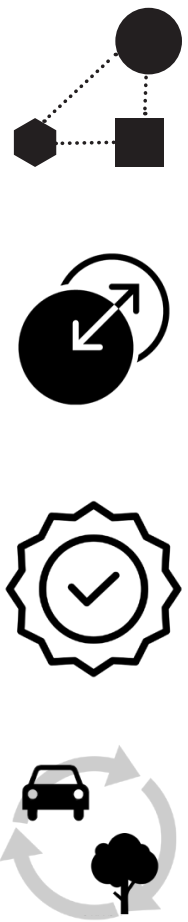

Wider context transitions - Work with existing thoroughfares and facilitate new ones.

Close context transitions - Link spaces to one another, Remove obstructions.

Quality of space - Increase vegetation, Improve paving, create spaces for sitting and standing.

Flexibility - Keep as much parking as possible whilst enhancing the space, Make the space flexible to the weekend and weekday setting

By combining the two sets of criteria each space that is designed in will be improved based on the lessons learned from the comparative analysis template. However they will also be approved by the council in terms of how the public space reflects the objectives laid out for urban design in the city. The emphasis on the importance of car parking uncovered during the community engagement research was the only key point of difference between the criteria from research and the criteria set by Wellington City Council. 


\section{Transitions between space Close context transition}

Creating open space is important for transitional areas. A space that is closed off to pedestrians with visual and/or physical obstructions deters movement. In these examples, the front of the church was the area of interest.

The edge condition between territories often lacks design thought, however, as discussed in the literature review in chapter two, edges are a crucial element in public spaces. People often position themselves along edges, rather than venturing further into a space. The edge often signifies the area between public and private, or semi-private, space.

Designing along edges and identifying different boundaries is an important aspect in any design; however, it is crucial that whatever is implemented does not act as a barrier, both physically, visually and psychologically. To engage with people, designing around edges must not obstruct the user from the space.

The following diagrams show various ways that the front space of churches will be designed.

There is a fine line between adding to a space and adding too much to a space. While some elements of the design may be visually appealing on their own, the combined effect may deter passers-by from the space. Creating an area that is open, interesting and inviting is key to a successful entrance space. 


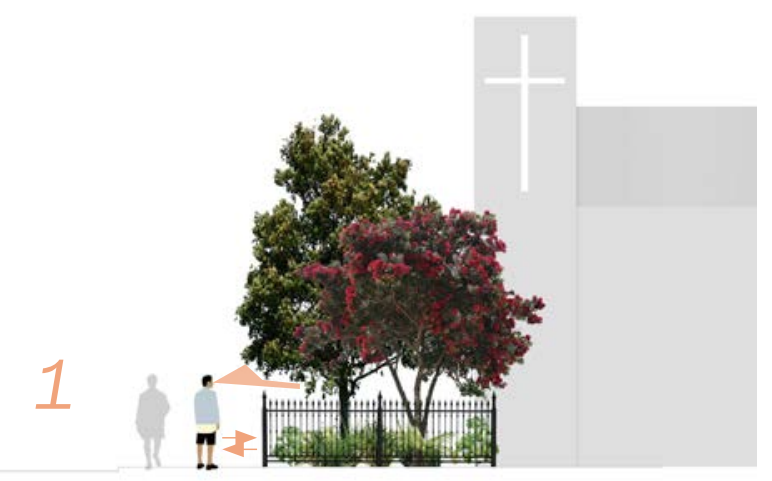

Blocked vision and movement

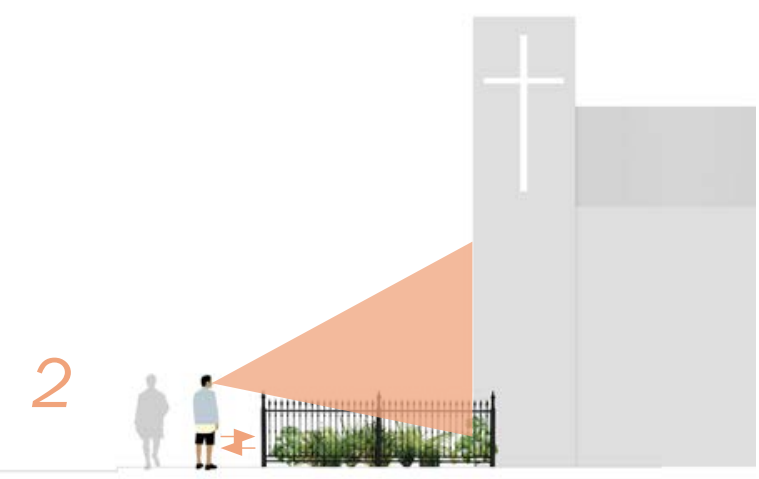

Blocked movement and partially blocked vision

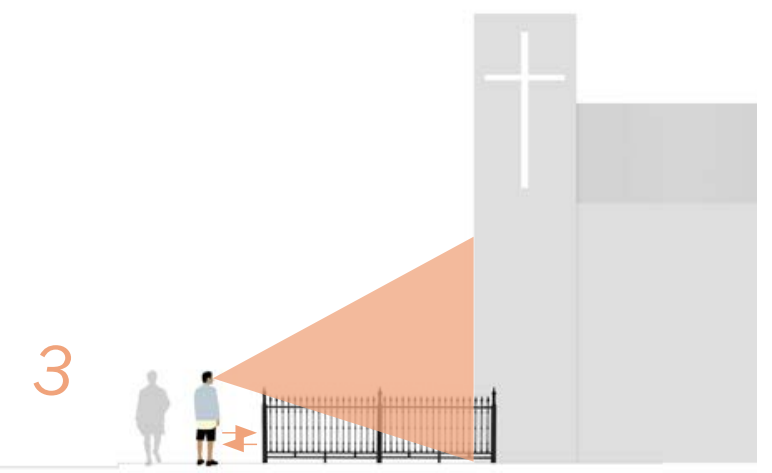

Partially blocked vision and movement

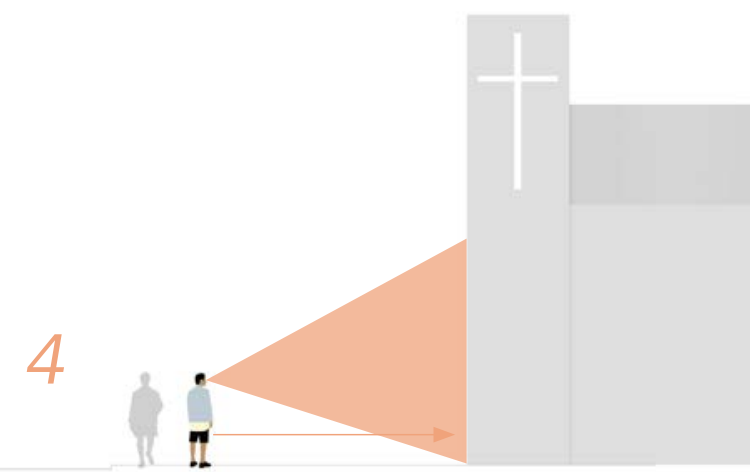

Unobstructed vision and movement 


\section{Inviting public space Quality of space - strategic paving}

The paving and ground situation in the churches analysed is generally very poor. The materiality in the space matches that of the surrounding areas, creating a lack of interest.

Inviting paving techniques will be used to create interest and improve the quality of the space. Paving surfaces is a basic design tool that can dramatically affect how people perceive a space. Properly maintained, paving can lead people into a space. Directional paving techniques are particularly useful in entrance areas and transitional zones.

Current ground conditions in each site
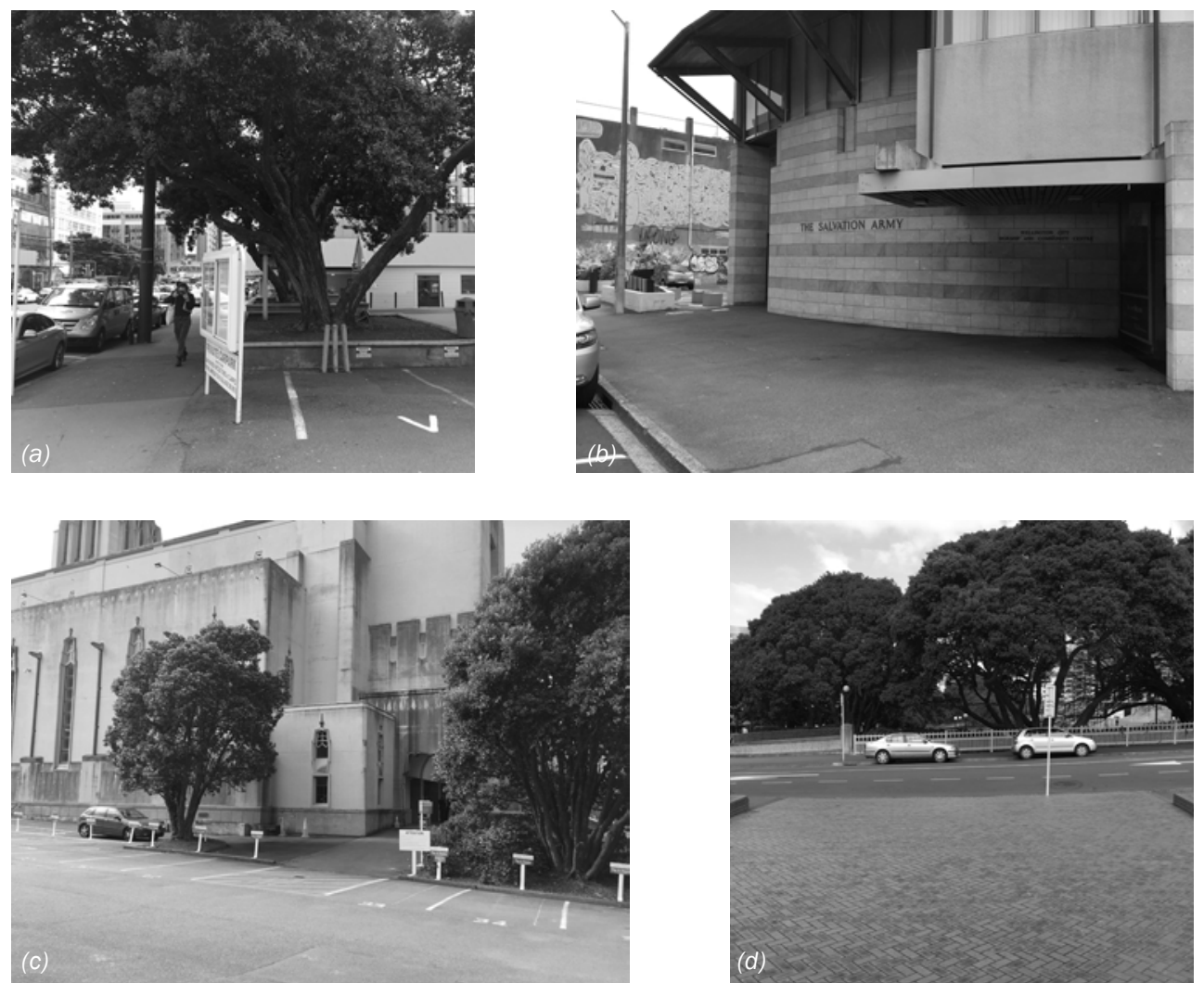


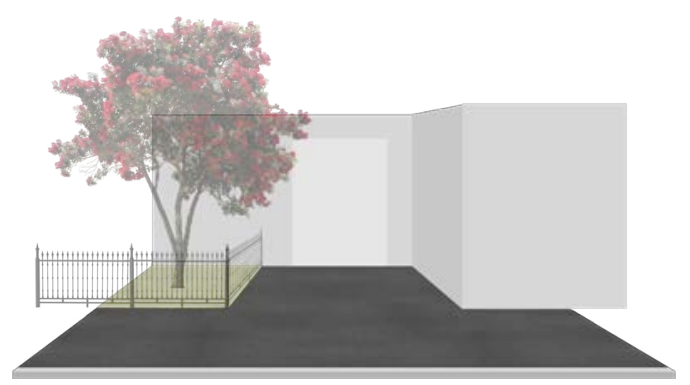

1 No change in paving

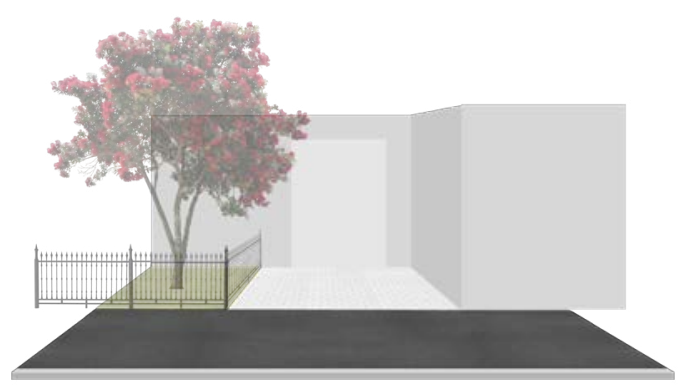

2 Paved area in site - increase in quality of space

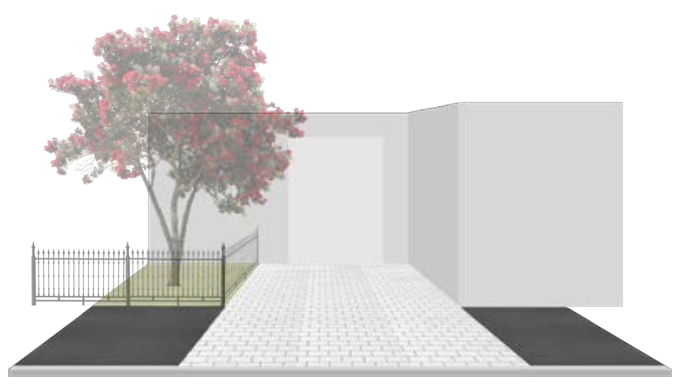

Paving extends out into footpath - change in pace

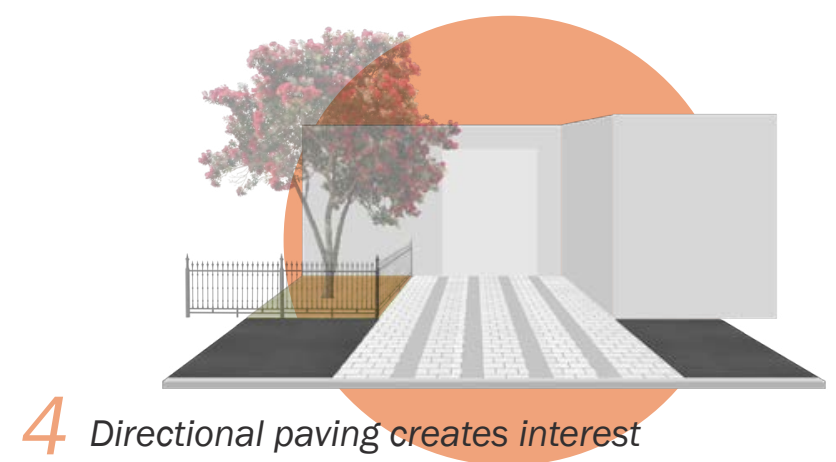




\section{Inviting public space Quality of space - strategic seating \& planting}

Offering different seating options in the space appeals to different users. As identified in the literature review in chapter two, some people prefer to sit in intimate spaces where they can escape from their surroundings. However, some people prefer to sit along thoroughfares, where they can observe peoples movement and activity.

It is important to provide both options as it appeals to a more diverse range of people. It also means the site is not cluttered with too many objects, or left bare with too few.

Current extent of seating in each space
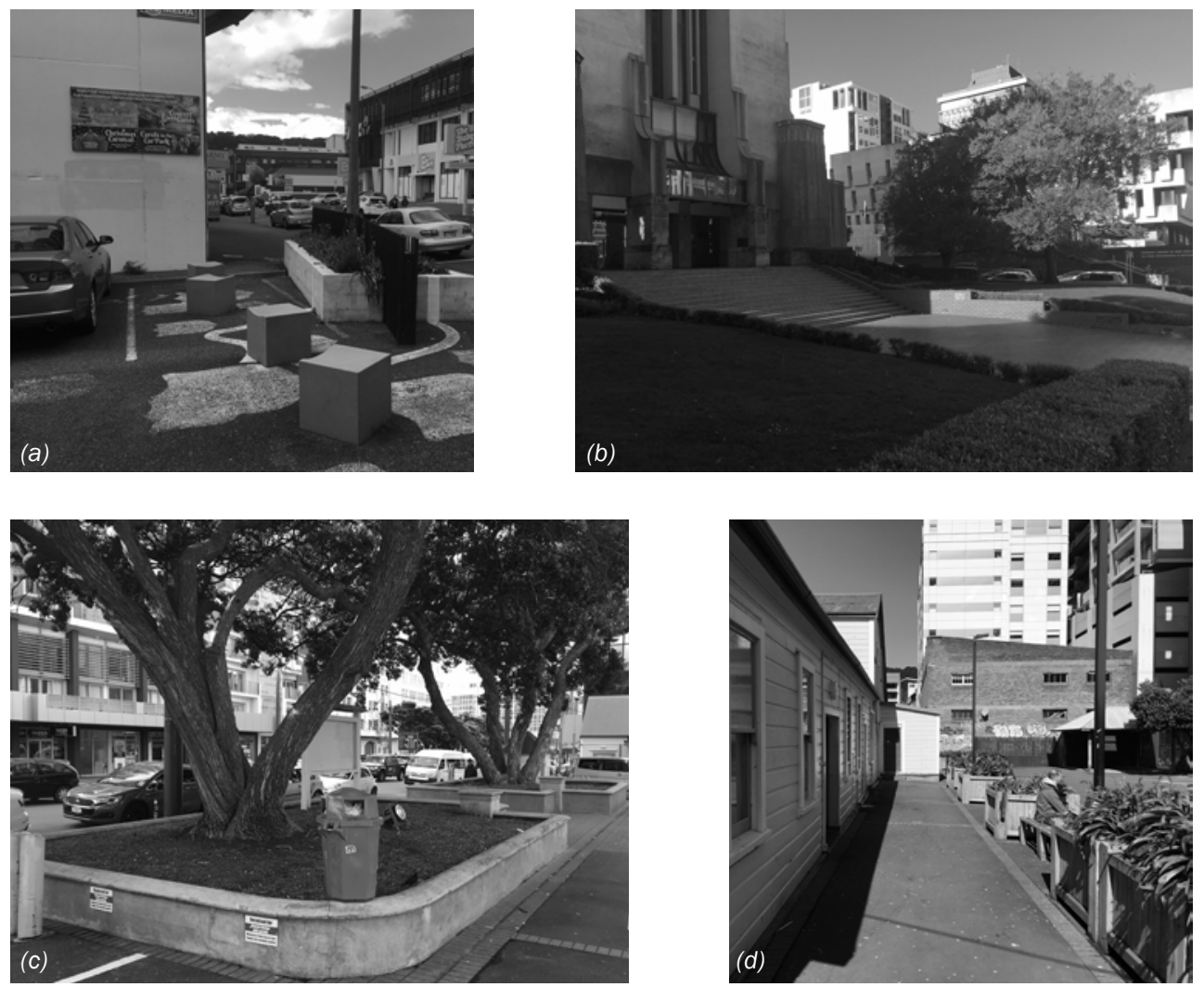

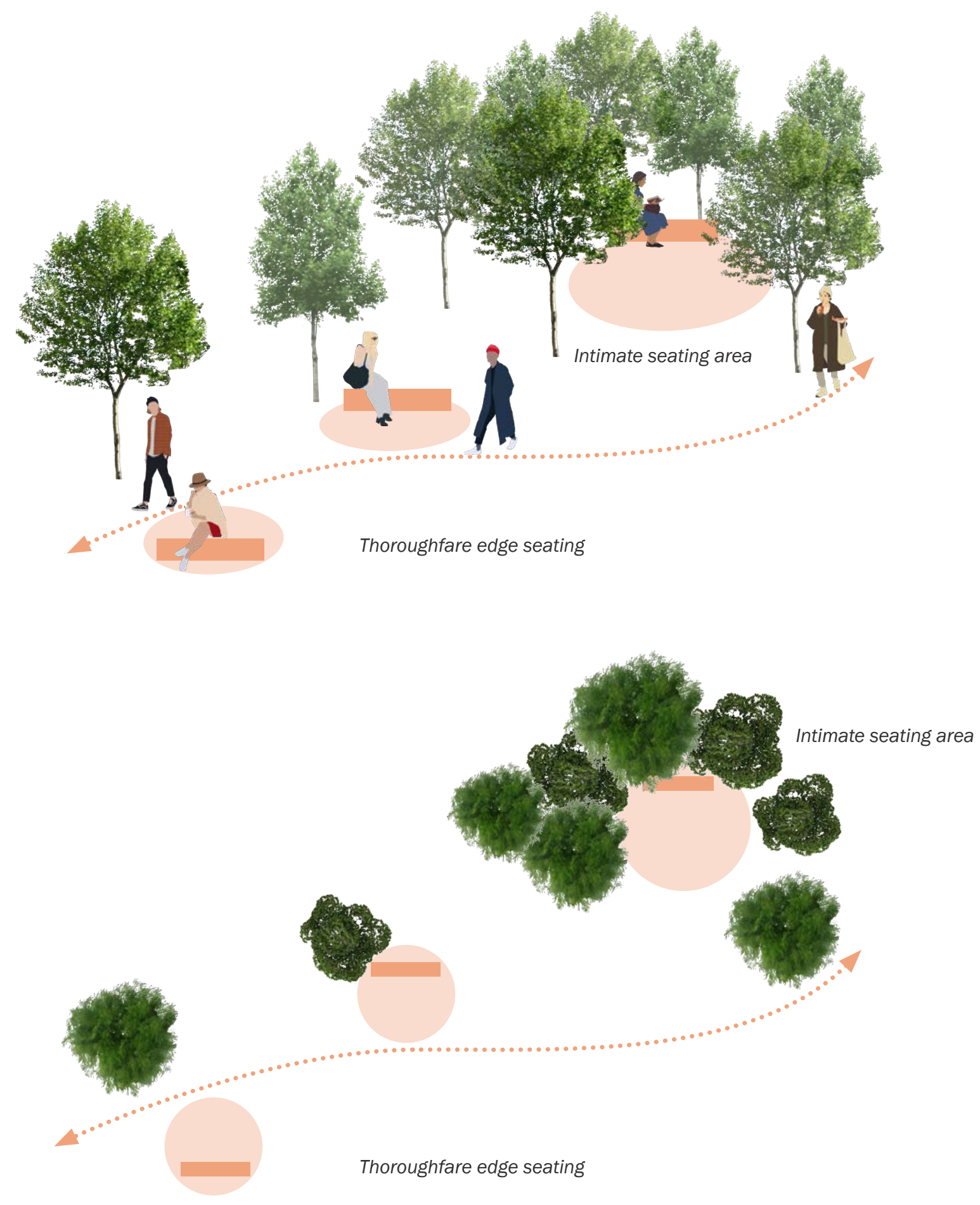


\section{Inviting public space \\ Flexibility}

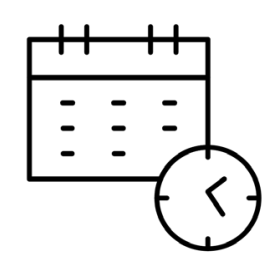

Weekly changes

MTWTFS S

The atmosphere and function of each site changes depending on the day of the week.

On a Sunday, when church services are held, the exterior space of the church is predominantly used for car parking. Sunday services attract the largest number of people to the site than any other day of the week.

For this reason, design needs to accommodate both weekday and weekend use. Creating multifunctional design elements that can be manoeuvred would enable the space to change to suit the demands of its users. As such, the design needs to have a multipurpose focus, enabling car parking while facilitating public engagement and creating a space that people feel welcome in.

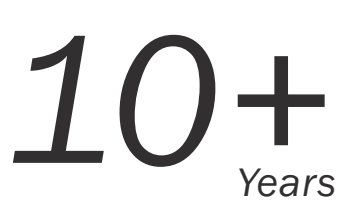

Long term changes
In talks held with both the Wellington City Salvation Army and Wellington Methodist Church, it became evident that redesigning and repurposing their respective exterior spaces was already being considered.

Wellington City Salvation Army suggested that the car park area could transform into a social housing block or retail shops in the future.

This established some conditions for the design of the space. The design would need to be as flexible as possible, taking into account future plans to potentially transform the site. 
Weekday situation

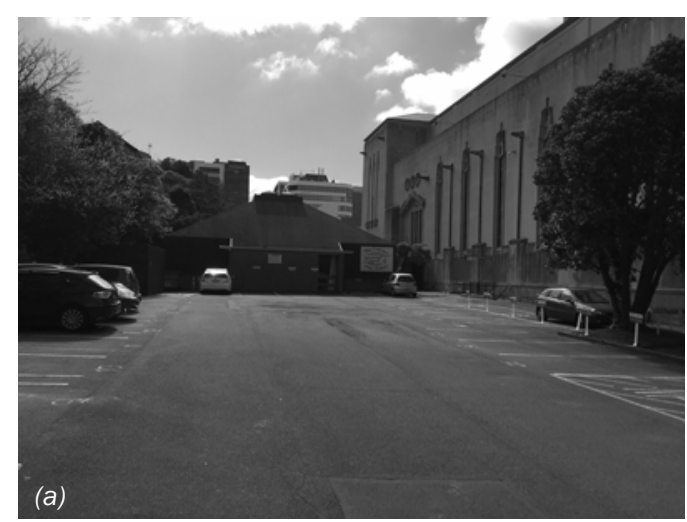

Weekend situation

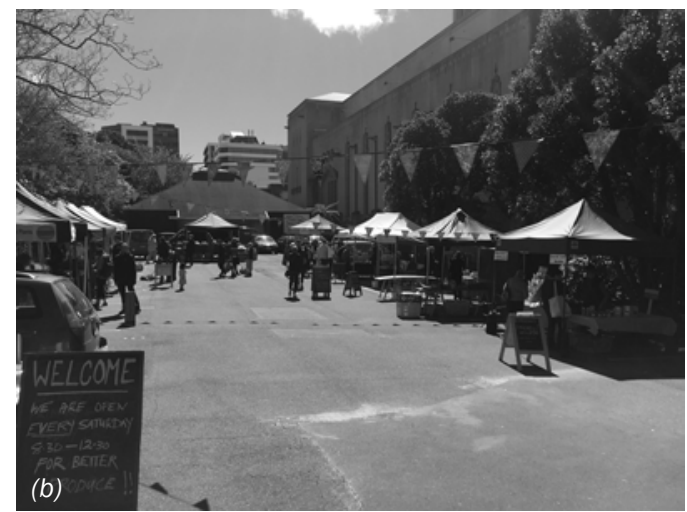

Wellington Cathedral of St Paul
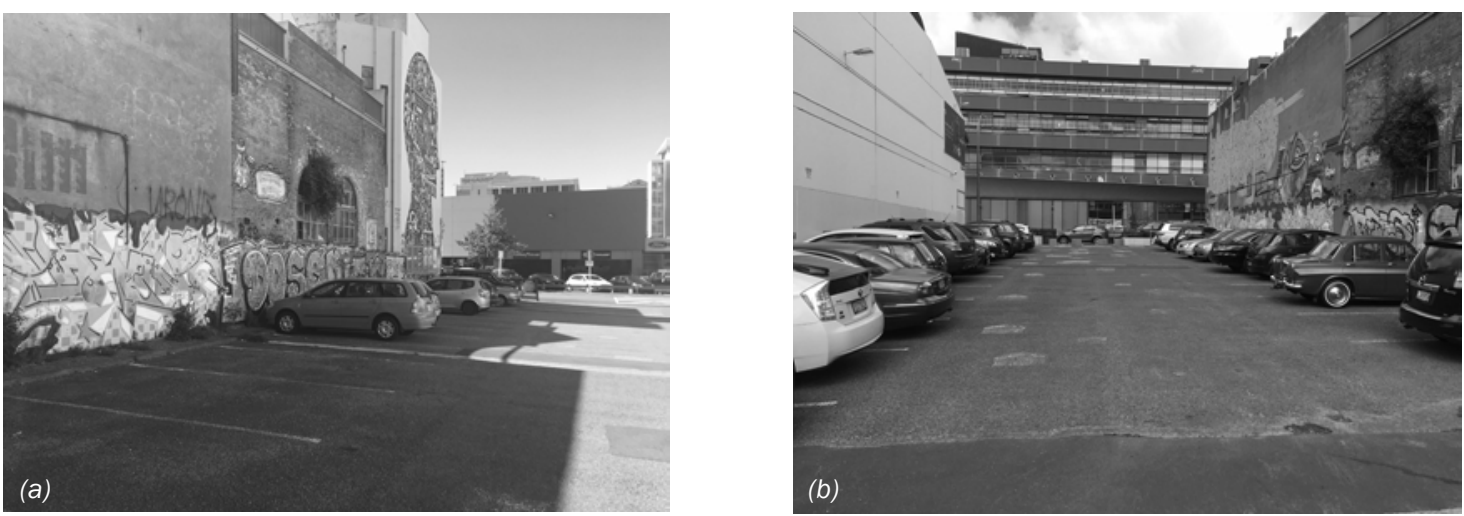

Wellington City Salvation Army
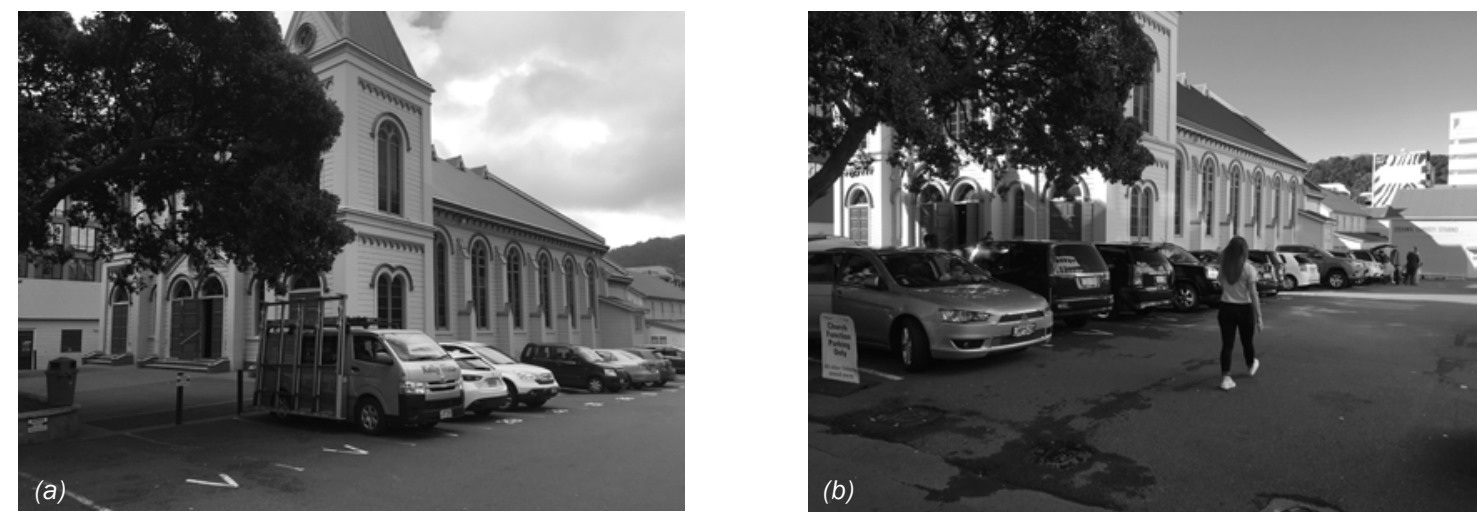

Wellington Methodist Parish 


\section{Inviting public space - flexibility Moveable urban furniture - Multi-space design}

Due to the multipurpose nature of each site throughout the week, movable urban furniture could be considered for each space.

Moveable furniture enables a space to be altered to serve multiple purposes. The area dedicated to car parking at each site is an ideal space to implement this technique. During the week, when the car park is generally emptier, moveable furniture could be used to create an appealing recreational area. On a Sunday, or other times when parking is needed, the furniture can be moved out of the way to enable parking.

Iteration One: $3000 \mathrm{~mm} \times 1500 \mathrm{~mm}$

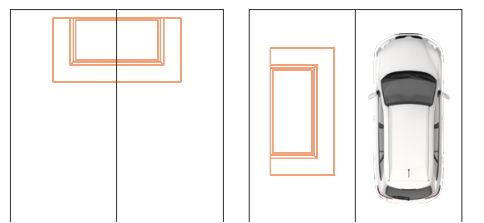

Furniture is too small

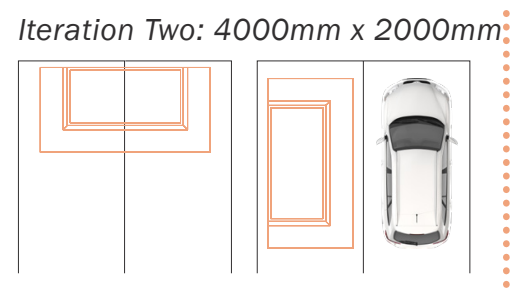

Iteration Three: $5000 \mathrm{~mm} \times 2500 \mathrm{~mm}$

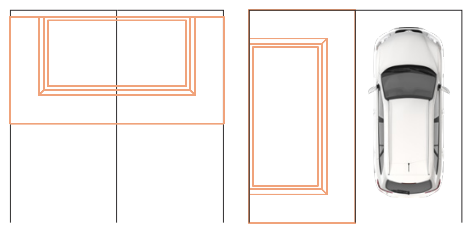

Iteration two is the most practical option in terms of size, taking up one to two car park spaces depending on orientation. Unlike the previous two options, this iteration maximises the available space, while also allowing cars to be in the neighbouring car park.
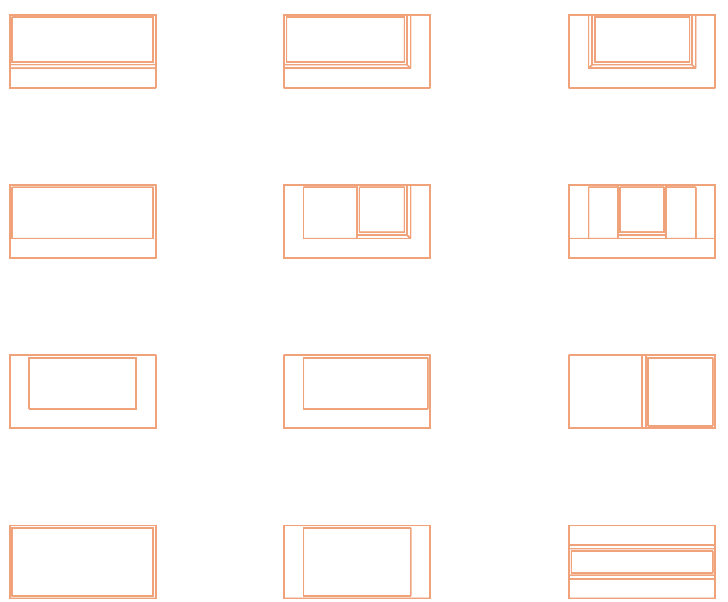

With the addition of vegetation to the seating, a sense of privacy and intimacy can be achieved. The planting adds a backdrop to the seating and shields people from public view.
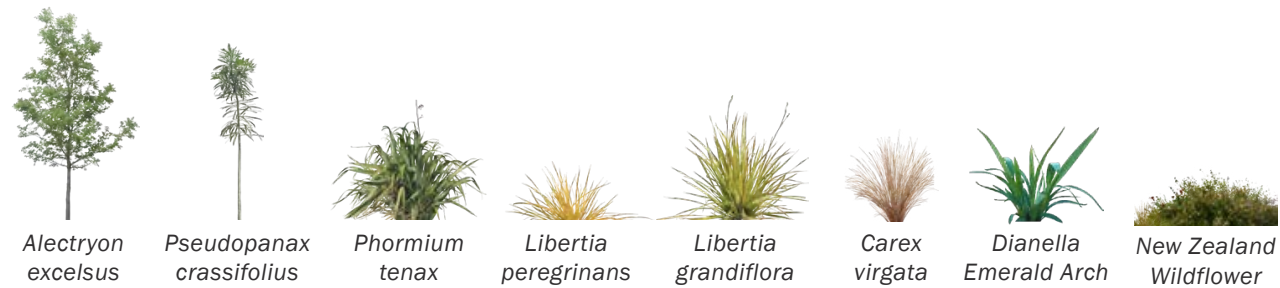

The vegetation chosen for the plant boxes utilises relatively low maintenance plants. These plants will also add colour and interest to the space. 


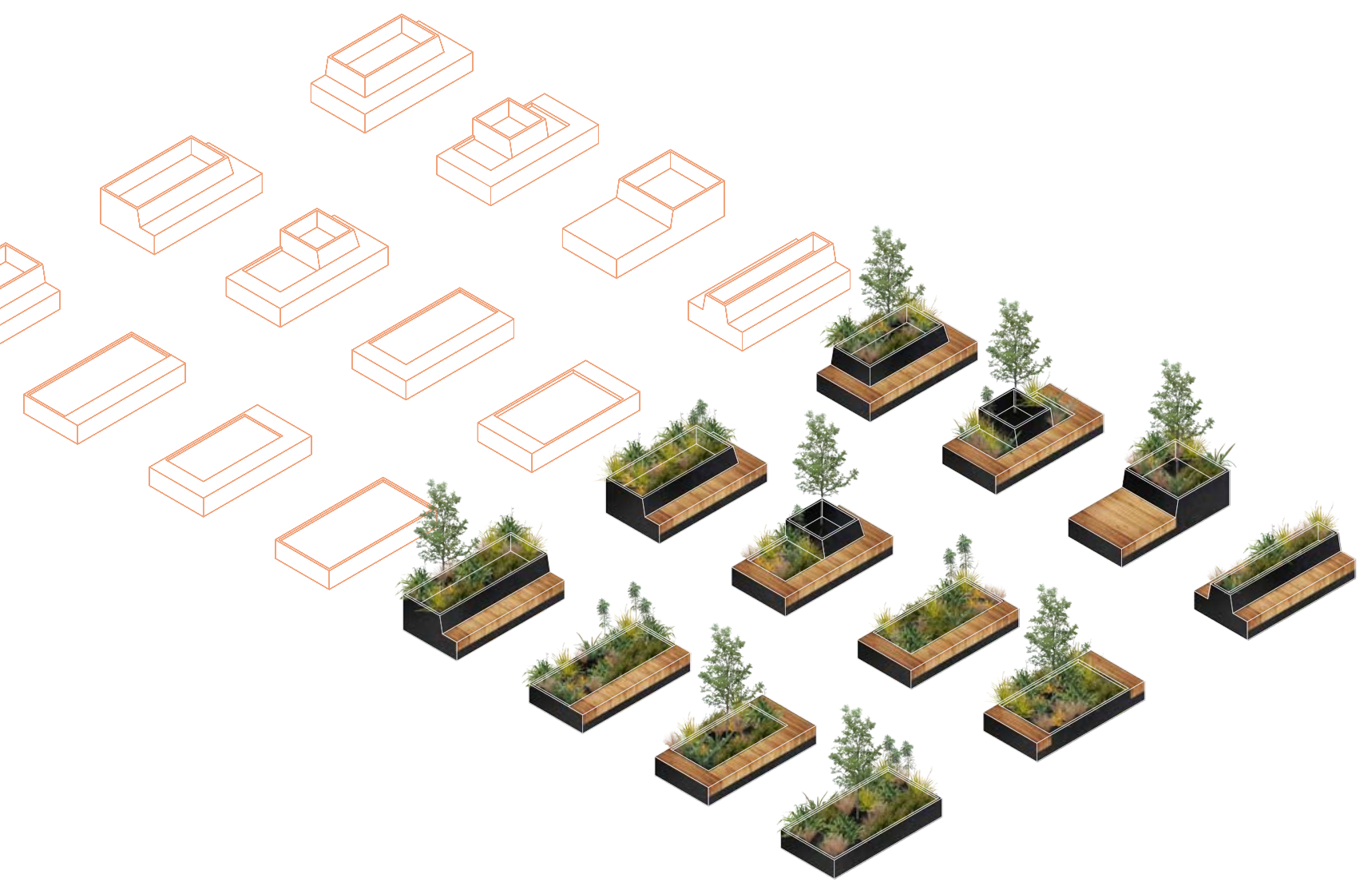




\section{Design techniques and guidelines conclusion}

By positioning the research criteria alongside the Wellington City Council's urban design criteria, the criteria of this research align with that of the council.

Some design techniques address multiple objectives established from the research. Strategic paving, for example, could be applied to creating inviting public space and transitions between spaces. Paving between two spaces creates coherency, assisting in both wide and close context transitions, while also improving the general look and feel of the space.

Referring to current images of each space during this phase of the research, allowed for a better visualisation of how techniques may be implemented, while highlighting the key areas of where these techniques could be best incorporated. 


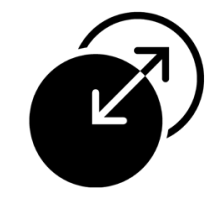

Transitions between space

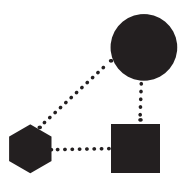

Wider context transitions

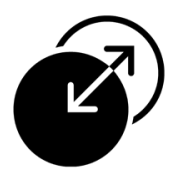

Close context transitions
Work with existing Link spaces to one thoroughfares facilitate new ones another

Remove obstructions

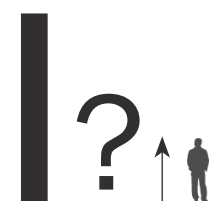

Inviting public space
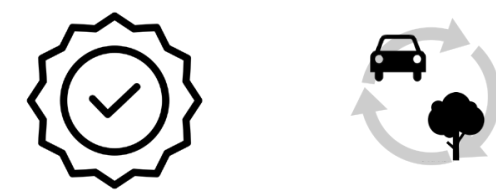

Quality of Space

Flexibility

Increase Vegetation Keep as much parking Improve Paving as possible whilst

Create spaces for enhancing the space sitting and standing Make the space flexible to the weekend and weekday setting 


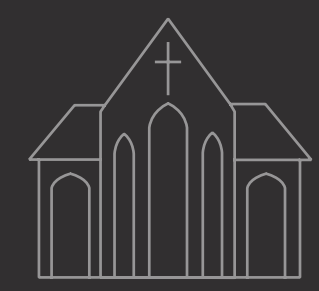

CHAPTER SIX 


\section{Design Implementation}

This chapter uses the design techniques and guidelines gathered from the literature review and precedents, highlighted in the previous chapter, applying them to each of the three sites.

For each site, the design proposes a new concept for designing in church space; placing more importance on the external space of the church, rather than the building.

The criteria for design was based around the initial aims and objectives of the research and was a result of the comparative analysis and community engagement process. The transitions between space have been split into wider context transitions and close context transitions. Inviting public space incorporates improving the quality of space and making the space flexible.

This chapter is split into three sections, with a section dedicated to each site.

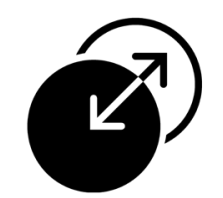

Transitions between space

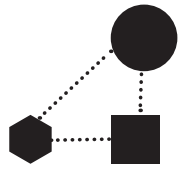

Wider context transitions

Work with existing Link spaces to one thoroughfares and facilitate new ones

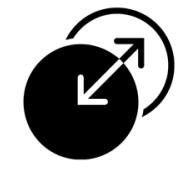

Close context transitions

Remove obstructions

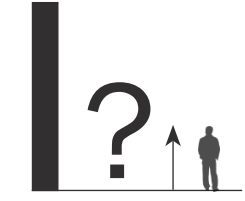

Inviting public space

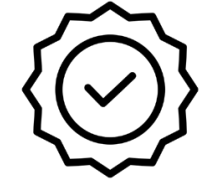

Quality of Space

Vegetation Improve Paving Create spaces for sitting and standing
Keep as much parking as possible whilst enhancing the space Make the space flexible to the weekend and weekday setting 


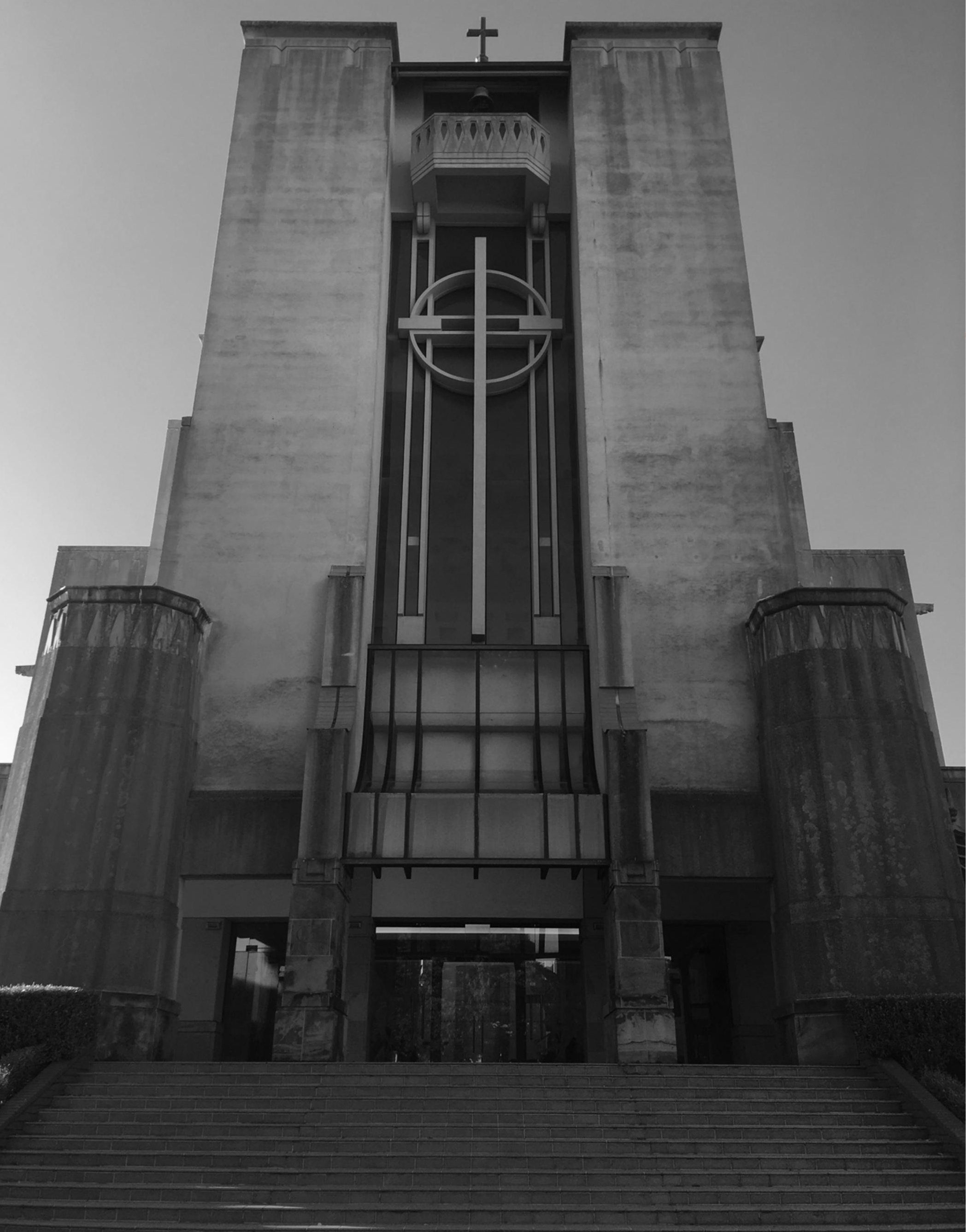




\section{Wellington Cathedral of St Paul}

Design iterations and development

The following area was chosen as the focus for design. This focus enabled the research to explore better transitions in both the sites wider and close context.

The site does not have a strong connection to its wider context. Establishing a thoroughfare through the space is important for connecting the church to its surrounding area. Two close context transitions between the street, church entrance and car park could be improved.

Making the space flexible to accommodate weekend and weekday use could also be explored in this area. This would require designing with the Saturday markets in mind, by creating rest spots along the edge of the car park for users to enjoy.

Designing in this area could improve the quality of space as a whole. By improving the overall quality of the space through each design move, the space will become more inviting.

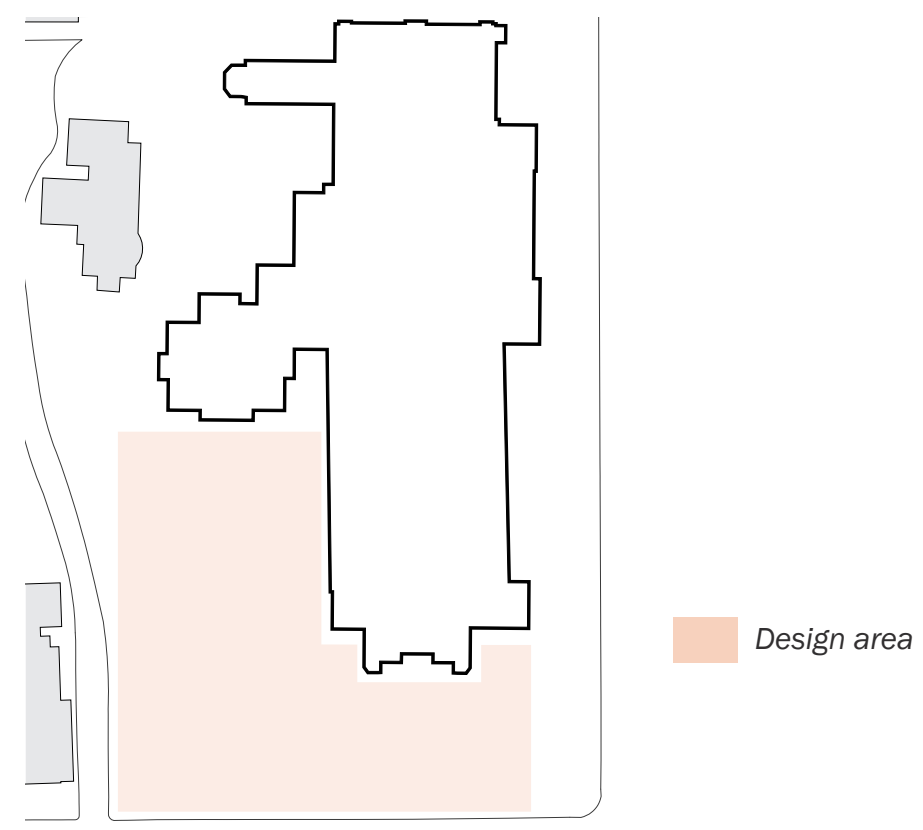




\section{Designing in the specified area}

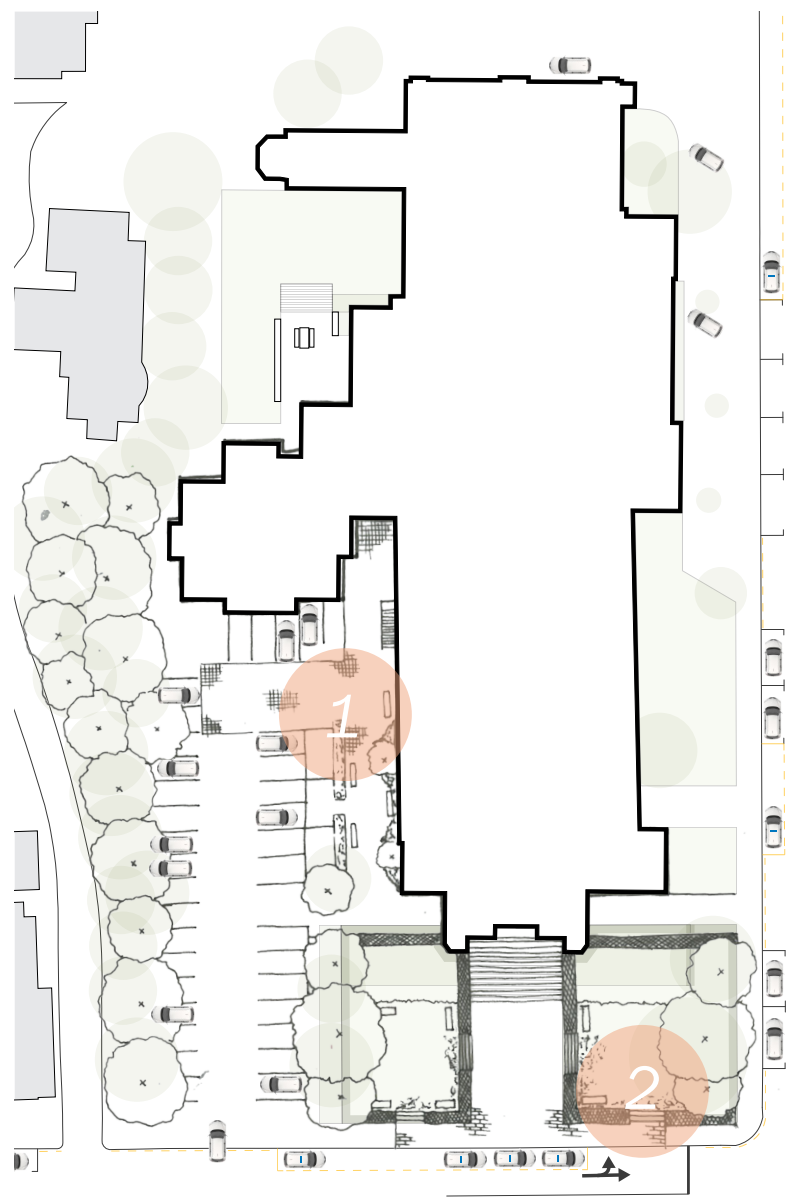

N $1: 1000$

\section{8}

Available car parks

1 Iteration one considers establishing a thoroughfare through the site, implementing paving along areas that aren't used for parking.

2 The lawn areas in front of the church are made more accessible by creating gaps in the hedging.

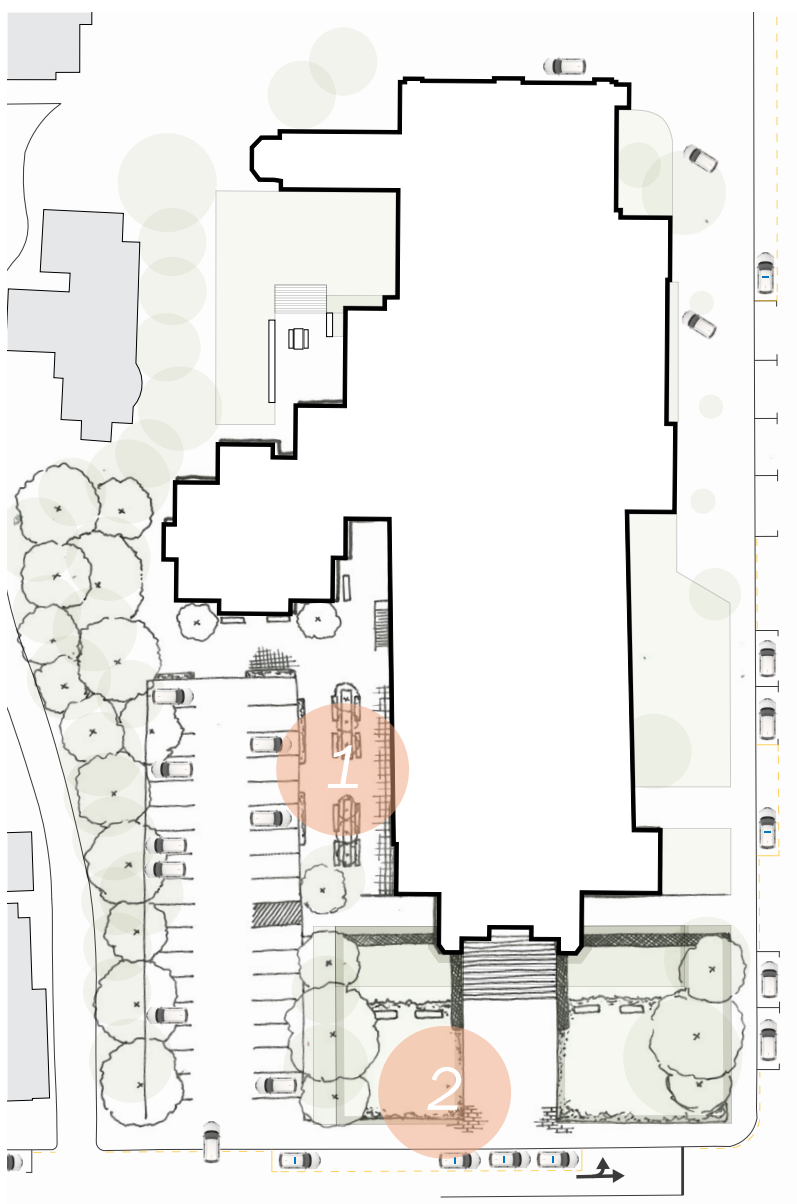

1:1000

\section{3}

Available car parks

$1 \quad$ Planting is used more heavily here, along with seating to make the site more permanent.

2 The front lawn area is made accessible by removing the hedging on the street frontage. 


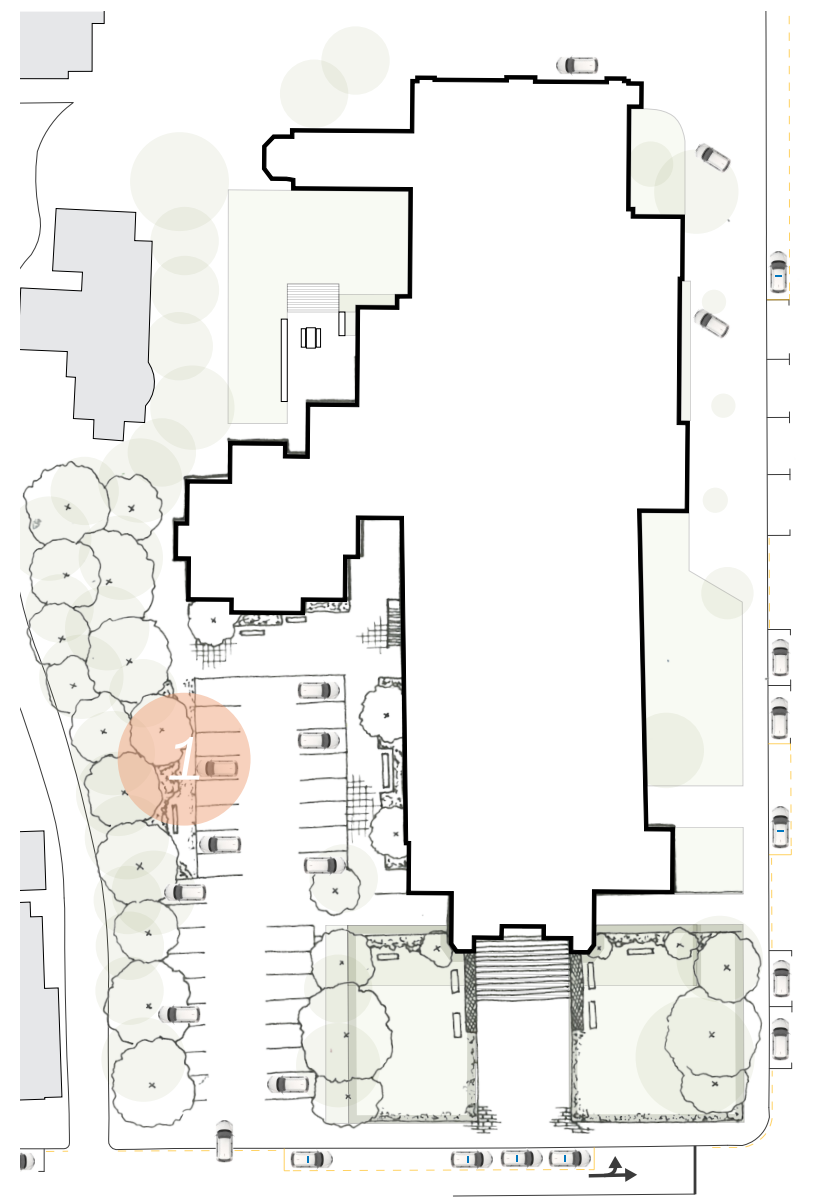

$1: 1000$

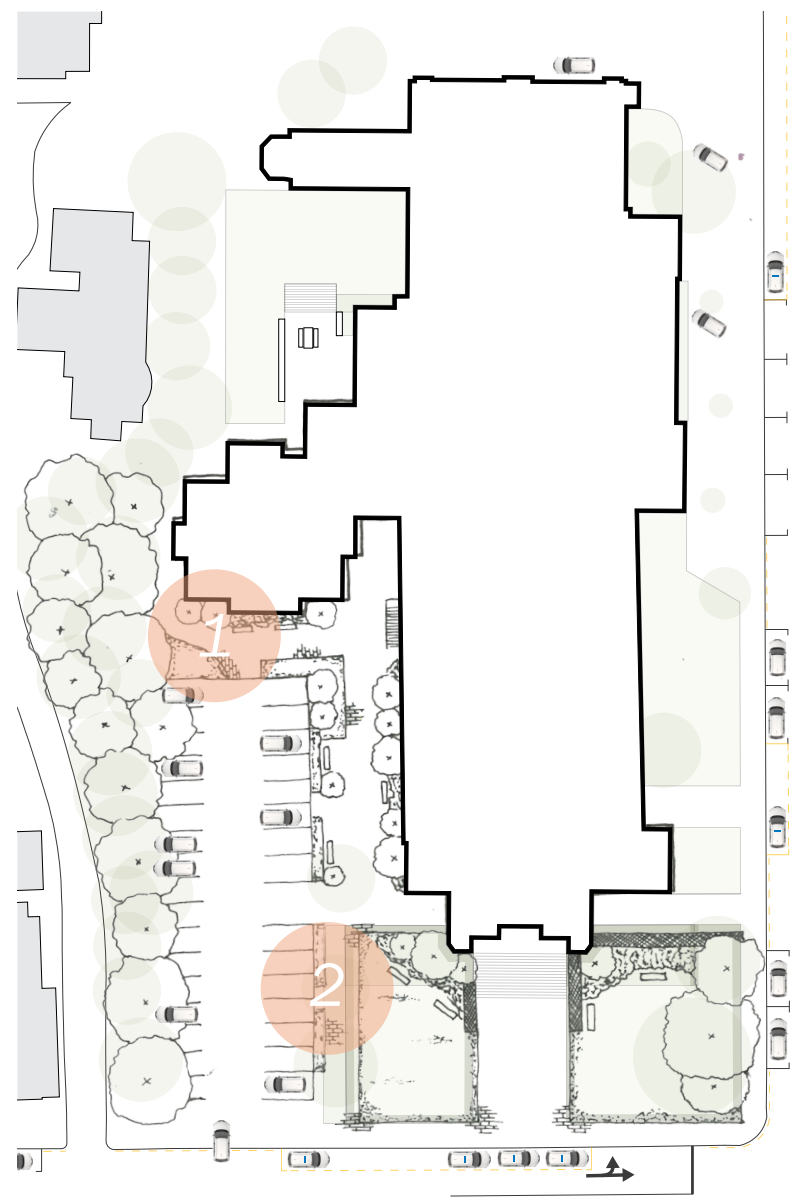

N $1: 1000$

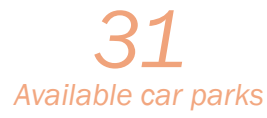

1

Shifting the car park off centre allows space on the western side for public engagement. Having this space wrap around the car park will be useful in terms of the market day programme. The market would be surrounded by public space, with seating instead of a car park.

This could also have a negative impact however, as the public engagement and moments of permanency would be on the wrong side of the car park. 


\section{Transitions between space Wider context transition}

Establishing a defined thoroughfare creates the opportunity for more people to use the space. As identified in the analysis of this site, there are a number of areas around the church that are significant public spaces. Creating a link between these areas enables the opportunity for people to interact in the exterior space of the church. For this reason, the pathways and movement through site need to be enticing to attract the passer-by.

Being so close to Parliament, there was a desire to create a space similar to the Parliament grounds. Many people in the surrounding area utilise the Parliament grounds, whether on their lunch break or passing through. It was for this reason that the space in front of the church and the thoroughfare through the site were chosen as key design areas. The exterior space of the church could serve as an extension to the parliament grounds, becoming a place where local people gather on their lunch break or walk.

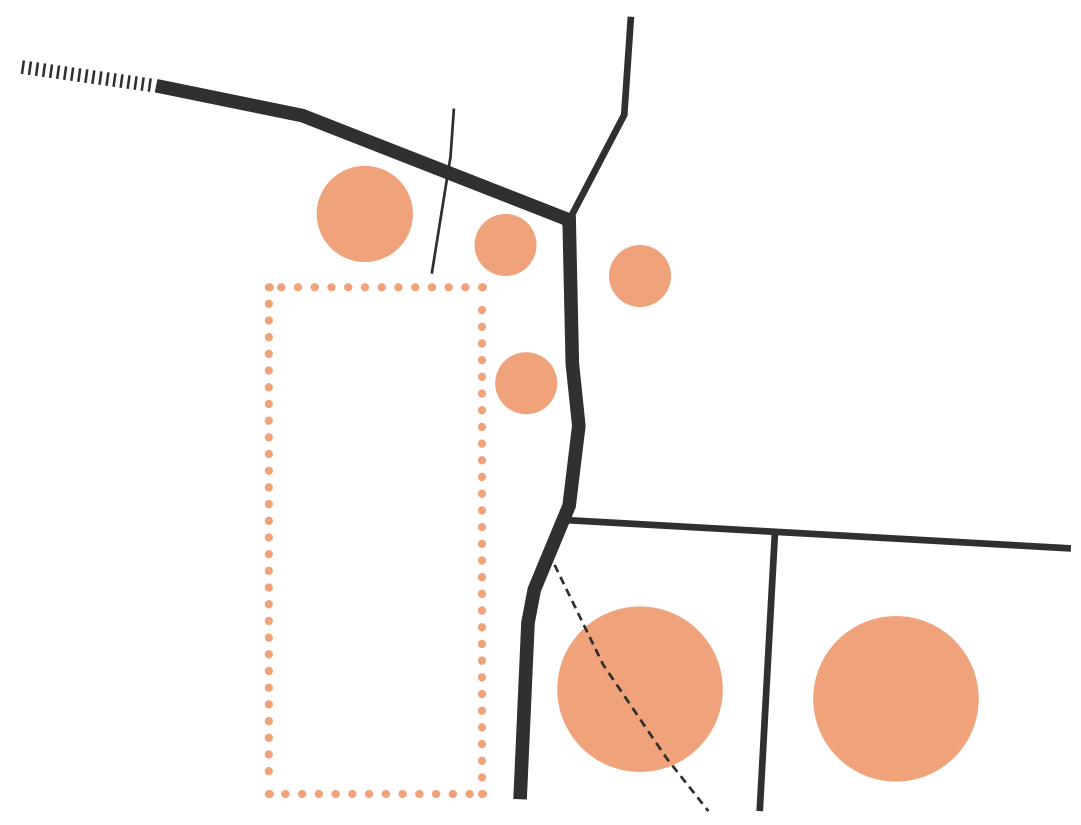

Fig.6.07. (Above) Desired transitions through the site 


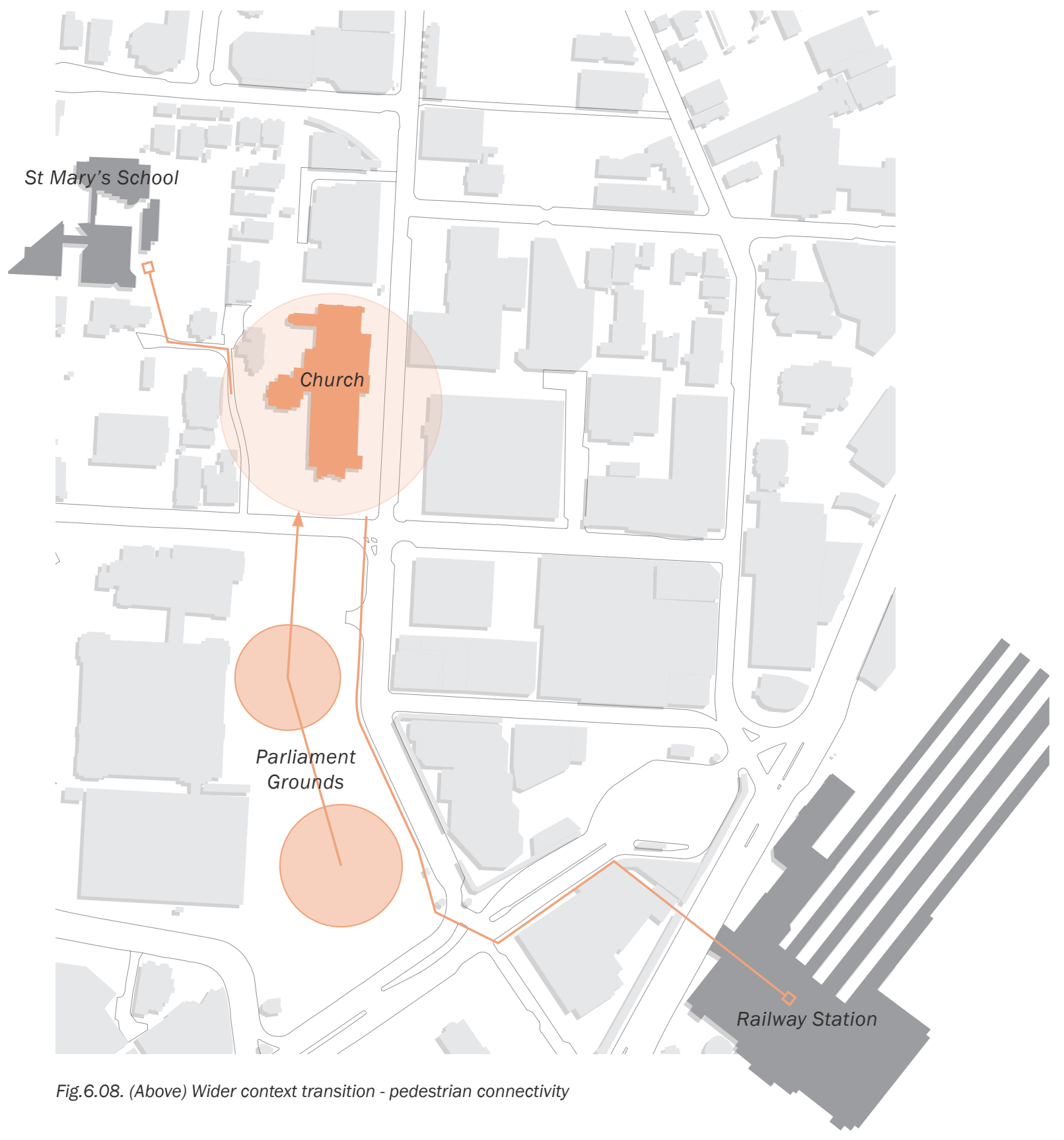




\section{Transitions between space Close context transition}

The following concepts explore the transitional area in front of the church and between the church car park and entrance. Making the space more open and receptive to movement was the goal in each iteration.

Careful consideration was given to designing in this space, making sure that any intervention did not clutter the space. Too much clutter in the transition area could make these valuable and integral areas in a site function as less of a transition zone and more of an obstruction to the space.

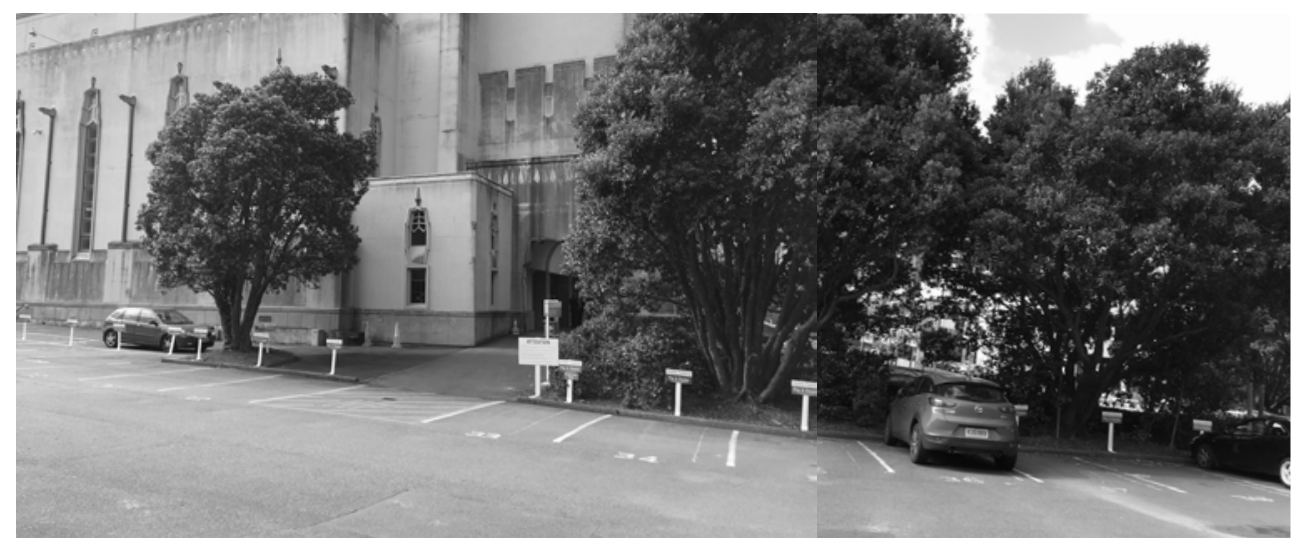

Front of church and car park current situation
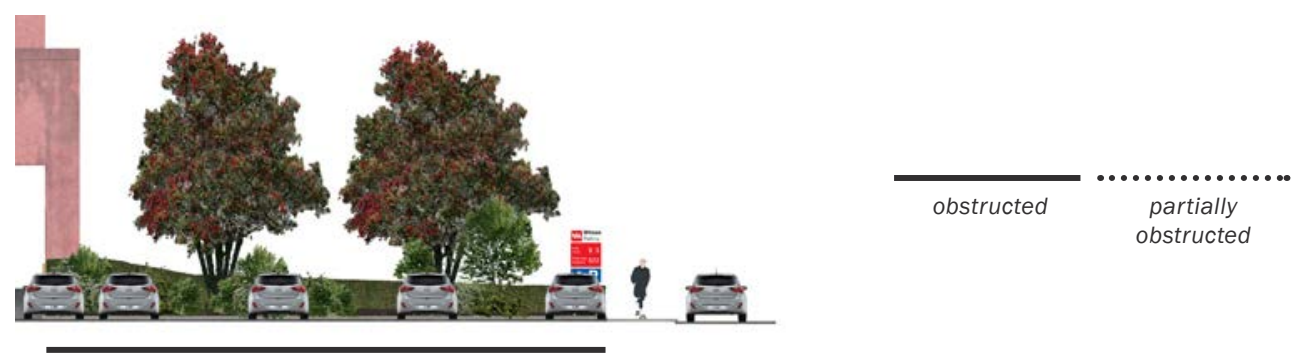

The vegetation between the car park and front of church space restricts movement and usability. There is no coherency between the two spaces. 


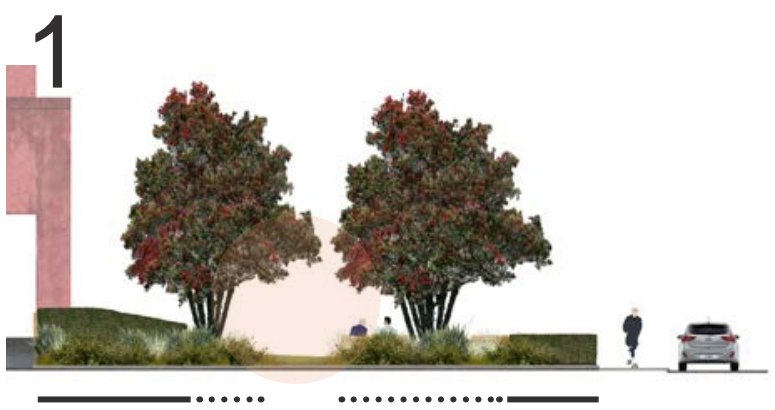

A gap is made in the hedge to make the lawn area accessible.
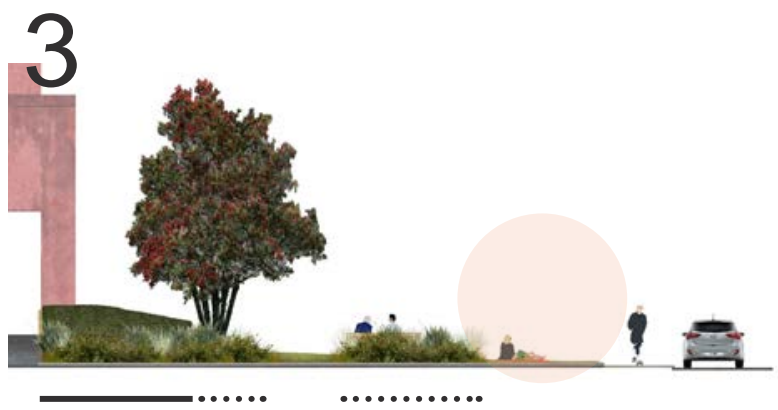

The hedge running along the footpath is removed to allow pedestrians to walk freely from the footpath into the space.

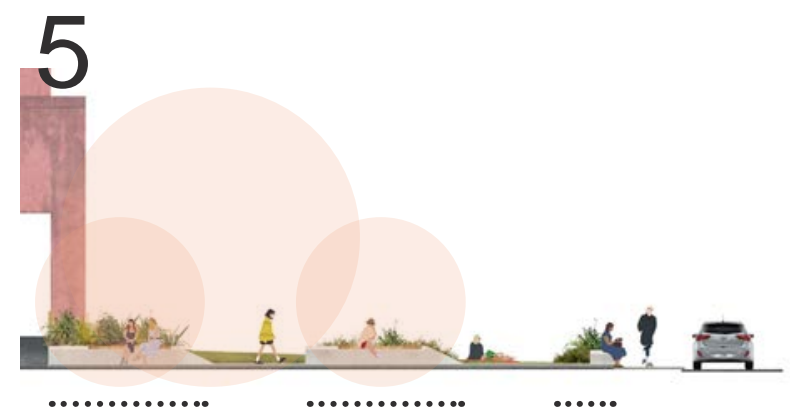

The second tree is removed to completely open up the space. Seating is also added along the lawn.

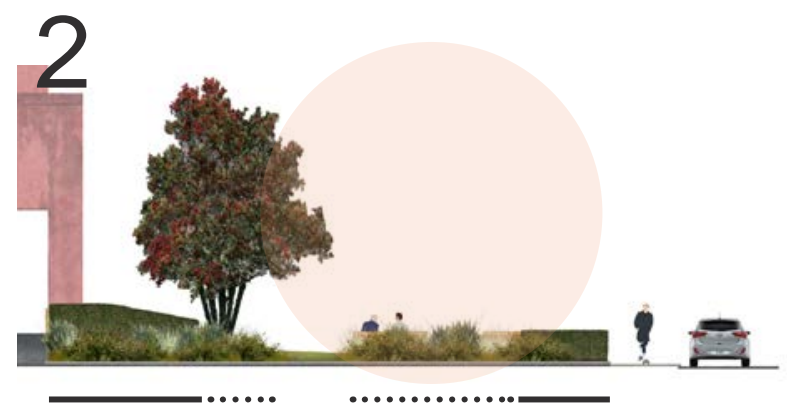

The tree closest to the road is removed to create a more open space.

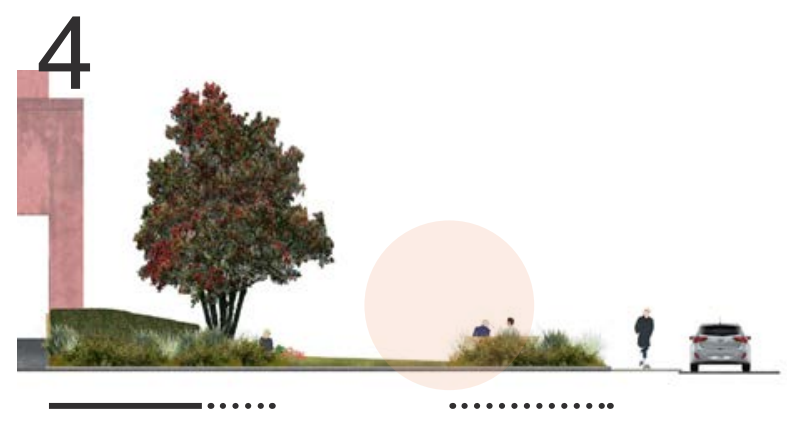

The gap between the planting is enlarged to allow for an easier transition between the front space and car park.

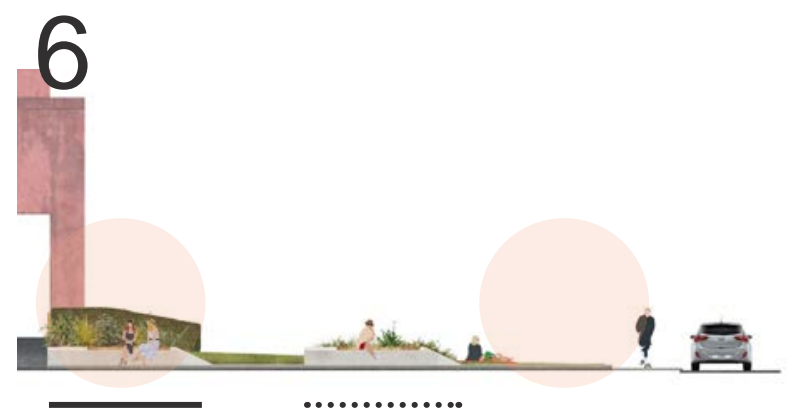

Planting is removed from where the site intersects with the footpath. There are no vertical elements in the space. 


\section{Transitions between space Close context transition}

Establishing a pathway that cuts through the site increases the amount of foot traffic in the space. This creates an opportunity for the church community and general public to interact.

Creating an area that passers-by can spill into is a way of facilitating movement through the site. By removing the hedge surrounding the lawn area, the space becomes more usable. This does pose some risk however, as it could open the area too much, creating a physiological barrier when entering a space.

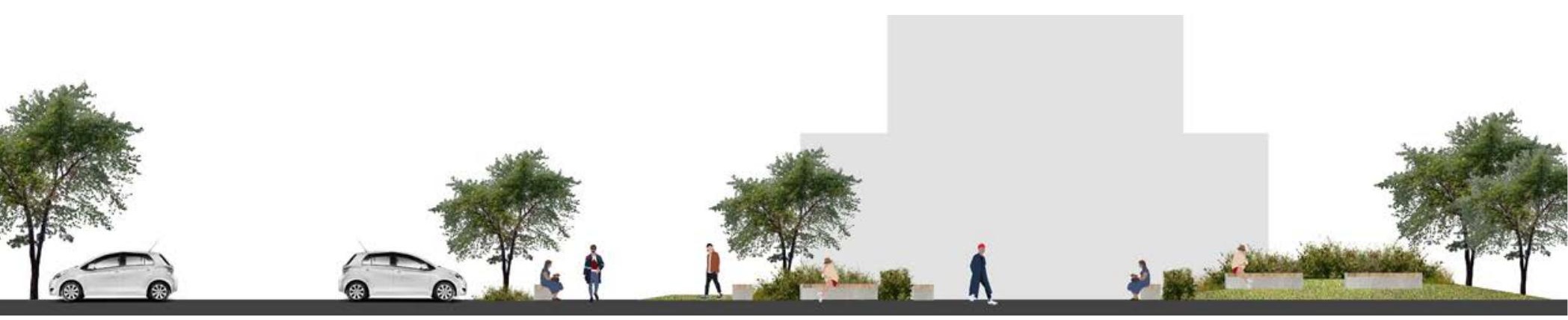


Creating pathways

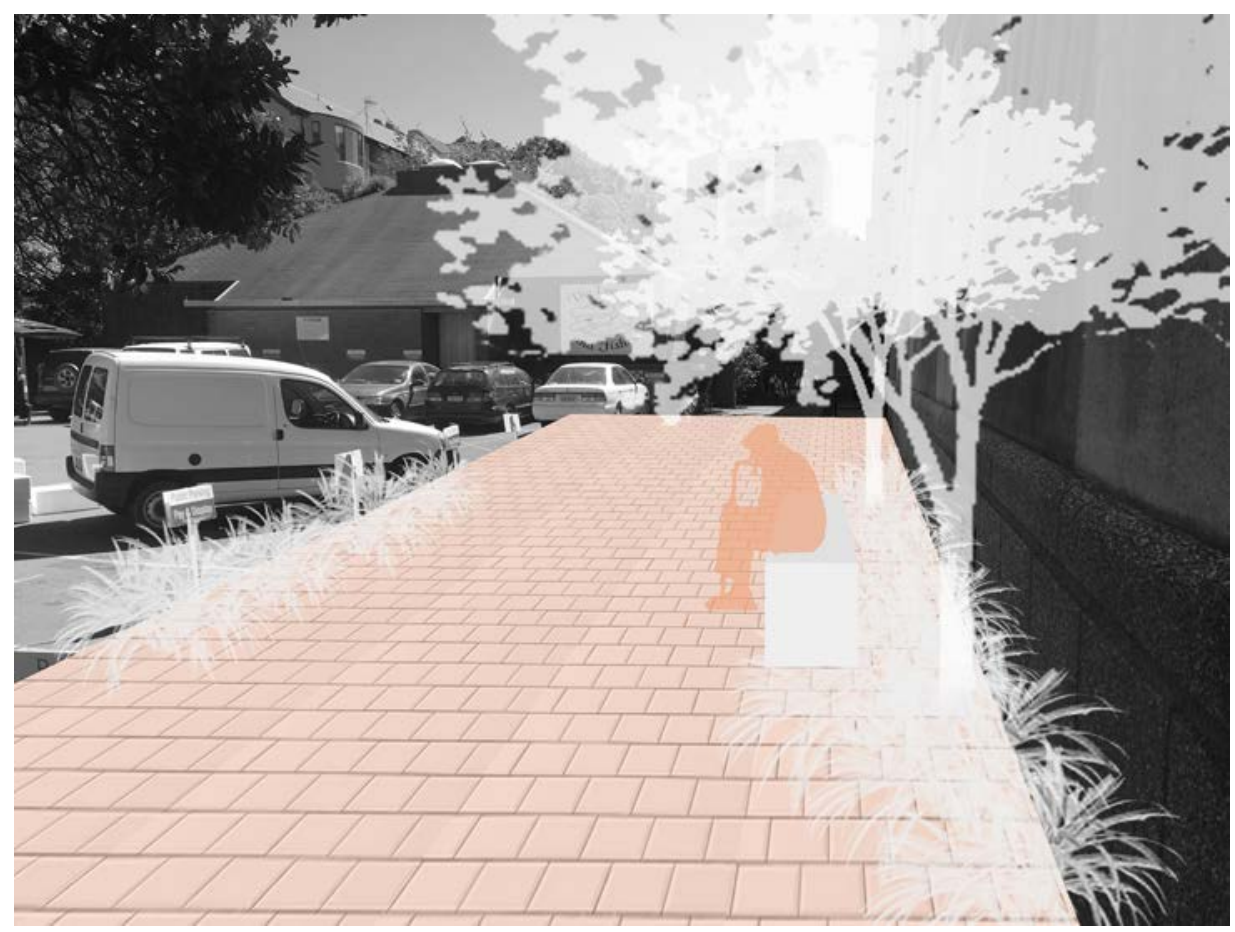

Paving and openness

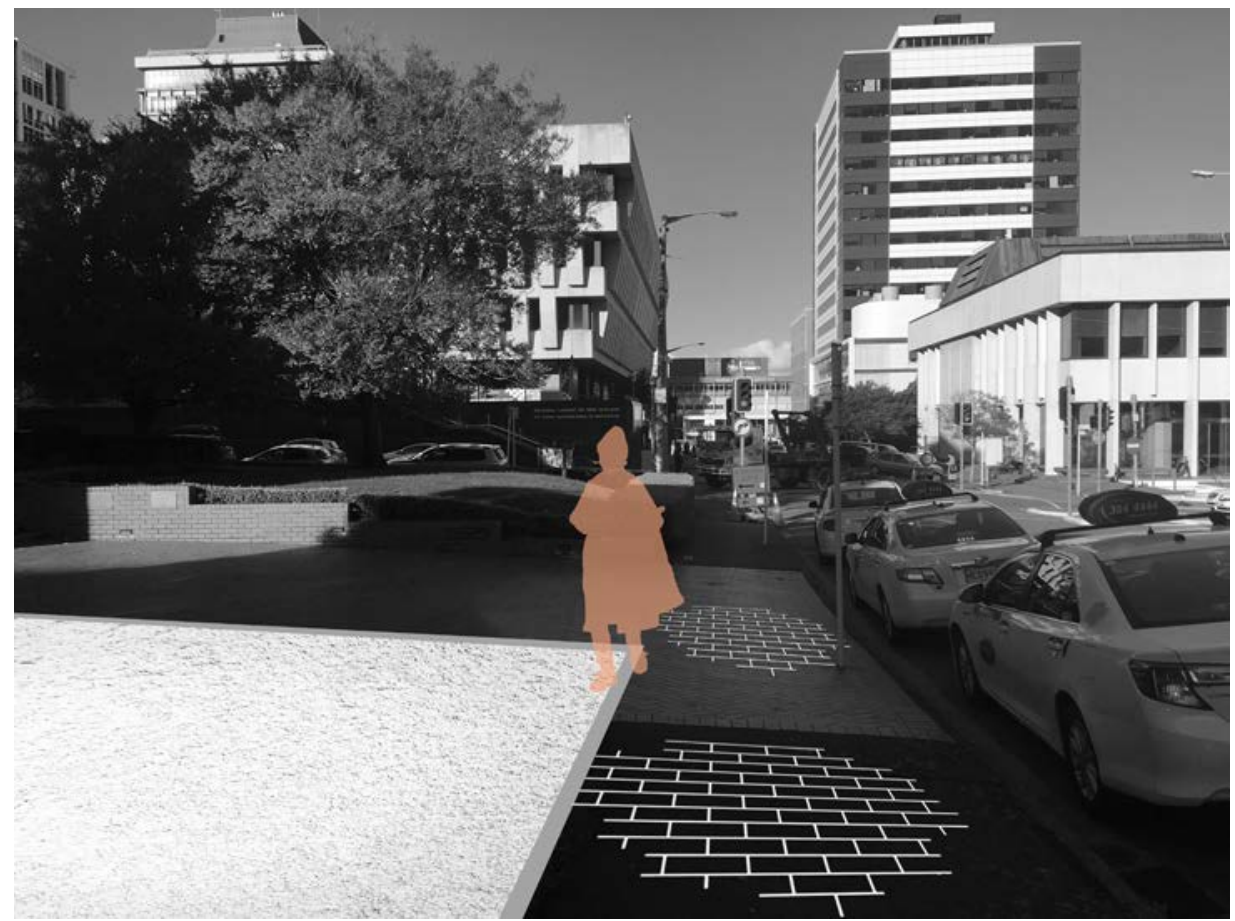




\section{Inviting public space Quality of space - strategic seating \& planting}

Creating a more fluid paved pathway contrasts the current designs symmetrical nature. The proposed design creates a slower-paced atmosphere in the site. In addition, there are rest areas placed along the path for people to use. This technique was taken from the modern church design precedent, where pathways used in the space were fluid, slowing pedestrian movement. By employing this technique in this site, the pathways are safer as people no longer need to pass through the car park space.

In conjunction with this, there are rest areas placed along the path for people to use. These rest areas employed the strategic seating technique from the previous chapter providing seating along the thoroughfare and more private seating in the front space.

B4 Island Heart Garden - France
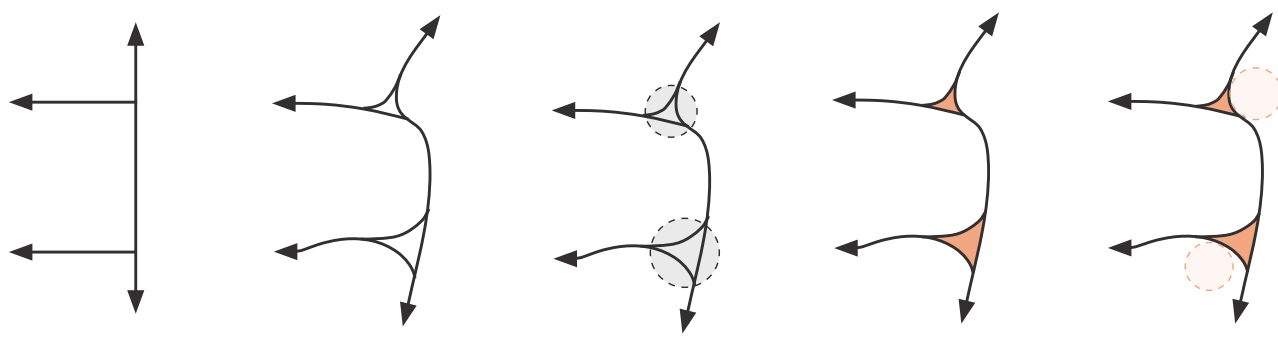

Proposed changes to pathways - Wellington Cathedral of St Paul

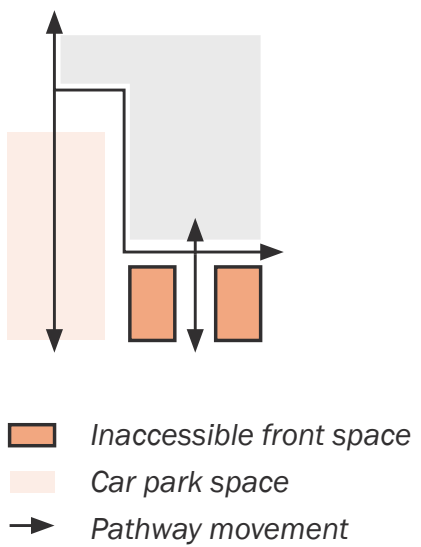

$\rightarrow$ Pathway movement

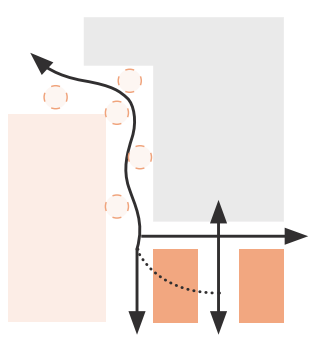

Front space made accessible Car park space

$\rightarrow$ Pathway movement

Rest \& recreational areas 


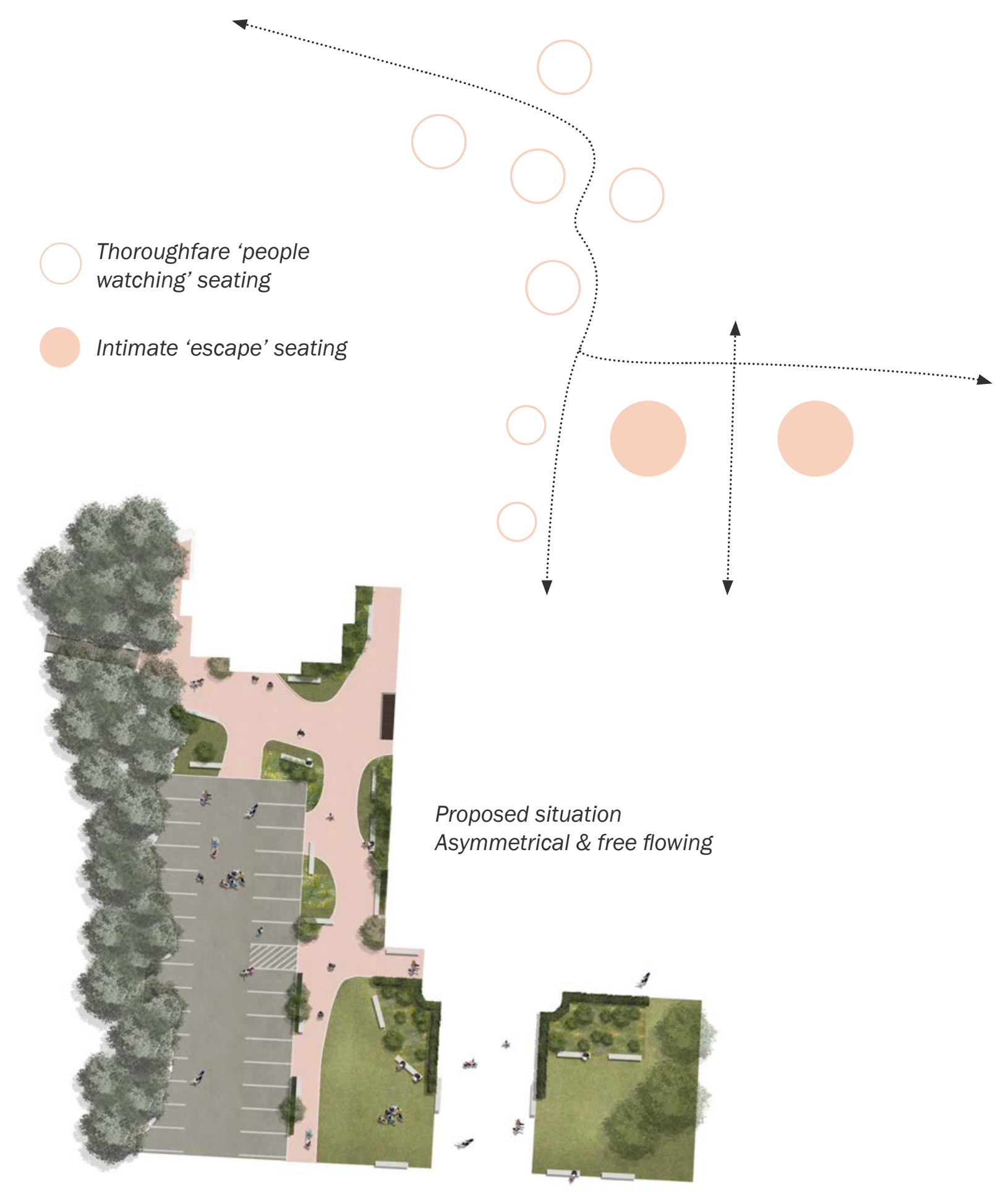




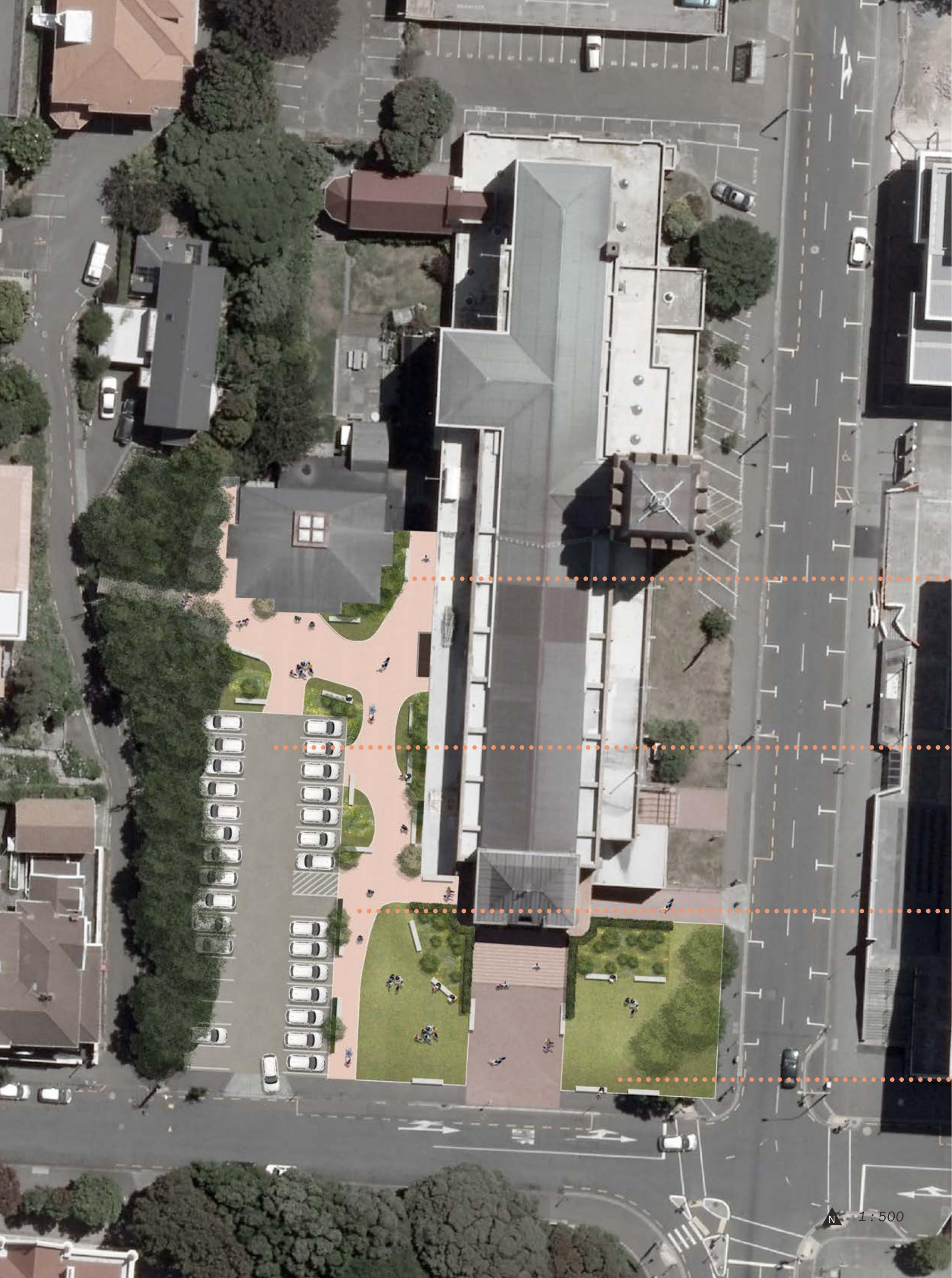


Final plans - flexibility

1 Sunday morning plan

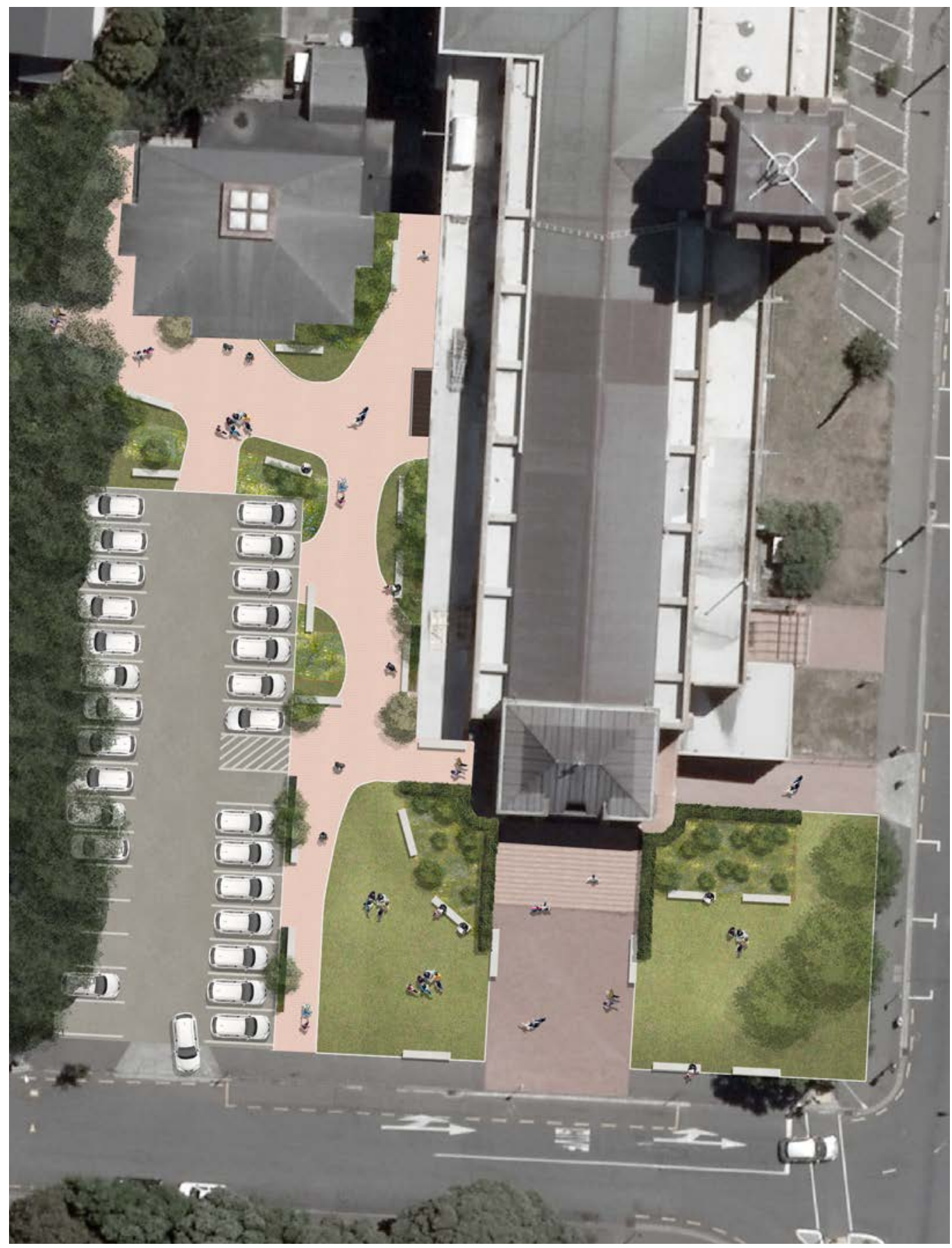

N 1:500 
2 Saturday market plan

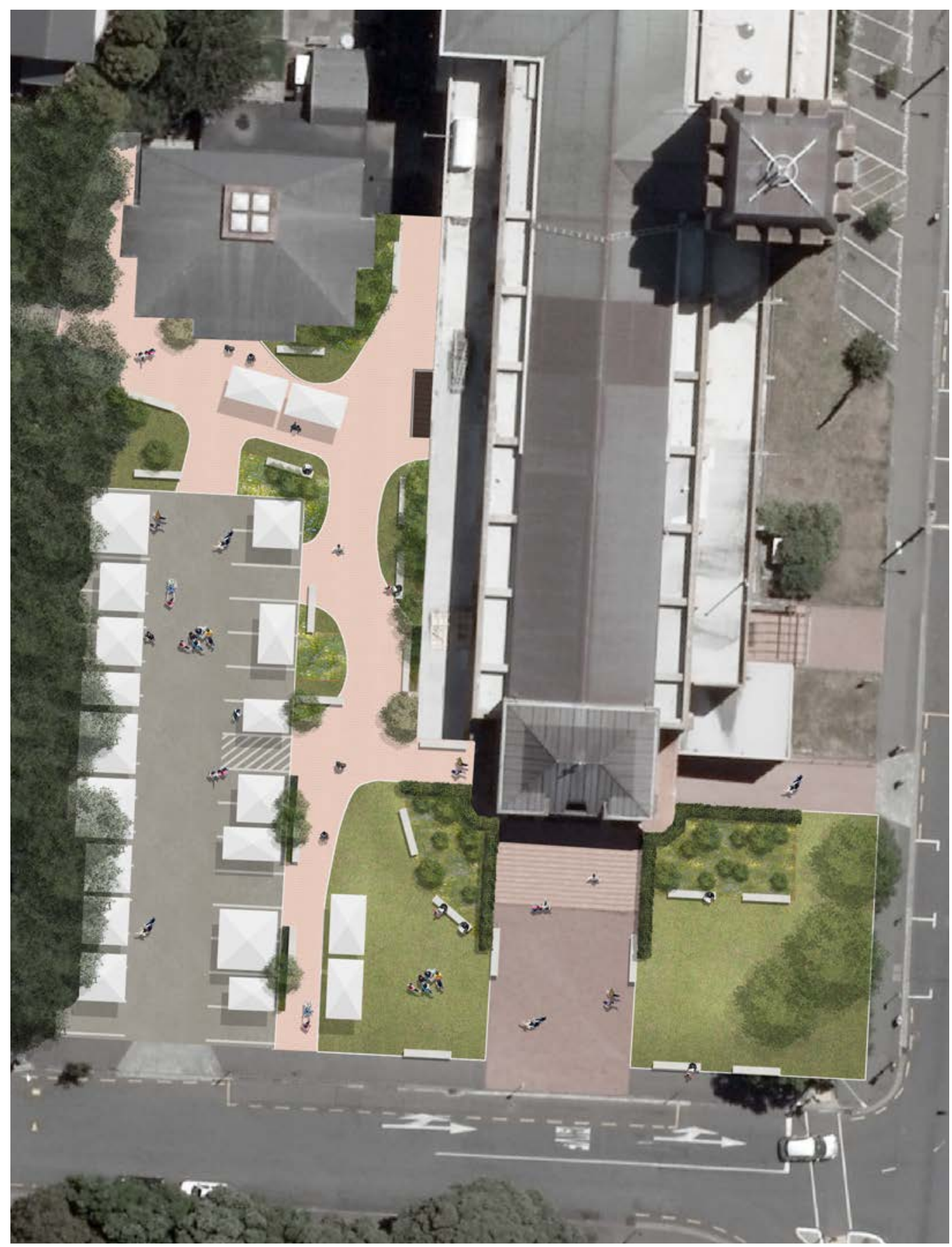

A $1: 500$ 



\section{Wellington City Salvation Army}

Design iterations and development

The following area was chosen as the focus for design. This focus enabled the research to explore creating better transitions in the sites close context. The site already has strong transitions to its wider context, with many people using the car park as a thoroughfare. The close context transition between the church entrance and car park could be improved.

This is another area where making the space flexible to accommodate weekend and weekday use could be explored. The space would also need to be flexible enough to incorporate any future designs to the site, whether in the form of social housing or retail shops.

Designing in this area could improve the quality of space as a whole. By improving the overall quality of the space through each design move, the space will become more inviting.

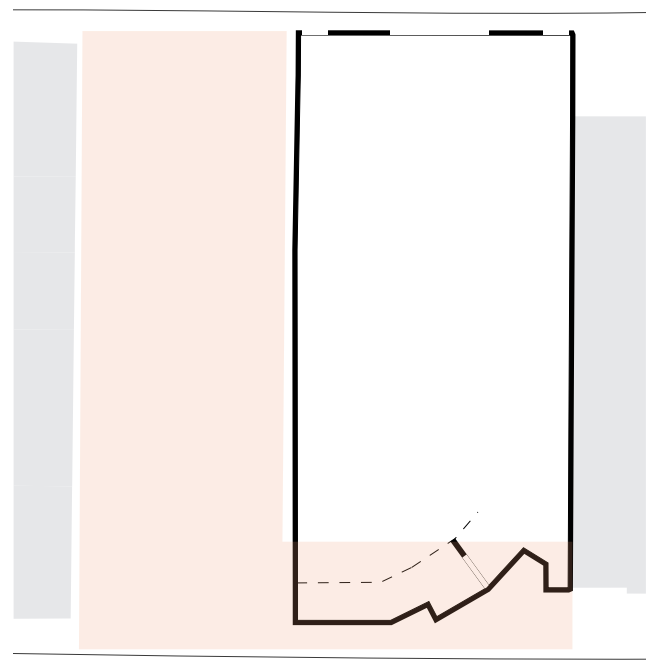




\section{Designing in the specified area}

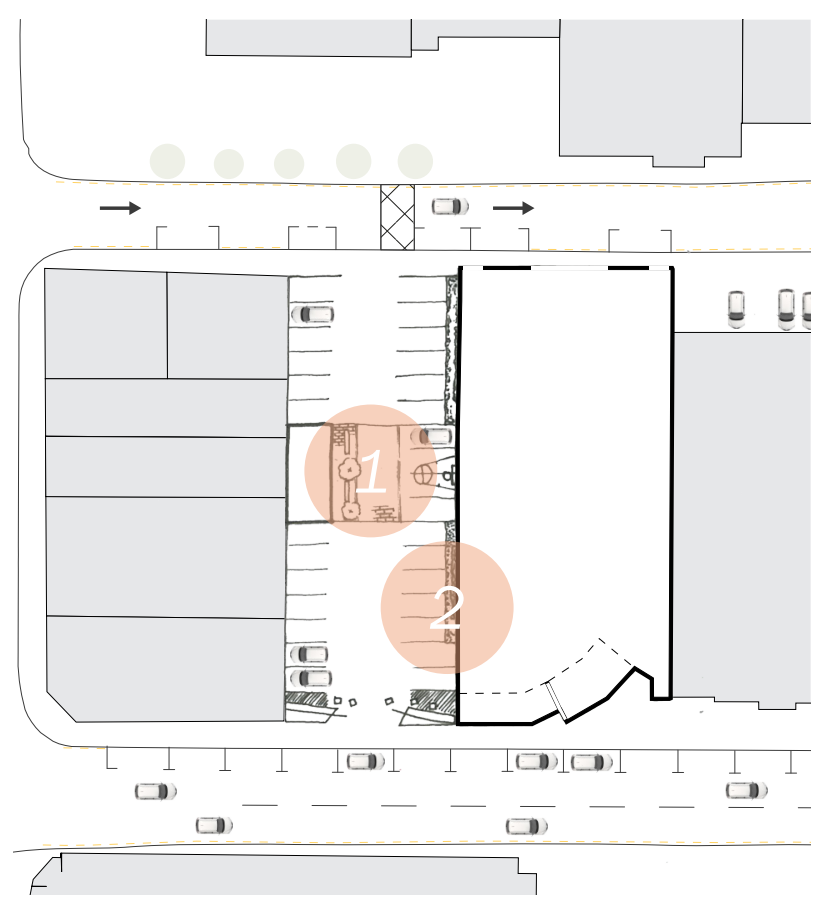

N 1:1000

\section{0}

Available car parks

1 A zone in the centre of the car park allows for interactions such as coffee trucks and basketball.

2 Planting along the edge of the building adds colour and vibrancy and combats against the domineering and bland wall.

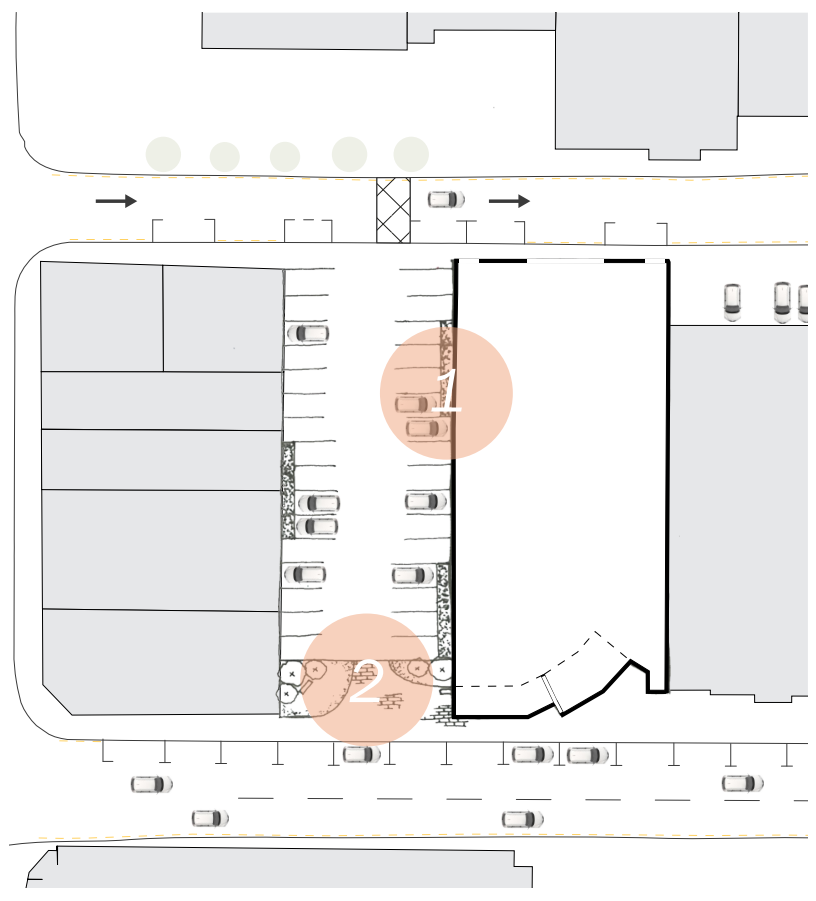

N $1: 1000$

\section{2 \\ Available car parks}

1 Rain gardens line the exterior wall, catching water run-off from the buildings and car park, and adding visual appeal.

2 Planting and garden space in front of the car park. The transition from car park to church is now much stronger and less tight. 


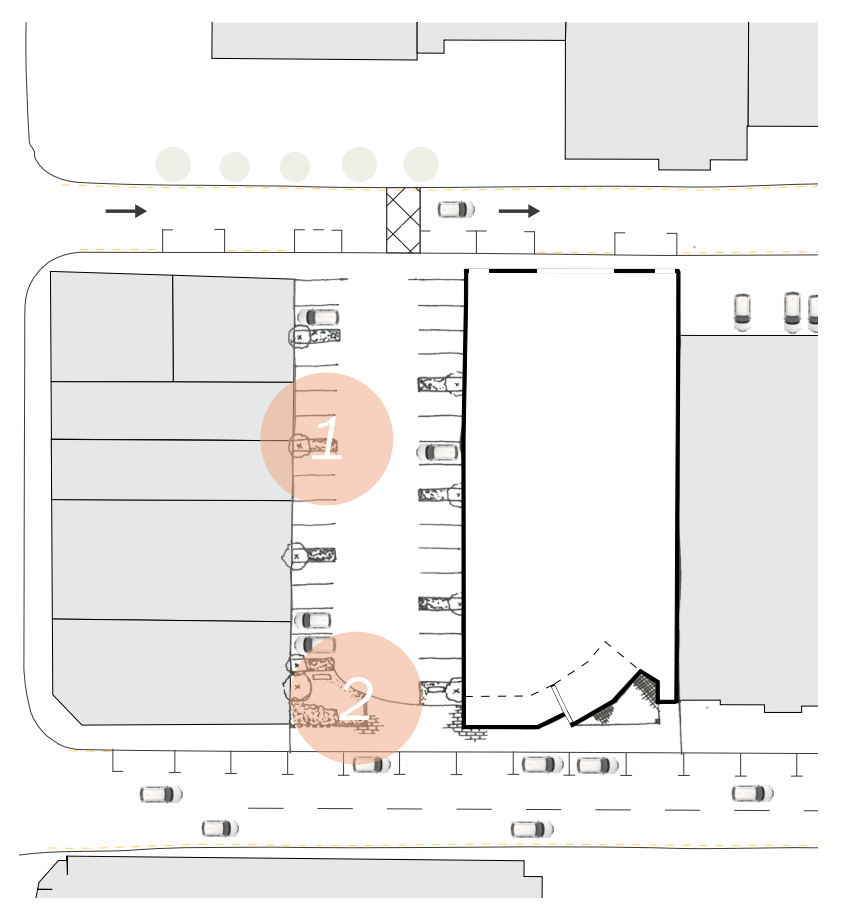

N $1: 1000$

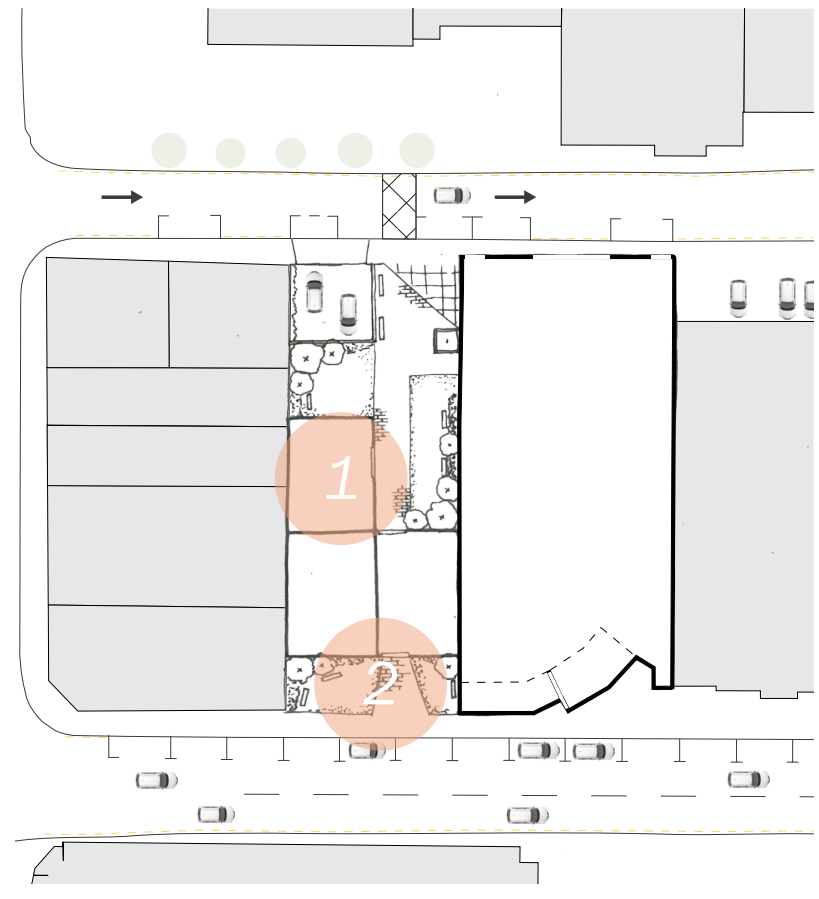

N $1: 1000$

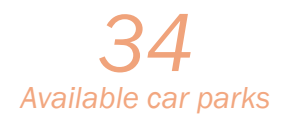

1 This iteration relocates the car park underground to allow buildings to be built at ground level. In a longterm plan, the space could be converted to supply social housing or other programming. Both the building dwellers and members of the church would share the outdoor space.

2 A zone at the end of the car park creates a space where people can rest. 


\section{Transitions between space Close context transition}

The following iterations are based around the micro territories and transitions through the site. Currently, the church car park has no element of permanency and with State Highway One running adjacent to it, creating one is difficult. There are two main zones when looking at this particular area of the site, the road to footpath transition and the transition from the footpath to the site's exterior space (currently a car park).

These iterations explore techniques of obstruction and openness to achieve elements of permanency. By blocking busy State Highway One to the pedestrians passing by, the site becomes less noisy and vehicle focussed. By simply planting along these two areas and creating a seating element, the site becomes less transitional and more permanent.

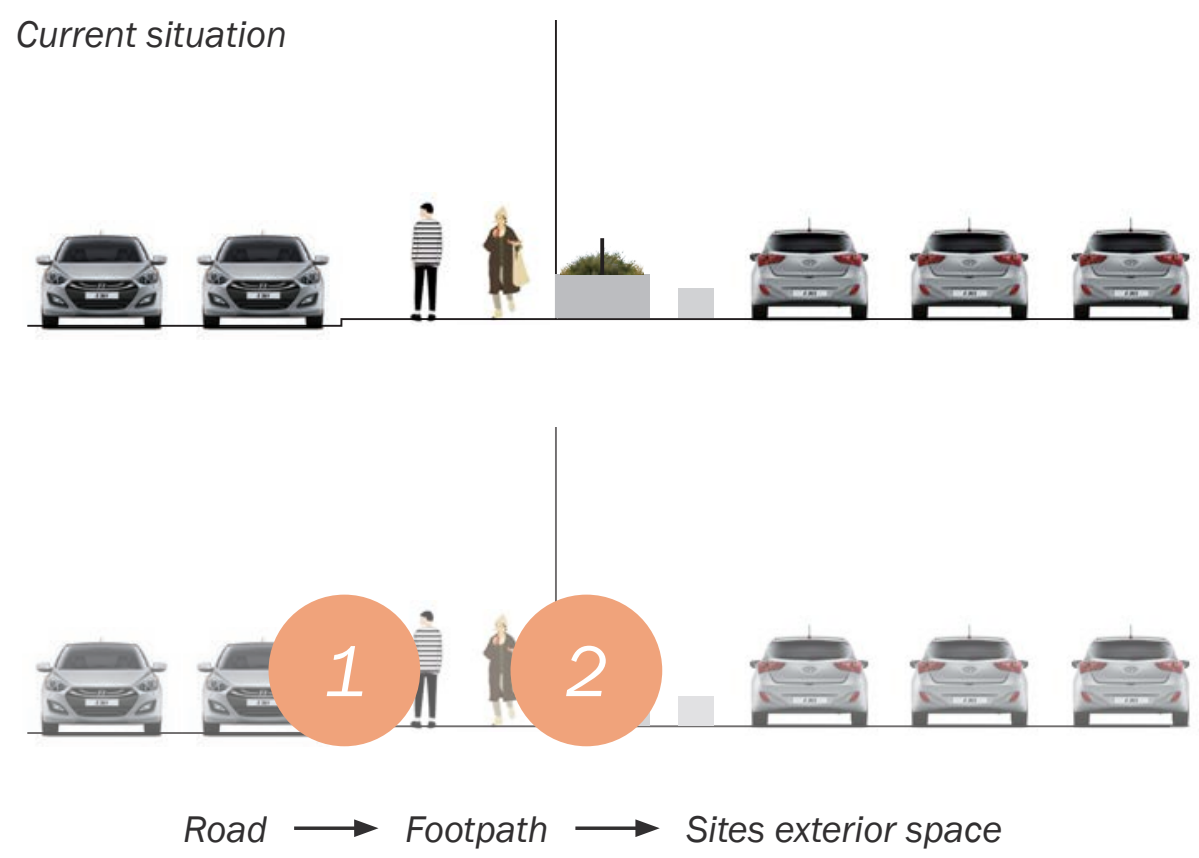




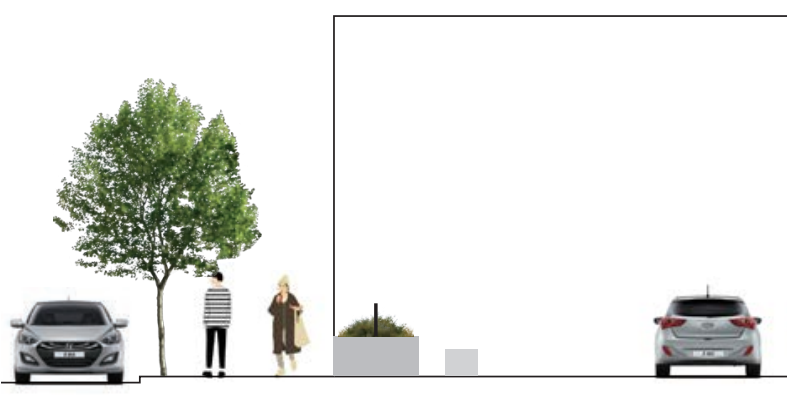

Planting trees along the edge of the road and footpath help to distract the attention of the pedestrian from the road to the church and its exterior space.

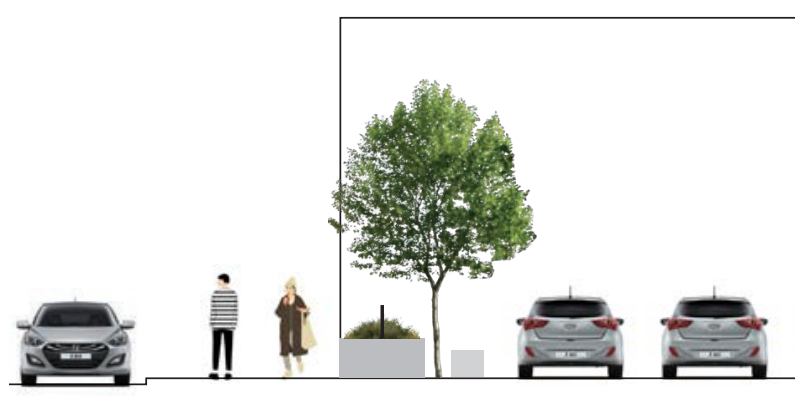

Planting trees behind the current planter box means that the car park is more hidden to the road.

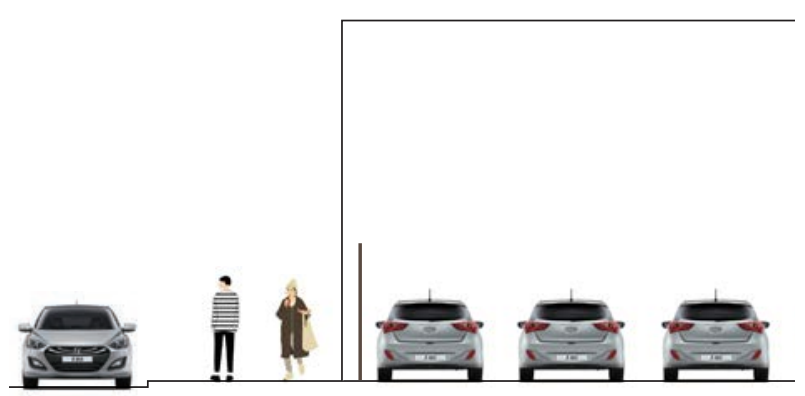

Removing the current planter boxes and constructing a wall hides the car park from the road, however does not create any moments of permanency or rest and obstructs movement through the site.

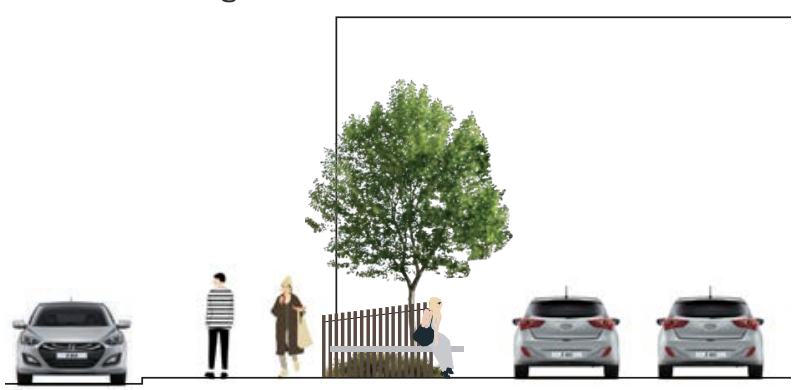

Seating is added to the planting and fenced area to make the space more permanent.

Fig.6.30. (Above) Iterations of the transitions between the footpath and car park

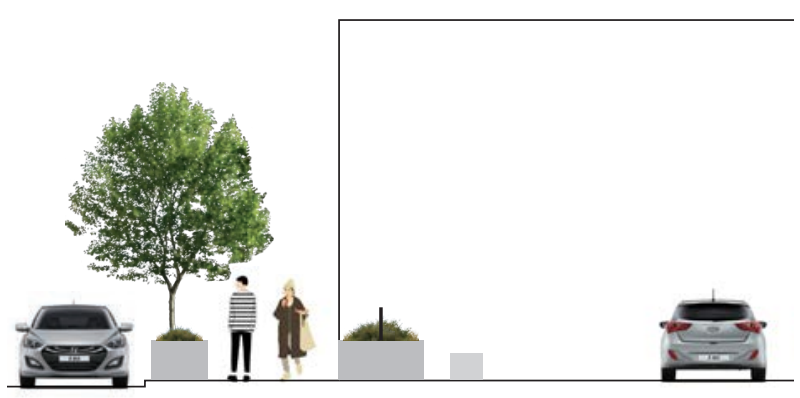

Using planter boxes along the road and footpath creates more of a physical obstruction between the road and the church's exterior space.

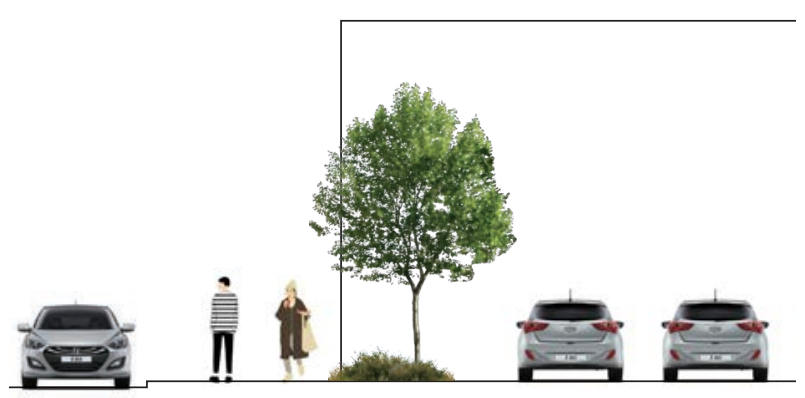

Removing the current planter boxes and replacing them with wildflower planting softens the space. This, however, limits permanency with the removal of seating.

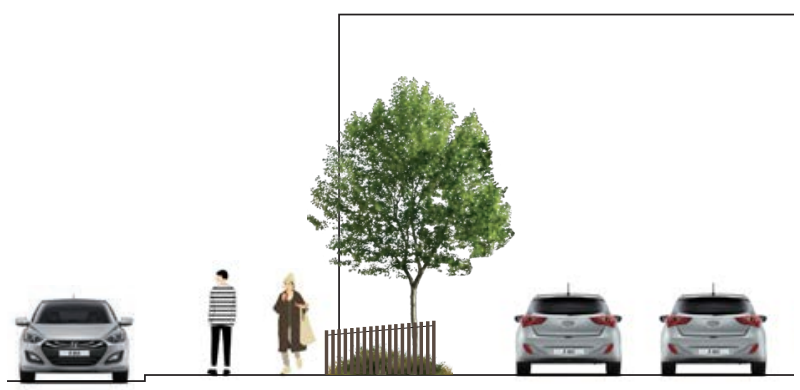

Low fencing helps to identify the two areas. With a lower fence, the site can be removed from the road physically, but not visually.

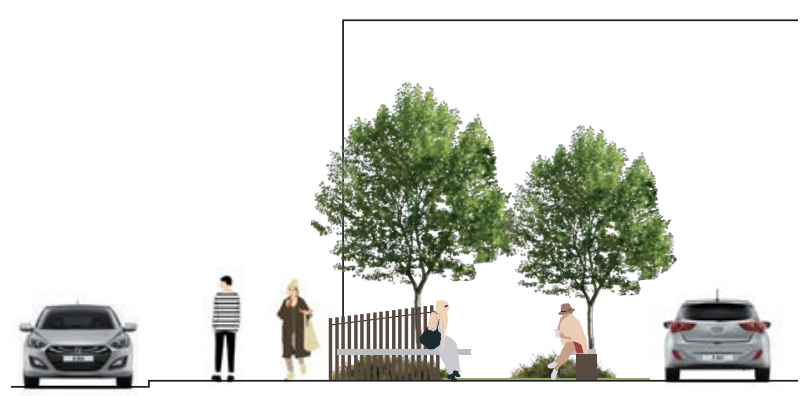

Multiple seats are added to the space to create opportunities for interaction. Lawn is also added to the seated area to make the space more comfortable. 


\section{Transitions between space Close context transition}

Using techniques gathered from the literacy review and precedents, the transitions from each area of the site are made more fluid and manoeuvrable by making the space open and inviting.

Improving the quality of the space with vegetation, seating and paving makes the space more desirable to passers-by. Social and optional activities are more likely to take place with the improvement in the quality of the space.

\section{Front of space design}

Seating and planting along the exterior wall detracts from the wall's dominance. Seating not only caters for passers-by, but members of the church community who may be elderly and need to sit down while they wait to be collected. Planting along the edge of the footpath and road distracts and blocks users of the space from the heavy traffic flow of State Highway One.

\section{Paving and openness}

Paving helps to increase the quality of the space. Currently, the broken asphalt is untidy and plain. Paving adds more interest to the site and helps to draw people towards the main entrance.

By removing the current plant boxes, the exterior space becomes more accessible.

Basketball

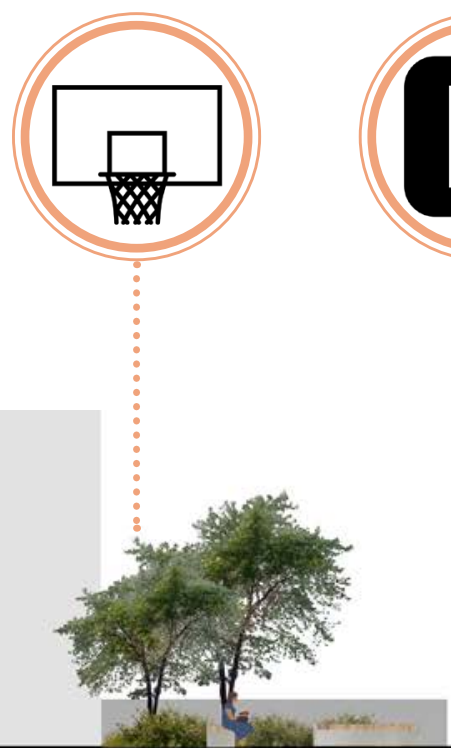

Parking

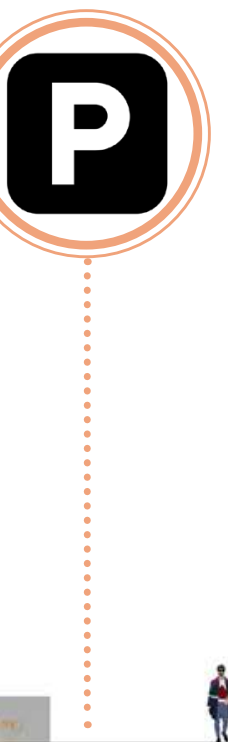

Thoroughfare
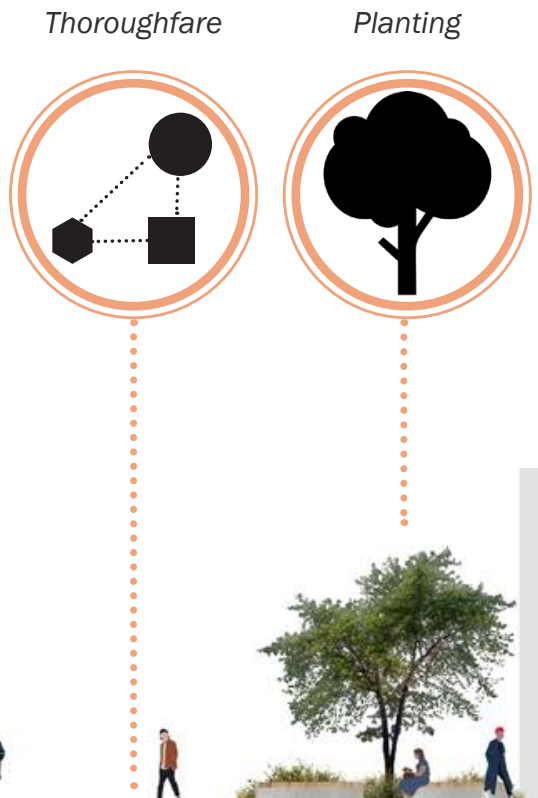

Seating

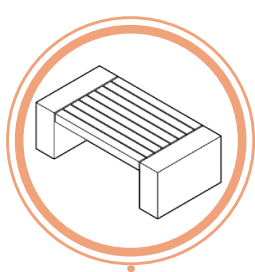




\section{Front of space design}

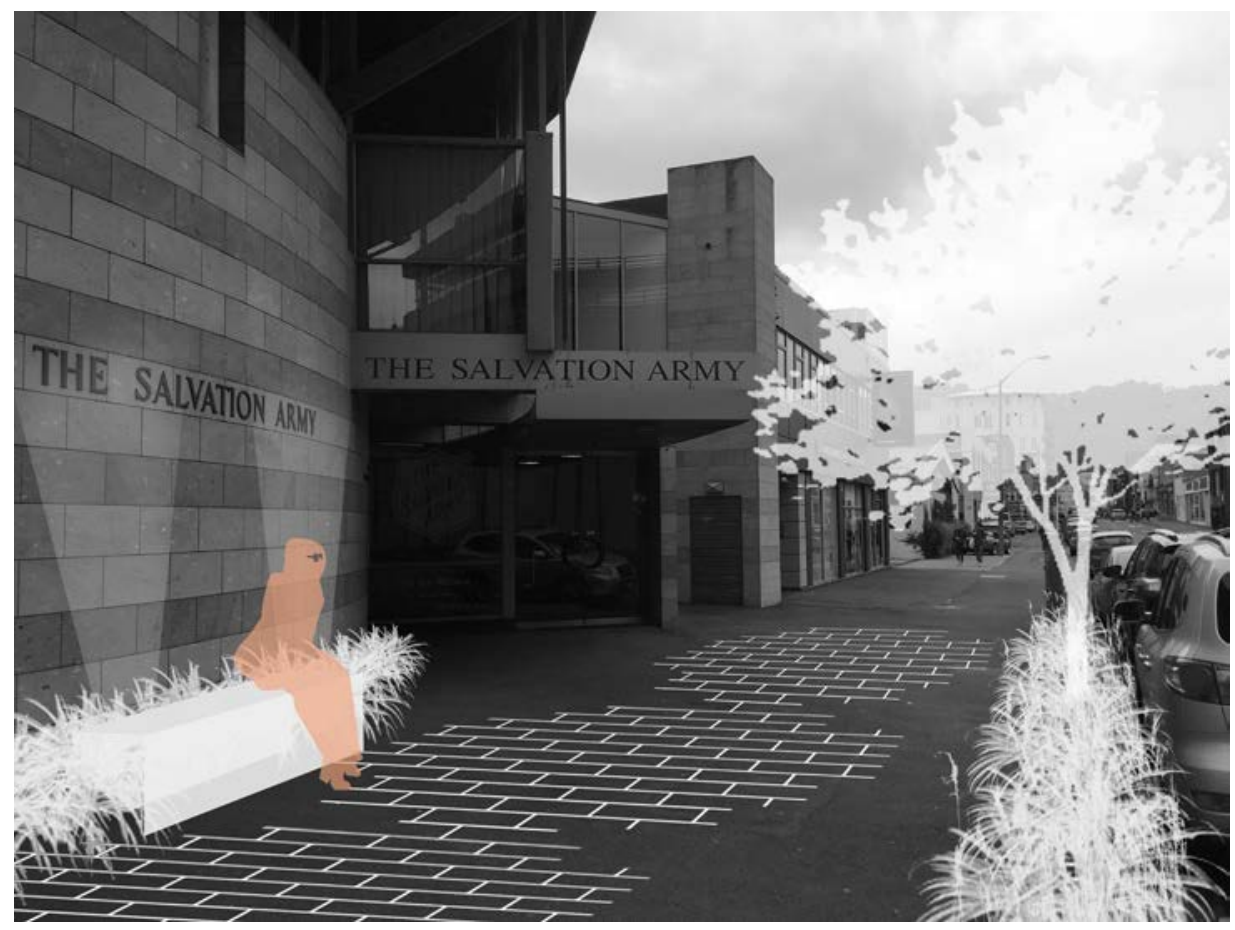

\section{Paving and openness}

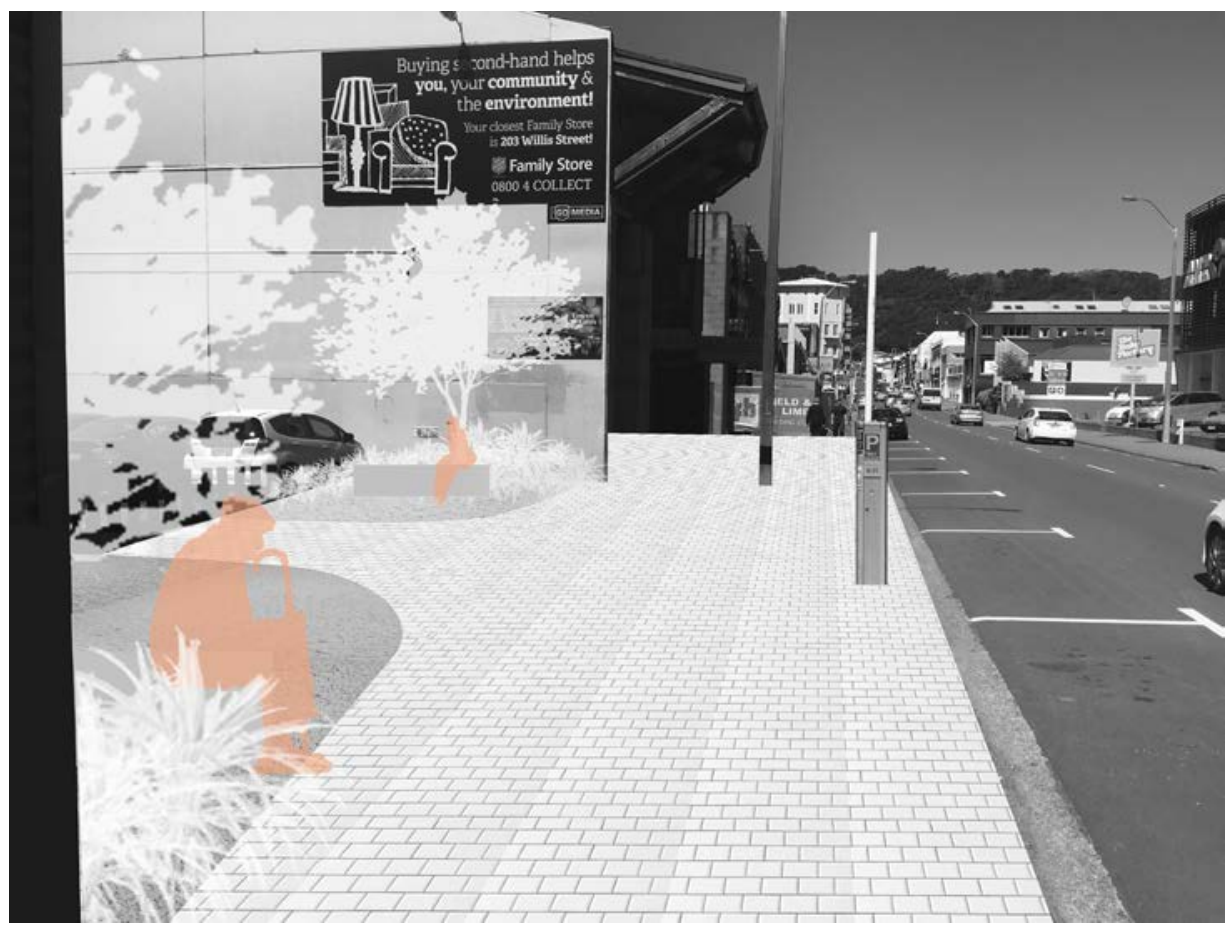




\section{Inviting public space Quality of space \& flexibility}

Vegetation is used to add more colour and texture to the space, making the car park more engaging and less functionality based. Planting along the wall creates more colour and vibrancy in the site. It adds a softer texture, contrasting to the brick of the neighbouring building and asphalt of the car park.

Vegetation and rain gardens

Planting coming out from the edges of the site into the car park space is not necessary. Colour and texture can still be added to the site when planting runs along the edges. For this reason, vegetation would be more appropriately used along the edges of the space. By doing this, the space still benefits from the colour and texture that vegetation provides, without taking up valuable space in the car park area.

Moveable urban furniture

Despite taking up only one to two parking spaces for each seat, given the size of the car park, too many car parks would have to be removed for the seating to be worthwhile. To create a substantial space, there would need to be at least five seat/planters, which would mean removing up to ten spaces.

This investigation into moveable furniture was an important step for design, as it is currently a popular design choice in the industry. Though it may not be utilised in this site, movable furniture could be used elsewhere in the design process.

Seating

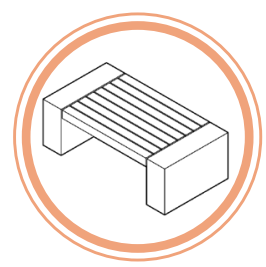

Planting

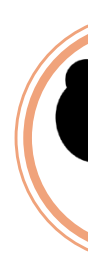

Basketball

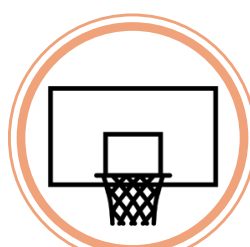

Parking

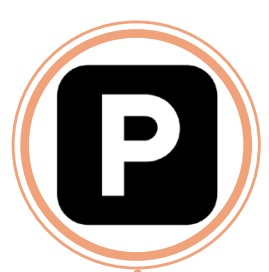


Vegetation and rain gardens

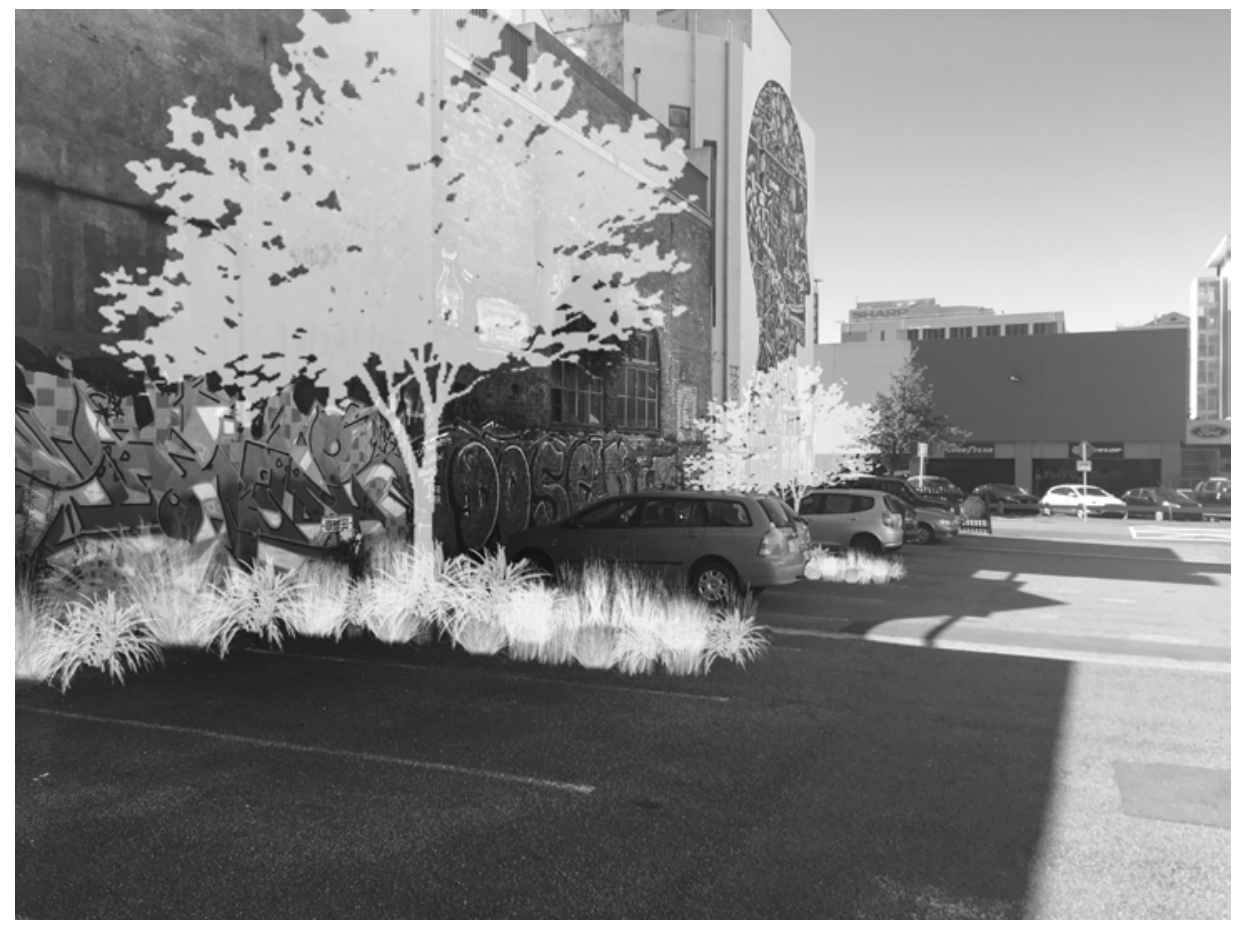

Moveable urban furniture

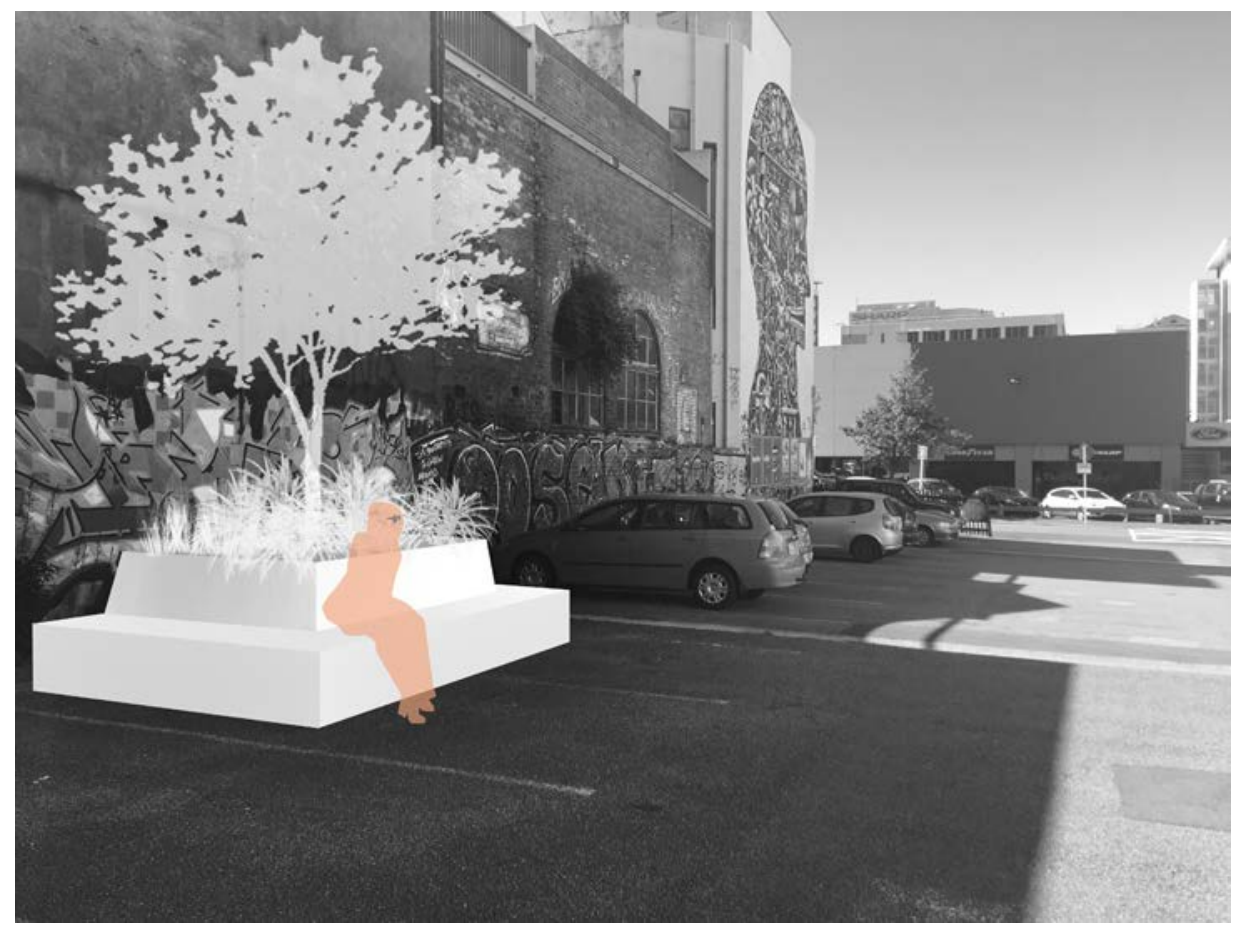

Fig.6.34. (Left) Section showing proposed design in the car park space 


\section{Inviting public space Quality of space}

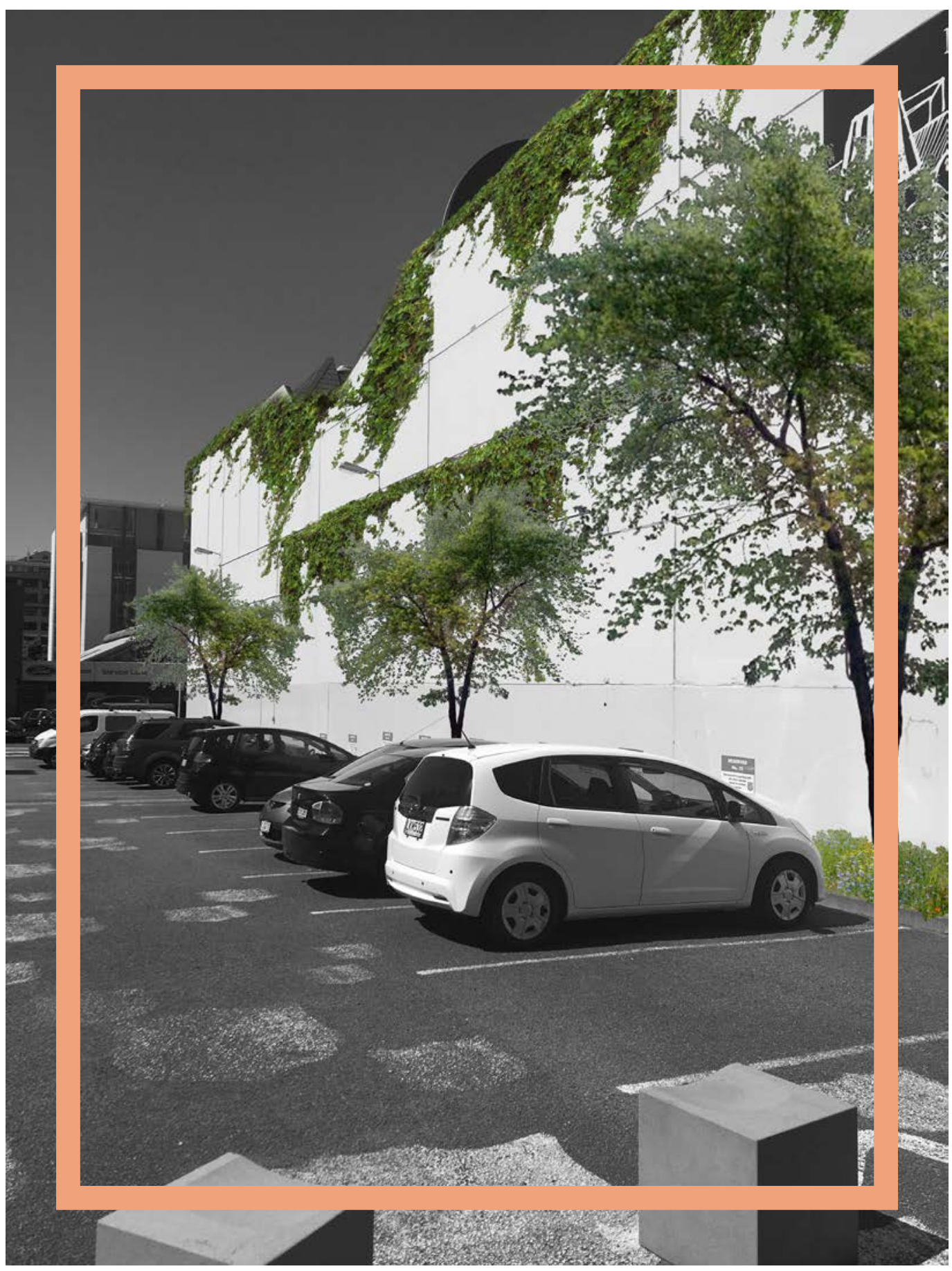




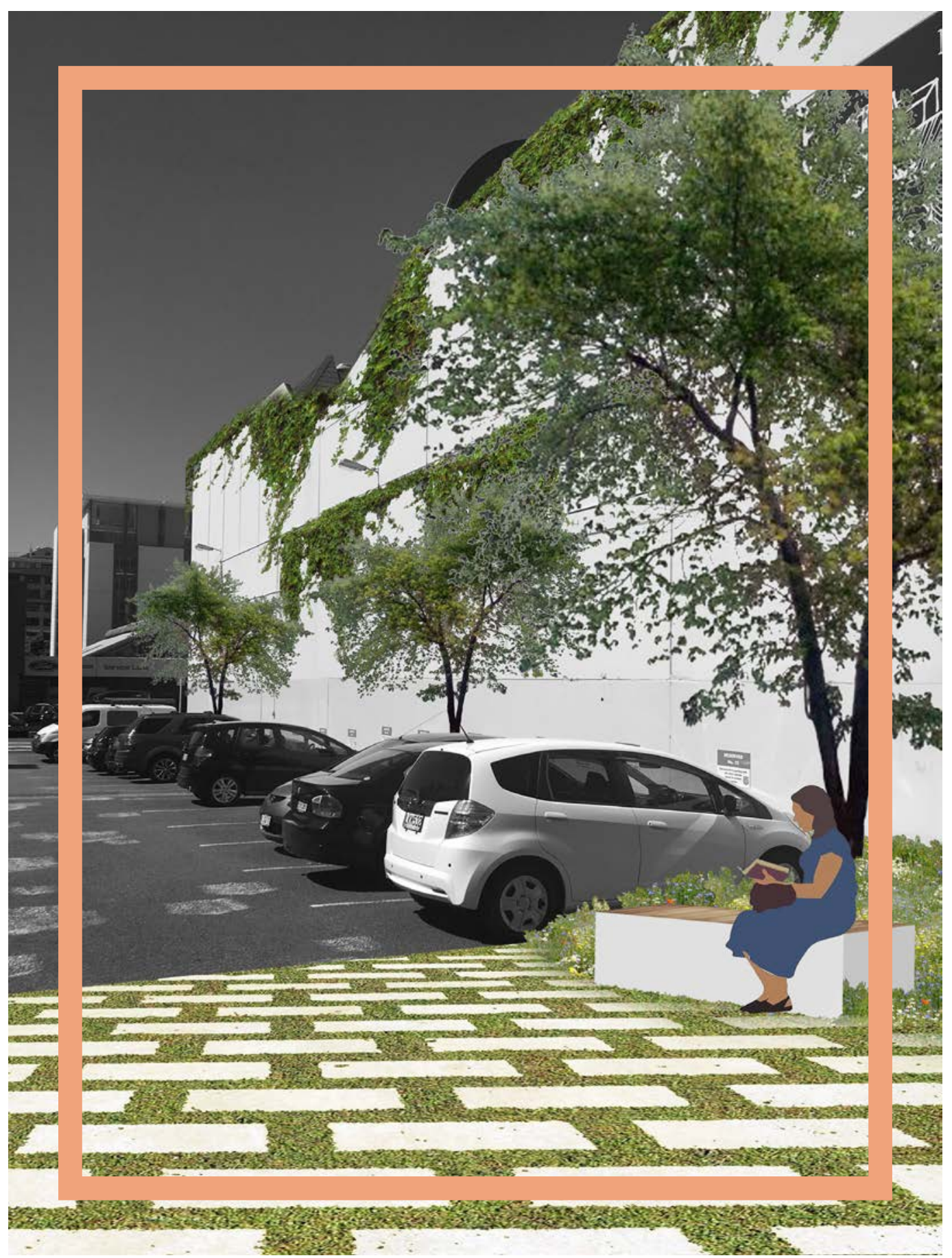



Final plans - flexibility

1 Weekday plan

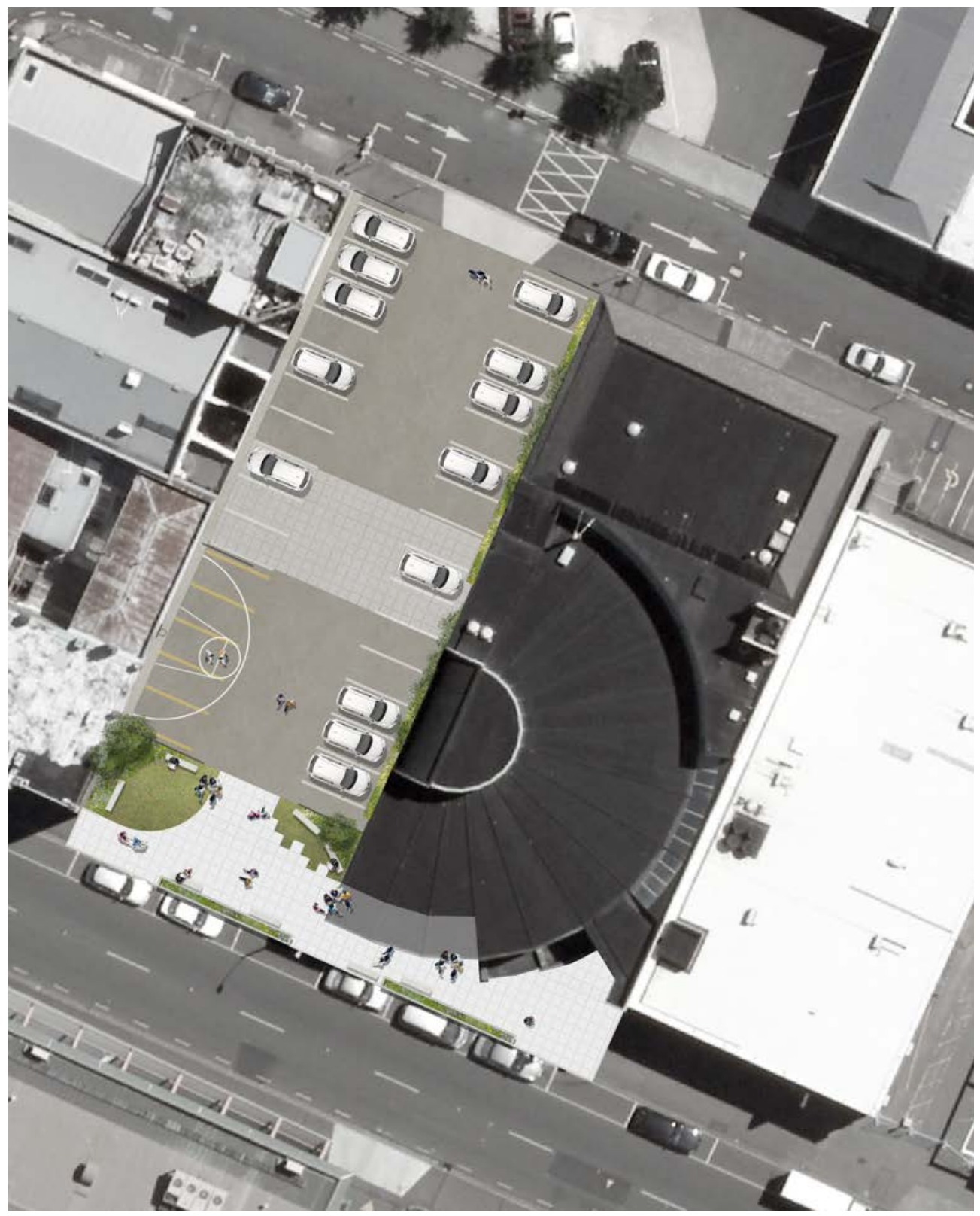

A $1: 500$
2 Sunday morning plan

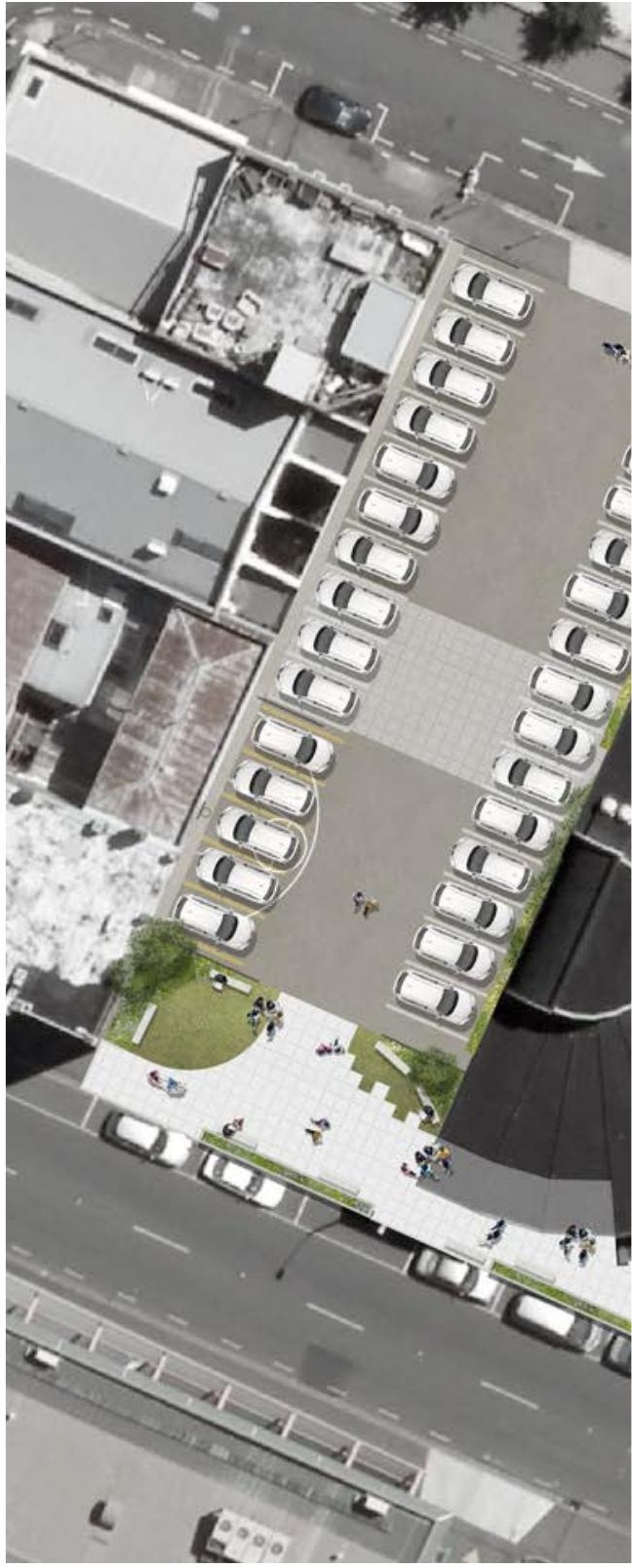

N $1: 500$ 

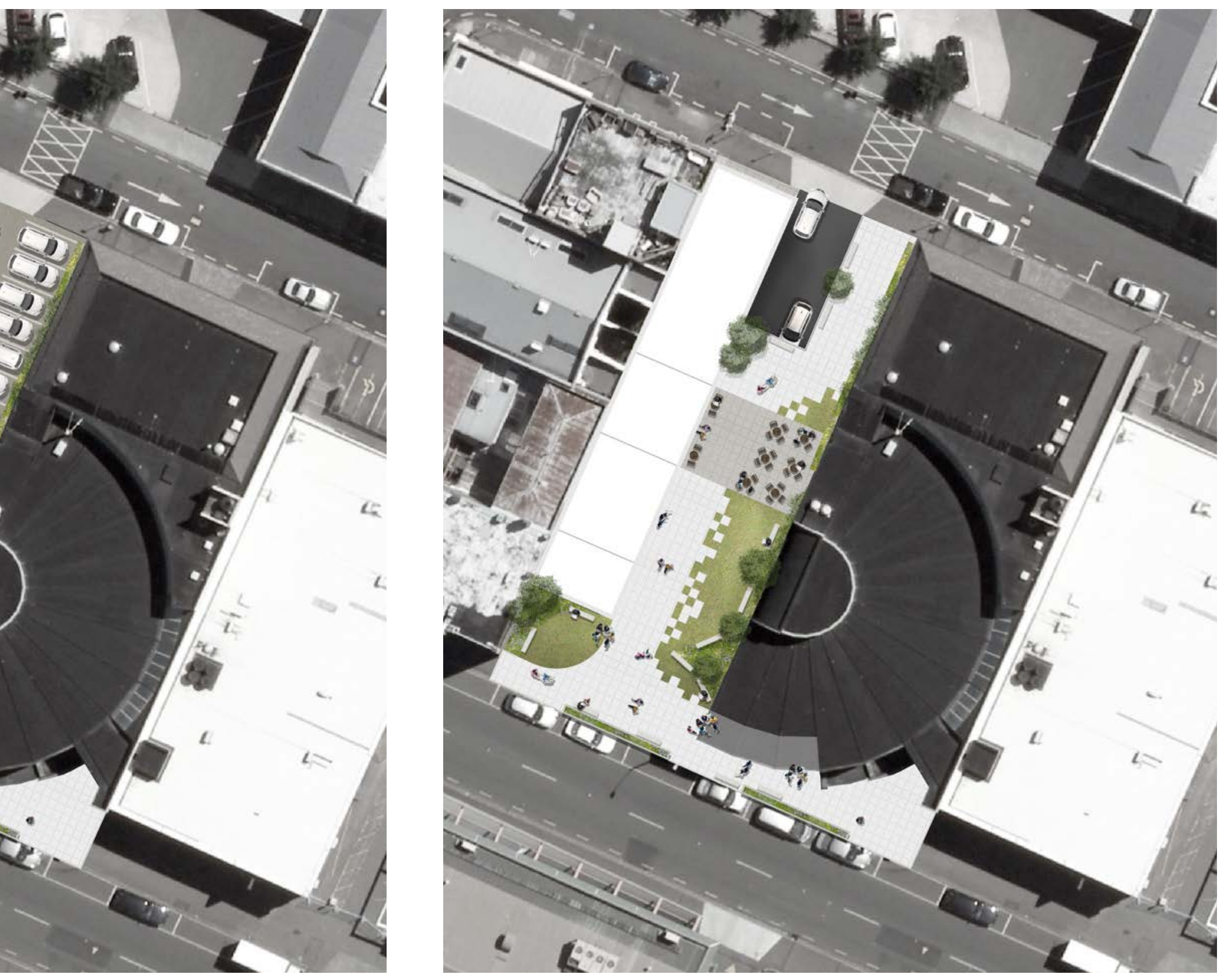

A $1: 500$ 



\section{Wellington Methodist Parish}

Design iterations and development

The following area was chosen as the focus for design. This focus enabled the research to explore better transitions in the close context. The site had a strong wider context transition with the area providing a popular thoroughfare for a number of people.

Two close context transitions were improved. These transitions were between the street and church entrance and between the church entrance and the car park.

Making the space flexible for the change between the weekend and weekday setting was also able to be explored in this area. This meant looking at creating elements of play in the space, whilst also providing parking options on a Sunday.

Designing in this area could improve the quality of space as a whole. By improving the overall quality of the space through each design move, the space will become more inviting.

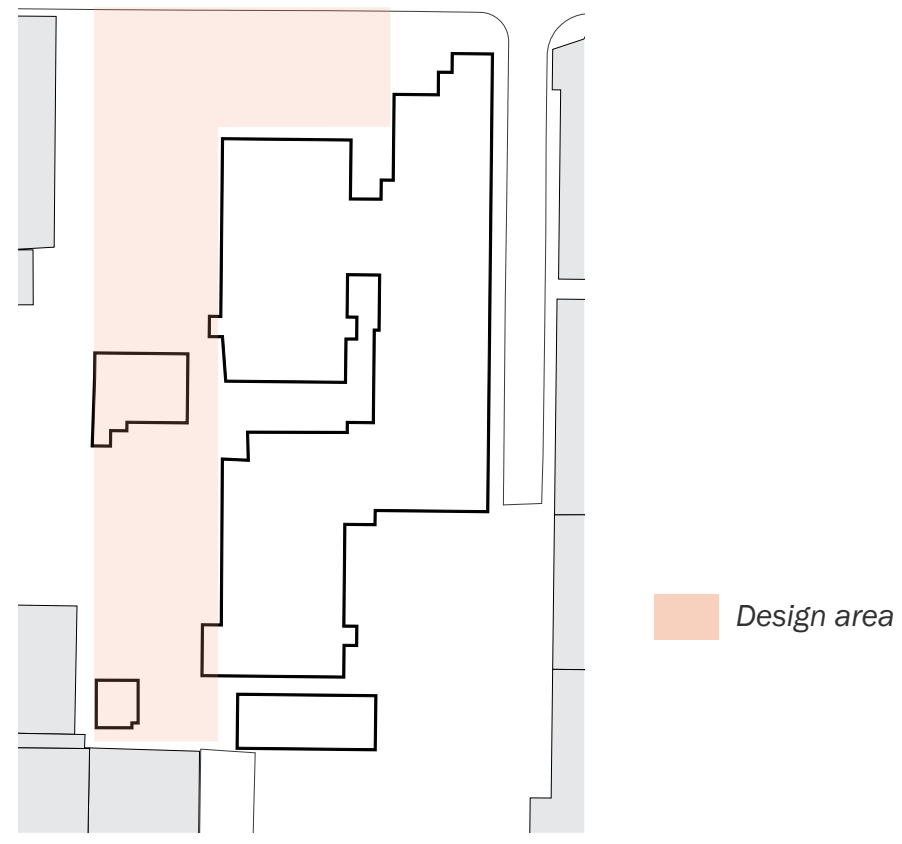




\section{Designing in the specified area}

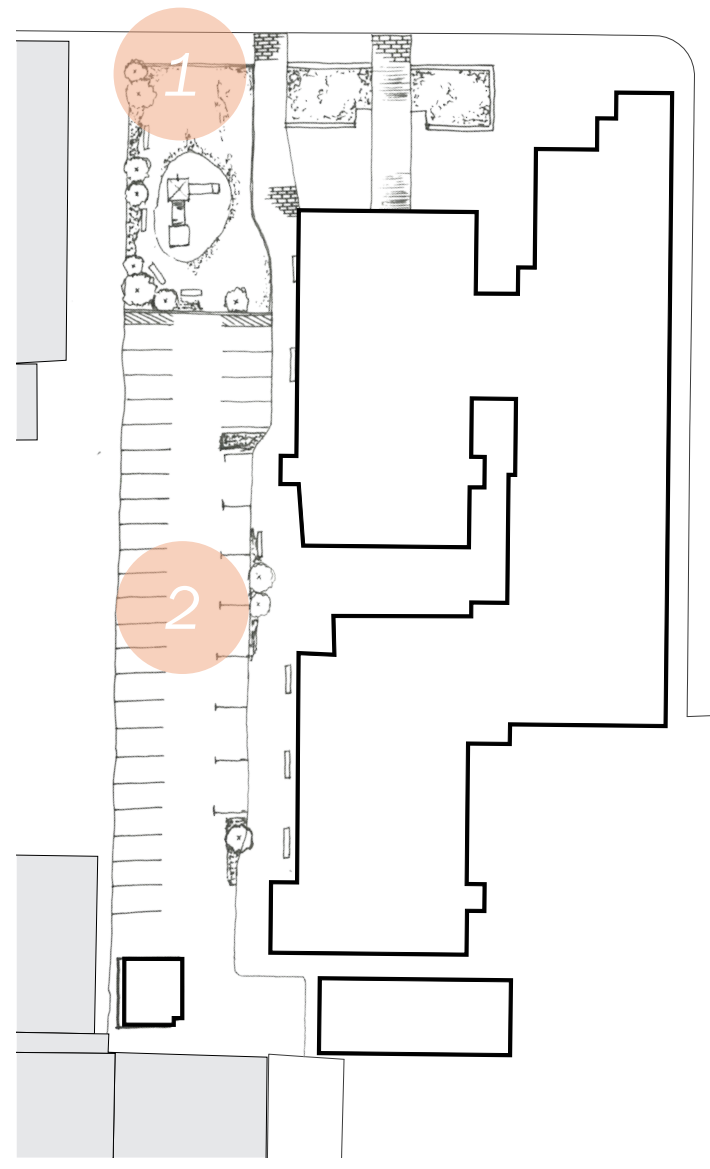

$1: 1000$

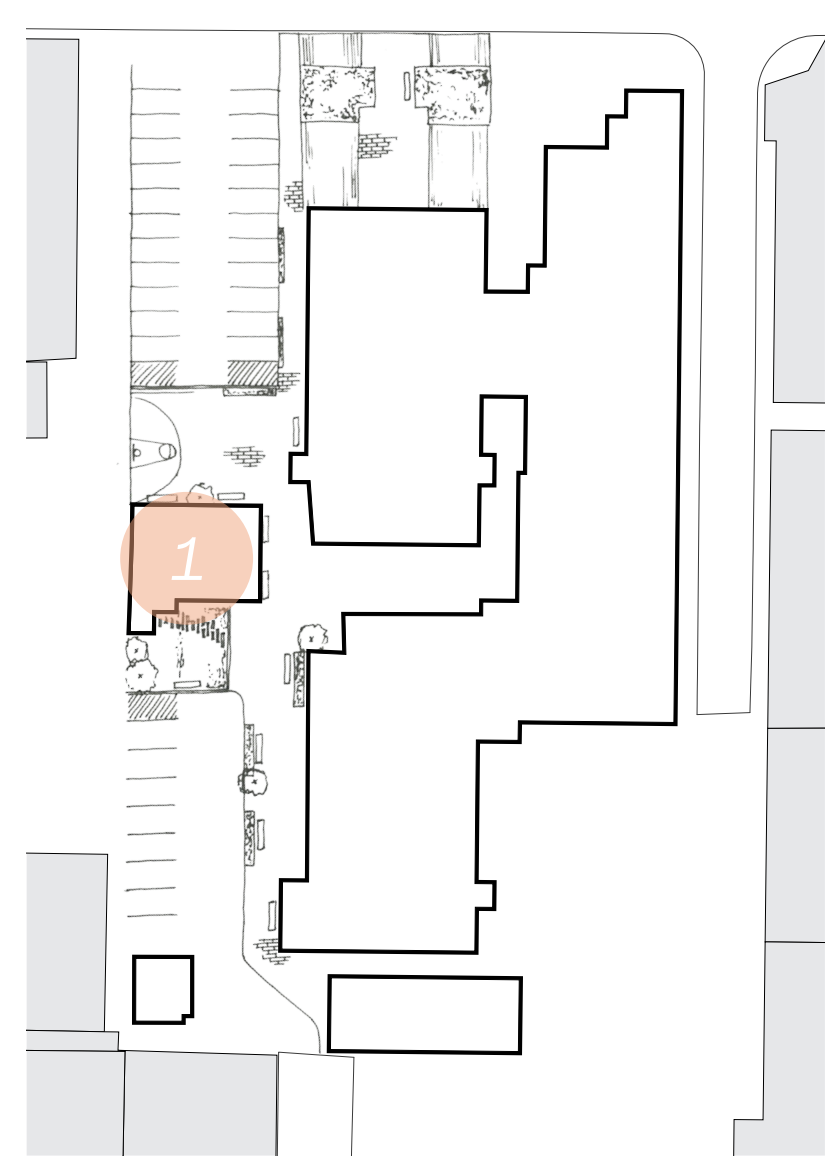

$1: 1000$

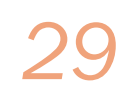

Available car parks

1 A playground and basketball space create areas that the young people of the church can play in, as well as the public. This public interaction was one of the desires of the community that came out of the community engagement.

Having both activities in this area allows quick access to and from the social halls. 


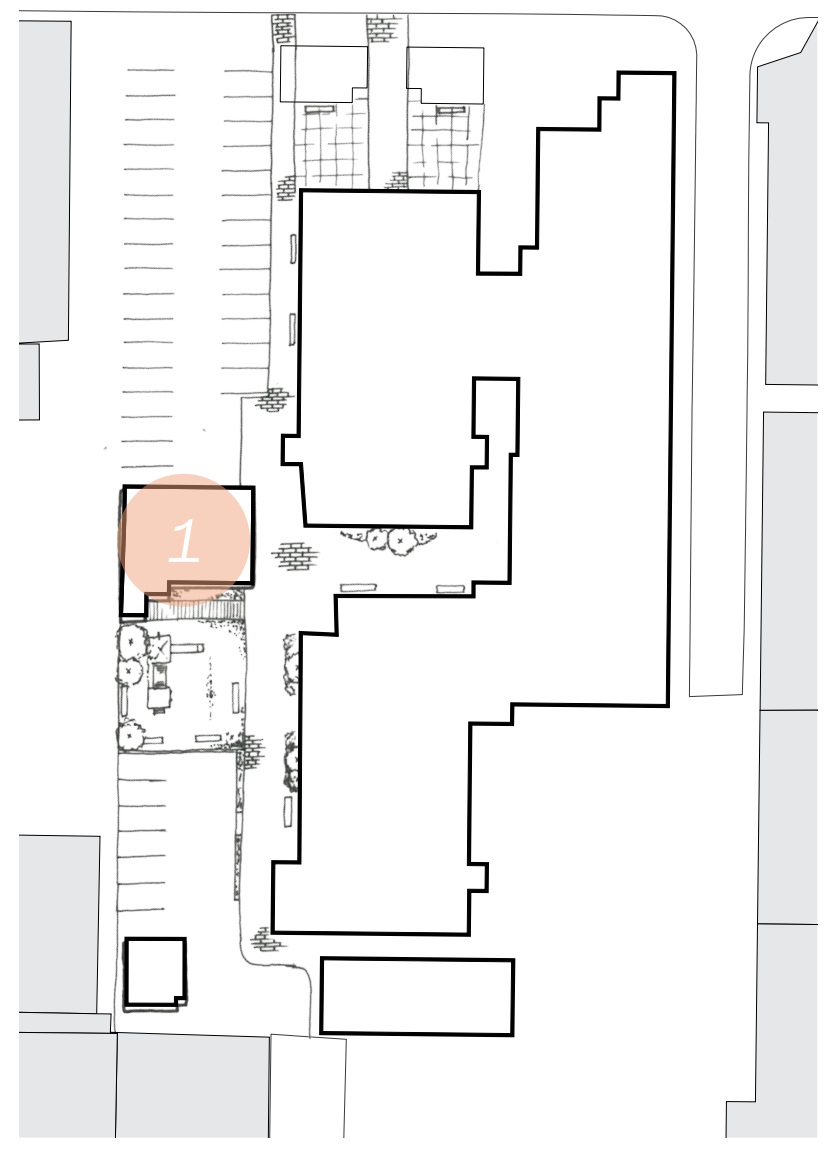

ه 1:1000

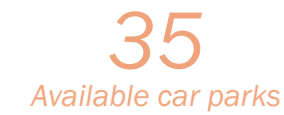

1 A playground is added to the space behind the drama studio and is linked with the social hall spaces. This location allows for the general public using the site as a thoroughfare and the church community to mix.

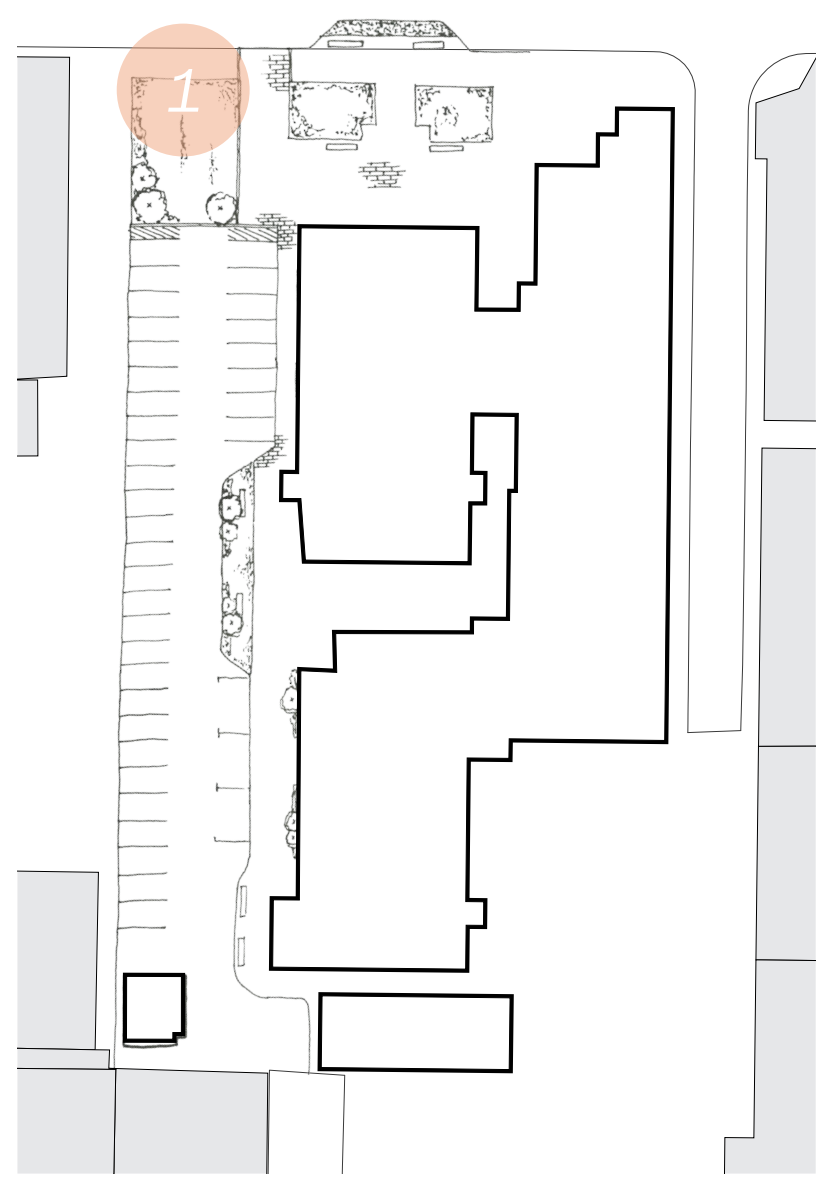

$1: 1000$

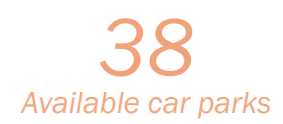

1 This option blocks the car park from Taranaki Street, instead proposing access from the other end. This allows space to be created nearer the front of the church. By doing this, there would be more activity in front of the church and the two communities can easily interact - there is no playground in this option, however. 


\section{Transitions between space Close context transition}

The following iterations explored the transition zone from the street to the church. The main feature investigated was working around the two large pohutukawa trees that dominate the space. The trees are surrounded by two planter boxes that restrict the potential for design. With the trees designated as heritage trees, altering or moving them is difficult.

These iterations explore how the trees and planter boxes can be designed around.

This has been examined in three different ways.

1 The first: looking at how elements of play can be introduced to engage the trees with the space in a more experiential way;

The second: looking at how changing the levels of the ground can minimise the effect that the trees have on the space.

The third: looking at how constructing shelter could further encourage people to use the space and mitigate against the effect that the nesting birds in the trees above have on the space. 

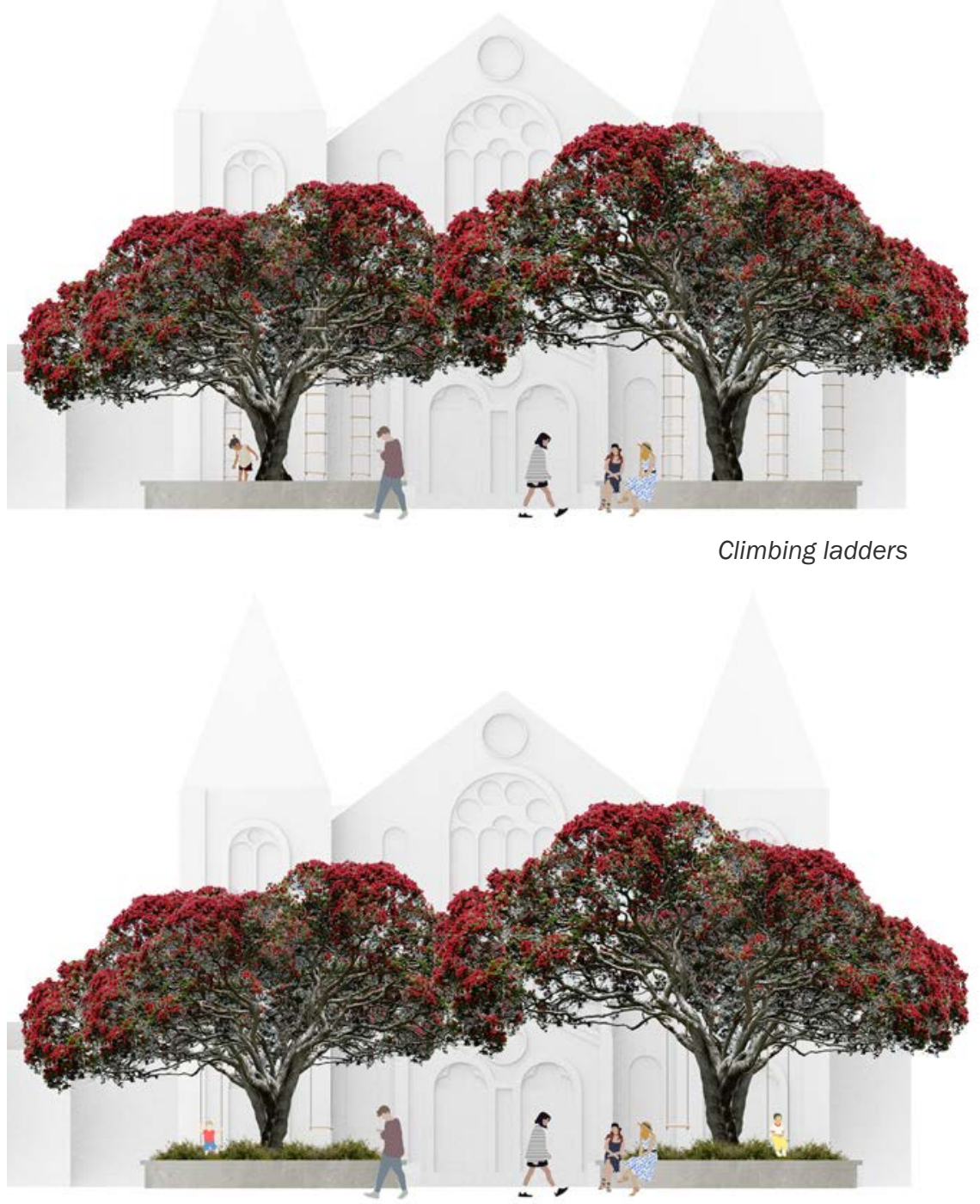

Swings coming off tree branches

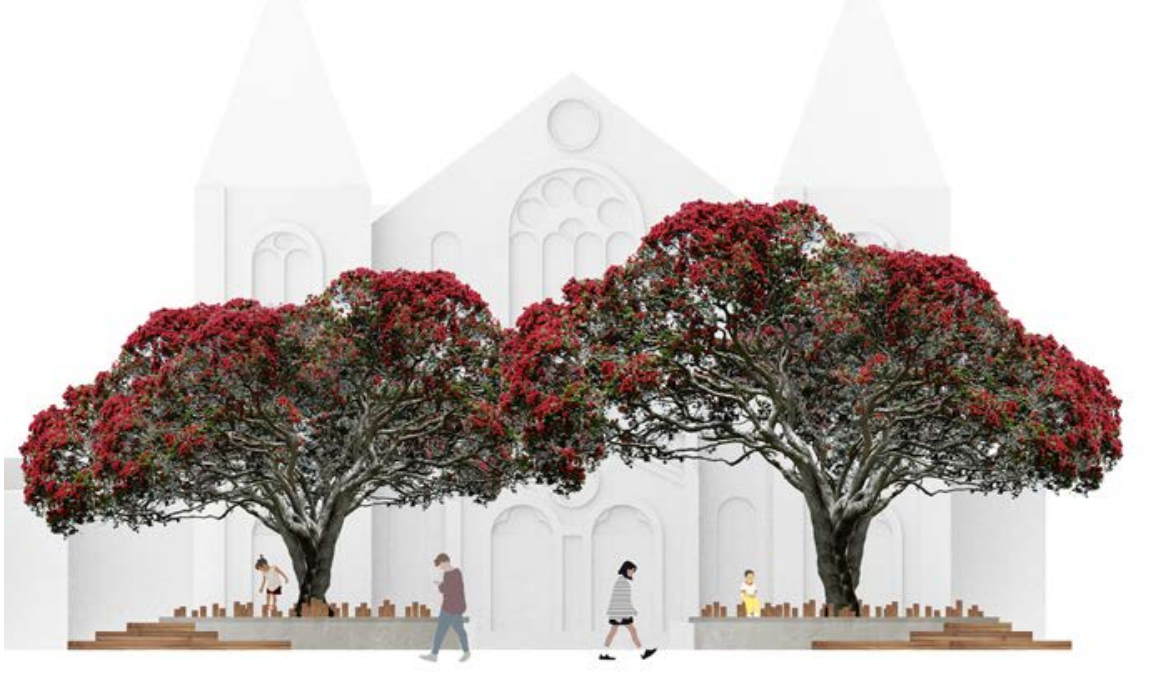

Wooden stepping logs
Play - Activating plant boxes by engaging children

\section{Conclusions}

These iterations pose problems with safety. While encouraging play may help to activate the space, having children playing so close to the road could be problematic in terms of both pedestrian movement and safety.

Fig.6.49. (Above) Iterations exploring elements of play in the transition between the footpath and church 


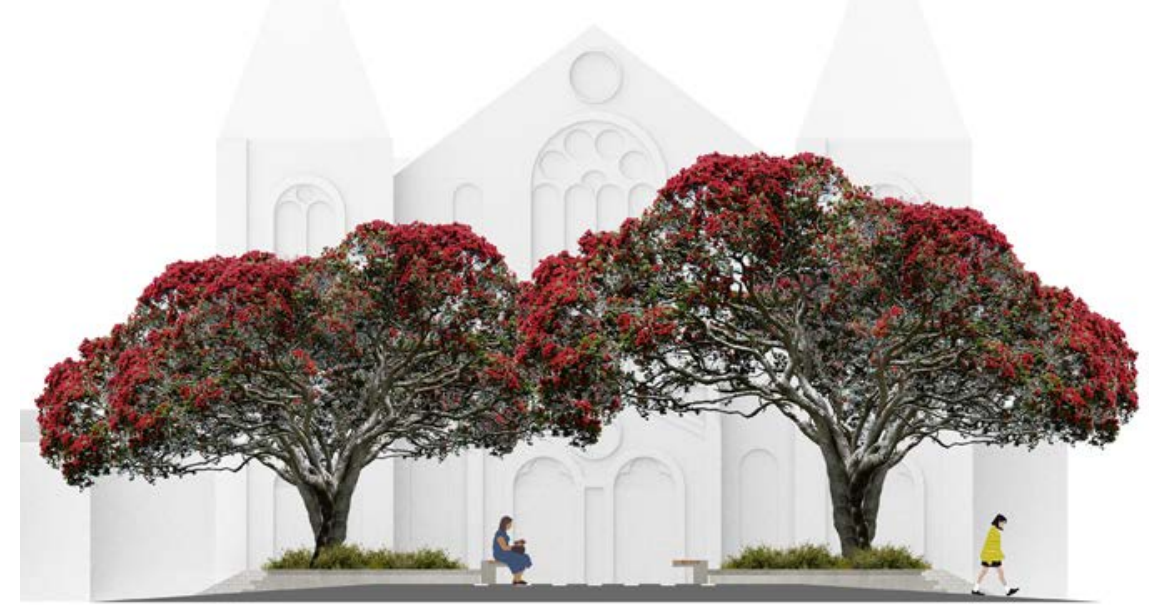

3 degree slope

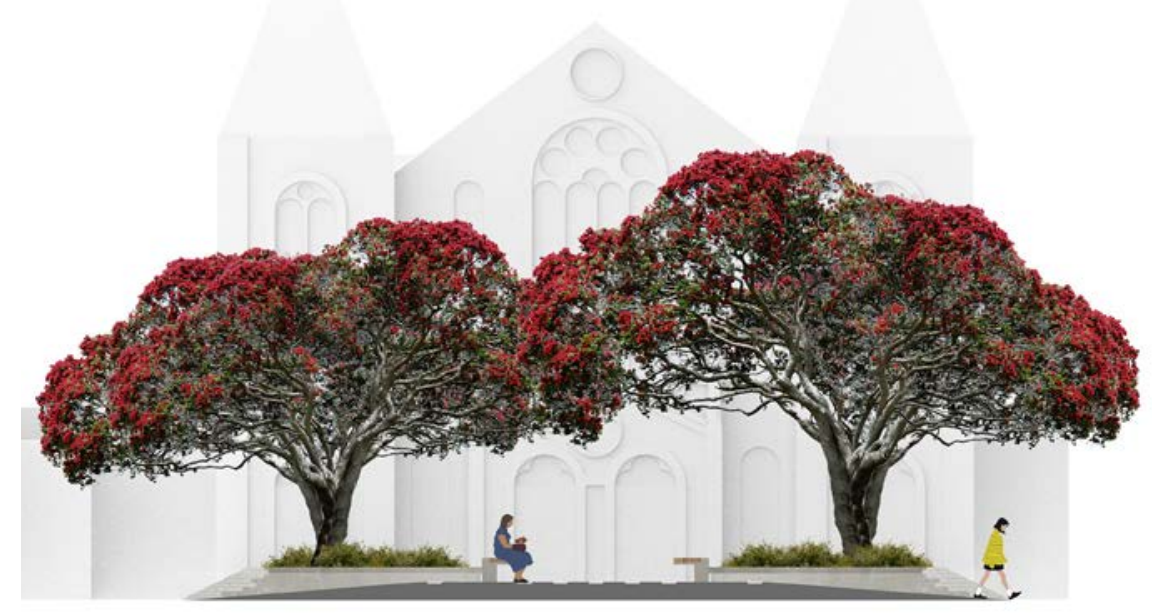

5 degree slope

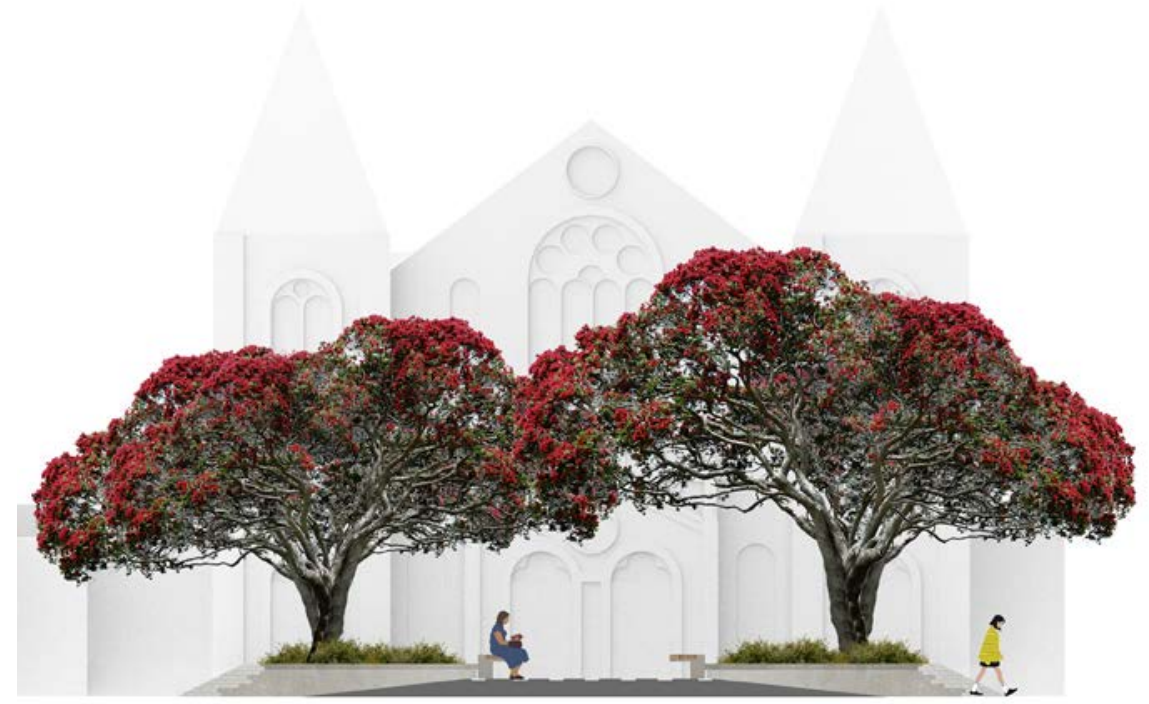

Slope and levels - Making the impact of the planter boxes less obstructive by raising the height of the footpath

\section{Conclusions}

By altering the height of the ground between the two planter boxes and church, there is less obstruction to the site. The maximum slope that these ramps can be is twenty degrees. The ideal situation would be ramps that are as shallow as possible, making it comfortable and usable for all people. 


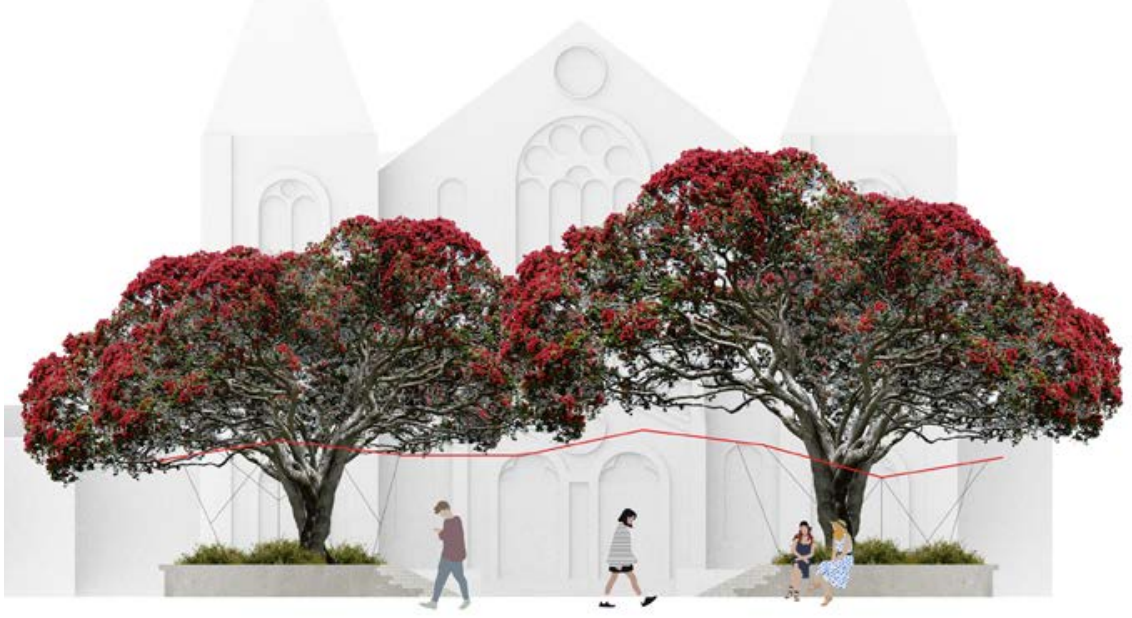

Metal minimalist shelter structure

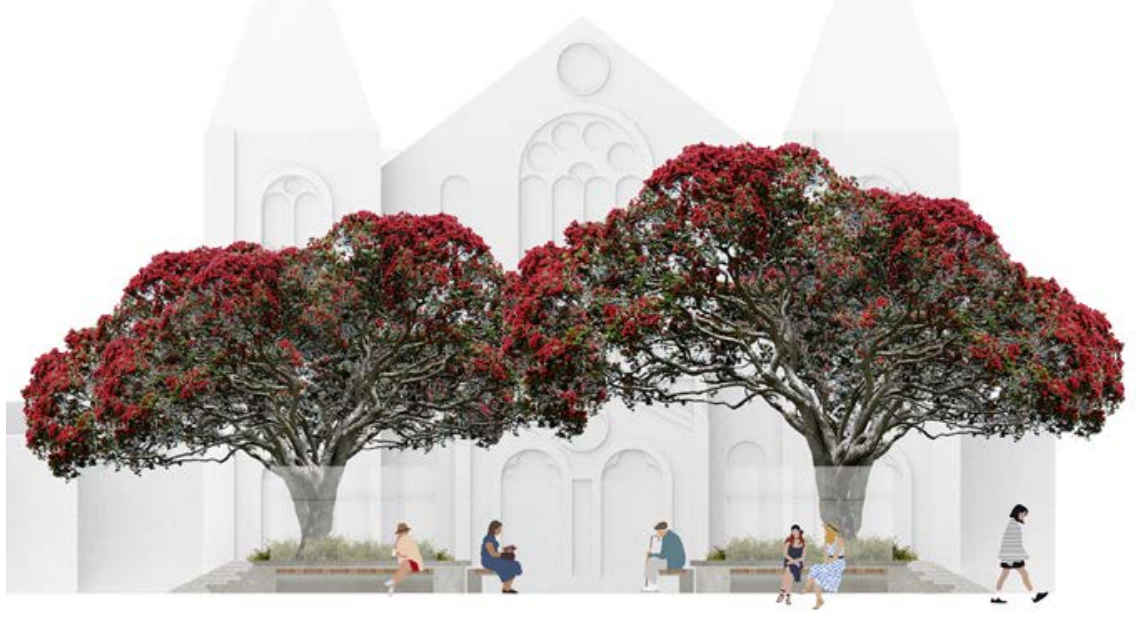

Glass shelter above seated area

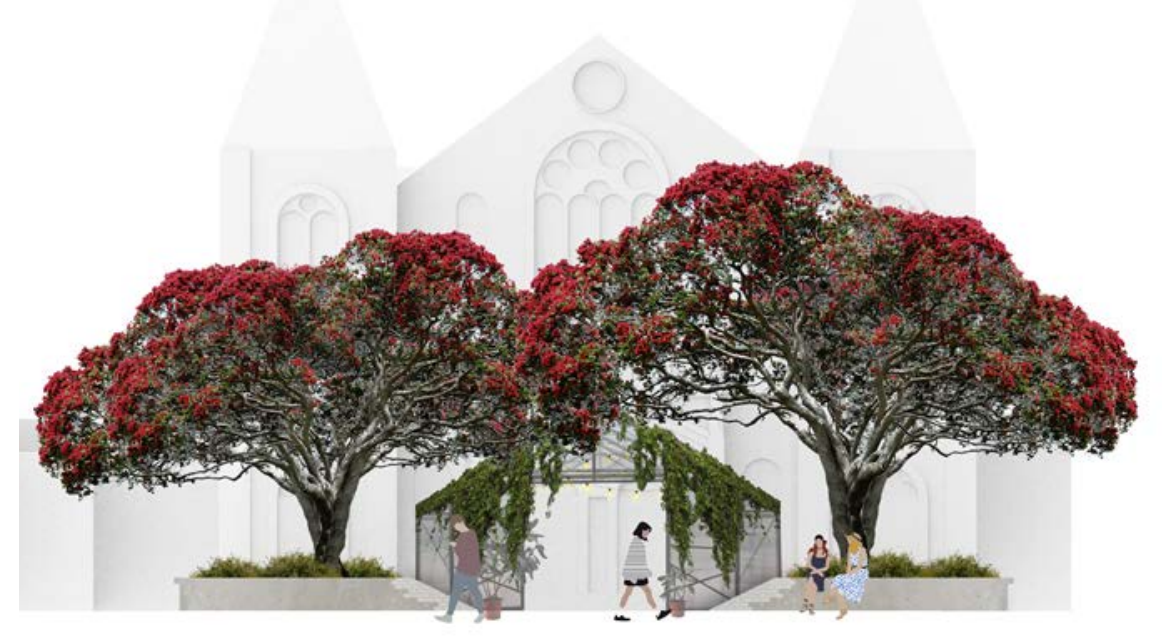

Glass house
Shelter - Working around the nesting birds by creating shelter under trees

\section{Conclusions}

To mitigate against the nesting birds in the trees above, forms of shelter were explored. However, the implication of this was that by adding shelter structures to the area, the space became more cluttered and closed off to the street both physically and visually. This only added to the obstruction already caused by the two pohutukawa trees already present.

Fig.6.51. (Above) Iterations exploring shelter in the transition between the footpath and church 


\section{Transitions between space Close context transition}

To engage with a larger proportion of the local population, the space between the cafe and church could become a shared space, allowing the cafe to spill out into the external space of the church. This would create a vibrant atmosphere that would draw more people into the space.

Because the shared space is outside the entrance to the church administration office, further investigation into how that space may work was needed. This would help to identify how the two territories may work together.

A brief investigation was undertaken on Plum Café on Cuba Street. This example shows how a popular thoroughfare can pass through a space used by a cafe.

The thoroughfare in this example is far busier than the thoroughfare that will be created at the church site.
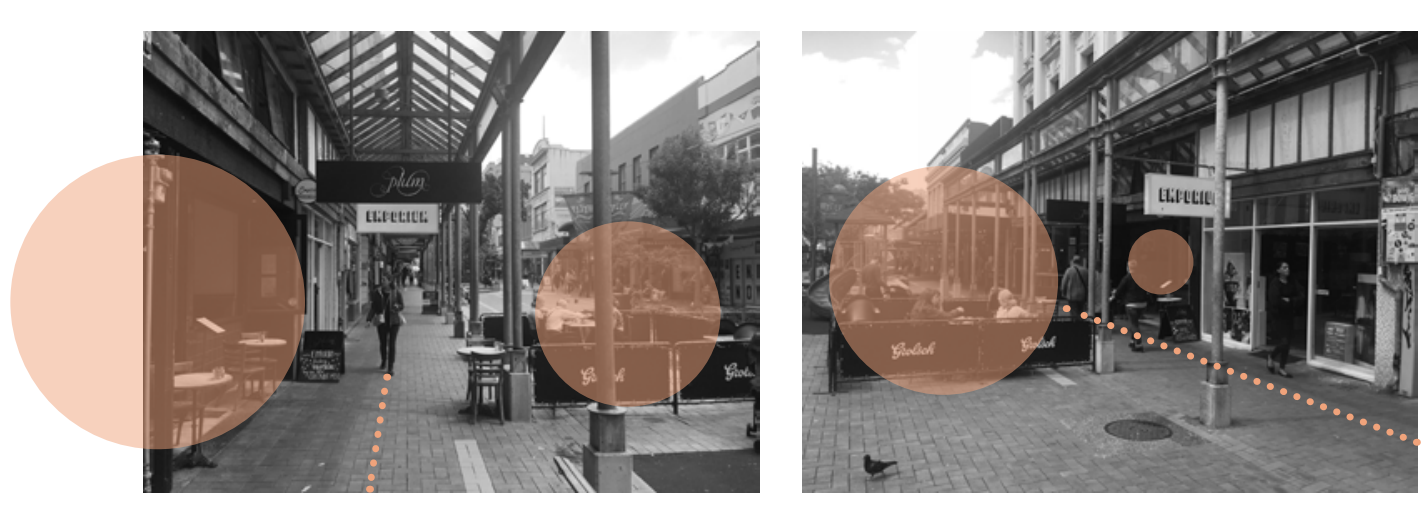

Plum cafe and Cuba Street example 

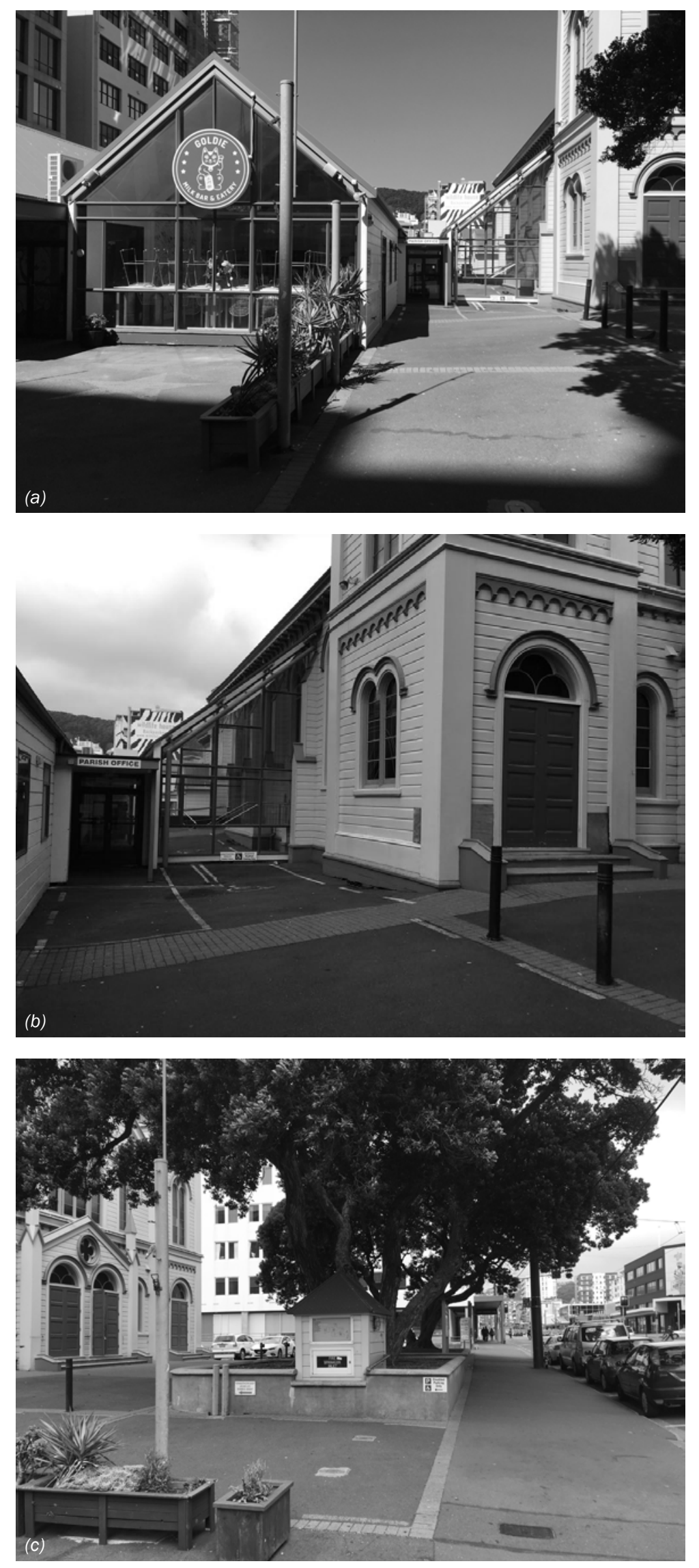


\section{Transitions between space Close context transition}

Screen shelter, planting and seating

Implementing a shelter design protects against nesting birds and allows people to use the space more; however, the structure would have the negative effect of blocking vision to the church just as the trees currently do.

\section{Elevated ramp}

By elevating the footpath to a point just below the top of the tree planter, the effect that these planters have on people's movement is less prominent. The pace of pedestrians in this area would also naturally slow as they go up the ramp. This enhances the opportunity for interest in the space and could entice people into the front space of the church as they become more aware of their surroundings.

Using directive-paving techniques in this front area has the potential to draw people into the space. The pace of pedestrians would again slow and it would add more interest to the space.

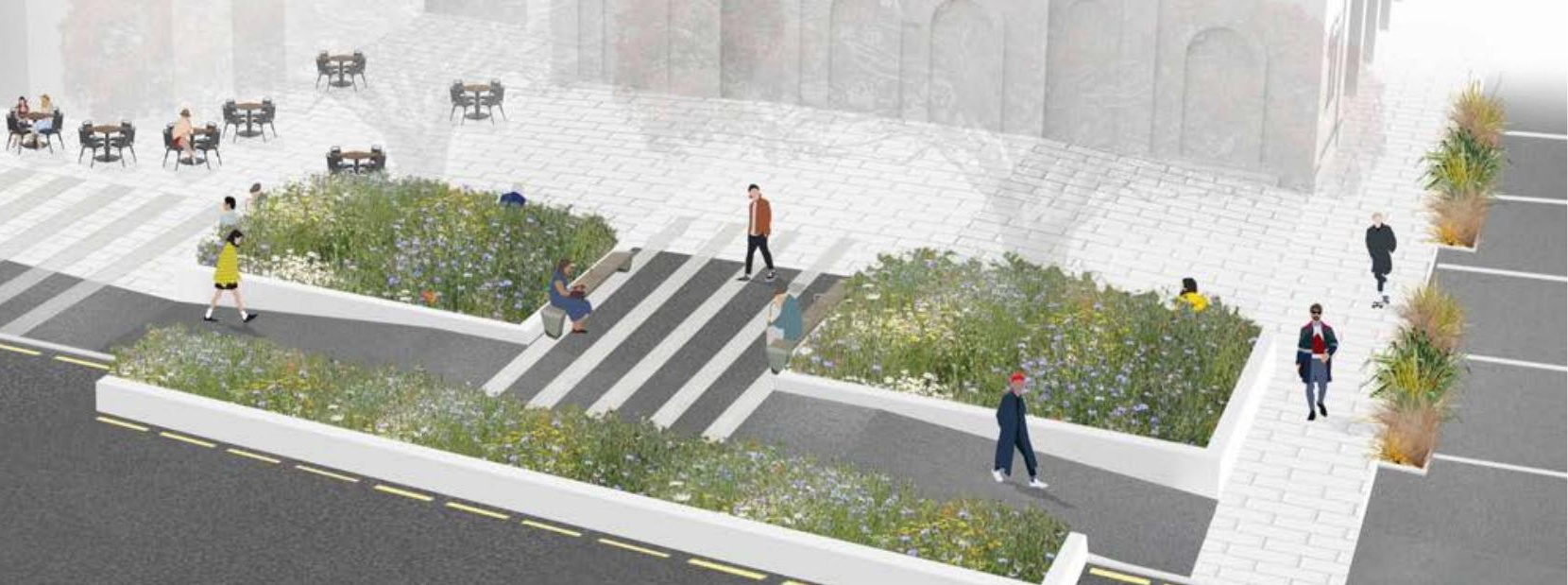


Screen shelter, planting and seating

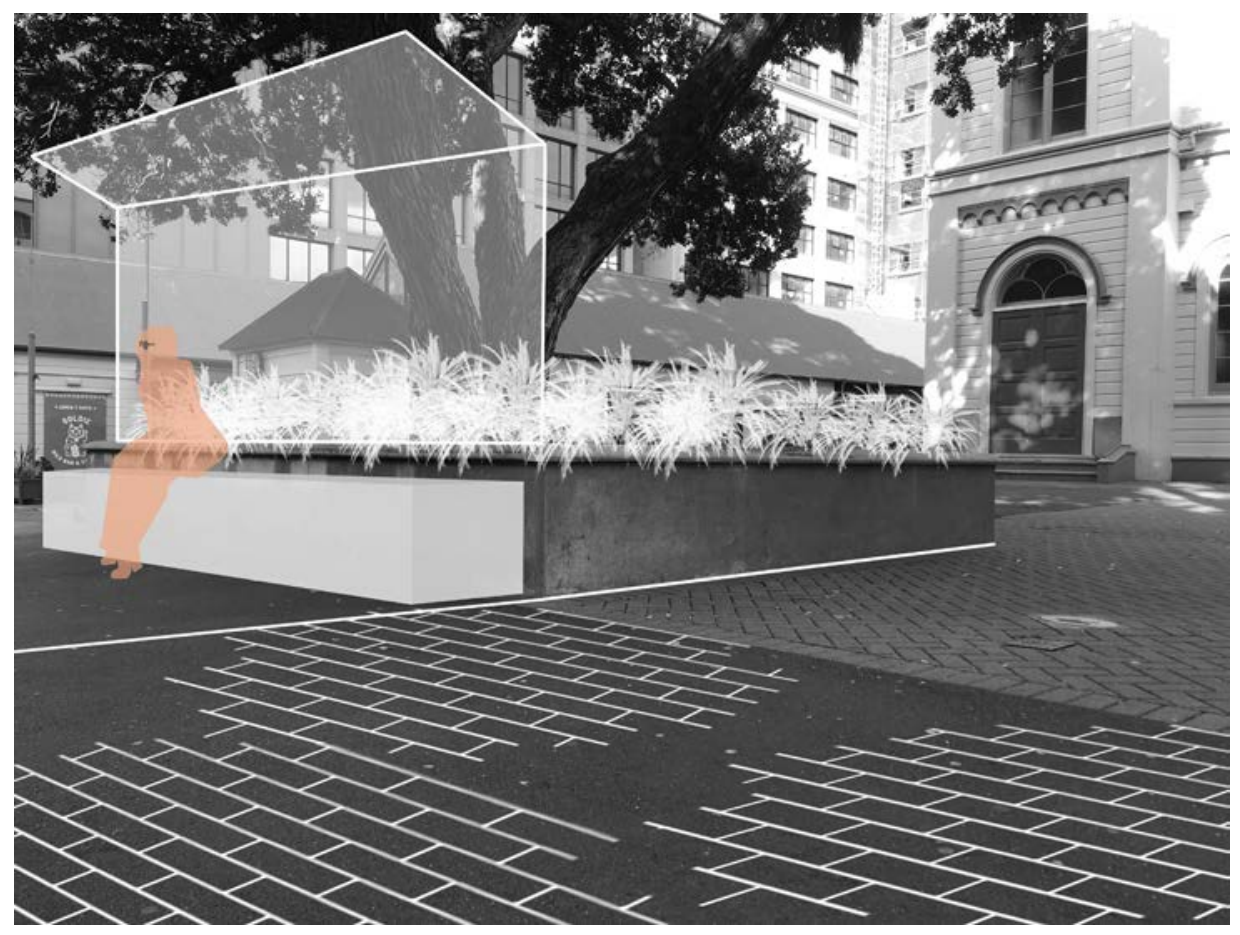

Elevated ramp

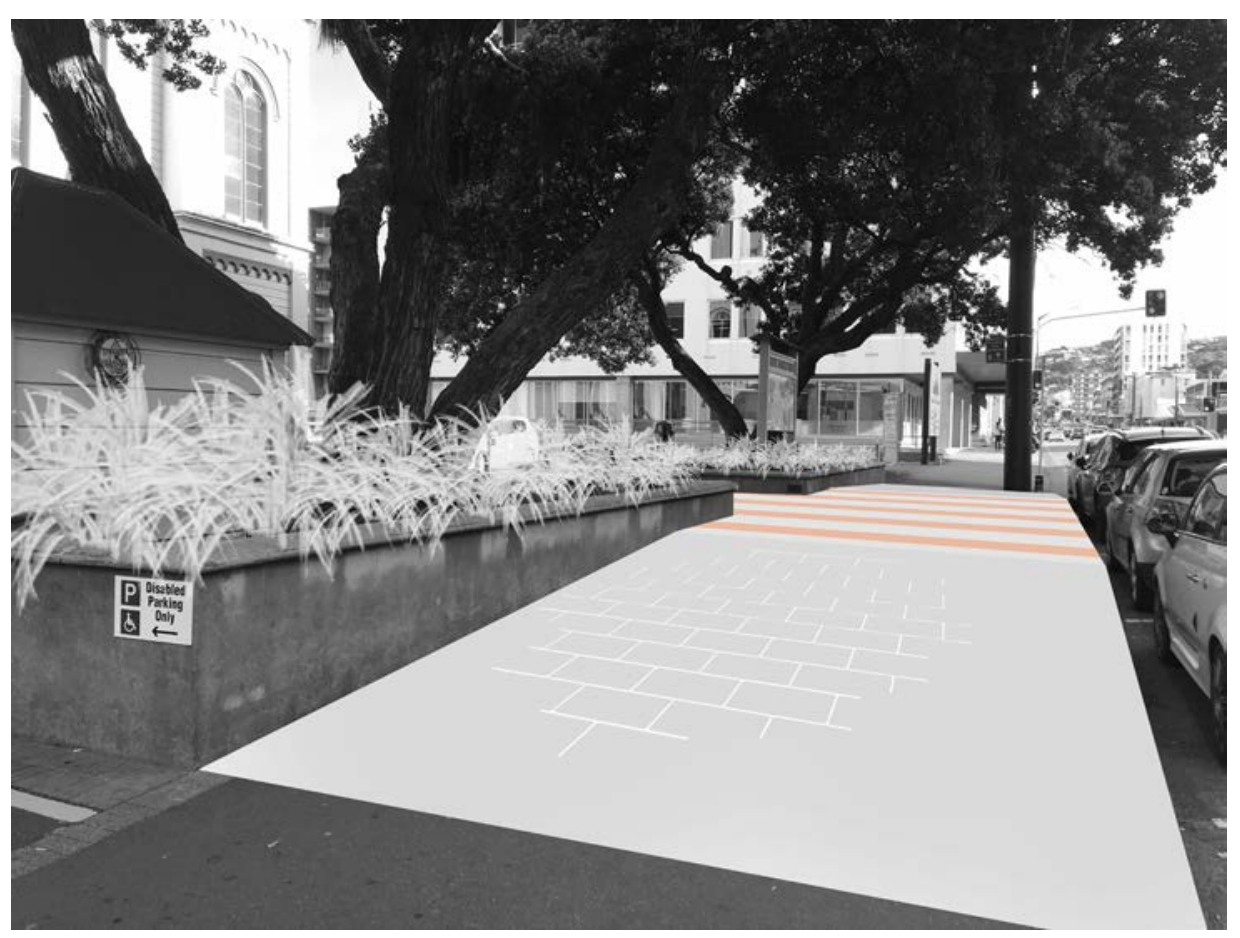




\section{Transitions between space Wider context transition}

The representative of the Wellington Methodist Parish revealed that the drama school studio is an old building that could be relocated or removed in the future to make way for other buildings that could be used for the same programme.

The building is currently used by various user groups and sits in the middle of the exterior space, creating the two parking areas. Opposite the building is the social hall where activities are often held. There is an opportunity for the space to become more open to create a spill-out zone, the idea being that if the drama studio were to be removed or relocated, a new space could be created that could encourage passers-by transitioning through the thoroughfare to use the space. There would then be an opportunity for the two groups to mix and interact with one another.

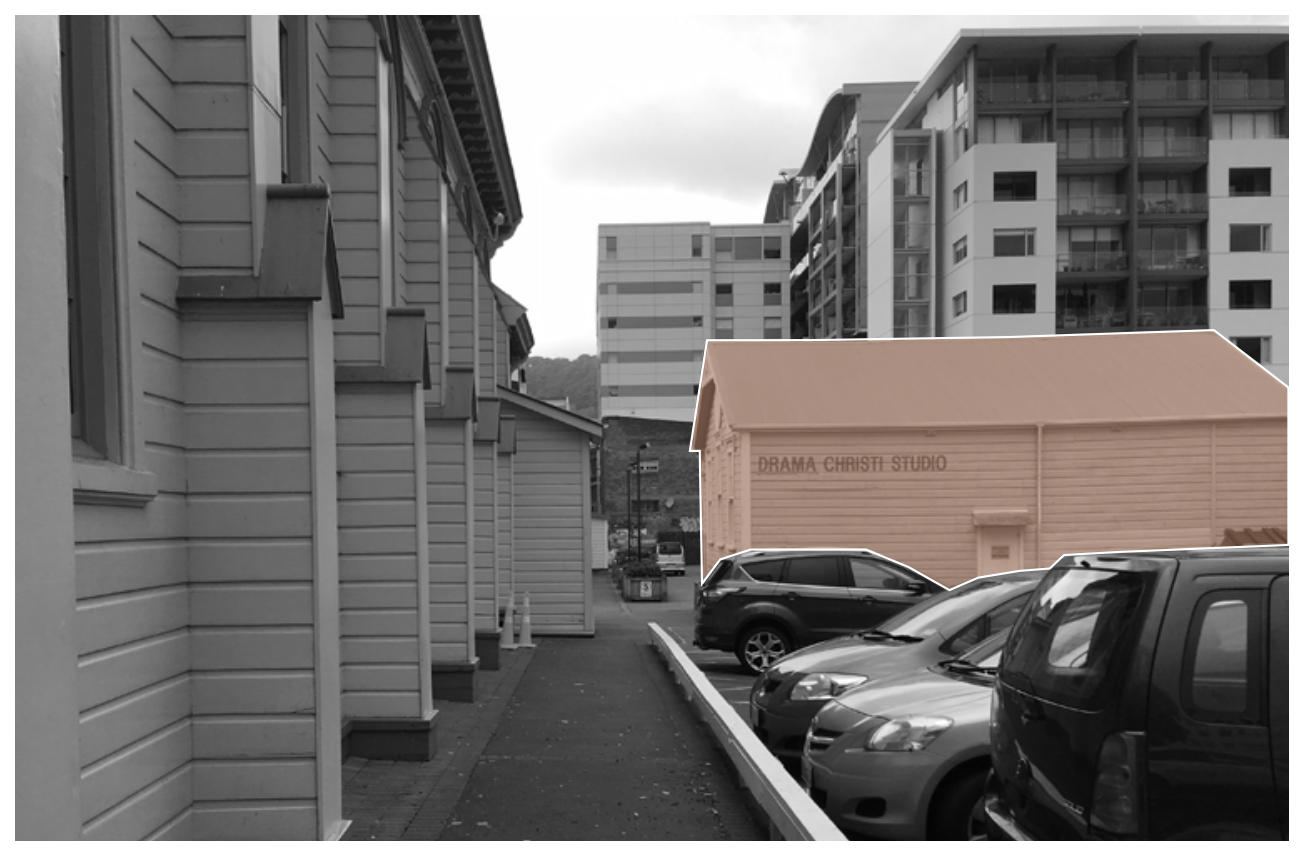

Fig.6.57. (Left) Drama studio to be repositioned in site Fig.6.58. (Right) Wider context transition 

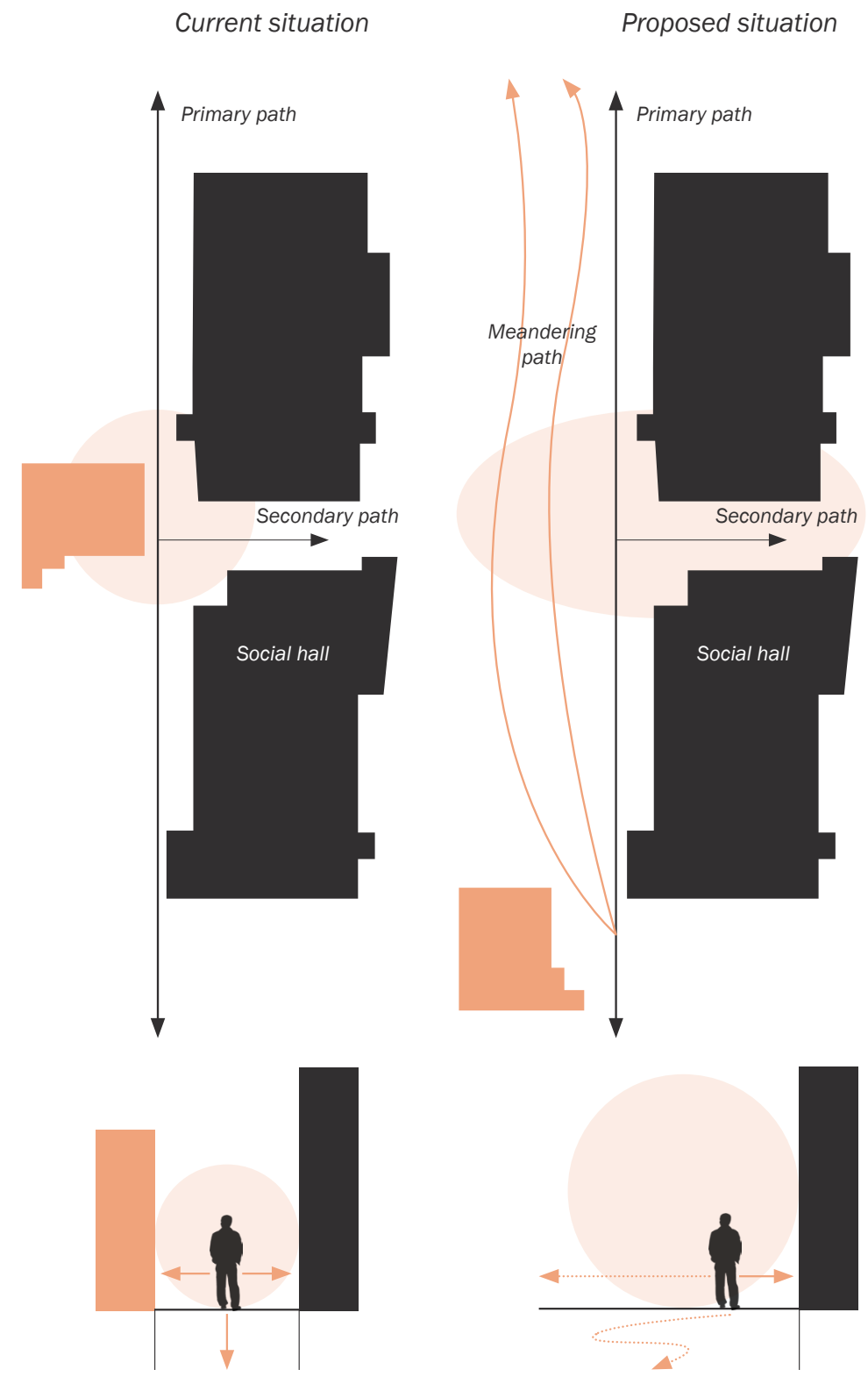

Proposed situation

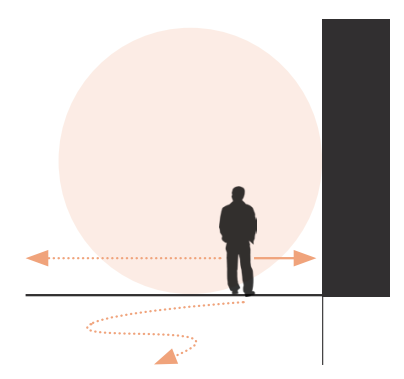




\section{Inviting public space Quality of space \& flexibility}

Playground and social space

By removing the drama studio building, the space can be converted into a playground and social area. Having a safe place for church community kids to enjoy was one of the desires identified in survey feedback. However, this space would not only benefit the church in terms of a place for the children to play in, it would also attract people in the surrounding area. As recorded in the analysis of this site, many of the surrounding buildings are residential apartment blocks. The space created in this area could act as a backyard space for the people that live in these buildings. This would mean that greater opportunity for interaction between the church and residential community could take place.

\section{Thoroughfare edge}

The thoroughfare that cuts through the site is strong, despite pedestrians having to navigate through the car park. By paving along the pathway next to the church, the quality of space is improved, making a more obvious and safer thoroughfare through the space. Using ground lighting along the pathway reinforces the feeling of safety at night-time and increases spatial awareness.

Planting helps to define the path as much as the wooden barrier, however the result is more visually appealing and less harsh. It also adds a softer texture, creating a more balanced space.

Seating along the edge of the church allows for moments of rest along the thoroughfare. Placing seats in the gaps between the vertical architectural elements also maximises the available space. 
Playground and social space

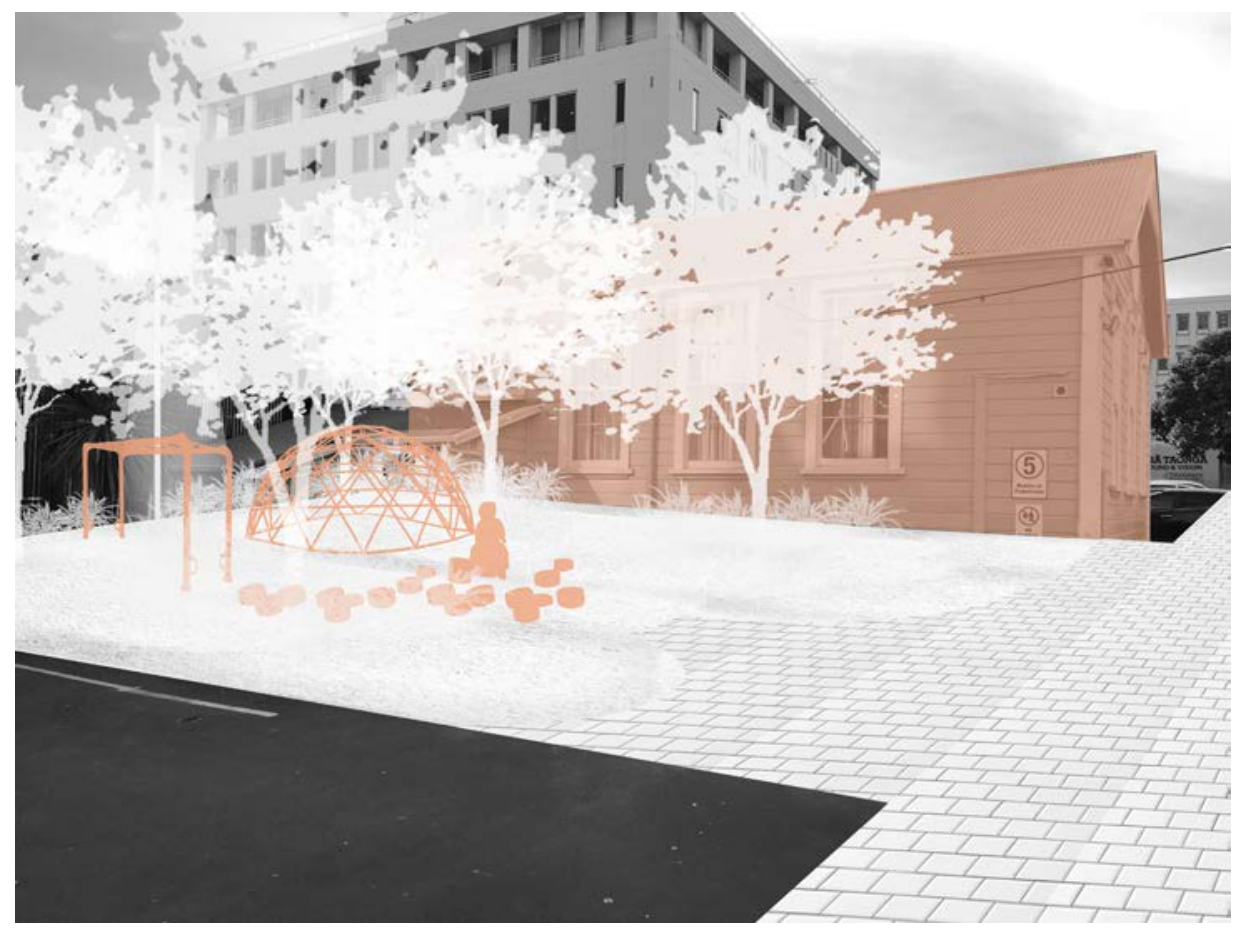

Thoroughfare edge

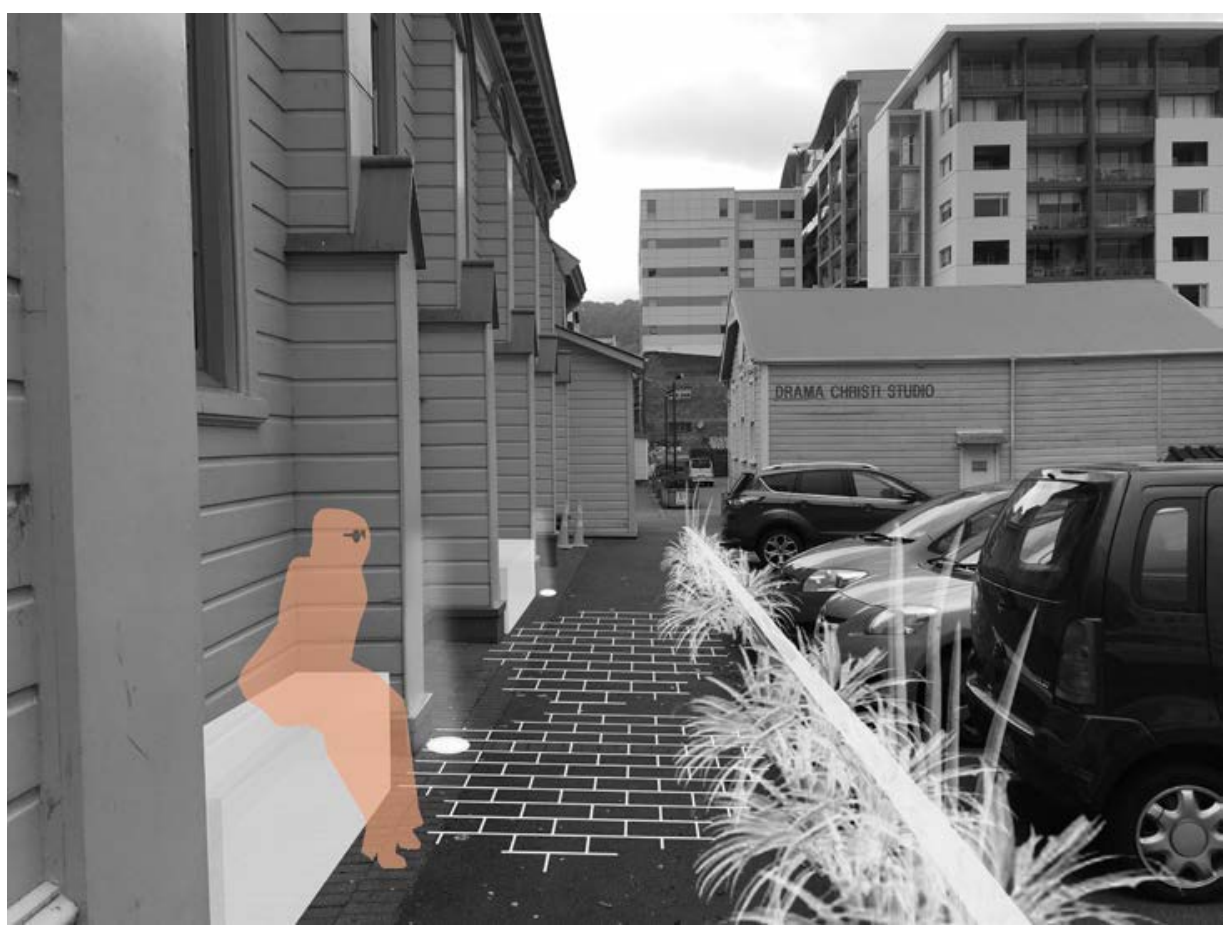


Inviting public space Quality of space \& flexibility
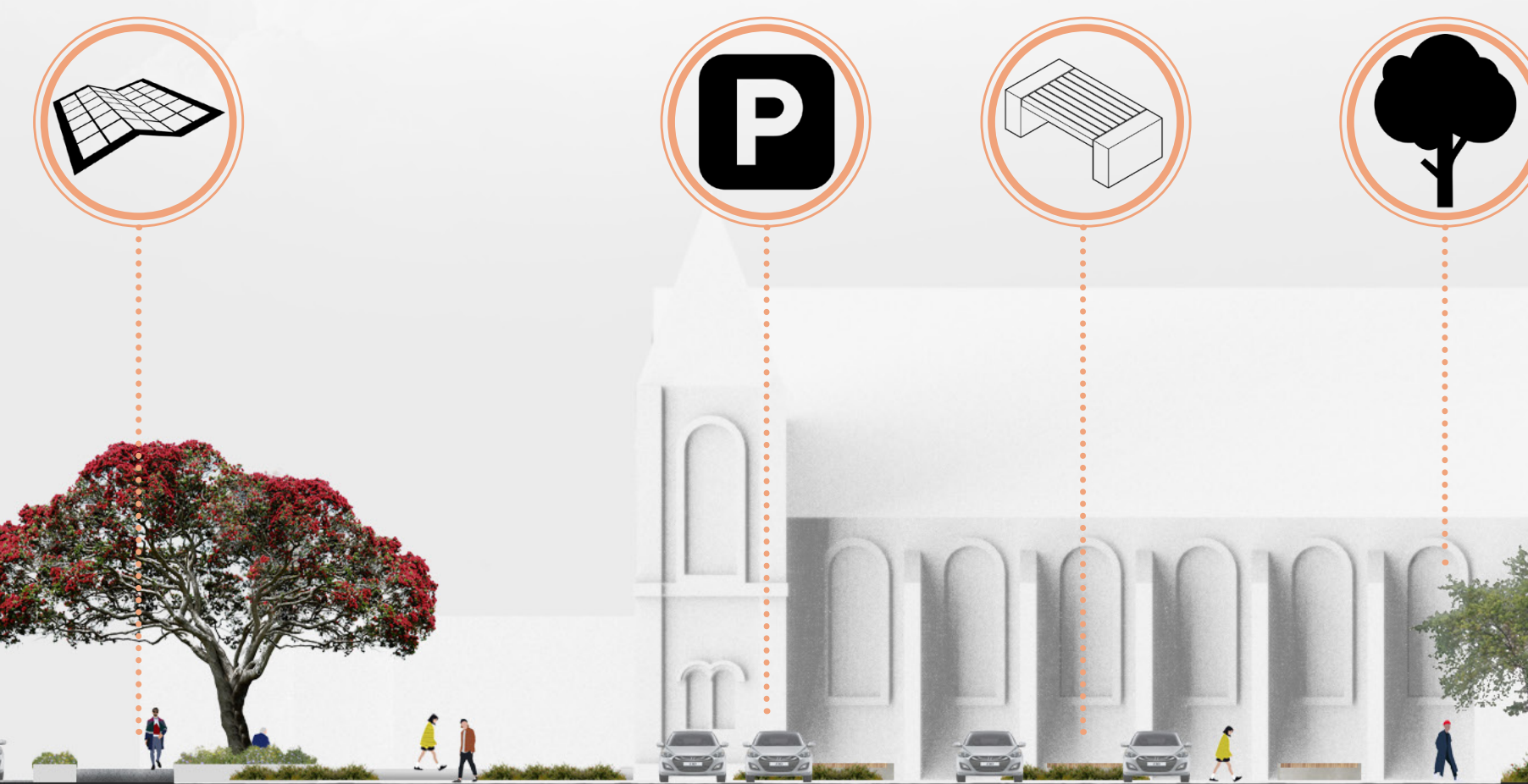

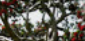


Playground

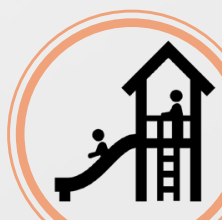

(1)
Basketball

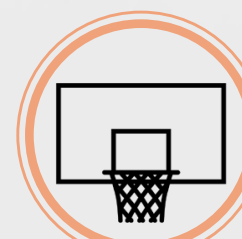

Relocated

drama studio

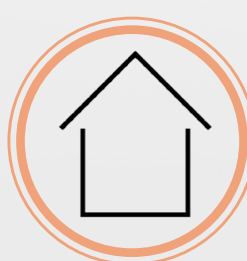

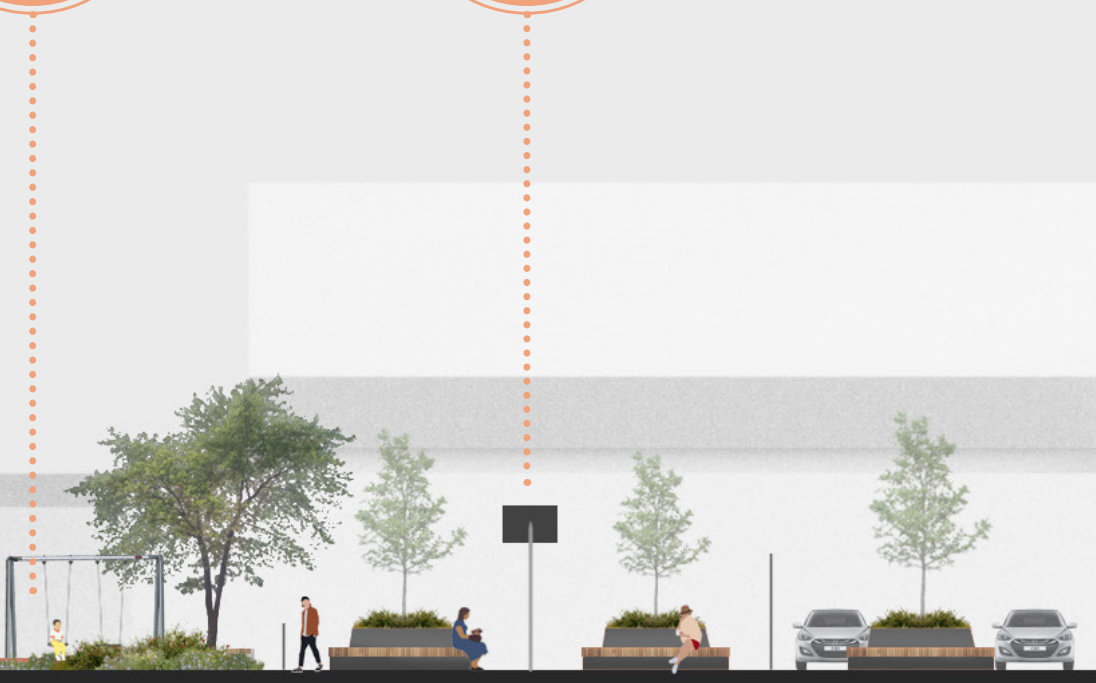




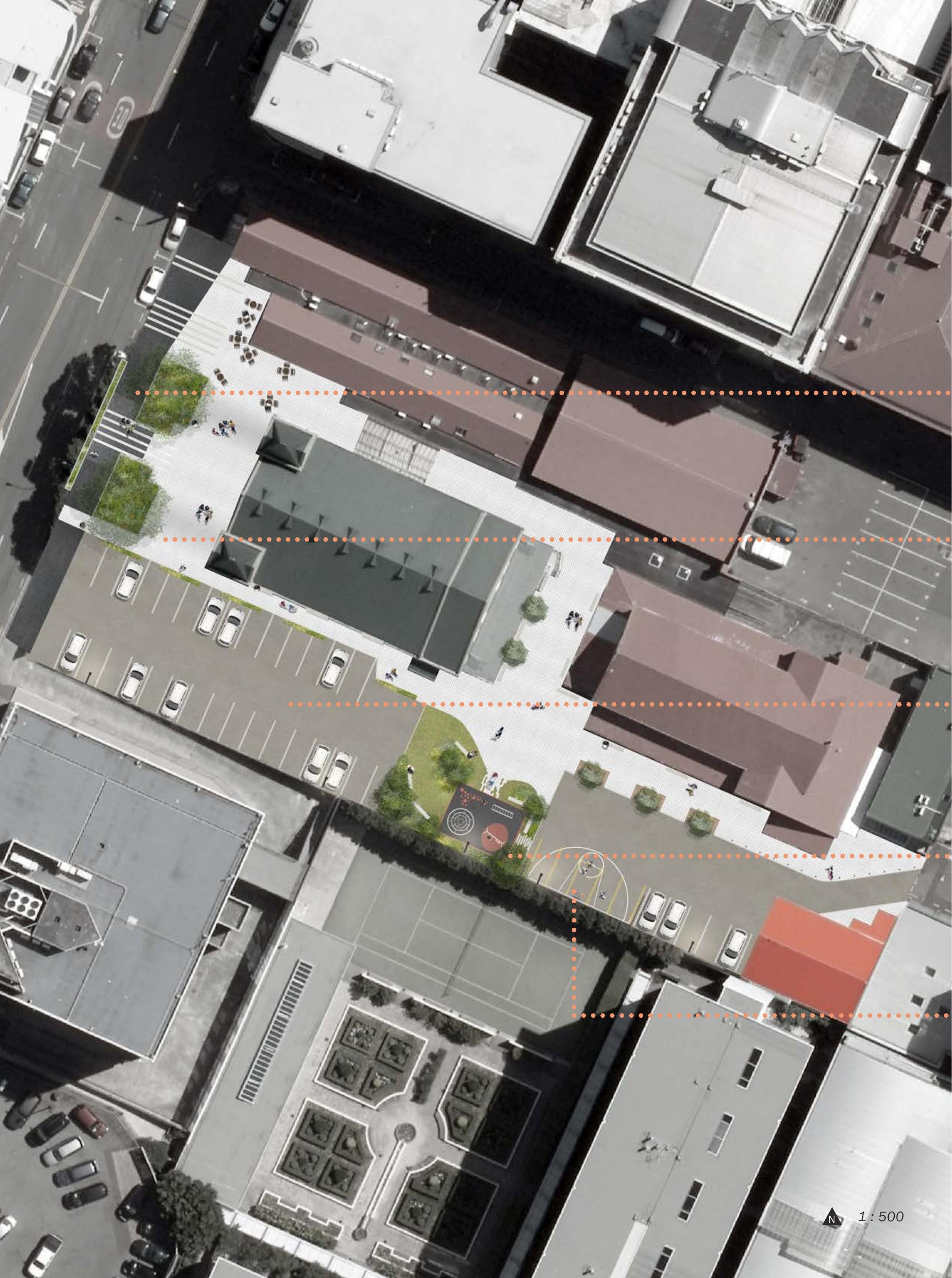




\section{Wellington Methodist Parish - Final proposal}

Ramp intervention

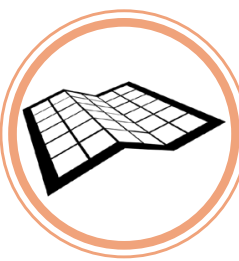

Seating

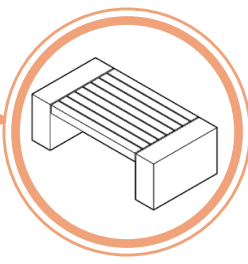

Parking

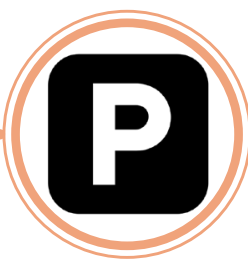

Vegetation

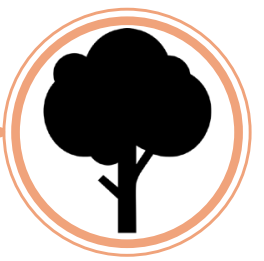

Basketball

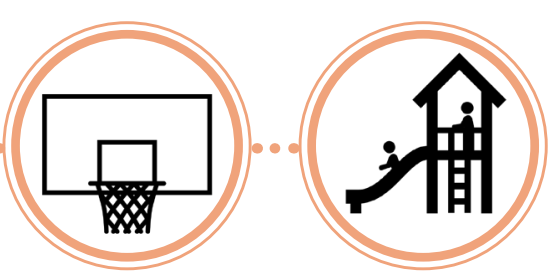
door.

\section{Playground}

By raising the footpath in front of the church, obstruction caused by the pohutukawa trees is less significant. The boxes that the trees are planted in are now just above ground level, meaning they do not direct movement and dictate people's paths as much as the current situation. The elevated section spills into the church, providing easier access to the building. This is also more welcoming to people relying on wheelchair access who can now enter through the front

The design proposes significantly more seating in the space as a whole. Seating is used in both spaces of permanency and rest and areas of thoroughfare. This provides people with more options for interacting with the space.

The car park as a whole loses six parking spaces with the intervention in the space. There are forty parks available on a Sunday and thirty-five during the week. The same tactic utilising the basketball court in the Wellington City Salvation Army car park is used here.

The vegetation used in this area of the site helps to create pockets of intimacy in the space. It encompasses the playground, which creates a sense of safety in the space. It also helps to set boundary points in the site and assists in the breaking up of the two car parking areas.

A basketball court and playground are situated in the space that was once the drama studio building. This area is a significant for community engagement as it is opposite the church social hall and in the middle of a well-established thoroughfare. 
Final plans - flexibility
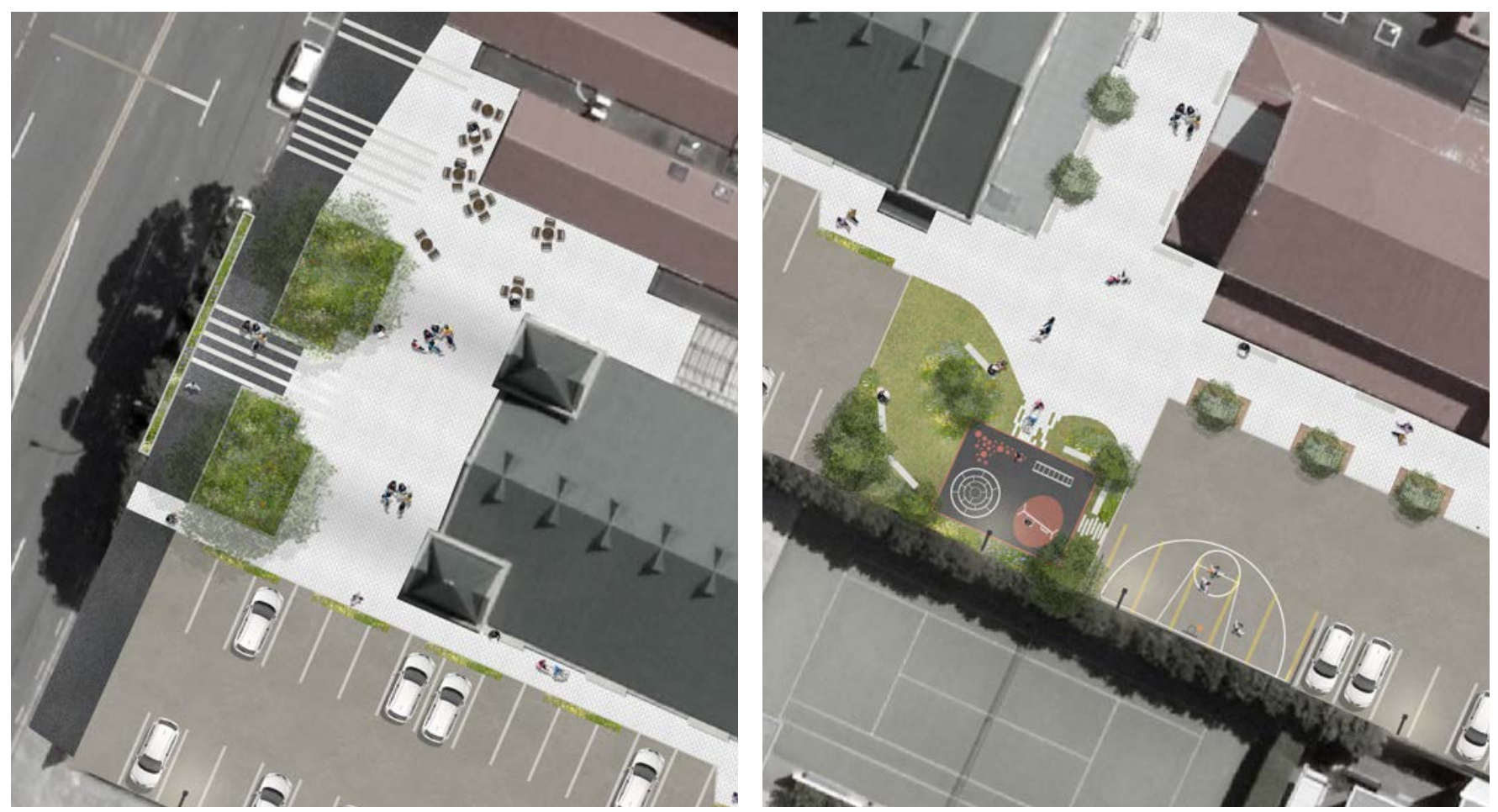

N $1: 500$

Weekday situation

N 1:500

Weekday situation
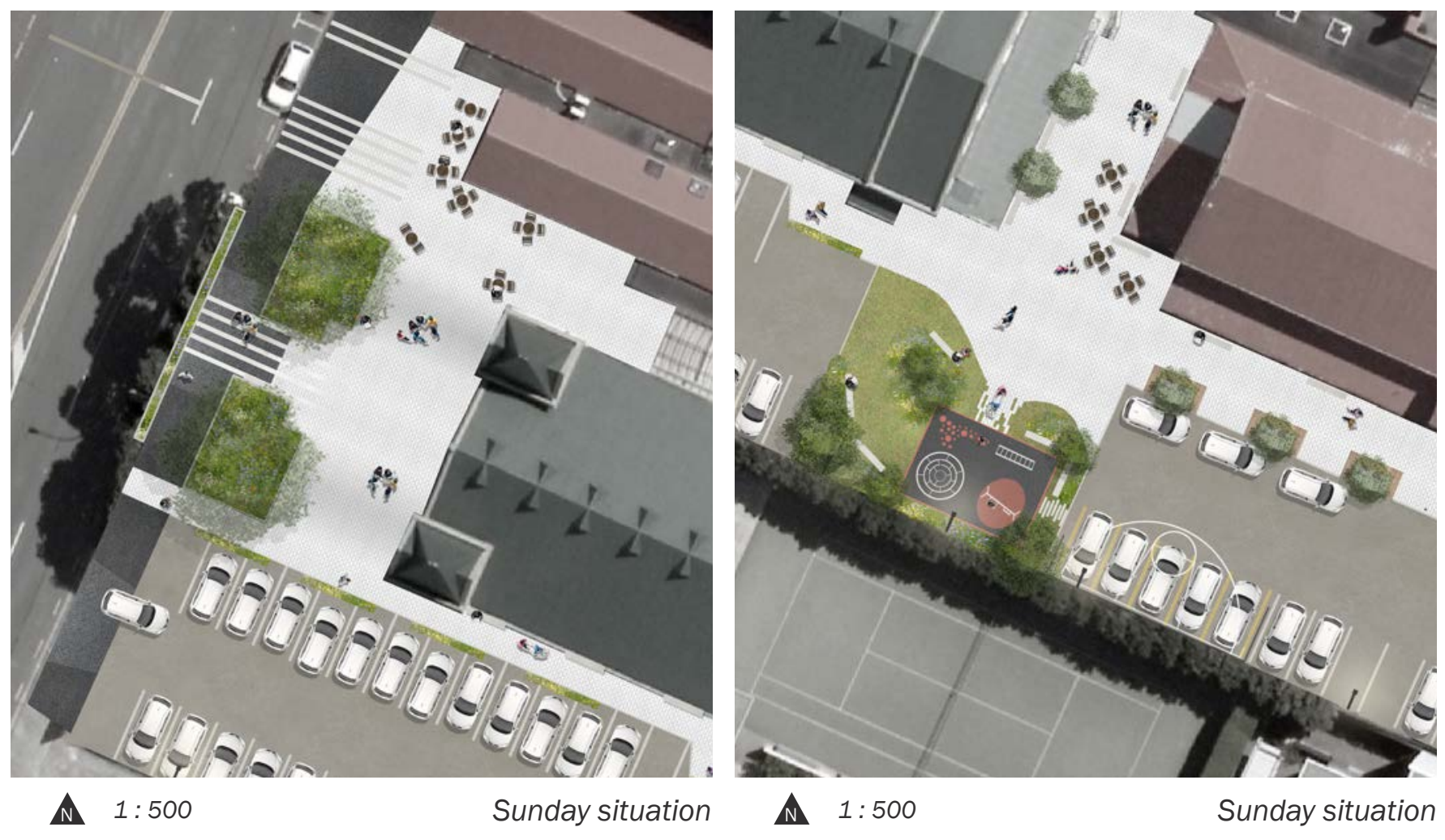

N $1: 500$

Sunday situation

N $1: 500$

Fig.6.63. (Top) Weekday situation Fig.6.64. (Bottom) Sunday situation 


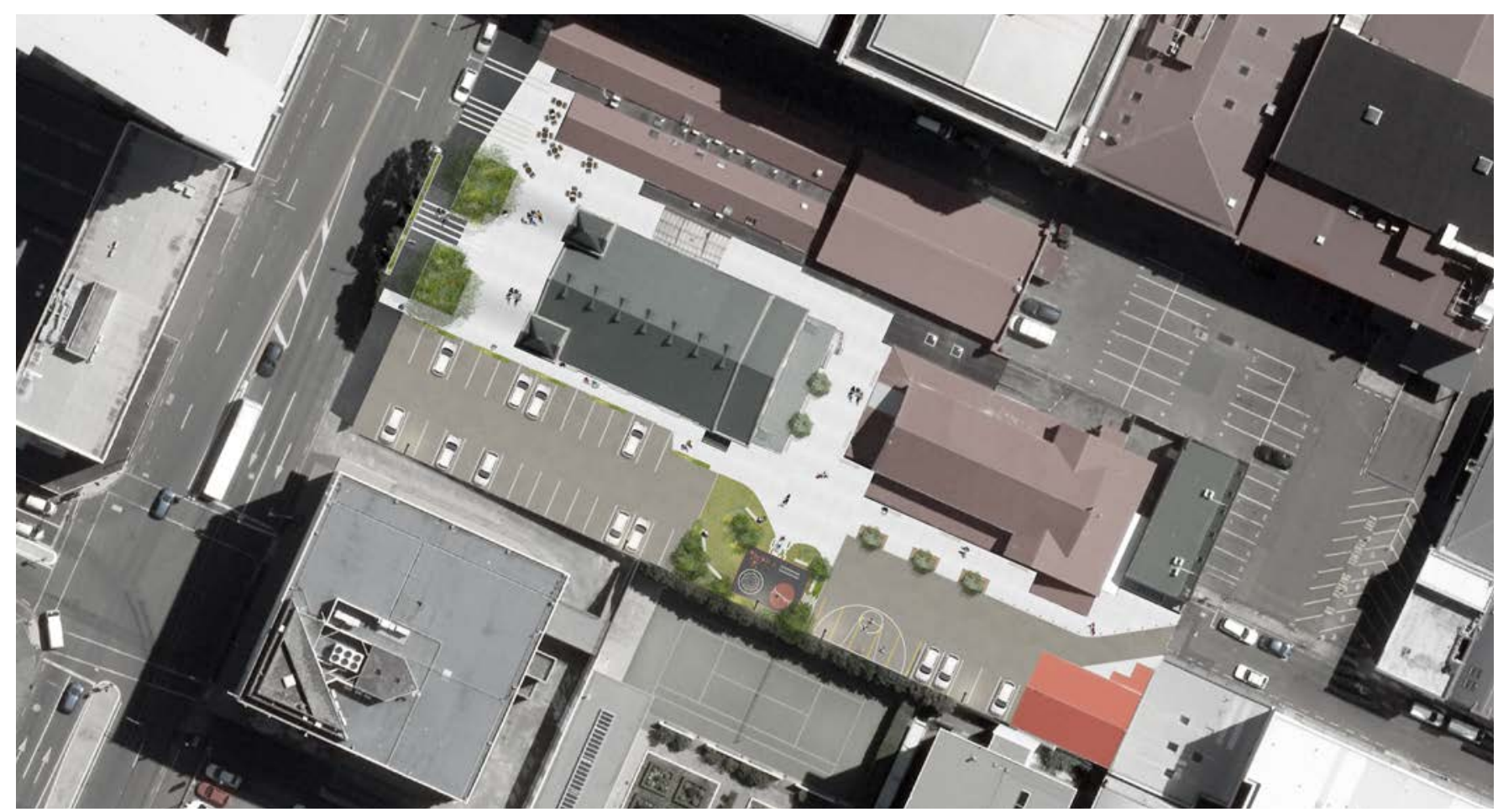

N $1: 1000$

Weekday situation

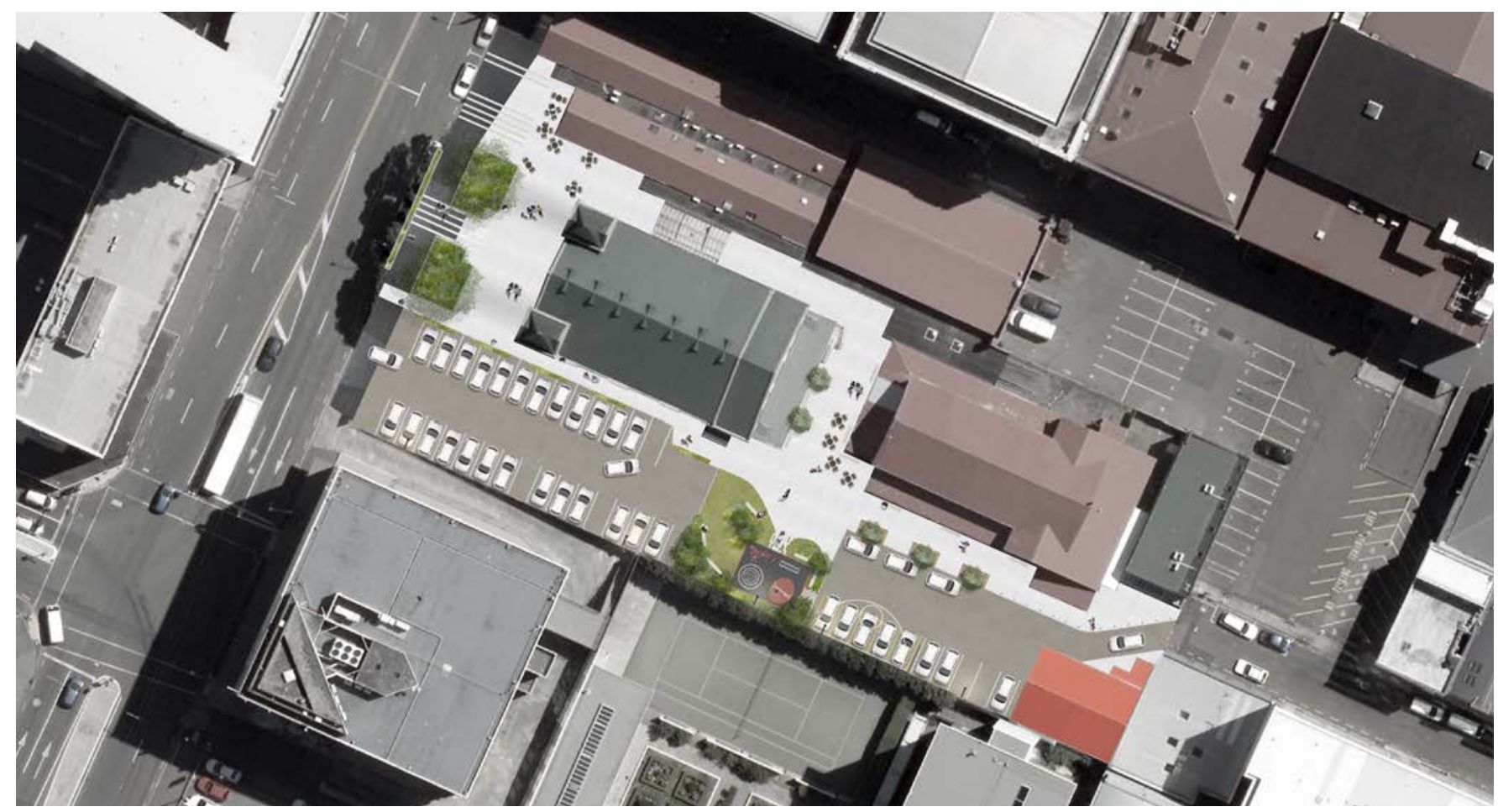

1:1000

Sunday situation

Fig.6.65. (Top) Weekday situation

Fig.6.66. (Bottom) Sunday situation 


\section{Design implementation conclusions}

The four key categories of design criteria arising from comparative analysis and community engagement heavily assisted the design phase. Each proposed design element was based around one or more of these key criteria.

Improving the wider context transitions at each site will help connect the church to its surroundings by allowing greater pedestrian access. By focussing on the close context transitions, pedestrian movement can be facilitated towards the church and will help to connect different areas in the space, such as the car park to the front entrance.

Making each space more inviting to the public means placing significant emphasis on improving the quality of each space. This was seen as a crucial aspect of design intervention and was thus considered in every design decision. By focussing on improving the quality of each space, the sites are now more receptive to social and optional activities.

When creating a space for people to congregate, planting needs to be strategic in order to enhance edge spaces. This was carefully considered when designing for each site. Planting was proposed along the edges of buildings, being careful not to block any windows or entrance ways.

The proposed design interventions are somewhat limited by the need for car parking at each church space, however, community feedback established car parking to be crucial aspect at each site. Proposed designs take this into account, while accommodating changes to the volume of used car parks across the week. 


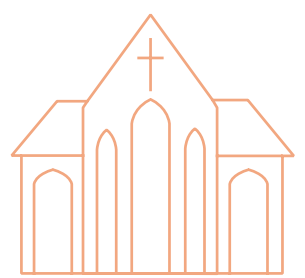

201 


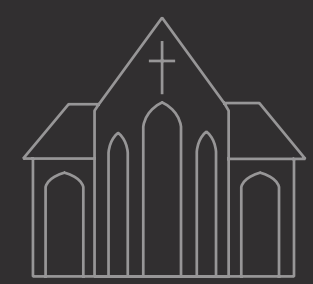

CHAPTER SEVEN 


\section{Conclusion}

The role of this research and design was to transform the way churches in Wellington interact with their environment, focussing less on the experiential nature of the building, and more on what is practicable and will invite people into the space. Each design aims to open up areas of the city that have been segregated and closed off to the general public, providing space for both the members of the church and the general public. It specifically focuses on creating vibrant moments of permanency without losing the more mundane, but necessary, features of the current space.

The proposed design of each space challenges the thinking around typical church design, advocating more emphasis on the exterior space of the church than the building. The old and, in some cases, current thinking around designing churches is to focus solely on the architecture. That thinking has meant that the space outside the building is often neglected and fails to facilitate movement from the footpath to the church. However, by placing more emphasis on external features and creating spaces that people can use, interactions in each site would be more permanent and less thoroughfare based.

The overall results of this research came from a balanced mix of two key features of methodology; analysing the New Zealand model and using case studies to understand the situation at a local level, and using collaborative design to gain the perspective of the people in the church community. Both research methods produced criteria, which influenced and informed the final design of each church space.

The comparative analysis helped to identify the issues that many churches face. It also identified commonalities across different churches, which in turn, identified the churches that were to be analysed further and designed in.

The community engagement and participatory design elements of the research were particularly important as they enabled the design process to be guided by a deeper understanding of how and why the sites function. Having established connections with the three churches, the research is also able to assist with any future design work. 


\section{Conclusion}

The spaces created at each church enable interaction between two key groups; the respective church communities and the general public. Each space has been designed to be more accessible to the general public and encourage recreational activity, while better fulfilling the needs of the church community.

Early in the research process, spatial issues excluding people from each church site were identified. Functional aspects of the sites, such as the car park, dominated the exterior design, with only small sections dedicated to recreation or public enjoyment.

By creating open spaces and improving the edge conditions, the churches would have more presence at street level. Improving the quality of the space in these areas with the addition of planting, seating and paving would make the area sympathetic to the surrounding environment, with fewer harsh materials and hard textures.

The design criteria and resulting designs act as a model for future church design or redesign. The criteria are more specific to existing church buildings, however, can also be applied to new church projects. The design criteria and research as a whole could also be implemented in other areas of public space where the main emphasis has been on the building rather than the exterior space. 


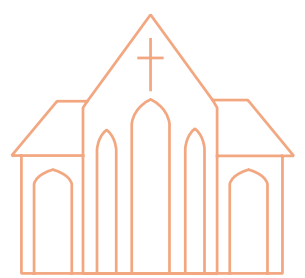




\section{Bibliography}

Architizer. St. Patricks Square. n.d. 05 April 2018.

Barrie, Thomas. The Sacred In-Between; The Mediating Roles of Architecture. Abingdon, Oxon: Routledge, 2010.

Botton, Alain de. Religion for Atheists. New York: Pantheon Books, 2012.

British Library. The medieval Church c.1300s. n.d. 15 June 2018. <http://www.bl.uk/learning/ timeline/item100359.html>.

Christchurch City Council. Christchurch City Contextual History Overview. Christchurch, n.d. Document.

Crewe, Katherine. "The Quality of Participatory Design: The Effects of Citizen Input on the Design of the Boston Southwest Corridor." Journal of the American Planning Association (2001): 437-455.

Dee, Catherine. Form and Fabric in Landscape Architecture, A Visual Introduction. London and New York: Spon Press, 2001.

Dora, Veronica della. "Engaging Sacred Space: Experiments in the Field." Journal of Geography in Higher Education (2010): 163-184.

Gehl, Jan. Life Between Buildings: Using Public Space. Island Press, 2011.

Hamilton-Baillie, Ben. "Shared Space: Reconciling People, Places and Traffic." Built Environment (2008): 161-181.

Krier, Rob. Urban Space. London: Academy Editions, 1979.

Lister, John W. Want to Create an Inviting and Attractive Public Space? 22 December 2017. 0714 2018.

Ministry for the Environment. Urban Design Toolkit. Wellington: Ministry for the Environment, 2006. 
Perceval, W B. Pictorial New Zealand. Cassell and Company. Limited, 1895.

Peterson, Steven. "Urban Design Tactics." Architectural Design Magazine (1978): 81.

Setha Low, Dana Taplin, Suzanne Scheld. Rethinking Urban Parks: Public Space and Cultural Diversity. University of Texas Press, 2005.

Shaw, Savill and Co. The New Zealand Handbook. Oxford University: Stanford, 1879.

Stuff. Where to go to discover New Zealand's Chinese heritage. 07 February 2016. 25 August 2018. <https://www.stuff.co.nz/travel/destinations/nz/76317109/null>.

The Re-Emergence of The Public Square. 30 November 2010. 03 September 2018. <https:// www.pps.org/article/the-re-emergence-of-the-public-square>.

Thorsten Bürklin, Michael Peterek. Basics Urban Building Blocks. Basel: Birkhäuser, 2008.

Trueman, C N. Medieval Church Architecture. 05 March 2015. 03 September 2018.

Wellington Cathedral of StPaul. Our History. n.d. 25 August2018. <https://www.wellingtoncathedral. org.nz/our-history>.

Wellington City Council. Urban design. n.d. 19 August 2018.

Wellington City Heritage - Saunders. Edward J Saunders. 08 November 2016. 25 August 2018.

Wellington City Heritage. Wesley Methodist Church and Hall. 05 July 2017. 25 August 2018.

Whyte, William H. City - Rediscovering the Center. University of Pennsylvania Press, 1988.

Wikipedia. List of countries by vehicles per capita. 2017. 29 October 2018. 


\section{List of figures}

\section{All figures not attributed are authors own}

Figure 1.01. The Origin and Decline of the Papal States

Reference: The Origin and Decline of the Papal States. Web. <www.thoughtco.com/the-papal-states-1789449>08 June 2018

Figure 1.02. Beginning of the Republic Messine

Reference: Migette, Auguste. Beginning of the Republic Messine. 14 January 2009. Web. <fr.m.wikipedia.org/wiki/Fich ier:Commencement_r\%C3\%A9publique_messine_Auguste_Migette_1862.jpg> 08 June 2018

Figure 1.03. Florence: View with the Chain

Reference: Rosselli, Francesco. Florence: View with the Chain. Web. <commons.wikimedia.org/wiki/File:Florence_-View_with_Chain_-_woodcut.png> 08 June 2018

Figure 1.04. Filippo Brunelleschi's Dome

Reference: Filippo Brunelleschi's Dome for Santa Maria Del Fiore. 19 September 2018. Web. <fiveshoutsout.com/ filippo-brunelleschi-linear-perspective/> 04 October 2018

Figure 1.05. Brunelleschi's Dome

Reference: Brunelleschi's Dome. 20 March 2017. Web. <theculturetrip.com/europe/italy/articles/16-interesting-factsabout-florence-cathedral/> 04 October 2018

Figure 1.06. Florence and Palazzo Rucellai

Reference: Florence and Palazzo Rucellai. 20 May 2013. Web. <dessenhillman.tumblr.com/post/50925772961/ urban-form-and-architecture> 08 June 2018

Figure 1.07. Wellington Museum Historical Map Len Cloth

Reference: Wellington Museum Historical Map Len Cloth. 18 December 2015. Web. <www.museumswellington.org. nz/?attachment_id=69822> 23 August 2018

Figure 1.08. Whitcombe's Map of Auckland City and Suburbs

Reference: Whitcombe. Whitcombe's Map of Auckland City and Suburbs. Web. <digitalnz.org/records/29954637> 23 August 2018

Figure 1.09. Edward Jollie's 1850 Plan of Central Christchurch

Reference: Edward Jollie's 1850 Plan of Central Christchurch. Web. <www.ccc.govt.nz/assets/Documents/CultureCommunity/Heritage/ChristchurchCityContextualHistoryOverviewFull-docs.pdf> 12 December 2018

Figure 1.11. Church Square St. Remigius, Borken Image 3

Reference: Church Square St. Remigius, Borken Image 3. 3 January 2017. Web. <www.landezine.com/index. php/2017/01/church-square-st-remigius-borken/> 05 April 2018 
Figure 2.03. Thorsten Burklin and Michael Peterek's 'transitions from the private space of the building to the public space of the city.

Reference: Thorsten Bürklin, Michael Peterek. Transitions from the private space of the building to the public space of the city, 2017. Basel. Basics Urban Building Blocks. Thorsten Bürklin, Michael Peterek. Basel: Birkhäuser, 2017. p14. Book

Figure 2.07. Church Square St. Remigius, Borken Image 1

Reference: Church Square St. Remigius, Borken Image 1. 3 January 2017. Web. <www.landezine.com/index. php/2017/01/church-square-st-remigius-borken/> 05 April 2018

Figure 2.08. Borken, St. Remigius

Reference: Borken, St. Remigius. 20 July 2014. Web. <commons.wikimedia.org/wiki/File:Borken,_St.-RemigiusKirche_--_2014_--_2272_--_Ausschnitt.jpg> 05 April 2018

Figure 2.09. Church Square St. Remigius, Borken Image 2

Reference: Church Square St. Remigius, Borken Image 2. 3 January 2017. Web. <www.landezine.com/index. php/2017/01/church-square-st-remigius-borken/> 05 April 2018

Figure 2.10. Church Square St. Remigius, Borken Image 3

Reference: Church Square St. Remigius, Borken Image 3. 3 January 2017. Web. <www.landezine.com/index. php/2017/01/church-square-st-remigius-borken/> 05 April 2018

Figure 2.11. St. Patricks Square Image 1

Reference: St. Patricks Square Image 1. Web. <architizer.com/projects/st-patricks-square/> 15 March 2018

Figure 2.12. St. Patricks Square Image 2

Reference: St. Patricks Square Image 2. Web. <architizer.com/projects/st-patricks-square/> 15 March 2018

Figure 2.13. St. Patricks Square Image 3

Reference: St. Patricks Square Image 3. Web. <architizer.com/projects/st-patricks-square/> 15 March 2018

Figure 2.14. St. Patricks Square Image 4

Reference: St. Patricks Square Image 4. Web. <architizer.com/projects/st-patricks-square/> 15 March 2018

Figure 2.15. B4 Island Heart Garden Image 1

Reference: B4 Island Heart Garden Image 1. Web. <www.tnplus.fr/projets/parcs-et-jardins/> 15 March 2018

Figure 2.16. B4 Island Heart Garden Image 2

Reference: B4 Island Heart Garden Image 2. Web. <www.tnplus.fr/projets/parcs-et-jardins/> 15 March 2018

Figure 2.17. B4 Island Heart Garden Image 3

Reference: B4 Island Heart Garden Image 3. Web. <www.tnplus.fr/projets/parcs-et-jardins/> 15 March 2018

Figure 2.18. B4 Island Heart Garden Image 4

Reference: B4 Island Heart Garden Image 4. Web. <www.tnplus.fr/projets/parcs-et-jardins/> 15 March 2018 
Appendices 


\section{TE WHARE WāNANGA O TE ĊPoKo O TE IKA A MĀUI \\ Socialising Sacred Space \\ CONSENT TO INTERVIEW}

This consent form will be held for 1 year.

Researcher: Thaddeus Young, School of Architecture, Victoria University of Wellington.

- I have read the Information Sheet and the project has been explained to me. My questions have been answered to my satisfaction. I understand that I can ask further questions at any time.

- I agree to take part in an audio recorded interview.

I understand that:

- I may withdraw from this study at any point before $01 / 09 / 2018$ and any information that I have provided will be returned to me or destroyed.

- The identifiable information I have provided will be destroyed on 01/03/2019.

- Any information I provide will be kept confidential to the researcher and the supervisor.

- I understand that the results will be used for a M asters Thesis in Landscape Architecture.

- My name will not be used in reports, nor will any information that would identify me.

Yes $\square \quad$ No $\square$

- I would like a copy of the recording of my interview:

Yes $\square \quad$ No $\square$

- I would like a copy of the transcript of my interview:

Yes $\square$ No $\square$

- I would like a summary of my interview: $\quad$ Yes $\square$ No $\square$

- I would like to receive a copy of the final report and have added my email Yes $\square$ No $\square$ address below.

Signature of participant:

Name of participant:

Date:

Contact details: 


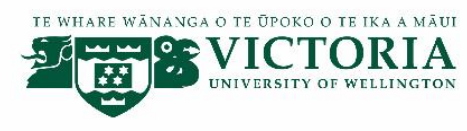

\section{Socialising Sacred Space}

\section{INFORMATION SHEET FOR PARTICIPANTS - Interview}

You are invited to take part in this research. Please read this information before deciding whether or not to take part. If you decide to participate, thank you. If you decide not to participate, thank you for considering this request.

\section{Who am I?}

My name is Thaddeus Young and I am a M asters student in Landscape Architecture at Victoria University of Wellington. This research project is work towards my design thesis where the majority of the project is research by design.

\section{What is the aim of the project?}

The project will look to make spaces in the city more social and inclusive. It will do this by integrating spaces surrounding churches into the urban fabric of Wellington city so that public life will be more vibrant and lively. Many of these sacred spaces are not utilized to their full potential and the few that are used by the public, are mostly used as thoroughfares. I will look to create spaces of permanency where activities and programs can take place. These could be activities run out of the church or more public activities.

The three key objectives of my research are;

- To make more areas of public space;

- Develop a better transition between the church as a building and the space that surrounds it;

- To increase the size of the communities that use the space.

This research has been approved by the Victoria University of Wellington Human Ethics Committee 0000026379.

\section{How can you help?}

You have been invited to participate because you are a member of this church or have insight into the running of the church. If you agree to take part, I will interview you in a location of your choosing. I will ask you questions about the church in general and your specific church. The interview will take one hour. I will audio record the interview with your permission and write it up later. You can choose to not answer any question or stop the interview at any time, without giving a reason. You can withdraw from the study by contacting me at any time before $01 / 09 / 2018$. If you withdraw, the information you provided will be destroyed or returned to you. 
Appendix B: Ethics Information Sheet - Interview

\section{What will happen to the information you give?}

You will not be named in the final report but your organisation will be named (provided you have the authority to agree to this on behalf of the organisation).

Only my supervisors and I will read the notes or transcript of the interview. The interview transcripts, summaries and any recordings will be kept securely and destroyed on 01/03/2019.

\section{What will the project produce?}

The information from this research will be used in my M asters in Landscape Architecture. This is a studio-based independent research by design project.

\section{If you accept this invitation, what are your rights as a research participant?}

You do not have to accept this invitation if you don't want to. If you do decide to participate, you have the right to:

- choose not to answer any question;

- $\quad$ ask for the recorder to be turned off at any time during the interview;

- $\quad$ withdraw from the study before 01/09/2018;

- ask any questions about the study at any time;

- receive a copy of your interview recording;

- $\quad$ receive a copy of your interview transcript;

- $\quad$ read over and comment on a written summary of your interview;

- be able to read any reports of this research by emailing the researcher to request a copy.

If you have any questions or problems, who can you contact?

If you have any questions, either now or in the future, please feel free to contact:

\section{Human Ethics Committee information}

If you have any concerns about the ethical conduct of the research you may contact the Victoria University HEC Convenor: Dr Judith Loveridge, email hec@vuw.ac.nz, phone (04) 463 6028. 


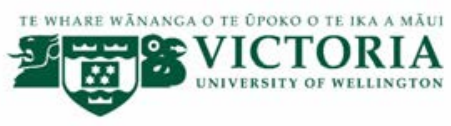

\section{Socialising Sacred Space}

\section{INFORMATION FOR PARTICIPANTS - Anonymous survey}

You are invited to take part in this research. Please read this information before deciding whether or not to take part. If you decide to participate, thank you. If you decide not to participate, thank you for considering this request.

\section{Who am I?}

My name is Thaddeus Young and I am a M asters student in Landscape Architecture at Victoria University of Wellington. This research project is work towards my design thesis where the majority of the project is research by design.

\section{What is the aim of the project?}

The project will look to make spaces in the city more social and inclusive. It will do this by integrating spaces surrounding churches into the urban fabric of Wellington city so that public life will be more vibrant and lively. Many of these sacred spaces are not utilized to their full potential and the few that are used by the public, are mostly used as thoroughfares. I will look to create spaces of permanency where activities and programmes can take place. These could be activities run out of the church or more public activities.

The three key objectives of my research are;

- To make more areas of public space;

- Develop a better transition between the church as a building and the space that surrounds it;

- To increase the size of the communities that use the space.

This research has been approved by the Victoria University of Wellington Human Ethics Committee 0000026379.

\section{How can you help?}

You have been invited to participate in this research because you are a member of this church. If you agree to take part you will complete a survey. The survey will ask you questions about your involvement with the church. The survey will take you 10 minutes to complete and can be completed by means of physical hand-in or online.

\section{What will happen to the information you give?}

This research is anonymous. This means that nobody, including the researchers will be aware of your identity. By answering it, you are giving consent for us to use your responses in this research. Your answers will remain completely anonymous and unidentifiable. Once you submit 
Appendix C: Ethics Information Sheet - Survey

the survey, it will be impossible to retract your answer. Please do not include any personal identifiable information in your responses.

\section{What will the project produce?}

The information from my research will be used in my Masters in Landscape Architecture. This is a studio-based independent research by design project.

If you have any questions or problems, who can you contact?

If you have any questions, either now or in the future, please feel free to contact me:

\section{Human Ethics Committee information}

If you have any concerns about the ethical conduct of the research you may contact the Victoria University HEC Convenor: Dr Judith Loveridge, email hec@vuw.ac.nz, phone (04) 463 6028. 


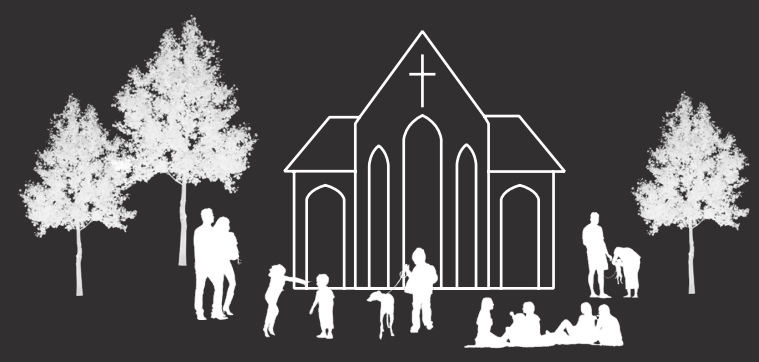

